\title{
V. Die Zeugen Jehovas in den Kriegsjahren
}

\section{Die regionalen Neuansätze eines organisierten Widerstandes während des Krieges}

Nach den Verhaftungsaktionen des Jahres 1937 waren die Aktivitäten der IBV im Reichsgebiet weitgehend zum Erliegen gekommen, so daß in den Jahren 1938/39 eine organisierte Gegenwehr praktisch nicht existierte. Erst langsam gelang es den weiterbestehenden Gruppen - zumeist kleine Zirkel mit einem überdurchschnittlich hohen Anteil an Frauen -, miteinander Verbindung aufzunehmen und in den einzelnen Regionen erneut festere Kommunikationsstrukturen zu schaffen. Wenn auch das Organisationsgefüge durch den Staat weitgehend zerschlagen worden war, so hatte dies dennoch den Bekennermut vieler Zeugen Jehovas nicht brechen können. Für ihre Entschiedenheit und auch Entschlossenheit zum „Bekennen“ bedurfte es nicht des Anstoßes und der Anleitung durch Bezirksdiener oder andere Funktionsträger der Glaubensgemeinschaft. Dies belegen die Handlungen vieler einzelner, die - nunmehr weitgehend auf sich allein gestellt - an die früheren, durch die IBV-Leitung koordinierten Aktionen anzuknüpfen suchten. Beispielsweise wurden durch den 29jährigen Zeugen Jehovas August Drda aus Homberg, wie es im Fahndungsersuchen der Staatspolizeistelle Würzburg vom 16. März 1938 heißt, „wiederholt und zuletzt in der Nacht zum 22.2.1938 größere Mengen IBV-Flugschriften ,Rechtfertigung ' und ,Regierung' in verschiedenen Städten Deutschlands durch Abwurf in den Häusern zur Verteilung gebracht" schwarzes Papier gewickelt und die Titelseite entfernt gewesen sei.

$\mathrm{Zu}$ jener Zeit sind organisierte Aktionen nennenswerten Umfanges lediglich in den Gebieten zu verzeichnen, die dem Deutschen Reich einverleibt worden waren. In Österreich hatten die Zeugen Jehovas, die dort seit Mitte 1935 verboten waren und deshalb bereits in der Illegalität standen², als am 12. März 1938 deutsche Truppen die Grenze überschritten, schon intensive Vorbereitungen für die unter der Herrschaft der Nationalsozialisten zu erwartende Situation zunehmender Repression und Verfolgung getroffen ${ }^{3}$. Diesem Zweck diente unter anderem ein Ende August 1937 in Prag veranstalteter Kongreß der Zeugen Jehovas ${ }^{4}$, an dem ungefähr 200 Angehörige der im Vergleich zum deutschen Zweig sehr viel kleineren

1 BA, Sammlung Schumacher/267 I, Staatspolizeistelle Würzburg, RdS vom 16.3.1938.

$2 \mathrm{Zu}$ der - sich allerdings zumeist auf die Beschlagnahme von Druckschriften, Hausdurchsuchungen und kurzfristige Arreststrafen beschränkenden - Verfolgung der Zeugen Jehovas in Österreich unter der austrofaschistischen Regierung von Dr. Kurt Schuschnigg vgl. Jahrbuch 1938, S. 202f.; Jahrbuch 1989, S. 92-98; siehe auch oben S. 247, Anm. 112.

$3 \mathrm{Zu}$ Verfolgung und Widerstand der österreichischen Zeugen Jehovas 1938-1945 vgl. vor allem den - auch zahlreiche Dokumente einbeziehenden - Länderbericht im Jahrbuch 1989, S. 98-134, und die verschiedenen, im Literaturverzeichnis ausgewiesenen Veröffentlichungen des DÖW; ferner Lichtenegger, Wiens Bibelforscherinnen, S. 138-165; Luza, Austria, S. 63-65.

4 Zu dem Prager Kongreß vgl. Jahrbuch 1938, S. 216; Jahrbuch 1989, S. 98f.; Neugebauer, Wien, S. $166 f$. 
österreichischen IBV-Organisation teilgenommen hatten ${ }^{5}$. Unter Berücksichtigung der Erfahrungen in Deutschland, wo zahlreiche Festnahmen wegen mangelnder Vorsichtsmaßnahmen hatten geschehen können, wurden den österreichischen Glaubensgeschwistern auf dieser mehrtägigen Versammlung von den Mitarbeitern des Prager Zweigbüros und des Berner Zentraleuropäischen Büros Anweisungen und Ratschläge für die illegale Arbeit erteilt. Dabei diente als Orientierung das im September 1936 in Deutschland eingeführte Zellenmodell; eine analoge Aufteilung in Bezirke, Gruppen und Zellen wurde beschlossen. Auch wurden Verhaltensregeln vereinbart, die das Risiko von Aufdeckungen verringern sollten.

In den ersten Märztagen 1938 hatte die Watch Tower Society angesichts der zu erwartenden Ereignisse ihr Gebäude in der Wiener Pouthongasse 12, in dem seit 1923 das österreichische Zweigbüro untergebracht war, verkauft. Danach verließ der Leiter des österreichischen Zweiges - anscheinend auf Anweisung der Zentrale der Watch Tower Society - das Land in Richtung Schweiz ${ }^{6}$. Nach der Flucht des bisherigen Leiters übernahm ein Mitarbeiter des Wiener Zweigbüros, der 52jährige Vertreter August Kraft, die Führung der in der Illegalität wirkenden österreichischen IBV-Sektion. Kraft richtete zielstrebig die Untergrundarbeit an den im Vorjahr auf der Prager Hauptversammlung erteilten Instruktionen aus. Die Gruppen wurden verkleinert, Verteilerstellen eingerichtet und Zusammenkünfte nur noch mit größter Vorsicht an wechselnden Treffpunkten, zum Beispiel in Parkanlagen, durchgeführt. August Kraft verzichtete auch weitgehend auf die Einschaltung von Mittelsmännern und nahm die Kontakte zu den Verantwortlichen in den einzelnen Bezirken selbst wahr. Aus diesem Grunde war er ständig zwischen Klagenfurt, Innsbruck und Wien unterwegs. Auch um den Schriftenschmuggel kümmerte er sich persönlich. In der ersten Zeit nach der Eingliederung Österreichs wurden der „Wachtturm" und andere Bibelforscherschriften von Schweizer Glaubensgeschwistern über die Grenze nach Vorarlberg gebracht. Dort übernahm Kraft die Schriften und brachte sie jeweils über mehrere Zwischenstationen, wo Kuriere aus anderen Bundesländern die für ihren Bezirk vorgesehenen Ausgaben entgegennahmen, bis nach Wien. Gleichzeitig wurde in der Donaustadt, da die Zahl der eingeschmuggelten Exemplare für die dortige Bibelforschergemeinde, der fast drei Viertel der österreichischen Bibelforscher angehörten, nicht ausreichte, mit der Vervielfältigung des „Wachtturms“ auf einem einfachen Umdruckapparat begonnen. Wie schon in den letzten Jahren in Deutschland ${ }^{7}$, waren an der Herstellung der Schriften auch dort Frauen besonders intensiv beteiligt.

Der „Wachtturm“ wurde im Keller einer am Wiener Stadtrand gelegenen Gärtnerwohnung gedruckt. Die Vorsichtsmaßnahmen waren groß. So war der Raum

5 Die Tätigkeitsberichte der Watch Tower Society weisen für das letzte Jahr vor dem Verbot in Österreich eine Zahl von 476 „Verkündigern“ aus. (Jahrbuch 1935, S. 153). Im Jahre 1937 betrug ihre Zahl 549 (Jahrbuch 1989, S. 135). Während die 25.000 bis 30.000 deutschen Zeugen Jehovas einen Anteil an der Gesamtbevölkerung von 0,38\%o ausmachten, betrug dieser bei den insgesamt mit höchstens 700 Gläubigen zu veranschlagenden österreichischen Zeugen Jehovas lediglich 0,1\%o. Die Missionserfolge der Zeugen Jehovas in Österreich beliefen sich also in etwa auf ein Viertel der im Deutschen Reich erzielten.

6 Vgl. Jahrbuch 1989, S. 99f.

7 Siehe S. 233 und S. 259. 
besonders gesichert, verdunkelbar und als Werkstatt getarnt. Schreibmaschine und Vervielfältigungsapparat wurden nach jeder Benutzung gut verstaut: In einem Teil des Kellers, dessen Fußboden gepflastert war, wurde die Stein- und Erdschicht entfernt, bis man auf Holzdielen stieß. Hinter diesen verbarg sich seitwärts weiter unten ein neben dem Haus gelegener Hohlraum, in dem man alle Utensilien lagerte. Die Schriftenhersteller hatten so neben dem ohnehin mühseligen Abzugsverfahren jedesmal ein ordentliches Stück Ausschachtungsarbeiten zu verrichten.

Die österreichischen Zeugen Jehovas entfalteten eine rege Tätigkeit, wobei der Beteiligungsgrad im Vergleich zu den deutschen Glaubensgeschwistern - von denen nach der nationalsozialistischen Machtergreifung jede(r) zweite sich an Widerstandsaktivitäten beteiligte - noch wesentlich höher war. Neben der durch die geringe Gesamtzahl bewirkten engeren Bindung wird dies auch auf die das Werk im katholischen Österreich seit den frühen zwanziger Jahren begleitenden Schwierigkeiten und die damit verbundene gesellschaftliche Ausgrenzung zurückzuführen sein. Beides trug dazu bei, daß die Zeugen Jehovas in Österreich aus einem entschlossenen und bereits ,verfolgungserprobten“ Mitgliederstamm bestanden ${ }^{8}$.

$\mathrm{Zu}$ einer größeren Anzahl von Verhaftungen kam es am 4. April 19399. An diesem Tag hielten die Zeugen Jehovas ihre Gedächtnismahlfeiern ab. Das Berliner Geheime Staatspolizeiamt hatte mit Runderlaß vom 21. März 1939 die Staatspolizeistellen von dem Termin in Kenntnis gesetzt und angeordnet, sämtliche Wohnungen der im jeweiligen Dienstbezirk wohnenden Anhänger der IBV zu überprüfen ${ }^{10}$. Die Kontrollen waren im „Benehmen mit den zuständigen Außenstellen des SD“ durchzuführen ${ }^{11}$.

Am 25. Mai 1939 wurde der österreichische Landesleiter August Kraft in Wien festgenommen. Obgleich die illegale Arbeit zuvor sehr stark auf ihn zugeschnitten war, erholte sich die österreichische IBV-Sektion vergleichsweise schnell von diesem Schlag. Für den Fall seiner Festnahme hatte Kraft nach Rücksprache mit dem Berner Büro den 47jährigen Wiener Gemischtwarenhändler Peter Gölles mit der Übernahme der Leitung betraut. Dessen Lebensmittelgeschäft wurde nun zum Umschlagplatz und Mittelpunkt der illegalen Arbeit in Österreich. Des Nachts wurde in Kellerräumen der ,Wachtturm“ gedruckt, der tagsüber im Wurstpapier eingeschlagen oder in der Gemüsetüte verborgen über den Ladentisch an jene „Kunden“ weitergegeben wurde, die als Kuriere tätig waren. Im Gegensatz zu Kraft, der - ständig auf Reisen - die Landesleiterfunktion aus dem Untergrund heraus wahrge-

$8 \quad$ Vor dem Hintergrund, daß mindestens 445 österreichische Zeugen Jehovas während der Jahre 1938 bis 1945 zeitweise inhaftiert waren (siehe S. 325), und unter Berücksichtigung einer „Verkündigerzahl“ für das Jahr 1937 von 549 ist die Annahme gerechtfertigt, daß mehr als $80 \%$ der österreichischen Zeugen Jehovas sich an der Untergrundtätigkeit beteiligten.

9 Vgl. Jahrbuch 1989, S. 112f.; EB Alois Moser, 23.5.1986.

10 BA, Sammlung Schumacher/267 I, o. B1., zit. im RdErl. der Staatspolizeistelle Würzburg vom 27.3.1939.

11 Die Zuständigkeiten von Gestapo und SD bei der Gegnerüberwachung waren mit dem sogenannten „Funktionstrennungserlaß“ vom 1.7.1937 geregelt worden. Im Fall der Kirchen, Sekten und sonstigen religiösen und weltanschaulichen Zusammenschlüssen sah die verabredete Arbeitsteilung so aus, daß die Gestapo ,, alle Einzelfälle“ bearbeitete, während der SD die Zuständigkeit für ,, alle allgemeinen und grundsätzlichen Fragen“ zugesprochen bekam. Vgl. Meldungen aus dem Reich, Band 1, S. 14. 
nommen hatte, führte Gölles seine „Doppelexistenz“ fort. Die Reisetätigkeit übernahm für ihn der Berliner Kaufmann Ernst Bojanowski, der im Vorjahr aus Deutschland nach Österreich geflüchtet war. Bojanowski versorgte die Gruppen in den verschiedenen Landesteilen mit den in Wien gedruckten Schriften. Außerdem drängte er darauf, daß sich die durch Verhaftungen geschwächte Organisation erneuerte, ermutigte zur Mitarbeit und half bei der Gründung neuer Gruppen. Vor der Durchführung von regelmäßigen Bibelkreisen, an denen wie üblich mehrere Personen teilnahmen, soll Bojanowski gewarnt haben, um Kettenreaktionen bei Festnahmen zu vermeiden ${ }^{12}$. Neben ihm beteiligte sich noch ein weiterer deutscher Zeuge Jehovas maßgeblich an der Untergrundtätigkeit der österreichischen IBV-Sektion. Während Bojanowski für die Verteilungsaufgaben zuständig war, übernahm jener Ludwig Cyranek zusammen mit der Wiener Bibelforscherin Anna Voll die Verantwortung für die Herstellung des „Wachtturms" sowie weiterer Bibelforscherschriften. Unter anderem wurden auch Nachdrucke des Buches „Faschismus oder Freiheit" angefertigt, dem eine von Watch Tower-Präsident J. F. Rutherford am 2. Oktober 1938 in New York auf einer Kundgebung gehaltene Rede zugrunde lag13.

Im Oktober 1939 gelang es der Gestapo jedoch, nach der Verhaftung eines Zeugen Jehovas, der laut Tagesrapport der Wiener Gestapo ,die Namen der Leiter der IBV in fast sämtlichen Wiener Gemeindebezirken" 14 bekanntgab, eine größere Anzahl von Personen in Haft zu nehmen. Im Zusammenhang mit dieser Verhaftungsaktion erfuhr die Gestapo auch von der Vervielfältigung des "Wachtturms“ im Keller der Gärtnerwohnung des Grundstückes Grinzinger Allee 54. Doch die Geräte dort waren bereits vorsorglich beiseite geschafft worden. In den nächsten Wochen und Monaten wechselte der Standort der „Presse“ oftmals, bis in einem Schrebergartenhaus ein erneutes Versteck angelegt wurde. Die Gestapo suchte unterdessen mit großem Aufwand nach der illegalen Druckerei. „Erst nach umständlichen Ermittlungen", so das Wiener Sondergericht im Urteil gegen die Schriftenhersteller, ,konnte der Herstellungsort der Druckschriften festgestellt, der Schacht entdeckt und die darin untergebrachten Vervielfältigungsapparate mitsamt der Schreibmaschine und dem übrigen Material aufgefunden und sichergestellt werden."15

$\mathrm{Zu}$ jener Zeit wurde es immer schwieriger, die Verbindungen mit dem Berner Büro aufrechtzuerhalten. Auch die Einfuhr von Wachtturm-Ausgaben über Bratislava (Slowakei) war nur noch für kurze Zeit möglich. Als für die Überbringung

12 Vgl. Zinnhobler, Oberösterreich, S. 199, 204-206.

13 Die als Erstdruck 1939 in New York erschienene und in hoher Auflage verbreitete Schrift richtete sich gegen alle „totalitären Mächte“ (genannt wurden: der Papst, Hitler, Stalin, Franco und Mussolini), wobei der Hitlerfaschismus als deren grausamste Komponente geschildert wurde. „Faschismus oder Freiheit“ meint dabei nicht etwa den Gegensatz zwischen einem autoritären Regime und einem demokratischen Gemeinwesen; der Titel darf also nicht im Sinne einer politischen Kampfschrift mißverstanden werden. Vielmehr zielt auch diese Themenstellung auf die für die Bibelforscherlehre zentrale "Streitfrage“, die in den Worten Rutherfords lautet: „Soll die Welt durch den auf den Thron erhobenen König Jehovas, durch Christus, in Gerechtigkeit regiert werden, oder sollen selbstsüchtige Willkür-Diktatoren über sie herrschen? Allerdings können Menschen diese Streitfrage nicht entscheiden; aber bald wird der Herr sie lösen, und ein jeder Mensch muß sich für die eine oder die andere Seite entscheiden und die Folgen tragen." (Rutherford, Faschismus oder Freiheit, S. 3)

14 Gestapo Wien, Tagesrapport vom 2.11.1939, zit. nach Jahrbuch 1989, S. 105.

15 SG Wien, 1 KLs 29/40, Urteil vom 28.1.1941, zit. nach ebenda, S. 110. 
von Schriften kein Weg mehr gefunden werden konnte, gelang es jedoch, über die italienische Grenze Diapositive von Wachtturm-Artikeln ins Land zu schaffen. Eine im Westen Tirols ansässige Zeugin Jehovas fertigte nach deren Vergrößerung Matrizen für die Vervielfältigung an; die Übergabe der Abzüge erfolgte auf einer hochgelegenen Alm, von der aus die weitere Verteilung vorgenommen wurde.

Zwei Monate nach der Verhaftungsaktion, um die Jahreswende 1939/1940, hatten Ernst Bojanowski, Anna Voll und Ludwig Cyranek Wien verlassen, um in Deutschland die Widerstandsaktivitäten der IBV zu koordinieren. Der österreichische Landesleiter Peter Gölles wurde im Rahmen einer vom Reichssicherheitshauptamt für den 12. Juni 1940 angeordneten „staatspolizeilichen Aktion“, die - wie es im Erlaß heißt - ,generell für das ganze Reichsgebiet“ galt und ,schlagartig durchzuführen" 16 war, zusammen mit 44 anderen Bibelforschern festgenommen ${ }^{17}$. Nach den beiden Verhaftungsaktionen vom Oktober 1939 und Juni 1940 war die Untergrundorganisation der österreichischen Zeugen Jehovas weitgehend zerschlagen. Wie zuvor in Deutschland bestanden jetzt lediglich noch kleine Zirkel, die nur noch gelegentlich zusammenfanden und keine größere Wirksamkeit mehr zu entfalten vermochten.

Gegen die Verhafteten gingen die Verfolgungsinstanzen mit großer Härte vor. Zumeist wurden sie nach den neuerlassenen Kriegsgesetzen wegen „Teilnahme an einer wehrfeindlichen Verbindung“ oder wegen „Zersetzung der Wehrkraft“ zu hohen Gefängnis- und Zuchthausstrafen verurteilt, wobei das Strafmaß sich in der Mehrzahl der Fälle zwischen zwei und drei Jahren Zuchthaus bewegte ${ }^{18}$. Nach der Strafverbüßung erfolgte in der Regel ihre Überstellung in ein Konzentrationslager. Von der Gestapo wurden aber auch zahlreiche Zeugen Jehovas, ohne daß gegen sie ein Strafverfahren angestrengt wurde, unmittelbar in die KZs eingewiesen. Die Zahl der Todesopfer war - nicht zuletzt aufgrund der mörderischen Bedingungen, denen in den Jahren 1939 bis 1942 die im KZ Mauthausen inhaftierten Bibelforscher ausgesetzt waren ${ }^{19}$ - sehr hoch. Insgesamt wurden von der österreichischen IBV-Sektion, die 1937, also vor der „Angliederung“, 549 „Verkündiger“ umfaßte, soweit bekannt, 445 Angehörige für Monate oder Jahre in Gefängnissen

16 Gestapo-Erlaß vom 8.6.1940, zit. nach ebenda, S. 108f.

17 Vgl. Neugebauer, Wien, S. 166f; Jahrbuch 1989, S. 109. Gegen die bei der Verhaftungsaktion im Juni 1940 festgenommenen Zeugen Jehovas fand vor dem SG Wien ein Verfahren statt, in dem gegen Peter Gölles wegen „Zersetzung der Wehrkraft“ die Todesstrafe beantragt wurde. Das Urteil des Sondergerichtes lautete auf zehn Jahre Zuchthaus.

$18 \mathrm{Vgl}$. Neugebauer, Wien, S. 168ff.

19 In dem bei Linz gelegenen KZ Mauthausen, in dem die Todesrate insgesamt sehr hoch lag - 1940 betrug sie $76 \%$ (vgl. Pingel, Häftlinge, S. 82) -, wurden in der Anfangszeit die Bibelforscher-Häftlinge, unter denen die Österreicher eine größere Zahl bildeten, zielstrebig zugrunde gerichtet. Nachdem Ende Februar 1940 im Lager eine Musterungskommission erschienen war und Berichten zufolge ungefähr 35 Zeugen Jehovas die Unterschrift im Wehrpaß verweigerten, wurden diese im Mauthausener Steinbruch systematisch zu Tode geschunden. Der strenge Winter 1939/1940 mit Temperaturen von 20 bis 30 Grad Kälte, Hunger und Mangel an Kleidung taten ein übriges, so daß allein in den vier Monaten zwischen Januar und April 1940 die Zahl der Opfer unter den dort inhaftierten 143 Zeugen Jehovas (Stand 1.1.1940) 52, nach anderen Angaben 53 Personen, betrug (36,37\%), wobei noch zu berücksichtigen ist, daß 25 Bibelforscher das „Glück“ hatten, am 18.2.1940 nach Dachau überstellt zu werden. Angaben nach Chêne, Mauthausen, S. 182; Gostner, 1000 Tage im KZ, S. 96; Marక̌álek, Mauthausen, S. 273; EB Hubert Mattischek, 27.5.1986; EB Alois Moser, 23.5.1986. 
oder Konzentrationslagern inhaftiert. Der nationalsozialistischen Verfolgung fielen mindestens 142 österreichische Zeugen Jehovas zum Opfer, von denen 94 in Konzentrationslagern oder Gefängnissen umkamen, während 48 nach straf- und wehrmachtgerichtlichen Todesurteilen hingerichtet wurden, wobei es sich zumeist um durch das Reichskriegsgericht abgeurteilte Kriegsdienstverweigerer handelte ${ }^{20}$.

Ähnlich wie in Österreich entfaltete die IBV auch in den deutschsprachigen Gebieten der Tschechoslowakei, die im Oktober 1938 als Reichsgau „Sudetenland“ dem ,Führer-Staat“ eingegliedert wurden, eine rege Tätigkeit. Verhaftungen von Zeugen Jehovas setzten hier sofort nach dem Einmarsch der Wehrmacht ein, da die pronazistische Sudetendeutsche Partei über IBV-Angehörige bereits im Vorwege Informationen zusammengetragen hatte ${ }^{21}$. Auch im folgenden Frühjahr wurden mehrere Aktionen gegen die IBV im Sudetengebiet durchgeführt ${ }^{22}$.

In der Tschechoslowakei, die auf Grund der Grenzlage etlichen deutschen Zeugen Jehovas eine zeitweilige Zufluchtstätte geboten hatte, traf das dortige Zweigbüro der Watch Tower Society unterdessen Vorkehrungen für den Fall, daß NaziDeutschland nach der „Heimholung“ des Sudetenlandes auch den Reststaat besetzen würde. Als am 30. März 1939, zwei Wochen nach der Annexion, die Gestapo im Prager Zweigbüro erschien, waren große Teile des Inventars und der Maschinen bereits außer Landes gebracht; drei Druckpressen gelangten beispielsweise in die Niederlande und dienten seitdem dort zur Herstellung von Bibelforscherschriften, die für die deutschen Glaubensgeschwister bestimmt waren ${ }^{23}$. Der aus Hamburg gebürtige frühere Leiter der WTG-Dienstabteilung und vormalige Prokurist des Magdeburger Bibelhauses, Heinrich Dwenger, der seit 1936 den tschechischen IBV-Zweig leitete und zeitweilig auch für das Werk in Ungarn zuständig war, hatte sich zuvor in die Schweiz abgesetzt, ,so wie die Gesellschaft ihm Anweisung gegeben hatte“ 24 . In den folgenden Wochen fahndete die Gestapo in der mit „Führererlaß“" vom 16. März 1939 als „Protektorat Böhmen und Mähren“ dem Reich einverleibten „Tschechei“ dann gezielt nach weiteren deutschen IBV-Angehörigen. Zunächst unbehelligt blieben dagegen die Zeugen Jehovas tschechischer Nationalität. Dies änderte sich ab etwa Anfang 1940, als die Verhaftungen auch auf tschechische und andere ausländische Zeugen Jehovas ausgeweitet wurden 25 .

\section{Radikalere Akzente}

Ungefähr seit Mitte 1939 formierten sich im ,Altreich“ Neuansätze eines organisierten Widerstandes. Eine zentrale Rolle bei der Reorganisation der deutschen IBV-

20 Zahlenangaben nach Jahrbuch 1989, S. 133f.; Cole, Jehovas Zeugen, S. 199. Leicht abweichende Zahlen nennt Radomir Luza: Danach starben 131 österreichische Zeugen Jehovas ,, at the hands of the Nazis"; 25 wurden hingerichtet. Vgl. Luza, Austria, S. 63.

21 Vgl. Jahrbuch 1938, S. 215f.; Grün, Pospischiel, S. 64ff.; EB Karl Hanl, 24.11.1987. Siehe auch S. $29 \mathrm{f}$.

22 Vgl. Sicherheitsdienst der SS, 1. Vierteljahreslagebericht 1939, Meldungen aus dem Reich, Band 2, S. 237.

23 Vgl. Jahrbuch 1986, S. 130.

24 Jahrbuch 1987, S. 146.

25 Zur Verfolgung der Bibelforschervereinigung in der Tschechoslowakei vgl. näher Jahrbuch 1972, S. 134-136. 
Sektion, die ihre führenden Funktionäre verloren hatte, übernahm der bereits erwähnte Ludwig Cyranek. Der 1907 geborene Cyranek gehörte zu den jüngeren dynamischen Kräften, verfügte aber gleichwohl bereits über eine längere Erfahrung in verschiedenen Tätigkeitsbereichen der Wachtturm-Gesellschaft. So hatte er seit Ende der zwanziger Jahre hauptamtlich im Magdeburger Zweigbüro mitgearbeitet, bis er im Oktober 1931 dem Ruf der Gesellschaft gefolgt und als Missionsarbeiter ins benachbarte Ausland gegangen war. In den nächsten drei Jahren knüpfte er Kontakte in den Niederlanden, in Frankreich, Jugoslawien, Österreich und in der Schweiz. Nachdem er 1934 nach Deutschland zurückgekehrt war und sich an den IBV-Aktivitäten im Widerstand beteiligt hatte, wurde er 1936 in Mannheim verhaftet und anschließend zu zwei Jahren Gefängnis verurteilt. Sofort nach seiner Haftentlassung begann Ludwig Cyranek damit, Vorbereitungen für einen Wiederaufbau der 1937/38 zerschlagenen illegalen Organisation zu treffen. Zu diesem Zweck besuchte er im Frühjahr 1939 in mehreren Orten Glaubensgeschwister und bat diese, ihn bei dem Vorhaben zu unterstützen.

$\mathrm{Zu}$ den aufgesuchten Personen gehörte Julius Engelhard, ein Dachdecker aus Karlsruhe ${ }^{26}$. Seit Juni 1939 druckte Engelhard nach Arbeitsschluß auf dem Vervielfältigungsgerät seines Arbeitgebers Bibelforscherschriften, für die eine pensionierte Lehrerin aus Bruchsal die Matrizen erstellte. Im Herbst 1939 wäre Engelhard der Gestapo, die durch Verrat von der von ihm benutzten Deckadresse erfahren hatte, beinahe in die Falle getappt. Doch obgleich ein Gestapo-Mann ihn beim Betreten des Hauses schon gefaßt hatte, gelang es ihm noch, sich loszureißen und auf der Straße in der Menschenmenge unterzutauchen. Die eingeleitete Fahndung verlief ergebnislos. Engelhard lebte seitdem im Untergrund, zunächst in Bruchsal und dann ab März 1940 in Essen. Dort leitete der von Cyranek im April des Vorjahres für eine Mitarbeit geworbene Paul Noernheim eine recht aktive IBV-Gruppe. Der Initiator und Aktivist Cyranek fand, nachdem er Ende 1939 nach einer halbjährigen Tätigkeit bei den Wiener Glaubensgeschwistern ins „Altreich“ zurückkehrte, im Südwesten und Westen ein mittlerweile eng geknüpftes Netz von Gruppen unentwegter IBV-Angehöriger vor. Allein im Ruhrgebiet beteiligten sich 1940 ungefähr 240 in verschiedenen Zellen organisierte Zeugen Jehovas an der Wiederaufnahme der Aktivitäten ${ }^{27}$. Von Stuttgart aus koordinierte Cyranek die Verteilung des „Wachtturms“ und der anderen Bibelforscherschriften. Cyranek verfaßte, wie zuvor die Reichsdiener, Tätigkeitsberichte über das Verkündigungswerk in Deutschland, die nunmehr in die Niederlande übermittelt wurden. Diese schrieb die für ihn als Sekretärin arbeitende Maria Hombach mit Zitronensaft auf Seiten, die mit belanglosem Text beschrieben waren. Im niederländischen Zweigbüro in Heemstede bei Haarlem wurde der Berichtstext durch Aufbügeln wieder sichtbar gemacht. Auch eine Vielzahl weiterer konspirativer Techniken, wie Decknamen und Tarnsprache (die WTG wurde z.B. als „Mutter“ bezeichnet), kamen zum Einsatz. Mit Hilfe eines gefälschten Passes gelang es Cyranek auch, zweimal in die Niederlande zu reisen, um mit dem dortigen IBV-Zweigdiener Robert Arthur Winkler und dem ehemaligen Prokuristen des Magdeburger Bibelhauses, Heinrich Dwenger, der sich

26 Zum folgenden vgl. Koch, M., Engelhard, S. 95ff.; BA, R 60 II/99-3.

27 Vgl. Steinberg, Essen, S. 165. 
1938 aus Prag über die Schweiz in die Niederlande abgesetzt hatte, das weitere Vorgehen in Deutschland zu beraten 28 .

Dem niederländischen Zweigdiener Winkler ${ }^{29}$ war von der Watch Tower Society nach der Auflösung des vorübergehend zuständigen Prager Büros die Verantwortung für den deutschen und österreichischen Zweig mit übertragen worden. Die nach der Verhaftung von Heinrich Dietschi und der weitgehenden Zerschlagung der IBV im Herbst 1937 verwaiste Funktion eines „Reichsdieners“ blieb hingegen bis Kriegsende unbesetzt ${ }^{30}$. Die Anleitung der im Deutschen Reich unter Führung von Ludwig Cyranek (Südwest- und Westdeutschland) und Peter Gölles (Österreich) operierenden Gruppen ${ }^{31}$ erfolgte von den Niederlanden aus; die der danach unter Führung von Narciso Riet und Julius Engelhard (Süd- und Westdeutschland, Österreich und „Protektorat Böhmen und Mähren“) sowie Wilhelm Schumann und Franz Fritsche (Magdeburg/Berlin) arbeitenden Organisationen erfolgte nach der Verhaftung Robert Arthur Winklers Ende Oktober 1941, soweit überhaupt noch möglich, direkt über das Zentraleuropäische Büro in Bern.

Die Reorganisation der IBV in einzelnen Landesteilen - im Norden und Osten des Reiches kam es während der Kriegsjahre allerdings zu keiner vergleichbaren Herausbildung von überregionalen Zusammenhängen ${ }^{32}$ - registrierte auch der Sicherheitsdienst der SS. Am 19. Februar 1940 berichtete der SD, daß die Bibelforscher ,durch zersetzende Propaganda in verschiedenen Orten des Reiches wieder in Erscheinung" getreten seien: „So wurden in Salzburg, Berlin, Plauen, Würzburg und Stuttgart Anhänger der internationalen Bibelforscher verhaftet. Es wurde festgestellt, daß verschiedene der Festgenommenen Anweisungen aus Holland erhielten."33 Verstärkte Aktivitäten der IBV meldeten die SD-Informanten zu dieser Zeit auch aus Berlin, Dortmund, Dresden, Graz, Karlsbad, Küstrin, Niederdonau

28 UaP Richard Singelenberg, Vernehmungsprotokoll Ludwig Cyranek, II B 1 - 69/40.

29 Der deutsche Zeuge Jehovas Robert Arthur Winkler leitete erst seit Anfang 1940 die niederländische IBV-Sektion. Nach seiner Festnahme am 21.10.1941 kam er über das KZ Vught nach Sachsenhausen, das er ebenso wie den ,Todesmarsch“ im April 1945 überleben konnte. $\mathrm{Zu}$ Winklers Person und Tätigkeit vgl. Graffard/Tristan, Bibelforscher, S. 148f., 211; Jahrbuch 1986, S. 134, 154ff,; Der Wachtturm, 1.6.1972, S. 335.

30 Abweichende Angaben in der Literatur, so bei Steinberg, der für die Kriegszeit „,von dem in den Niederlanden residierenden ehemaligen Reichsleiter Winkler" und dessen "Landesdiener" Ludwig Cyranek spricht (Steinberg, Essen, S. 165), und bei Koch, der in Engelhard den „Reichsdiener" sieht (Koch, M., Die kleinen Glaubensgemeinschaften, S. 423), sind nicht zutreffend. Steinberg hat sich bei der Interpretation der Gestapo-Akten täuschen lassen. Ein von der Gestapo Dresden unter anderem aufgrund der Vernehmungen von Ludwig Cyranek gefertigtes Schaubild über die „Illegale IBV in Deutschland und Österreich nach dem Stande vom 15.3.1940“ (abgedruckt in: Steinberg, Essen, S. 284) nennt als Reichsleiter für Deutschland und Österreich: „Winkler, Holland“. Bei „Winkler“ handelt es sich jedoch nicht um den einstigen Reichsdiener Fritz Winkler, sondern um den genannten Robert Arthur Winkler.

31 Den Anweisungen Winklers zufolge war für den Osten Deutschlands Hans Müller und für den Norden - zumindest zeitweilig - Ernst Bojanowski zuständig. Soweit bekannt, kam es in diesen Landesteilen aber nicht zu einer vergleichbaren überregionalen Wirksamkeit.

32 Vgl. Garbe, Gott mehr gehorchen, S. 199; Kühl, Friedrichstadt, S. 187; Marssolek/Ott, Bremen, S. 307.

33 Sicherheitsdienst der SS, Meldung Nr. 55 vom 19.2.1940, Meldungen aus dem Reich, Band 3, S. 776 . 
und Nord-Schleswig ${ }^{34}$. Zur erhöhten Aufmerksamkeit des SD trug auch die mit Kriegsbeginn an Bedeutung gewinnende Verweigerung des Militärdienstes durch die Zeugen Jehovas bei. In einem Bericht, den der Chef der Sicherheitspolizei und des SD, Reinhard Heydrich, am 20. Oktober 1939 dem Chef der Reichskanzlei, Reichsminister Hans-Heinrich Lammers, über ,die Einstellung der politischen Kirchen und Sekten zur gegenwärtigen Lage" erstattete, war unter Verweis auf die von den Zeugen Jehovas propagierte und praktizierte Kriegsdienstverweigerung die Rede davon, daß die Bibelforscher nunmehr zu „offener Sabotage und offenem Widerstand“ übergehen würden. Zum Beleg wurde auf den Fall des Funkers Berthold Mewes aus Paderborn verwiesen, der als "fanatischer Bibelforscher" seinem Abteilungskommandeur gegenüber erklärt habe, daß „sein Gewissen ihm verbiete, in der Wehrmacht Dienst zu tun“35.

Nach der Besetzung der Niederlande, Belgiens und Nordfrankreichs wurde es im Frühjahr 1940 zunehmend schwerer, den „Wachtturm“ und andere Schriften nach Deutschland einzuschleusen. Fast alle an Deutschland angrenzenden Staaten waren nunmehr in der Gewalt der Nationalsozialisten oder wurden von Regierungen beherrscht, die mit Hitler-Deutschland verbündet waren. In den dann noch auf dem europäischen Festland verbleibenden Staaten verfügte die Watch Tower Bible and Tract Society mit Ausnahme der Schweiz über keine ausreichende organisatorische Infrastruktur (so in den Balkanstaaten) oder war dort ebenfalls verboten beziehungsweise mit verbotsähnlichen Beschränkungen belegt (so in Portugal, Spanien und der Sowjetunion). Da die deutsch-schweizerische Grenze immer undurchlässiger wurde, wichen die IBV-Kuriere darauf aus, die Schriften in Einzelexemplaren oder entsprechende Manuskriptvorlagen zunächst von der Schweiz nach Frankreich oder nach Italien und dann von dort ins Deutsche Reich zu schmuggeln ${ }^{36}$. Doch auch der Aufbau neuer Übermittlungswege konnte nicht verhindern, daß die Versorgung mit Schriften zeitweise gänzlich unterbrochen wurde. Gleichzeitig bedeutete dies, daß eine Anleitung der noch verbliebenen im Untergrund tätigen IBV-Gruppen von seiten der Brooklyner Watch Tower-Zentrale nicht mehr beziehungsweise nur noch sehr sporadisch stattfand. Die Zeugen Jehovas in Deutschland waren in allen Fragen zunehmend auf sich allein gestellt.

Auch während der Kriegsjahre gelang es einigen IBV-Gruppen, Schriften illegal zu drucken. Die Texte wurden in kleiner Auflage verteilt. Sie dienten zur Stärkung der Angehörigen der eigenen Glaubensgemeinschaft. Die Vervielfältigung und das Erscheinen des „Wachtturms“ konnte in diesen Jahren allerdings nur dann geschehen, wenn den Kurieren die „Einfuhr“ des Materials dazu gelang. Soweit möglich, entnahm man die Artikel für den „Wachtturm" der in der Schweiz hergestellten deutschsprachigen Ausgabe, gegebenenfalls versuchte man, auf die Übersetzung anderssprachiger Ausgaben auszuweichen, natürlich nur, insofern diese überhaupt vorlagen. Auch ging man nunmehr dazu über, die „Wachttürme“ um eigene, selbst-

$\overline{34}$ Vgl. Sicherheitsdienst der SS, Meldung Nr. 26 vom 8.12.1939, Nr. 30 vom 18.12.1939, Nr. 57 vom 23.2.1940, Meldungen aus dem Reich, Band 3, S. 547, 581 f., 797.

35 Der Chef der Sicherheitspolizei und des SD, Bericht über die gegenwärtige politische Haltung der Kirchen und Sekten, mit Anschreiben vom 20.10.1939 dem Chef der Reichskanzlei übermittelt, abgedruckt in: Poliakov/Wulf, Das Dritte Reich, S. 194-198 (195).

36 Vgl. Der Wachtturm, 1.1.1979, S. 22. 
verfaßte Beiträge oder andere Hinzufügungen zu erweitern. So wurden zum Beispiel „Wachttürme“ um auszugsweise Abschriften von Abschiedsbriefen ergänzt, die von verurteilten kriegsdienstverweigernden Zeugen Jehovas an ihre Angehörigen vor der Urteilsvollstreckung geschrieben worden waren („Briefe von Brüdern, die um der Wahrheit und Gerechtigkeit willen von Satans Dienern ermordet wurden") 37 .

Inhaltlich rückte neben solchen Schriftstellen, die das Verfolgungsschicksal der Rechtgläubigen zum Thema haben (z. B. 1. Petr; Hebr 10, 32-34; 1. Ko 4, 12; Mt $5,10)$ und der für die Bibelforscherlehre zentralen Offenbarung des Johannes nun verstärkt apokalyptisches Gedankengut aus dem Buche Daniel in den Mittelpunkt der biblischen Betrachtungen. In den „Betrachtungen über die Prophezeiungen Daniels" wurde die in dieser Schrift enthaltene Endzeitvision vom Ringen des Königs des Südens (Ägypten) gegen den König des Nordens (Syrien, Babylonien) ${ }^{38}$, die die in hellenistischer Zeit waltenden Diadochenkämpfe theologisch reflektiert, auf die gegenwärtige Kriegslage projiziert ${ }^{39}$. Danach standen Hitler und die Achsenmächte (das Reich des Nordens) den alliierten Staaten (dem Reich des Südens) unversöhnlich gegenüber. In ihrem verzweifelten Kampf um die Totalherrschaft über die Erde werde zunächst der „König des Nordens“ untergehen und der „ewigen Vernichtung" anheimfallen, danach werde dieses Schicksal auch seinen Widerpart ereilen. Im Anschluß an diese Entscheidungsschlacht werde zum Segen der Menschheit eine gerechte Regierung unter der Regentschaft Christi errichtet werden. In solchen und ähnlichen Variationen zum Thema „Harmagedon und das kommende Gottesreich“" wurde der Zweite Weltkrieg als Teil eines göttlichen Planes gedeutet, als offenkundiger Beweis für das unaufhaltsame Herannahen des Endes der alten Welt ${ }^{40}$.

Während des Krieges wurde daneben in unregelmäßiger Folge ein „Mitteilungsblatt der deutschen Verbreitungsstelle des W.T. an alle treuen Zeugen Jehovas in Deutschland“ erstellt. Ebenso wie bei den zu jener Zeit verteilten „Wachttürmen“ handelte es sich um maschinenschriftliche Rundschreiben im Umfang von zumeist sechs bis zehn Seiten ${ }^{41}$. Im „Mitteilungsblatt" standen Fragen im Mittelpunkt, die unmittelbar die Lage der Zeugen Jehovas in Deutschland betrafen. Spezielle bibli-

37 Vgl. beispielsweise Wachtturm: „Erkenntnis“, o. D. [1941], UaP Günther Pape; Wachtturm: „Fürchtet Euch nicht“”, o. D. (Bericht über das Schicksal des Zeugen Jehovas August Dickmann, der 1939 erschossen wurde, weil ,er dem Rufe zum Abschlachten von Menschenbrüdern nicht folgte"), zit. nach Neugebauer, Wien, S. 173.

Dan 11, 40ff.

39 Vgl. Hetzer, Augsburg, S. 642.

40 Der alternde WTG-Präsident Joseph Franklin Rutherford, für den der Beginn des Zweiten Weltkriegs das untrügliche Herannahen des Weltenendes bestätigte und der deshalb „felsenfest“ mit „Harmagedon“, aber keineswegs mit einer erneuten Nachkriegsperiode rechnete, starb am 8.1.1942. Sein Nachfolger Nathan H. Knorr löste die Glaubensgemeinschaft ein Stück weit aus dieser unmittelbaren Untergangsorientierung; in Brooklyn erkannte man, daß es auch noch vor dem Ende des gegenwärtigen „Weltensystems“ für das Predigtwerk zahlreiche Aufgaben zu erledigen galt.

41 Die einzelnen Schriften sind äußerst schwer zu identifizieren. Zuweilen ist eine Zuordnung kaum möglich, da angesichts der Verfolgungssituation die Vervielfältigungen gewöhnlich ohne irgendwelche näheren Angaben (Titel, Datum etc.) erschienen. Der Wachtturm war zumeist mit dem Kürzel „W.T.“ gekennzeichnet, während das „Mitteilungsblatt der deutschen Verbreitungsstelle des W.T.“ mit dem Kürzel „M.“ benannt wurde. 
sche Themen behandelnde Wachtturm-Artikel wurden zum Beispiel daraufhin befragt, welche Folgerungen aus ihnen für das konkrete Verhalten zu ziehen seien. Das „Mitteilungsblatt“ war insofern geprägt von Ratschlägen und Handlungsanweisungen. So wurde beispielsweise in einem Anfang 1942 verbreiteten „Mitteilungsblatt" dazu aufgefordert, nicht nur für alle nationalsozialistischen Sammlungen jede Unterstützung zu verweigern, sondern auch dem Deutschen Roten Kreuz keinerlei Spenden zukommen zu lassen: „Das Deutsche Rote Kreuz unterstützen, heißt den ,Krieg ' unterstützen. Wenn die Nazis etwas Gutes tun wollen für ihre Verwundeten, dann sollen sie ihren mörderischen Krieg beenden und keine Verwundeten mehr schaffen." 42 Im September des gleichen Jahres berichtete das „Mitteilungsblatt“ über die von der SS in der Sowjetunion verübten Kriegsgreuel. Zwar könne man sich nicht für die Richtigkeit derartiger Meldungen verbürgen, aber man halte die SS für ,durchaus fähig hierzu; denn wer den Reichstag anzündet und es anderen in die Schuhe schiebt, der ist auch zu weiteren Taten dieser Art fähig“43. Vor dem Hintergrund dieser Verbrechen sei der Untergang Deutschlands vorgezeichnet. Ein Vierteljahr vor Stalingrad findet sich die folgende Feststellung: „Es ist das Verdienst Hitlers und seiner Nazi, dieses blühende Land ruiniert zu haben. Hunger, Elend, Zerfall sind kennzeichnend für die Lage Deutschlands.“

Die politischen und wirtschaftlichen Verhältnisse im Reich wurden mit jenen, in der NS-Propaganda als Schreckgespenst hingestellten Verhältnissen in der Sowjetunion verglichen, da dieser Vergleich zeige, daß die ausgegebene Parole von der „Rettung Deutschlands vor dem Bolschewismus“ nur der Rechtfertigung des Angriffskrieges diene:

„Angenommen, der Bolschewismus hätte Deutschland überflutet, was hätte es dann für Veränderungen gegeben? Gar keine! Die Nazi-Presse wies immer kritisierend auf Dinge hin, die typisch und charakteristisch für das bolschewistische Rußland sein sollen, und ausgerechnet in diesen Zügen gleichen sich Sowjetrußland und Nazi-Deutschland wie ein Ei dem anderen. Rußland hat einen grausamen Diktator, den haben wir auch. Dort herrscht blutiger Terror, bei uns ebenfalls. Rußland hat die GPU und wir die Gestapo. Dort Sibirien und GPU-Gefängnisse, hier die Konzentrationslager und Gestapo-Keller.“

Wenn derartige Ausführungen auch Reminiszenzen an eine politikwissenschaftliche Totalitarismustheorie wecken, so wird man gleichwohl hierin keinen politischen Deutungsversuch zu sehen haben. In der Sicht der Verfasser der „Mitteilungsblätter" war weiterhin das gegenwärtige Weltgeschehen ursächlich auf eine Offensive Satans und des von ihm getragenen ,römischen Religionssystems“ zurückzuführen, wobei allein schon die Begriffswahl eine weitere Radikalisierung signalisierte. So wurde der Papst nun als ,oberster Religionsgangster“ oder „Gangsterhäuptling“ bezeichnet; er sei der „sichtbare Hauptschuldige an diesem Kriege“,

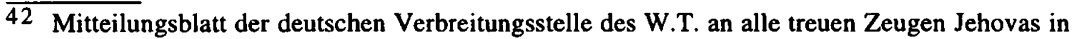
Deutschland, o. D. [Anfang 1942], zit. nach Kalous, Bibelforscher, Anhang 26a.

43 DCB, Mitteilungsblatt der deutschen Verbreitungsstelle des W.T., September 1942, zitiert in der Anklageschrift des Oberreichsanwaltes beim VGH, 8 J 131/43, vom 3.8.1943. Die folgenden Zitate sind ebenfalls dieser Schrift entnommen. 
und in den Diensten dieses „Totalitätsgottes" stünden in Deutschland Hitler, in Italien Mussolini und in Spanien Franco.

Beim Vergleich mit dem die Ansichten der Watch Tower-Leitung darstellenden „Wachtturm“ zeigt sich das im Inland verfaßte „Mitteilungsblatt“ als keineswegs zurückhaltend. Vielmehr entsteht der Eindruck, als dominierten extreme Positionen unter den im Untergrund beziehungsweise in den Konzentrationslagern wirkenden Aktivisten. Die Glaubensgeschwister wurden zur Intensivierung des Widerstandes und zu entschlossenem Bekenntnis im Angesicht des Feindes aufgerufen. Rücksichtnahmen auf persönliche Umstände wurden als Glaubensschwäche ausgelegt. Halbe Sachen sollte es nicht geben im sich zuspitzenden Kampf mit den ,satanischen Mächten“, es galt, so die offenkundige Botschaft des „Mitteilungsblattes“, stets aufs Ganze zu setzen.

Dies veranschaulicht besonders deutlich das mit „Beantwortung einiger Fragen“ überschriebene „Mitteilungsblatt“ vom Juli 1942, das sich mit jenen Punkten auseinandersetzte, die zu Kontroversen und Abweichungen geführt hatten. Dazu zählten in erster Linie die Frage des waffenlosen Kriegsdienstes und des Eides, der Umgang mit den aus der Gemeinschaft Ausgeschlossenen und das Verhältnis zu jenen, die sich zurückgezogen hatten und sich abwartend verhielten. Von einem radikalen Standpunkt aus erfolgte eine scharfe Abrechnung mit den „Lauen“ und „Furchtsamen“ in den eigenen Reihen. Wer beispielsweise im waffenlosen Dienst eine mögliche, zumindest dem christlichen Tötungsverbot Rechnung tragende Alternative zur kompromißlosen, in jedem Fall das Todesurteil nach sich ziehenden Kriegsdienstverweigerung sah, und sich deshalb zu einem derartigen Dienst bereit erklärte, habe sich - selbst wenn auf die Ablegung des Eides verzichtet wurde ${ }^{44}$ in die „Falle des Teufels“ locken lassen und seinen Bund mit Jehova gebrochen. Denn es käme ,nicht auf Eid und Schießen an, sondern darauf, ob man Satans Organisation dient oder nicht“. Nicht unzutreffend fügte das „Mitteilungsblatt“ hinzu: „Das Schießen ist die allerletzte Wirkung einer ganzen Kette von Handlungen, die notwendigerweise vorausgehen müssen, um das Schießen zu ermöglichen, und alle, die in dieser Kette mitwirken, sind genau so nötig und genau so verantwortlich wie der am Ende der Kette stehende Schütze. "45 Es gelte jedoch für

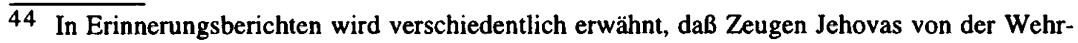
macht bzw. von den Kriegsgerichten der Verzicht auf die Eidesleistung angeboten wurde. Beispielsweise sei es einem seit Anfang der zwanziger Jahre aktiven Bibelforscher, der schon im Ersten Weltkrieg als Offizier gedient hatte und über einige einflußreiche Verbindungen verfügte, nach der Heranziehung zur Wehrmacht ermöglicht worden, unter Verzicht auf die Ableistung des Eides im Heimatgebiet zu dienen (vgl. EB Bruno Knöller, 23.11.1987). Von der Verordnungs- bzw. Gesetzeslage her war dieser Weg eigentlich ausgeschlossen. Durch das Gesetz über die Vereidigung der Beamten und der Soldaten der Wehrmacht vom 20.8.1934 wurde der auf die Person des „Führers“ zu leistende Fahneneid (RGBl. 1934 I, S. 785) für alle Wehrmachtangehörigen bindend; nur Mennoniten wurden auf Antrag vom Eid befreit und leisteten statt dessen ein Gelöbnis verbunden mit Handschlag (Bestimmungen für die Vereidigung im Heer und in der Luftwaffe vom 20.9.1935, abgedruckt in: Dade, Fahneneid, S. 50; Heckel, Wehrverfassung, S. 182, Anm. 2). Diese Möglichkeit galt ausschließlich für Angehörige dieser Glaubensgemeinschaft (siehe auch S. 167, Anm. 54). In der Literatur vertretene gegenteilige Annahmen (so bei Fauck, Fahneneid, S. 472) sind unzutreffend.

45 „Beantwortung einiger Fragen. Mitteilungsblatt der deutschen Verbreitungsstelle des W.T.“, Juli 1942 (Kopie in Besitz des Verf., Hervorhebung im Original). Die folgenden Zitate entstammen dieser Schrift. 
alle Aufrichtigen eine kompromißlose Haltung einzunehmen und keinerlei Versuchungen zu erliegen ${ }^{46}$ : „Wir haben Kenntnis von dem Verlauf einer Anzahl von Voruntersuchungen und Verhandlungen gegen kriegsdienstverweigernde Zeugen Jehovas und wissen daher, daß fast immer der Versuch gemacht wurde und jedenfalls noch immer gemacht wird, gerade mit dieser verkehrten Schlußfolgerung, die treuen Zeugen Gottes in die Falle zu locken.“

Doch noch könnten jene, die ihr Verhalten nicht an den „Richtlinien des Gesetzes Gottes“ ausgerichtet hätten, ,ihren Fehler wieder gutmachen“, allerdings nur „durch eilige Umkehr“. Um zu demonstrieren, wie diese auszusehen habe, erfolgte der Abdruck eines Briefes, in dem ein Zeuge Jehovas, der nach einem ausgesprochenen Todesurteil „sich betören ließ, Kriegsdienst zu tun“, über seine nunmehrige Sinnesänderung berichtete. Spätestens seitdem er das ,grausame Morden“ an der Ostfront gesehen habe, sei ihm klargeworden, daß es gegen Gottes Wille sei, hier wie auch immer mitzutun. Aus diesem Grunde habe er die Uniform wieder abgelegt. Nun gebe es für ihn kein „zurück, nur noch ein vorwärts“: „Und wenn ich noch einmal zum Tode verurteilt werden sollte, wäre mir [dies] gleich. Lieber will ich für den Herrn sterben als für eine Organisation, deren Ende immer näher rückt. [...] Schluß mit der Organisation Satans, es lebe die Theokratie!“ Das „Mitteilungsblatt“ kommentierte: „Seine jetzige Stellungnahme ist der einzig mögliche Weg, ihn vor der Vernichtung zu bewahren." Denn niemand könne zwei Herren dienen: „Man kann keinerlei Kriegsdienst tun und gleichzeitig ein Diener der Theokratie sein."

Beständig wurden die Zeugen Jehovas durch diese Rundschriften ermahnt, ihren Glauben allen Widerständen zum Trotz unbeugsam zu behaupten. Die eindringlichen Beteuerungen, im Widerstand nicht schwach zu werden und sich nicht zu fügen, wurden verbunden mit den Verheißungen für die „Getreuen“ auf der einen, und den Verwerfungen für die „Untreuen“ auf der anderen Seite. Die 1942/43 unter den Zeugen Jehovas kursierende Wachtturm-Ausgabe „Trost für die Verfolgten“ bringt dieses Anliegen besonders deutlich zum Ausdruck ${ }^{47}$. Danach müsse sich das gesamte Handeln der Zeugen an der einzigen Frage messen lassen, welche Regierung herrschen soll, ,diejenige Jehovas oder die des Verfolgers“. Kompromisse seien deshalb undenkbar, es gebe nur klare Entscheidungen. Jeder wisse um die Folgen seiner Wahl, die auf die kurze Formel „Heiligung oder Verdammnis“ gebracht werden könnten:

"Alle, die die Verfolgung bis ans Ende geduldig ertragen und ihre Lauterkeit bis zum Tode bewahren, haben einen Anteil an der Rechtfertigung des Namens Jehovas. Sämtliche Segnungen begleiten dieses Vorrecht. [...] Alle, die ihre Lauterkeit nicht bewahren, unterstützen die Argumente des Teufels und werden sein Los, das ist die ewige Vernichtung, teilen. [...] Der Lohn, den Gott schenkt, ist sicher und unverwelklich und größer als alle selbstsüchtigen Belohnungen, die die gesamten Feindesorganisationen auf Erden denen geben, die der Verfolgung nachgeben. Die, die

$46 \mathrm{Zu}$ den Versuchen der Kriegsgerichte, bei den Angeklagten einen Sinneswandel herbeizuführen, siehe S. 384-388.

47 UaP Günther Pape, W.T.-Ausgabe: „Trost für die Verfolgten“, o. D. [1942]. Die Zeugen Jehovas bezogen sich dabei auf das Wort aus der Bergpredigt Jesu, daß denjenigen, die um der Gerechtigkeit willen Verfolgung erleiden, das Reich der Himmel ist. Vgl. Mt. 5, 2. 
Gesetzlosigkeit gegen Jehova Gott hassen und für die Gerechtigkeit seiner theokratischen Regierung eintreten, werden gesalbt, um Genossen seines ihm gleichenden Sohnes zu sein.“

\section{Untergrundaktivitäten}

Auch in den von deutschen Truppen besetzten Ländern wurden die Zeugen Jehovas hart und rücksichtslos verfolgt ${ }^{48}$. Die deutschen Behörden erließen zumeist ${ }^{49}$ wenige Wochen oder einige Monate nach der Besetzung das Verbot der jeweiligen IBV-Ländersektion ${ }^{50}$. Große Opfer forderte die Verfolgung in den Niederlanden. Dort hatte die Gestapo nach dem Einmarsch der Wehrmacht am 10. Mai 1940 ähnlich wie in der Tschechoslowakei im Vorjahr - sofort die Fahndung nach den aus Deutschland emigrierten Zeugen Jehovas aufgenommen ${ }^{51}$. Drei Wochen später, am 29. Mai, erfolgte durch Erlaß des Reichskommissars Arthur Seyß-

48 Die Verfolgung ausländischer Zeugen Jehovas und deren Beweggründe haben Geschichtsschreiber zuweilen vor Rätsel gestellt. So spricht der polnische Historiker Andrzej J. Kamiński von der ,merkwürdigen Logik der Nazis“, die auch polnische Bibelforscher in die KZs verschickten, ,, anstatt sie als die einzigen Polen zu prämieren, die keine Waffe gegen Hitler in die Hand nehmen wollten" (Kaminski, Konzentrationslager, S. 205). Kamiński hat damit auf die generelle Paradoxie der Verfolgung von Kriegsdienstverweigerern in „Feindstaaten" hingewiesen. Diese Überlegung reduziert jedoch den Konflikt zwischen Nationalsozialismus und Bibelforscherlehre auf die Frage des Waffendienstes und verkennt damit die tieferen Ursachen jenes Konfliktes. Das Motiv für das Vorgehen gegen ausländische Zeugen Jehovas war, deren Betätigung für eine religiöse Organisation zu unterbinden, die spätestens seit der Verfolgung der deutschen Glaubensgeschwister heftig gegen die nationalsozialistische Bewegung agitierte. Zum Beleg kann auch auf eine Aussage von Arthur Seyß-Inquart am 12.6.1946 vor dem Internationalen Militärgerichtshof in Nürnberg verwiesen werden. Nach Angaben des ehemaligen Reichskommissars wurde in den Niederlanden das Vermögen der Bibelforscher ,konfisziert, und zwar wegen ihrer Stellungnahme, der Kriegsdienstverweigerung". Auf sofortiges Nachfragen des Anklägers, ob das bedeuten würde, man sei gegen Ausländer vorgegangen, weil sie sich nicht in den Dienst der ,deutschen Kriegsanstrengungen“ stellten, antwortete SeyB-Inquart, daß die niederländischen Bibelforscher nicht deshalb verboten worden seien, ,weil sie sich geweigert hätten in der deutschen Armee zu dienen, sondern sie sind verboten worden, weil man grundsätzlich gegen die Bibelforscher war" (Der Prozeß gegen die Hauptkriegsverbrecher, Band XVI, S. 127).

49 Eine Ausnahme scheint Dänemark darzustellen, denn die dortigen Zeugen Jehovas konnten auch während der Kriegsjahre Schriften der Watch Tower Society öffentlich verbreiten und sogar Kongresse abhalten (vgl. Länderbericht Dänemark im Jahrbuch 1993, S. 99-107). Zwar wurden nach der Aufkündigung der Kooperation durch die dänische Regierung und deren Rücktritt am 29.8.1943 auch für die Zeugen Jehovas die Betätigungsmöglichkeiten eingeengt, insgesamt gesehen wurden ihnen jedoch von der deutschen Besatzungsmacht „keine größeren Anfeindungen entgegengebracht" (ebenda, S. 101).

50 In einem Teil der besetzten Länder waren bereits vor dem deutschen Einmarsch staatliche Maßnahmen gegen die Zeugen Jehovas ergriffen worden: In Polen, wo die Zeugen Jehovas in der Vorkriegszeit durch die „Katholische Aktion“ stark bekämpft wurden, erließ das Innenministerium 1937 ein Verbot von Druck und Verbreitung des „Wachtturms“, 1938 wurde das Büro in Lodz geschlossen (vgl. Jahrbuch 1994, S. 198ff.). Zehn Monate nach der Okkupation, am 4.7.1940, erging eine Auflösungsverfügung der IBV durch die Gestapo-Leitstelle Kattowitz. Vgl. Majer, Fremdvölkische, S. 388, Anm. 5. Auch in Frankreich war das Zweigbüro der Watch Tower Society bereits acht Monate vor der Besetzung, am 18.10.1939, und damit noch zu Zeiten der Regierung Daladier geschlossen worden (vgl. Knorr, Jehovas Zeugen, S. 14; zur Verfolgung französischer Zeugen Jehovas während der deutschen Besatzung vgl. Der Wachtturm, 15.11.1980, S. 5-10).

51 Zur Verfolgung der Zeugen Jehovas in den Niederlanden während der deutschen Besatzung vgl. Jahrbuch 1986, S. 135-169; weitere Angaben beruhen auf: EB Johan Wildschut, 25.6.1986; AfW HH, 220305; VVN, Komiteeakten K 14. 
Inquart das Verbot der Organisation. Die ungefähr 500 niederländischen IBVAngehörigen führten ihr Verkündigungswerk dessenungeachtet fort und entfalteten dabei eine rege und öffentlichkeitswirksame Widerstandstätigkeit. Ihre Unbeugsamkeit und die Schriftenkampagnen führten den Zeugen Jehovas zahlreiche neue Interessierte zu. Obgleich durch die seit Herbst 1940 in größerer Zahl erfolgten Festnahmen geschwächt, verzeichnete das Werk beachtenswerte Missionserfolge. Während der fünf Jahre von August 1940 bis August 1945 stieg die Zahl der „Verkündiger" von 501 auf 3.125 an $^{52}$. Von den 426 niederländischen Zeugen Jehovas, die während der deutschen Besatzung verhaftet und von denen vermutlich 200 bis 250 in Konzentrationslager nach Deutschland verschleppt wurden, starben 117 infolge der extremen Arbeitsbedingungen, an Hunger und Mißhandlungen ${ }^{53}$.

In den mit dem Deutschen Reich verbündeten Staaten waren die Zeugen Jehovas ausnahmslos ebenfalls verboten, wobei die Härte der Repression von Land zu Land schwankte ${ }^{54}$. Starken Verfolgungen waren die Zeugen Jehovas im Ungarn des Reichsverwesers Nikolaus von Horthy und durch die „Hlinka-Garde“ in der Slowakei des Präsidenten Dr. Josef Tiso ausgesetzt ${ }^{55}$, während in Italien die härtesten Maßnahmen erst im Herbst 1943 nach der faktischen Machtübernahme durch das nationalsozialistische Deutschland einsetzten.

Das italienische Zweigbüro der Watch Tower Society war bereits 1932 von der Regierung geschlossen worden. Etwa drei Jahre später nahmen die Repressionen $\mathrm{zu}$, so daß die italienischen Zeugen Jehovas ihre Tätigkeit nur noch im verborgenen weiterführen konnten. Nachdem am 22.8.1939 die Anweisung zur Konfiszierung aller Bibelforscherschriften ergangen war, erfolgte das Verbot offiziell erst durch ein Dekret des Innenministeriums vom 13.3.1940. Die Verfolgung erreichte aber nicht die Intensität und Brutalität derjenigen, die von den Nationalsozialisten ausging. Nach dem Sturz Mussolinis im Juli 1943 wurden die Zeugen Jehovas aus den Gefängnissen freigelassen, mußten dann aber in der Phase der „Faschistischen Republik Italien" erneute Verfolgungen auf sich nehmen ${ }^{56}$.

Hingegen glich die Hatz auf die Zeugen Jehovas in Ungarn derjenigen im Deutschen Reich. Nachdem bereits 1937/38 umfangreiche Polizeiaktionen gegen die dortigen IBV-Angehörigen stattgefunden hatten, zu deren Begründung die Presse ähnlich wie in Deutschland verbreitete, ,die Agitatoren der Sekte“ handelten „im Auftrage der kommunistischen Internationale“, wurden im Anschluß an die

52 Vgl. Jahrbuch 1986, S. 170. Dietrich Hellmund nennt abweichende Zahlen, die jedoch eine ähnliche Steigerungsrate aufzeigen. Danach ist die Zahl der ,aktiven Zeugen Jehovas" während der fünfjährigen Besatzung der Niederlande von 317 auf 2166 angewachsen. Vgl. Hellmund, Zeugen Jehovas, o. S. (Kapitel IV, 3, Anm. 521).

54 Harte Ausmaße nahm die Verfolgung der Zeugen Jehovas auch in Japan an. Dort entzündete sich der Konflikt vor allem an der Nicht-Anerkenntnis der Göttlichkeit des Tenno durch die japanischen Zeugen Jehovas. Im Juni 1939 kam es in Japan zu so umfangreichen Festnahmen, daß es heute rückblickend oft heißt, es wurden ,alle“ Angehörigen der Glaubensgemeinschaft verhaftet und für Jahre interniert. Vgl. Matsue Ishii: Jehova vergißt seine Diener nicht, in: Der Wachtturm, 1.5.1988, S. 21-25.

55 Vgl. Jahrbuch 1938, S. 216-221; Knorr, Jehovas Zeugen, S. 14.

56 Zur Verfolgung der Zeugen Jehovas in Italien während der Jahre bis $1945 \mathrm{vgl}$. Graffard/ Tristan, Bibelforscher, S. 92ff.; Jahrbuch 1982, S. 156-179; Pierro, Testimoni di Geova; Rogerson, Zeugen Jehovas, S. 75. 
offizielle Verbotsverfügung vom 13.12.1939 zahlreiche Glaubensangehörige in Straflager eingewiesen ${ }^{57}$. Wie in den nationalsozialistischen Konzentrationslagern wurde ihnen dort eine Erklärung vorgelegt, in der sie ihrem Glauben abschwören sollten. Weigerten sie sich, mußten sie schwerste Mißhandlungen erdulden. Im Sommer 1943 wurden im Anschluß an erfolglose Aushebungen zum Militärdienst 160 inhaftierte Zeugen Jehovas in das serbische Konzentrationslager Bor deportiert. Nach der mit deutscher Unterstützung erfolgten Machtübernahme der faschistischen „Pfeilkreuzler“ und der Übertragung der Regierungsgewalt an deren Führer Ferenc Szálasi im Oktober 1944 kam es zu standrechtlichen Erschießungen von Zeugen Jehovas, die sich dem Waffendienst verweigerten. Die Zahl der insgesamt wegen Kriegsdienstverweigerung Hingerichteten wird mit 16 angegeben, weitere 26 ungarische Zeugen Jehovas starben infolge von Mißhandlungen. ${ }^{58}$

Verfolgt wurden die Zeugen Jehovas in Europa auch unter dem seit 1932 herrschenden Antonio de Oliveira Salazar in Portugal, unter dem Caudillo Francisco Franco in Spanien und in der UdSSR unter dem Generalsekretär der KPdSU Josef Wissarionowitsch Stalin ${ }^{59}$. Zwar unterlagen die Zeugen Jehovas während des Zweiten Weltkrieges auch in freiheitlichen Staaten zahlreichen Beschränkungen ${ }^{60}$, und es kamen auf sie - jedenfalls sofern dort die Wehrpflicht galt bzw. eingeführt wurde - schwere Belastungen zu, insbesondere die Verhängung von Gefängnisstrafen wegen der von ihnen praktizierten Militärdienstverweigerung, doch zeigen die Verhältnisse beispielsweise in Großbritannien und den USA, daß ,ein demokratisch strukturiertes Staatswesen auch in schwerer Bedrängnis Kompromisse bei der Behandlung Andersdenkender zulassen kann"61.

In Deutschland konnten während der Kriegsjahre auch die verstärkten Bemühungen der Gestapo die Untergrundtätigkeit der Zeugen Jehovas - von ihnen selbst als wiedererstarktes Predigtwerk bezeichnet - nie vollständig zum Erliegen bringen. Dabei verfügte die Geheime Staatspolizei in ihrem Kampf gegen die Bibelforschervereinigung seit etwa 1937/38 an entscheidender Stelle über einen wichtigen Informanten. Seit jener Zeit versorgte der im Berner Zentraleuropäischen Büro mitarbeitende und aus Dresden gebürtige IBV-Angehörige Hans Müller die Gestapo mit Auskünften über die illegale IBV-Organisation. Wie zahlreiche andere Verhaftungen dürften auch die Ende 1940 und Anfang 1941 erfolgten Festnahmen von Ludwig Cyranek, Ernst Bojanowski, Anna Voll und die des Essener Gruppendieners Paul Noernheim auf dessen Verrat zurückgehen ${ }^{62}$. Am 18. März 1941

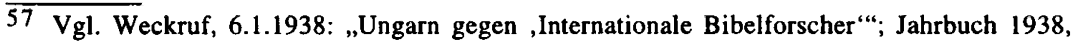
S. 216-221; Der Wachtturm, 15.7.1993, S. 9-12; sowie den Länderbericht Ungarn im Jahrbuch 1996, S. 67-115, zu den Jahren 1933-45: S. 76-95.

58 Vgl. Jahrbuch 1996, S. 95.

59 Vgl. Der Wachtturm, 1.3.1987, S. 21ff.; Der Wachtturm, 1.4.1989, S. 27; Erwachet!, 8.5.1993, S. 5-7; Solschenizyn, GULAG, S. 325; Zürcher, Kreuzzug, S. 44 ff; sowie die Erwähnungen in den betreffenden Jahrbüchern/Länderberichten der Zeugen Jehovas.

60 Nach Angaben der WTG wurden die Zeugen Jehovas oder ihre Literatur allein in 23 Nationen des Commonwealth verboten. Vgl. Jehovas Zeugen - Verkündiger des Königreiches Gottes, S 676, 721.

61 Lahrtz, Zeugen Jehovas, S. 44.

62 Vgl. Jahrbuch 1974, S. 179f.; Steinberg, Essen, S. 165f. Zum gleichen Zweck setzte die Gestapo auch in den Niederlanden einen von ihr vermutlich ebenfalls zur Zusammenarbeit genötigten IBV-Funktionär ein. Jener in den Akten als „,bekannter Bibelforscher“ bezeichnete 
verurteilte das Sondergericht I beim Landgericht Dresden Ludwig Cyranek ,wegen Zersetzung der Wehrkraft in Tateinheit mit Teilnahme an einer wehrfeindlichen Verbindung und Zuwiderhandlung gegen das Verbot der internationalen Vereinigung Ernster Bibelforscher" zum Tode; das Urteil gegen den 33jährigen IBV-Organisator wurde ein Vierteljahr später vollstreckt ${ }^{63}$.

Trotz dieses Rückschlages gelang es der im Westen und Südwesten gebildeten IBV-Organisation, sich danach erneut zu festigen. An die Stelle von Cyranek trat Julius Engelhard, der nach der Verhaftung Noernheims seinen Aufenthaltsort von Essen nach Oberhausen-Sterkrade verlegte, wo eine kleine, aber sehr aktive IBVZelle bestand. Dort organisierte Engelhard in Zusammenarbeit mit den Zellenmitgliedern von Anfang 1941 bis März 1943 den Druck von 27 verschiedenen Ausgaben des „Wachtturms“ in einer Auflage von zunächst 240, später 360 Exemplaren. Hinzu kamen die Herstellung der in unregelmäßigen Abständen herausgegebenen „Mitteilungsblätter der deutschen Verbreitungsstelle des W.T.“ sowie der Druck weiterer Bibelforscherschriften. Von Oberhausen aus gelangten über ein $\mathrm{Ku}$ riernetz jeweils wenige Exemplare an IBV-Gruppen in großen Teilen des Reichsgebietes. So bestanden zum Beispiel Verbindungen nach München, Mannheim, Mainz, Speyer, Berlin, Dresden und Wien. Seit Anfang Dezember 1942 wurden auch Bibelforscher-Häftlinge, die von der SS beim Ausbau der $20 \mathrm{~km}$ südwestlich von Paderborn gelegenen Wewelsburg zur zentralen SS-Ordensburg eingesetzt wurden und sich im dortigen $\mathrm{KZ}$ Niederhagen befanden ${ }^{64}$, zunächst sporadisch, dann sogar regelmäßig mit Ausgaben des „Wachtturms“ versorgt. Bibelforscherinnen aus der Umgebung stellten den Kontakt zwischen der illegalen IBV-Organisation aus dem Raum Oberhausen-Essen und den Wewelsburger Häftlingen her. Sie versteckten die „Wachtturm“-Ausgaben zusammen mit heimlichen Briefen unter Grabplatten auf dem Wewelsburger Friedhof oder in anderen „toten Briefkästen“, die sie an Orten plazierten, an denen tagsüber Arbeitskommandos eingesetzt wurden 65 .

Julius Engelhard führte zahlreiche Reisen selbst durch, um mit den örtlichen Gruppen Absprachen über die Untergrundtätigkeit zu treffen und die „Dienstberichte" entgegenzunehmen. Die Kontakte mit der Auslandsleitung in den Nieder-

Informant verhalf der Gestapo anscheinend aber zu keinen vergleichbaren Fahndungserfolgen. Vgl. Jahrbuch 1986, S. 127; UaP Richard Singelenberg, Vernehmungsprotokoll Ludwig Cyranek, II B 1 - 69/40.

63 In dem Prozeß waren neben Cyranek noch fünf weitere Zeugen Jehovas angeklagt, gegen die hohe Zuchthausstrafen ausgesprochen wurden. So wurde Ernst Bojanowski zu zwölf Jahren und Anna Voll zu vier Jahren Zuchthaus verurteilt. Auszüge aus der Urteilsschrift sind abgedruckt in: Neugebauer, Wien, S. 170-173. Ludwig Cyraneks Abschiedsbrief vom 3. Juli 1941, dem Vorabend seiner Hinrichtung, ist abgedruckt in: Du hast mich heimgesucht, S. 341.

64 Vgl. Jahrbuch 1974, S. 201. Die Wewelsburg sollte nach den Vorstellungen Himmlers durch einen gigantischen Ausbau zur zentralen Repräsentationsstätte der SS umgestaltet werden. Um bei dem Bauvorhaben Häftlinge als kostengünstige Arbeitskräfte einsetzen zu können, erfolgte im Jahre 1939 die Errichtung eines Außenlagers des KZ Sachsenhausen, in das bis zum Frühjahr 1941, soweit bekannt, 302 Zeugen Jehovas eingeliefert wurden. Damit stellten die Bibelforscher in diesem KZ zunächst sogar die größte Häftlingsgruppe. Dies änderte sich 1942, als in das seit dem 1.9.1941 zum selbständigen „Konzentrationslager Niederhagen“ erklärte KZ vor allem sowjetische Häftlinge eingewiesen wurden. Vgl. Brebeck, Wewelsburg, S. 154, 157; Hüser, Wewelsburg, insbes. S. 73ff.; John, Wewelsburg (1996), S. 37ff., $70 \mathrm{f}$.

65 Vgl. John, Wewelsburg (1996), S. 128. 
landen und in der Schweiz nahm großteils die fast 60jährige Auguste Hetkamp wahr, die zusammen mit den Familien ihrer Kinder das Rückgrat der Sterkrader IBV-Zelle bildete. Die mit der umfangreichen Tätigkeit verbundenen Kosten, zu denen auch Miete und Lebensunterhalt für die illegal lebenden Funktionäre gehörten, wurden durch Unterstützungszahlungen von Glaubensgeschwistern (,Gute Hoffnung-Gelder") bestritten.

Am 3. April 1943 wurde Julius Engelhard verhaftet, nachdem kurz zuvor die Essener IBV-Gruppe ,ausgehoben“ worden war66. Im Zuge einer größeren Aktion erfolgten weitere Festnahmen, die zur Zerschlagung der in Oberhausen und in anderen Orten des Rheinlandes tätigen IBV-Organisation führten. Nach über einjähriger Schutz- und Untersuchungshaft fanden im September 1944 Massenprozesse gegen insgesamt 83 Beteiligte vor dem Oberlandesgericht Hamm statt, in denen zumeist hohe Zuchthausstrafen ausgesprochen wurden ${ }^{67}$. Gegen acht „Rädelsführer" aus Oberhausen, Mülheim und Essen, unter ihnen Julius Engelhard und Auguste Hetkamp, verhandelte am 2. Juni 1944 der sechste Senat des Volksgerichtshofes wegen „Wehrkraftzersetzung“ ( 5 Abs. 1 Zif. 1 KSSVO) und - da der „Kriegsmacht des Reiches Schaden“ durch die Bibelforscherschriften zugefügt worden sei - auch wegen ,landesverräterischer Feindbegünstigung“ ( $91 \mathrm{StGB}$ ). In Anbetracht der „Schwere ihres Verschuldens“ und der „Gefährlichkeit der Tat“ wurden die acht Angeklagten ausnahmslos zum Tode verurteilt ${ }^{68}$.

Mit der Zerschlagung der Gruppe um Julius Engelhard und Auguste Hetkamp im Frühjahr 1943 war auch der Übermittlungsweg von Schriften in das KZ Niederhagen (Wewelsburg) unterbrochen. Da seit der Verlegung nahezu aller Gefangener des Lagers Ende April/Anfang Mai 1943 (die Auflösung erfolgte aufgrund der angeordneten Einstellung aller kriegsunwichtigen Bauvorhaben) und dem alleinigen Verbleib eines aus 47 Bibelforschern und zwei politischen Häftlingen bestehenden ,Restkommandos“ dort eine relativ große Bewegungsfreiheit herrschte ${ }^{69}$,

$\overline{66}$ In einem Bericht der Gestapo-Außendienststelle Essen vom 29.3.1943 über einen zwölf Tage zuvor verhafteten 43jährigen Berginvaliden und die - vermutlich in den Verhören erprügelten Ermittlungsergebnisse heißt es zynisch: „Nach anfänglicher hartnäckiger Weigerung bequemte er sich schließlich, diejenigen Bibelforscher zu nennen, mit denen er in letzter Zeit Bibelbesprechungen abgehalten hat." (Außendienststelle Essen, Schreiben vom 29.3.1943, abgedruckt in: Widerstand und Verfolgung in Essen, Dokument Nr. 25)

67 Vgl. Steinberg, Essen, S. 166, 374f.

68 BA, R 60 II/99-3, VGH, 7 (8) J 191/43, Urteil vom 2.6.1944. Die Todesurteile gegen Auguste Hetkamp und Klara Stoffels wurden am 11.8.1944 in Berlin-Plötzensee vollstreckt; drei Tage später, am 14.8.1944, starben ihre vier männlichen Mitverurteilten, Friedrich Stoffels, Paul Weseler, Johann Hörstgen und Wilhelm Bischoff, unter der Guillotine in Brandenburg-Görden. Im Fall des Hauptbeschuldigten Julius Engelhard sind weder Hinrichtungsort noch -datum bekannt. In einem Fall wurde durch Verfügung des RJM vom 29.11.1944 das Urteil im Gnadenverfahren in eine zehnjährige Zuchthausstrafe umgewandelt. Vgl. Ehrenbuch Plötzensee, S. 133; Ehrenbuch Brandenburg-Görden, Band 6, S. 236f.; Gebhard, Zeugen Jehovas, S. 196-198; Koch, M., Engelhard, S. 103; Steinberg, Essen, S. 166; DCB, Karteikarten Gefängnis Berlin-Plötzensee.

69 Die Belegstärke des „Restkommandos“ verminderte sich infolge einiger weniger Einzelüberstellungen im Zeitraum vom Mai 1943 bis zum August 1944 auf insgesamt 42 Häftinge (40 Bibelforscher und zwei politische Gefangene). Diese verblieben bis zur Befreiung durch die US-Armee am 2. April 1945 in Wewelsburg. Die Arbeits- und Lebensbedingungen im „Restkommando", das zu Unterhaltungs- und Reparaturarbeiten eingesetzt wurde und unter anderem die Burg mit einem Tarnanstrich zu versehen hatte, waren vergleichsweise erträglich: Die Ver- 
entschloß sich die kleine Wewelsburger Bibelforschergemeinde zum umgekehrten Weg. Nachdem die Beschaffung einer Schreibmaschine aus den Trümmern eines durch Brand zerstörten Gebäudes und - im Eigenbau - die Herstellung einer primitiven Vervielfältigungsapparatur gelungen war, begannen die KZ-Häftlinge sozusagen im Schatten der SS-Ordensburg - mit dem Druck des „Wachtturms“. Die Bibelforscherinnen, über die bereits der illegale Kurierdienst lief, organisierten das Papier und die Druckerfarbe. Sie sorgten auch für den Vertrieb, so daß bis zum Kriegsende auf diese Weise Zeugen Jehovas in verschiedenen Orten Nordwestdeutschlands mit der ,geistigen Speise“ versorgt wurden 70 .

In ähnlicher Weise wie die von Cyranek und Engelhard geführte Untergrundorganisation agierten auch die von Narciso Riet sowie von Wilhelm Schumann und Franz Fritsche geleiteten Gruppen. Der aus Mülheim (Ruhr) gebürtige und „Franzl“ genannte Narciso Riet, der in Deutschland als Sohn italienischer Eltern geboren worden war, bemühte sich im engen Kontakt mit der Oberhausener Gruppe auch in Österreich um den Neuaufbau der dort nach der Verhaftungsaktion vom Juni 1940 brachliegenden Untergrundarbeit ${ }^{71}$. Während sich die Erfolge bei dem durch die hohe Zahl an Festnahmen stark geschwächten österreichischen IBV-Zweig in Grenzen hielten, gelang es Riet Anfang 1942, die Wiederaufnahme der seit 1940 in der Tschechoslowakei weitgehend eingestellten IBV-Aktivitäten zu initiieren. In Zusammenarbeit mit der 30jährigen Prager Bibelforscherin Marie Teubel reorganisierte er in Prag, Pilsen und einigen anderen Orten IBV-Gruppen, die das Predigtwerk erneut begannen, Zusammenkünfte ausrichteten, Bibelforscherschriften in deutscher und tschechischer Sprache verbreiteten und auch den „Haus zu Haus“Dienst aufnahmen. Narciso Riet, der unermüdlich zwischen den verschiedenen Teilen des „Großdeutschen Reiches“ unterwegs war und auch in Süd- und Westdeutschland IBV-Gruppen reaktivierte, organisierte und koordinierte gleichzeitig den zunehmend umfangreicheren Schriftenschmuggel zu den Bibelforscher-Häftlingen in einzelnen Konzentrationslagern ${ }^{72}$. Als Riet sich durch die Gestapo beobachtet wähnte, floh er vor der drohenden Verhaftung nach Italien. Von seinem neuen Quartier aus, dem unweit der Schweizer Grenze am Comer See gelegenen Cernobbio, entfaltete Riet erneut eine rege Wirksamkeit. Er übersetzte dort in Absprache mit dem Schweizer Zweigbüro den über die Grenze geschmuggelten „Wachtturm“ ins Italienische, verteilte die vervielfältigten Exemplare anschließend an Mittelsmänner in Nord- und Mittelitalien und hielt weiterhin die Verbindung nach Österreich aufrecht. Ende Dezember 1943 wurde Riet in Cernobbio von der Gestapo aufgespürt. Das Reichssicherheitshauptamt konnte nach einer langen Fahndungszeit den Erfolg vermelden, daß der „Verbindungsmann zwischen dem

pflegung war ausreichend, die Gefangenen konnten sich unbeaufsichtigt zu ihren jeweiligen Arbeitsstellen begeben, und die zunächst zwölfköpfige SS-Wachmannschaft wurde im Laufe der Zeit auf vier SS-Leute verringert. Nach der Bildung des „Restkommandos“, d. h. in den letzten zwei Kriegsjahren, waren unter den Wewelsburger Gefangenen keine Todesfälle mehr zu beklagen; auch Mißhandlungen sind für diese Zeit nicht bekannt. Vgl. Hüser, Wewelsburg, S. 82, 99-106; John, Wewelsburg (1996), S. 122ff.

70 Vgl. Jahrbuch 1974, S. 201; John, Wewelsburg (1996), S. 128f.

71 Die folgende Darstellung beruht auf: Jahrbuch 1982, S. 176-178; Jahrbuch 1989, S. 104; DCB, VGH, $6 \mathrm{~J}$ 91/44, Urteil vom 9.11.1944.

72 Siehe S. $445 f f$. 
Bibelhaus in Bern und der illegalen IBV in Deutschland und im Protektorat" und damit der Verantwortliche für den ,organisatorischen Aufbau der illegalen IBV“ ausgeschaltet worden $\operatorname{sei}^{73}$.

Die durch Riet im süddeutschen Raum zusammengeführte Organisation diente auch - ähnlich wie die im Westen unter Engelhard operierenden Gruppen - anderen als AnstoB. In Augsburg zum Beispiel hatte der im Dezember 1941 nach fast sechsjähriger Gefängnis- und KZ-Haft entlassene Georg Halder - angespornt durch solche und ähnliche Impulse - die dortige IBV-Gruppe wieder enger zusammengeschlossen ${ }^{74}$. Mit Energie arbeitete Halder auf die Unterstützung der in den Konzentrationslagern einsitzenden Glaubensgeschwister hin. So organisierte er unter anderem Ende 1942 auch eine umfangreiche Sammlung von Geld und Lebensmitteln beziehungsweise Lebensmittelmarken. Die Sammlung diente zum einen dazu, Angehörige von inhaftierten oder verstorbenen Zeugen Jehovas zu unterstützen, und zum anderen zur Versendung von Paketen an die Gefangenen.

Georg Halder, der seinen Wirkungskreis über Augsburg auf ganz Schwaben und West-Württemberg ausgedehnt hatte, wurde Anfang 1943 zusammen mit etwa 15 Augsburger Zeugen Jehovas verhaftet ${ }^{75}$. Ebenfalls Ende Januar und Anfang Februar 1943 fanden in München und anderen Orten Süddeutschlands zahlreiche Festnahmen statt; der Oberreichsanwalt beim Volksgerichtshof führte gegen 66 Verhaftete mehrere Ermittlungsverfahren wegen Verbreitung von „Hetzschriften der IBV“ und prüfte eine Anklageerhebung wegen „Wehrkraftzersetzung“76. Ein Jahr später führte die Stapo-Leitstelle München eine Großaktion durch, die sich in erster Linie gegen IBV-Gruppen aus dem mittelfränkisch-württembergischen Grenzgebiet richtete. Nach einer Meldung des Reichssicherheitshauptamtes vom 21. April 1944 waren bis zu diesem Zeitpunkt bei der für noch nicht beendet erklärten GestapoAktion insgesamt 254 Personen verhaftet worden. Im RSHA-Bericht wurde vermerkt: „Die Beschuldigten werden laufend dem Volksgerichtshof wegen Wehrkraftzersetzung bzw. wegen Vorbereitung zum Hochverrat überstellt. [...] In den ersten Gerichtsverfahren wurden 49 Angeklagte zu Zuchthausstrafen von 2 bis zu 5 Jahren bzw. zu Gefängnisstrafen verurteilt. Gegen einen der Funktionäre wurde das Todesurteil ausgesprochen."77 Noch im gleichen Jahr wurden im Schwäbischen ungefähr 25 Zeugen Jehovas festgenommen, die mitgeholfen hatten, einen jungen, wehrdienstpflichtigen und gerade erst einberufenen Glaubensbruder zu

73 IfZ, MA 442/2, 5491527, RSHA-Meldung wichtiger staatspolizeilicher Ereignisse vom 21.4.1944. Narciso Riet kam ins KZ Dachau, wo er im Zellenarrest in Ketten gelegt wurde und schwerste Mißhandlungen erleiden mußte. Zu weiteren Ermittlungen wurde er nach BerlinPlötzensee und anschließend nach Brandenburg gebracht (vgl. USHRI, RG-02.058.01, Biography by Johannes Schindler, S. 44f.). Soweit bekannt, starb Riet, der im November 1944 zum Tode verurteilt wurde, Anfang 1945 in der Haft (vgl. Pierro, Testimoni di Geova, S. 6).

74 Vgl. Hetzer, Augsburg, S. 641-643; Kalous, Bibelforscher, Anhang 26.

75 IfZ, MA 442/2, 5490990, RSHA-Meldung vom 26.2.1943. Georg Halder wurde vom OLG München am 18.2.1944 wegen ,Zersetzung der Wehrkraft“ zum Tode verurteilt und am 4.4. 1944 in München-Stadelheim hingerichtet.

76 BA, R 22/3390, Bl. 130, Der Oberreichsanwalt beim VGH, Lagebericht vom 1.6.1943.

77 IfZ, MA 442/2, 5491527, RSHA-Meldung vom 21.4.1944. 
verbergen und ihn mit Lebensmitteln zu unterstützen. Die Verhafteten wurden der „Beihilfe zur Fahnenflucht" angeklagt ${ }^{78}$.

Auch an anderen Orten wurden „Wehrdienstflüchtige“ von ihren Glaubensgeschwistern verborgen ${ }^{79}$. In Berlin diente die in Hohengatow gelegene Wohnung der Zeitungsausträgerin Emmi Zehden sowie die Spandauer Gärtnerei des Bibelforscherehepaars Otto und Jasmine Muß drei Kriegsdienstverweigerern als Versteck $^{80}$. Zu dem seit 1940 untergetauchten und daraufhin steckbrieflich gesuchten Horst Günther Schmidt, einem Pflegesohn von Emmi Zehden, stieß im Oktober 1941 der mit ihm befreundete 19jährige Gerhard Liebold aus Plauen, der im Vormonat einen Gestellungsbefehl erhalten hatte. Mit neuer Identität und unter dem Namen Kurt Vogel arbeitete Liebold, der selbst den Gärtnerberuf erlernt hatte, fortan in dem Spandauer Betrieb mit. Die beiden jungen Männer beteiligten sich von ihrem Unterschlupf aus an den Aktivitäten der Berliner IBV-Gruppe. So wirkten sie an der Vervielfältigung des „Wachtturms“ und anderer Bibelforscherschriften mit. Anfang Dezember 1942 brachte Schmidt auch den 22jährigen fahnenflüchtigen Obergefreiten Werner Gaßner zu den Glaubensgeschwistern Muß. Gaßner war im September aus dem Kriegslazarett Niort (Frankreich) entlassen worden, hatte sich jedoch nicht bei seiner Einheit zurückgemeldet, sondern sich von der Truppe abgesetzt und bis nach Berlin durchgeschlagen. Doch nur einige Wochen später, am 28. Dezember 1942, wurden Werner Gaßner, Gerhard Liebold, das Ehepaar Muß und noch fünf weitere Personen festgenommen. Die „Wehrdienstflüchtigen“ Gaßner, Liebold und Schmidt wurden zum Tode verurteilt ${ }^{81}$; die Helfer klagte der Generalstaatsanwalt bei dem Kammergericht an, es unternommen zu haben, „andere der Erfüllung des Wehrdienstes zu entziehen“.

Die Ende Dezember 1942 Festgenommenen waren Teil einer größeren Organisation, die von Franz Fritsche, dem Gruppendiener der Berliner IBV, geleitet wurde. Nach der Zerschlagung der von Engelhard koordinierten westdeutschen Gruppen im Frühjahr 1943 lag das Hauptgewicht der illegalen Schriftenherstellung nun bei den Glaubensgeschwistern an der Spree. So wurden in der Zeit von Juni bis August 1943 auf einem Berliner Laubengrundstück bis zu eintausend Exemplare pro „Wachtturm“-Ausgabe gedruckt, die an Gruppen und einzelne nahezu im gesamten Reichsgebiet verteilt wurden. Seit August 1943 bezog die Berliner Gruppe zur Weiterverbreitung die Schriften aus Magdeburg, die dort von Wilhelm und Gerhard Schumann gedruckt wurden. Bereits in den Jahren zuvor bildete die von

78 EB Elise Kühnle, 23.11.1987; EB Bruno Knöller, 23.11.1987. Den Berichten zufolge wurde gegen eine Zeugin Jehovas ein Todesurteil ausgesprochen, allerdings nicht mehr vollstreckt.

79 Vgl. Struckmeier, Eickhorst, S. 23; Zipfel, Kirchenkampf, S. 197, Anm. 53; Neugebauer, Wien, S. 183.

80 Die folgende Darstellung beruht auf: IfZ, MA 442/2, 5490990, RSHA-Meldung vom 26.2. 1943; DCB, Der Generalstaatsanwalt bei dem Kammergericht, 12 OJs 549/44 (A), Anklageschrift vom 16.11.1944; DCB, Ersatz-Vollstreckungsband Emmi Zehden, VGH, 1 J 56/43; Ehrenbuch Brandenburg-Görden, Band 3, S. 54, 65; Haase, Praxis des Reichskriegsgerichts, S. 395; Zipfel, Kirchenkampf, S. 199f., 527-533.

81 Die vom Reichskriegsgericht verhängten Todesurteile gegen Werner Gaßner und Gerhard Liebold wurden am 9. April (Gaßner) und am 6. Mai (Liebold) 1943 in Brandenburg-Görden vollstreckt (vgl. Ehrenbuch Brandenburg-Görden, Band 3, S. 54, 65). Nur der vom Volks-

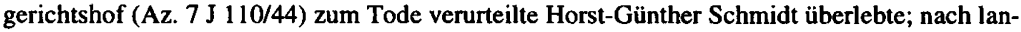
gem Aufenthalt in der Todeszelle wurde in seinem Fall die Vollstreckung ausgesetzt. 
dem 43jährigen Wilhelm Schumann, der von 1924 bis 1933 die Reproduktionsund chemigraphische Abteilung des deutschen Zweigbüros geleitet hatte, in Magdeburg betriebene Chiropraxis eine Art Anlaufpunkt für die im Untergrund agierenden Zeugen Jehovas ${ }^{82}$.

Die Gruppe um Franz Fritsche stand in enger Verbindung mit den in den Konzentrationslagern Ravensbrück und Sachsenhausen inhaftierten Glaubensgeschwistern und versorgte diese über in Außenkommandos und außerhalb der Lager eingesetzte Häftlinge während eines Zeitraumes von ungefähr eineinhalb Jahren regelmäßig mit den neuen „Wachtturm“-Ausgaben und anderen Schriften. In einem Bericht heißt es dazu: „Die Organisation funktionierte so gut, daß Bruder Fritsche Briefe an die Verwandten der Brüder, in andere Lager oder an ausländische Zweigbüros weiterleiten konnte. So war es möglich, daß innerhalb von eineinhalb Jahren einhundertfünfzig Briefe aus dem Lager und fast genauso viele in das Lager geschmuggelt wurden. [...] Einige wurden sogar vervielfältigt und dienten den Brüdern draußen und besonders den Verwandten derer, die inhaftiert waren, zur Ermunterung." 83

Im Januar und Februar 1944 gelang der Gestapo die „Aufdeckung“ der von Fritsche und Schumann geleiteten IBV-Organisation. Der Berliner Generalstaatsanwalt erhob im November 1944 gegen 76 Verbreiter und Bezieher von Schriften wegen ,Teilnahme an einer wehrfeindlichen Verbindung“ und ,Zersetzung der Wehr-

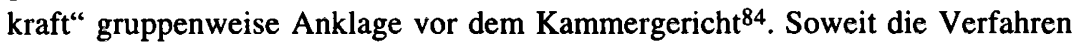
gegen die fast ausnahmslos älteren Zeugen Jehovas - zumeist handelte es sich um Frauen - noch vor Kriegsende zum Abschluß kamen, wurden sehr hohe Freiheitsstrafen verhängt.

Gegen ,die Hauptschuldigen, die Verfasser der neueren Schriften, die Funktionäre und ihre Helfershelfer", unter ihnen Franz Fritsche und Wilhelm Schumann, verhandelte im Oktober 1944 der Volksgerichtshof. Fritsche, Schumann und der 43jährige Werkskontrolleur Johannes Schindler ${ }^{85}$, der als „Kurier“ für die IBVOrganisation tätig war, wurden zum Tode verurteilt; die Urteile wurden jedoch nicht mehr vollstreckt ${ }^{86}$.

$\overline{82}$ Zu den Aktivitäten von Wilhelm Schumann vgl. auch Gebhard, Zeugen Jehovas, S. 199ff.

83 Jahrbuch 1974, S. 202. Vgl. auch ebenda, S. 199.

84 Die Verfahren wurden unter dem Sammelaktenzeichen 12 OJs 549/44 bei dem Kammergericht in Berlin geführt. Die Anklageschrift vom 18.11.1944, 12 OJs 549/44 (B), ist abgedruckt in: Zipfel, Kirchenkampf, S. 527-533.

85 Johannes Schindler, der - nachdem er zuvor im Brandenburger Zuchthaus lange Zeit in der Todeszelle zubringen mußte - im April 1945 durch die US-Amerikaner aus dem Gefängnis in Halle befreit wurde und der sechs Jahre später wegen Betätigung als Zeuge Jehovas, nunmehr durch DDR-Organe, erneut inhaftiert wurde, hat einen umfassenden Erinnerungsbericht verfaßt, der heute im United States Holocaust Memorial Museum in Washington verwahrt wird (USHRI, RG-02.058.01).

86 Die Akten des beim Volksgerichtshof unter dem Aktenzeichen 7 J 79/44 geführten Prozesses sind nicht erhalten geblieben. Nach Zipfel wurde die Vollstreckung der Todesurteile ausgesetzt, „da die Verurteilten als Zeugen für weitere, noch nicht abgeschlossene Verfahren zur Verfügung gehalten wurden" (Zipfel, Kirchenkampf, S. 199f.; die Angabe bei Gebhard, Zeugen Jehovas, S. 199, der zufolge das Urteil an Franz Fritsche vollstreckt worden sei, ist unzutreffend). 
In den Jahren 1944/45 konnten keine Bibelforscher-Organisationen mehr aufgebaut werden, die noch eine größere, überregionale Wirksamkeit zu entfalten vermochten. Für die letzten Kriegsmonate verlieren sich die Spuren; begründete Zweifel an der Aussage des Geschichtsberichtes der Zeugen Jehovas bestehen gleichwohl nicht: „Es ist jetzt nicht mehr genau festzustellen, wo um diese Zeit noch Der Wachtturm vervielfältigt wurde, aber er wurde vervielfältigt. " 87

Aber auch dort, wo die Reihen nach der Verhaftung der Aktivisten oder dem Rückzug derjenigen, die sich nicht mehr der Gefahr weiterer Verfolgung aussetzen wollten, stark gelichtet waren, wo also keine Zusammenkünfte mehr stattfanden und Verbindungen untereinander nur noch lose bestanden, gab es einzelne Widerstandshandlungen und Äußerungen ungebrochenen Bekennermutes ${ }^{88}$. Dies reichte vom „Zeugnisgeben für Jehova“ im öffentlichen Luftschutzkeller bis zum Abhören ausländischer Rundfunksender und der Weitergabe des Gehörten.

Neben der Solidarität mit verfolgten Glaubensgeschwistern gab es vereinzelt auch Taten christlicher Nächstenliebe und offenen Beistandes für aus anderen Gründen Verfolgte ${ }^{89}$. Beispielsweise half der schwäbische Landwirt Karl Uhlmann, der nach über zweijähriger Inhaftierung aus dem KZ Welzheim entlassen worden war, seinem ehemaligen Mitgefangenen und Arbeitskollegen aus der KZSchreinerei Friedrich Schlotterbeck, als der frühere württembergische KJVDLandesvorsitzende und aktive Widerständler Mitte des Krieges untertauchen mußte und ein Versteck suchte ${ }^{90}$. In Hamburg versteckte die Bibelforscherin Pauline Matschke zehn Monate lang den zur engeren Leitung der „Bästlein-Jacob-Abshagen-Gruppe" gehörenden Kommunisten Jonny Stüve, der sich im Oktober 1942 ,in letzter Minute dem Zugriff der Gestapo“ hatte entziehen können ${ }^{91}$.

Ebenfalls gab es einige Fälle, in denen Zeugen Jehovas - denen von den Nationalsozialisten nicht grundlos die ,Sabotierung der judenfeindlichen Tendenz unserer Weltanschauung durch den Gedanken der Menschengleichheit" 92 vorgeworfen

87 Jahrbuch 1974, S. 182 (Hervorhebung im Original).

88 Vgl. VVN HH, Komiteeakten K 16; EB Luise Polsterer, 6.6.1984; Hetzer, Augsburg, S. 640.

$89 \mathrm{Zu}$ Recht betont Brigitte Oleschinski, die die Geschichte der IBV im „Dritten Reich“ mit derjenigen der Quäker verglichen hat, daß im Unterschied zu den Quäkern, die ,ihre karitative Hilfe ... an keine religiöse Vorleistungen der Bedachten gebunden" hatten, bei den Zeugen Jehovas allerdings von einer "systematischen Hilfe" für Menschen außerhalb der eigenen Glaubensgruppe keine Rede sein könne. Angesichts des ,unerbittlichen staatlichen Druckes“ hätten die Zeugen Jehovas aber auch zwangsläufig ihr Augenmerk auf ,das Überleben der Glaubensgeschwister" richten müssen (Oleschinski, Religiöse Gemeinschaften, S. 100).

90 EB Elise Kühnle, 23.11.1987. In den unmittelbar nach Kriegsende veröffentlichten Erinnerungen Schlotterbecks heißt es: „Unbesorgt direkt sagte ich ihm, warum ich gekommen war. Er stopfte Brot, Speck und Butter in meinen Rucksack und begleitete mich ein Stück durch den Wald und sagte zum Abschied, ich könne kommen und bleiben." (Schlotterbeck, Erinnerungen, S. 298) Siehe auch S. 157, Anm. 9.

91 VVN HH, Komiteeakten M 8. (Es bleibt noch anzumerken, daß für die Hilfe sicherlich mit entscheidend war, daß Pauline Matschke mit einem Mitglied der Bästlein-Jacob-AbshagenGruppe verschwägert war.) Jonny Stüve wurde am 18.7.1944 verhaftet und verstarb sieben Tage später an den Folgen der ihm im Polizeigefängnis Fuhlsbüttel zugefügten Mißhandlungen. Zu Stüve und den Widerstandsaktivitäten der Bästlein-Jacob-Abshagen-Gruppe vgl. Bästlein, Hitlers Niederlage; Hochmuth/Meyer, Streiflichter, S. 363, 377ff., 601.

92 Herr, Bibelforscher, S. 87. In der NS-Propaganda wurde herausgestrichen, daß die Zeugen Jehovas für die „Rassengesetzgebung kein Verständnis“ (Hamburger Tageblatt, 14.5.1938) aufbrächten; das Sondergericht Weimar beklagte: „Was aus dem Deutschen Volke wird, ist ih- 
wurde - verfolgten Juden beistanden. Dies reichte von der Aufnahme freundschaftlicher Beziehungen über die Abgabe von Lebensmittelmarken bis hin zum Verbergen von Juden, die von der Deportation bedroht waren ${ }^{93}$. An einem organisierten Hilfswerk wirkte der Schriftsetzer Lothar Schirmacher mit, ein Sohn Kasseler Bibelforscher, dessen Widerstand sowohl religiös als auch politisch motiviert war. Schirmacher, der sich 1932 im Alter von 16 Jahren dem „Internationalen Sozialistischen Kampfbund“ angeschlossen hatte und zwei Jahre später wegen Verweigerung des „Deutschen Grußes“ von seiner Arbeitsstelle entfernt worden war, beteiligte sich an den Aktionen der Kasseler IBV-Gruppe. Nachdem er am 15. Dezember 1936 im Anschluß an die Verteilung des Flugblattes „Resolution“ festgenommen und anschließend wegen Bibelforscherbetätigung zu zwei Jahren Gefängnis verurteilt worden war, hatte er 1939 nach der Haftentlassung in Berlin Kontakt zu sozialistischen Freunden aufgenommen. Gemeinsam mit diesen verschaffte er jüdischen Bürgern falsche Papiere und half ihnen, ins Ausland zu entkommen oder in den Untergrund zu gehen ${ }^{94}$.

\section{Kriegsverordnungen}

Waren bereits in den Jahren 1937/38 die Urteile gegen die Zeugen Jehovas in der Strafhöhe deutlich angestiegen, so ging die Justiz während der Kriegsjahre nun mit unbarmherziger Härte gegen IBV-Angehörige vor. Die Rechtsprechung bot fortan kaum noch Anlaß, sie wegen ihrer „Milde“ und „Nachlässigkeit“ den Bibelforschern gegenüber zu schelten. Die gesetzliche Grundlage für verstärkte, drastische Strafen bildeten dabei zwei bei Kriegsbeginn in Kraft gesetzte neue Verordnungen.

Am Tag der Mobilmachung, dem 26. August 1939, trat eine die Strafbestimmungen wesentlich verschärfende „Verordnung über das Sonderstrafrecht im Kriege und bei besonderem Einsatz“, kurz auch „Kriegssonderstrafrechtsverordnung“ (KSSVO), in Kraft ${ }^{95}$, die in $\S 5$ den Straftatbestand der „Wehrkraftzersetzung" einführte. Diese für die Verfolgung aller Regimegegner folgenschwere und extensiv genutzte Vorschrift bestimmte, daß jeder Versuch der Wehrdienstentziehung, die öffentliche Aufforderung dazu und die Zersetzung des Willens zur „wehrhaften Selbstbehauptung“ mit dem Tode zu bestrafen sei. Die Todesstrafe galt

nen gleichgültig; Hauptsache und ihre alleinige Sorge ist, daß es denen wohlergehe, die sich als Zeugen Jehovas bekennen, mögen das Deutsche oder Nichtdeutsche, mögen es Juden, Neger oder Mongolen sein [...]. Sie kennen kein Volksbewußtsein. Die Menschen sind alle gleich, sagen sie." (BA, R 58/405, Bl. 31, SG Weimar, So. G. 4/36, Urteil vom 24.1.1936)

94 Vgl. Kammler, Kasseler Soldaten, S. 138-141.

95 Verordnung über das Sonderstrafrecht im Kriege und bei besonderem Einsatz (Kriegssonderstrafrechtsverordnung) vom 17.8.1938, RGBl. 1939 I, S. 1455. Die bereits im August 1938 erlassene KSSVO wurde im RGBI. am 26.8.1939 veröffentlicht; dieses ist jedoch ,, aus besonderen Gründen" erst am 31.8.1939 versandt worden (BA, R 22/2290, Bl. 328, OKW, Schnellbrief vom 31.8.1939). Den vorerst allein für die Aburteilung von Delikten nach der KSSVO zuständigen Kriegsrichtern - bis zum Erlaß der 7. DVO vom 18.5.40 waren in „Wehrkraftzersetzungsfällen“ auch Zivilpersonen der Militärgerichtsbarkeit unterworfen - wird die Verordnung bereits seit ihrer Abfassung im August 1938 bekannt gewesen sein, denn die Wehrmachtgerichte konnten sich ,schon im Frieden mit der Vorschrift vertraut machen“ (BA, R 22/2296, Bl. 461, OKW, Schreiben vom 19.4.1940 an das RJM). 
jetzt als „Normalstrafe“ “96, nur in „,minder schweren Fällen“ sollte von ihr abgewichen werden. Diese neue Strafvorschrift, die darauf abzielte, daß ,jede wehrfeindliche Agitation - von wem sie auch ausgeht - im Keime erstickt werden kann“"97, löste - wie der an den vorbereitenden Arbeiten beteiligte Ausschuß für Wehrrecht in der Akademie für Deutsches Recht befand - „eine alte nationalsozialistische Forderung"98 ein.

Die Fraktion der NSDAP hatte bereits 1930 im Reichstag den Antrag auf Erlaß eines „Gesetzes zum Schutz der deutschen Nation“ gestellt, nach dem die Untergrabung der Wehrkraft, die Teilnahme an wehrfeindlichen Bestrebungen und die Kriegsdienstverweigerung als „Wehrverrat“ grundsätzlich mit dem Tode bestraft werden sollten ${ }^{99}$. Seit spätestens Anfang 1934 wurde in Zusammenarbeit von Reichsjustiz- und Reichswehrministerium an speziellen Grundlagen für ein Kriegsrecht gearbeitet. Die berüchtigten und folgenschweren Regelungen der Kriegsverordnungen wurden schon damals vorgedacht und ausformuliert. So enthielt bereits ein Referentenentwurf aus dem Frühjahr 1934 eine Bestimmung über die „Zersetzung der Wehrbereitschaft", die in Kriegszeiten denjenigen mit Todesstrafe oder lebenslangem Zuchthaus bedroht wissen wollte, der öffentlich zur Verweigerung des Kriegsdienstes oder zu Angriffen gegen die deutsche Wehrbereitschaft auffordert oder anreizt ${ }^{100}$.

Im Juni 1934 wurde in diese Fassung eine Bestimmung über den Schutz des „völkischen Wehrwillens“ aufgenommen, so daß der Entwurf nunmehr auch bereits jene Formulierung enthielt, die in der Spruchpraxis der nationalsozialistischen Sondergerichte eine traurige Berühmtheit erlangen sollte, nämlich daß auch derjenige unter die gleiche Strafandrohung fällt, der ,,in anderer Weise öffentlich den Willen des deutschen Volkes zur wehrhaften Selbstbehauptung lähmt oder zersetzt" ${ }^{101}$. So lagen nicht nur die Aufmarschpläne, sondern auch die Regelungen für die Mobilmachung auf rechtlichem Gebiet seit langem in den Schubladen, als Hitler und die Wehrmachtspitze mit dem Überfall auf Polen den Zweiten Weltkrieg auslösten.

Die andere neue gesetzliche Regelung, die in Strafverfahren gegen Zeugen Jehovas in den Kriegsjahren regelmäßig Anwendung fand, war die am 25. November 1939 erlassene „Verordnung zur Ergänzung der Strafvorschriften zum Schutz der Wehrkraft des deutschen Volkes"102. Diese bestimmte in $\S 3$, daß derjenige,

96 Kohlrausch/Lange, Strafgesetzbuch, S. 798.

97 Militärstrafgesetzbuch/Schwinge ${ }^{5} 1943$, S. 397.

98 ZAkDR 2 (1935), S. 174-176 (175), Bericht des Ausschusses für Wehrrecht über die Sitzung vom 28.2.1935.

99 Verhandlungen des Reichstags, Anlagen zu den stenographischen Berichten. Band 440, Berlin 1930, Antrag IV/1741.

100 BA, R 22/962, o. B1., Vorschläge des Berichterstatters, Vizepräsident Grau, zum Abschnitt "Angriffe gegen die Wehrmacht" vom 14.5.1934.

101 BA, R 22/962, o. Bl., Vorschläge der Unterkommission XXI vom 4.6.1934. Ein Jahr später wurde in der Strafrechtskommission eine Veränderung dieses Paragraphen noch insofern vorgeschlagen, als nicht nur die tatsächlich erfolgte „Zersetzung des Wehrwillens", sondern bereits der Zersetzungsversuch unter Strafe gestellt werden sollte (BA, R 22/962, o. Bl., Strafrechtskommission, Protokoll der 78. Sitzung am 26.6.1935, S. 3f.). Damit war der spätere $\S 5$ der Kriegssonderstrafrechtsverordnung in allen wesentlichen Teilen vorformuliert.

RGB1. 1939 I, S. 2319. 
der ,an einer wehrfeindlichen Verbindung teilnimmt oder sie unterstützt, [...] mit Zuchthaus, in minder schweren Fällen mit Gefängnis bestraft" wird. Der Erlaß dieser Vorschrift trug dem Drängen auf Strafverschärfung in Bibelforscherverfahren Rechnung; die seit Mitte der dreißiger Jahre geforderte Verhängung von Zuchthausstrafen wegen bloßer Zugehörigkeit zur IBV wurde nun möglich. Damit trat die „Wehrkraftschutzverordnung“ beim juristischen Vorgehen gegen die Zeugen Jehovas faktisch an die Stelle der „Reichspräsidentenverordnung zum Schutz von Volk und Staat“ vom 28. Februar 1933, wobei mit der neuen gesetzlichen Regelung - neben der Erweiterung des Strafrahmens - zugleich auch, über die „verbotswidrige Betätigung" hinaus, die sich in der Zugehörigkeit artikulierende „wehrfeindliche Gesinnung“ unter Strafandrohung gestellt wurde. In den Gesetzeskommentaren wurde denn auch ausdrücklich hervorgehoben, daß für eine Aburteilung wegen Teilnahme an einer wehrfeindlichen Verbindung allein ,schon die Pflege einer wehrfeindlichen Gesinnung als solche“ genüge: „Jeder, der sich zu dieser Verbindung bekennt, nimmt an ihr teil." 103

Wie das ministerielle Kommentarwerk erkennen läßt, dürfte für die Abfassung dieser Bestimmung die Bekämpfung der IBV mit entscheidend gewesen sein ${ }^{104}$. Die als Verfasser zeichnenden Ministerialräte im Reichsjustizministerium Grau, Krug und Rietzsch erklärten, daß unter wehrfeindlichen Verbindungen auch Vereinigungen von Personen zu verstehen seien, ,die eine wehrfeindliche Gesinnung auf einer sektiererisch-religiösen Grundlage unter Verzicht auf jede Organisation“" pflegen würden, wobei zur Veranschaulichung hinzugefügt wurde: „Ein Beispiel für eine wehrfeindliche Verbindung sind die Internationalen Bibelforscher."105 Mit dem $\S 3$ der ,Wehrkraftschutzverordnung“ wurde damit das Bibelforscherbekenntnis als solches zu einer Straftat erklärt; die Vorschrift ist Ausdruck reinen Gesinnungsstrafrechtes.

Während die ,einfachen“ IBV-Angehörigen von den Sondergerichten wegen „Teilnahme an einer wehrfeindlichen Verbindung" abgeurteilt wurden, kam eine Ahndung strafbarer Handlungen wegen „Wehrkraftzersetzung“ nach § 5 KSSVO gegen die „Funktionäre“ zur Anwendung sowie dann, „wenn jemand seine wehrfeindlichen Bestrebungen in die Tat umzusetzen versucht" 106.

103 Nüse, Kriegsstrafrecht, S. 33.

104 Die Vorschrift trug in einem zweiten Absatz in bemerkenswerter Weise den operationalen Bedürfnissen der Gestapo Rechnung. Nach dieser Klausel blieb straffrei, ,wer das Fortbestehen der Verbindung verhindert oder einer Dienststelle des Staates von ihrem Bestehen Kenntnis gibt" ( $\$ 3$ Abs. 2 VOSchdW). Es ist zu vermuten, daß die Verfolgungsinstanzen hofften, mittels dieser ,besonderen Vorschrift über tätige Reue“ auch zu nachhaltigeren Erfolgen im Kampf gegen die IBV zu gelangen. Neben der Prämierung von Denunziantentum sollte diese Bestimmung auch den „Gedanken des Willensstrafrechts“ unterstreichen: „Wer zum Ausdruck bringt, daß er sich innerlich gewandelt hat und sich von seinem bisherigen Verhalten abkehrt, soll durch Straflosigkeit begünstigt werden." (Rietzsch, Wehrkraft, S. 79) Deutsches Strafrecht, S. 172.

106 Nüse, Kriegsstrafrecht, S. 33; vgl. auch Deutsches Strafrecht, S. 172f. Über das zahlenmäBige Verhältnis der beiden Deliktgruppen gibt eine Auswertung über die in den Jahren 19431945 am OLG München gegen insgesamt 155 Zeugen Jehovas geführten Verfahren Auskunft. Nach den bei Kalous, Bibelforscher, S. 41, veröffentlichten Angaben wurden 76 Zeugen Jehovas nach § 3 VOSchdW (wehrfeindliche Verbindung) und 20 Zeugen Jehovas nach $\S 5 \mathrm{Nr}$. $1 \mathrm{KSSVO}$ (Wehrkraftzersetzung) abgeurteilt. In 59 Fällen war der Tatbestand nicht feststellbar. 
$\mathrm{Zu}$ einer weiteren Verschärfung der Rechtsprechung gegen IBV-Angehörige kam es, als Anfang 1943 die Zuständigkeit der Sondergerichte für Verfahren nach $\S 5$ Abs. 1 Zif. 1 KSSVO auf den Volksgerichtshof beziehungsweise - bei Abgabe der Verfahren - auf die Oberlandesgerichte überging 107 . Waren bis dahin in den vor den Sondergerichten gegen Zeugen Jehovas geführten Prozessen nur selten Anklagen wegen ,öffentlicher Zersetzung der Wehrkraft“ erhoben und nur in wenigen Fällen Todesurteile ausgesprochen worden, so stieg mit der Zuständigkeit des Volksgerichtshofes nun auch die Zahl der Todesurteile merklich. Der Oberreichsanwalt beim Volksgerichtshof, der über eine mögliche Abgabe der Verfahren an die Generalstaatsanwaltschaften und damit an die Oberlandesgerichte zu entscheiden hatte, rechnete bei ,Zersetzungsfällen“ die Bibelforscher neben ehemaligen Marxisten, ,reaktionär orientierten Elementen“, Pazifisten und konfessionell - zumeist katholisch - gebundenen Personen zu den „Absichtstätern“, die er von den mehr aus persönlichen Beweggründen handelnden, ,weltanschaulich nicht gefestigten Personen" unterschieden wissen wollte ${ }^{108}$.

Nach Interpretation des Volksgerichtshofes handelte es sich beispielsweise bei der 39jährigen Helene Delacher um eine „gefährliche Täterin“. Gegen die Innsbrucker Bibelforscherin wurde der Vorwurf der „Wehrkraftzersetzung in Verbindung mit dem Versuch landesverräterischer Lügenhetze“ ( 90 f StGB) erhoben, weil sie versucht habe, ,wehrfeindliche Flugschriften der Internationalen Bibelforscher-Vereinigung [...] nach Italien zu schmuggeln"109. Helene Delacher war von einem Grenzpolizeibeamten im Juni 1943 gestellt worden, als sie auf einer Hochalm in der Nähe der österreichisch-italienischen Grenze ihrem in Norditalien lebenden Bräutigam einige Exemplare des „Wachtturms“ übergeben wollte. Ihrer Aussage, die Schriften seien nur für ihren Bräutigam zur Lektüre bestimmt gewesen, schenkte der Volksgerichtshof keinen Glauben. Statt dessen erschien ihm die Angeklagte als eine im Kurierdienst Eingesetzte, die zur weiteren Verbreitung in Italien bestimmte Schriften über die Grenze brachte. Die Frau wurde am 4. Oktober 1943 zum Tode und zu „dauerndem Ehrverlust“ verurteilt.

Acht Wochen später, am 30. November 1943, verurteilte der Volksgerichtshof unter dem Vorsitz seines Präsidenten die 53jährige Hausangestellte Martha Hopp wegen „Wehrkraftzersetzung“ zum Tode und ebenfalls zu „dauerndem Ehrverlust"110. Für Freisler hatte die aus Lübeck stammende, mit den Bibelforschern sympathisierende Frau als „für immer ehrlos“ zu gelten, da sie gegenüber einer Arbeitskollegin und einer Bekannten geäußert hatte, Deutschland werde den Krieg verlieren und die noch zu gewärtigenden Menschenverluste würden alles vorstellbare Maß überschreiten. Wer deutsche Frauen derart defaitistisch bearbeite, so befand der Gerichtshof, „der nagt an unserer Kampfkraft“.

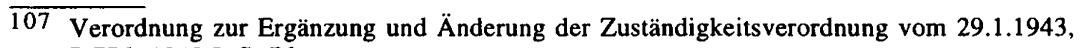
RGB1. 1943 I, S. 76.

108 BA, R 22/3390, B1. 134, Der Oberreichsanwalt beim VGH, Lagebericht vom 8.10.1943.

109 DCB, VGH, 8 J 131/43, Urteil vom 4.10.1943. Urteilsauszüge sind abgedruckt in: Maislinger, Die Zeugen Jehovas/Tirol, S. 375-378.

110 BA, R 60 V/342, VGH, 2 J 637/43, Urteil vom 30.11.1943. 
Über neun Zeugen Jehovas aus Neuß, Herne, Rheydt und Düsseldorf saß der sechste Senat des Volksgerichtshofes am 4. August 1944 zu Gericht ${ }^{111}$. Die sechs Frauen und drei Männer wurden eines Verbrechens der „Wehrkraftzersetzung in Verbindung mit landesverräterischer Begünstigung des Feindes" für schuldig befunden, da ,,sie sich sämtlich bis Dezember 1943 für die ,Internationale Bibelforscher-Vereinigung ' betätigt" hatten. Bei sieben Angeklagten verhängte der Gerichtshof die Todesstrafe, zwei wurden zu je sechs Jahren Zuchthaus verurteilt. Die Todesurteile wurden ausnahmslos vollstreckt: Vier Frauen, Helene Gotthold, Henriette Meyer, Luise Pakull und Else Woiecziech, wurden am 8. Dezember 1944 in Berlin-Plötzensee hingerichtet; drei Tage später wurden Wilhelm Hengeveld und Ernst Meyer in Brandenburg-Görden enthauptet. Zu Beginn des folgenden Jahres, am 12. Januar 1945, mußte zuletzt Mathilde Hengeveld in Plötzensee vor das Schafott treten 112 .

Zuweilen sah das Ergebnis der „Urteilsfindung“ des Volksgerichtshofes in ,Zersetzungsfällen" jedoch auch anders aus. Am 30. August 1944 stand vor den Richtern eine 68jährige Frau, die vom Oberreichsanwalt angeklagt wurde, durch bibelforscherische Reden der Art, daß gegenwärtig zwar noch ,der Satan“ regiere, aber nach der unausweichlich folgenden Vernichtung das Friedensreich Gottes aufgerichtet würde, einen Anschlag auf die „Wehrkraft des deutschen Volkes“ unternommen zu haben. Der Volksgerichtshof hielt diesen Vorwurf für überzogen, lehnte zudem eine Bestrafung wegen „Teilnahme an einer wehrfeindlichen Verbindung" ab und erkannte auf Freispruch. Die Urteilsbegründung zu diesem Fall enthält Ausführungen, die angesichts des ansonsten praktizierten Gesinnungsstrafrechts als bemerkenswert anzusehen sind. So war für die Richter zweifelsfrei erwiesen, „daß die Angeklagte die Lehren der Internationalen Bibelforscher-Vereinigung noch immer zur Grundlage ihrer religiösen Überzeugung macht"113. Das sei aber, so erklärten die Richter weiter, ,an sich nicht strafbar“. Die gesetzlichen Voraussetzungen einer nach der „Wehrkraftschutzverordnung“ strafbaren Handlung seien vielmehr nur dann gegeben, ,wenn diese religiöse Überzeugung auch betätigt und dadurch die wehrfeindlichen Bestrebungen der Bibelforscher-Vereinigung gefördert werden". Aus den inkriminierten Äußerungen lasse sich jedoch „eine werbende Tendenz im Sinne der Bibelforscher-Vereinigung nicht mit Sicherheit entnehmen". Selbst der gelegentlich von ihr geäußerte Standpunkt, daß Christen nicht auf Christen schießen dürften, sei, so der erste Senat des Volksgerichtshofes, ,nur der Ausdruck ihres Glaubens“, mit dem sie „,bestimmte Absichten nicht verbunden“ habe. Doch auch dies sich von der üblichen „Rechtsprechung“ des Volksgerichtshofes in Bibelforscherverfahren deutlich abhebende Urteil war zweifellos nicht von einer überraschenden Hinwendung zum Tatbestandsprinzip motiviert, sondern auch in diesem Fall kam nationalsozialistisches Rechtsdenken zur Anwendung. Nach Ansicht des Gerichtes wurde ein Freispruch nämlich nötig,

111 BA, R 60 II/108-4, VGH, 7 J. 58/44, Urteil vom 4.8.1944.

112 Angaben nach DCB, Karteikarten Gefängnis Berlin-Plötzensee; Ehrenbuch Plötzensse, S. 100, 104, 118, 121, 139; Ehrenbuch Brandenburg-Görden, Band 6, S. 401; UaP Frank Braßel, Jehovas Zeugen, Gruppe Herne, Bericht vom 22.1.1946.

113 DCB, VGH, 5a J 405/44, Urteil vom 30.8.1944. 
weil eine Bestrafung ,dem gesunden Volksempfinden“ widerspräche, da drei ihrer Söhne ,als deutsche Soldaten im Kampfe gegen den Bolschewismus“ stünden und diese sich ,in ihrer Opferbereitschaft enttäuscht fühlen“ müßten, wenn man gegen „ihre an der Schwelle zum Greisenalter stehende Mutter" vorginge.

Auch in Verfahren gegen ausländische Zeugen Jehovas wich der Volksgerichtshof von der „Regelstrafe“ ab. Am 9. November 1944 verhandelte das Gericht gegen acht Zeugen Jehovas aus dem „Protektorat Böhmen und Mähren“. Der auf „Zersetzung der Wehrkraft" lautenden Anklage wurde im Grundsatz beigepflichtet: „Dadurch, daß sie sich gegenseitig in ihrem Irrglauben bestärkten oder Außenstehende dafür warben, machten sie sich also der Wehrkraftzersetzung unter der tschechischen Bevölkerung im Protektorat schuldig (§ 5 Abs. 1 Ziffer 1 KSSVO).“114 Die Frage, inwieweit denn durch das Werben für die Bibelforscherlehre unter der tschechischen Bevölkerung überhaupt die Wehrkraft des „Deutschen Volkes“ in Mitleidenschaft gezogen werden konnte, scheint sich allerdings auch den Juristen des Volksgerichtshofes und den als Laienrichtern fungierenden Parteichargen gestellt zu haben. Bei den Erörterungen zur Strafzumessung klingt dies zumindest an. Der erste Senat des Volksgerichtshofes erkannte Milderungsgründe zu, da die Aktivitäten der Angeklagten ,im Hinblick auf die Befreiung des tschechischen Volkes von der Wehrpflicht unsere Wehrkraft nicht unmittelbar beeinträchtigten“. In Anbetracht dessen lautete das Urteil trotz der im Vergleich zu anderen Verfahren weit umfangreicheren Betätigung der Angeklagten für die IBV nicht auf Todesstrafe, sondern auf Zuchthaus- und in drei Fällen auf Gefängnisstrafe ${ }^{115}$.

Am 19. November 1943 stand die Berliner Zeitungsausträgerin Emmi Zehden vor den Richtern des Volksgerichtshofes. Die Pflegemutter des „Wehrdienstflüchtigen" Horst-Günther Schmidt, der - wie oben erwähnt - zusammen mit zwei Freunden untergetaucht war, wurde der ,landesverräterischen Feindbegünstigung und Wehrdienstentziehung “ beschuldigt, weil sie es ,in den Jahren 1940 bis 1942 in Berlin als Anhängerin der Vereinigung internationaler Bibelforscher unternommen“ habe, „drei Wehrpflichtige, die ebenfalls dieser Vereinigung angehörten, durch Gewährung von Unterschlupf und Verpflegung der Erfüllung der Wehrpflicht zu entziehen"116. Der Gerichtshof verurteilte die 43jährige Frau zum Tode und zu ,lebenslangem Ehrverlust“.

Drei Tage nach dem Urteilsspruch richtete Emmi Zehden ein Gnadengesuch an den Oberreichsanwalt beim Volksgerichtshof: „Mein Leben lang war ich ein fleißiger und ordentlicher Mensch, [ich habe] immer nur Gutes getan.“ Vom Frauen-

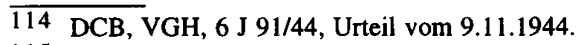

115 Auch in einem zwei Tage zuvor verhandelten Verfahren, das sich ebenfalls gegen eine „Protektoratsangehörige" richtete, die 1941 mehrere Bibelforscherschriften ins Tschechische übersetzt und bis zu ihrer Verhaftung an IBV-Zusammenkünften teilgenommen hatte, sah der VGH einen "minder schweren Fall“ als gegeben an, da die Angeklagte wegen ihrer "Befangenheit in dem religiösen Irrglauben" die "feindbegünstigende" Bedeutung ihres Tuns nicht erkannt habe. Das Urteil lautete auf vier Jahre Gefängnis. Vgl. DCB, VGH, 6 J 134/44, Urteil vom 7.11.1944; Wagner, Volksgerichtshof, S. 385, 630.

116 DCB, VGH, $1 \mathrm{~J}$ 56/43, Urteil vom 19.11.1943; zum Vorgang siehe oben S. 341f. Auszüge aus dem „Ersatz-Vollstreckungsband“ sind reproduziert in: „,... für immer ehrlos“. Aus der Praxis des Volksgerichtshofes, S. 22-32 (die folgenden Zitate entstammen den dort abgedruckten Dokumenten). 
gefängnis Berlin wurde am gleichen Tag zu dem Gnadengesuch Stellung genommen: „Die zum Tode verurteilte Emmy Zehden führt sich gut. Sie arbeitet trotz ihrer Fesselung als Strumpfstopferin. Sie beweist in ihrer Haltung große Selbstdisziplin. Da die Urteilsgründe hier unbekannt sind, vermag ich das Gesuch nicht ausdrücklich zu befürworten. " Nach mehr als einem halben Jahr und noch weiteren Eingaben der auf Gnade hoffenden Frau ordnete der mittlerweile zum Staatssekretär im Reichsjustizministerium avancierte Dr. Herbert Klemm ,mit Ermächtigung des Führers" die Vollstreckung an ${ }^{117}$. Danach waltete die präzise Routine einer tausendfach erprobten Mordmaschinerie. Nach der Überstellung in die Strafanstalt Plötzensee wurde Emmi Zehden am Freitag, dem 9. Juni 1944, nachdem ihr anderthalb Stunden zuvor die Anordnung der Vollstreckung offiziell eröffnet worden war, um 13.00 Uhr zur dortigen Hinrichtungsstätte geführt. Mit den Händen auf dem Rücken gefesselt, wurde sie dem Scharfrichter und seinen drei Gehilfen übergeben. Über die folgenden sieben Sekunden vermerkt das Vollstreckungsprotokoll: „Nach Feststellung der Personengleichheit der Vorgeführten mit der Verurteilten beauftragte der Vollstreckungsleiter den Scharfrichter mit der Vollstreckung. Die Verurteilte, die ruhig und gefaßt war, ließ sich ohne Widerstreben auf das Fallbeil legen, worauf der Scharfrichter die Enthauptung mit dem Fallbeil ausführte und sodann meldete, daß das Urteil vollstreckt sei.“ Die aus Anlaß der Vollstreckung entstandenen 122,18 RM an Kosten wurden der Geschäftsstelle der Reichsanwaltschaft beim Volksgerichtshof in Rechnung gestellt.

Ein genauer Überblick über den Umfang der vor dem Volksgerichtshof gegen Zeugen Jehovas geführten Verfahren ist aufgrund der fragmentarischen Überlieferungslage nicht möglich ${ }^{118}$. Lediglich zu elf Prozessen ließen sich Urteilsschriften oder andere Unterlagen ermitteln. In diesen elf Verfahren urteilte der Volksgerichtshof über insgesamt 37 Angeklagte. Davon wurden 25 Personen (13 Männer und 12 Frauen) zum Tode verurteilt ${ }^{119}$, gegen elf Personen wurde auf eine Zeitstrafe erkannt (Durchschnittsstrafmaß: 4,2 Jahre), und in einem Fall erfolgte ein Freispruch. So lückenhaft diese Angaben auch sind, so zeigen sie doch die drastische Strafverschärfung nach Übernahme der Verfahren in die Zuständigkeit des Volksgerichtshofes in den letzten zwei Jahren des dem Untergang entgegensteuernden Regimes. Das Wüten der Strafjustiz gegen Zeugen Jehovas erreichte damit in genau

117 RJM, Verfügung vom 31.5.1944, wiedergegeben in: „... für immer ehrlos“, S. 27.

118 Im Geschichtsbericht der WTG wird bei der Angabe der gegen Zeugen Jehovas im „Dritten Reich" ausgesprochenen Todesurteile nicht zwischen Urteilen der allgemeinen Gerichtsbarkeit (Sondergerichte, Oberlandesgerichte, Volksgerichtshof) und Urteilen der Kriegsgerichte (fast ausnahmslos Reichskriegsgericht) unterschieden. Nach den dortigen, unvollständigen Angaben wurden insgesamt 253 Zeugen Jehovas zum Tode verurteilt; die Zahl der Urteilsvollstreckungen wird mit 203 angegeben (Jahrbuch 1974, S. 182, 212). Es ist davon auszugehen, daß schätzungsweise $80 \%$ dieser Todesurteile von der Wehrmachtjustiz gegen Kriegsdienstverweigerer verhängt wurden. Demnach ist mit einer Zahl von ungefähr 50 durch die allgemeine Gerichtsbarkeit zum Tode verurteilter Zeugen Jehovas zu rechnen.

119 In mindestens 15 Fällen wurde das Todesurteil vollstreckt, in vier Fällen wurde einem Gnadengesuch stattgegeben. Von den verbleibenden sechs Urteilen ist nicht bekannt, ob sie vollstreckt wurden. Aufgrund der allgemein hohen Vollstreckungsquote bei Wehrkraftzersetzungsdelikten (vgl. Wagner, Volksgerichtshof, S. 279) wird vermutlich auch bei diesen Fällen die Zahl der Hinrichtungen die möglicher Begnadigungen um das Zwei- bis Dreifache überstiegen haben. 
dem Zeitraum seinen Höhepunkt, der für die KZ-Häftlinge mit dem „lila Winkel“ durch eine zunehmende Verbesserung ihrer Lebens- bzw. Überlebensbedingungen gekennzeichnet war ${ }^{120}$. Das Verhältnis hatte sich gewissermaßen umgekehrt: Bewahrten anfangs die Mühlen der Justiz die Zeugen Jehovas noch vor dem rigoroseren Vorgehen der Gestapo, so barg in den letzten Kriegsjahren die Zugehörigkeit zum Einflußbereich der SS für die im KZ missionierenden Zeugen Jehovas weniger Gefahren, als sie ihren außerhalb der Lager missionierenden Glaubensgeschwistern seitens der Justiz nun drohten.

Das unnachgiebige Vorgehen der Strafjustiz gegen die Zeugen Jehovas während der Kriegsjahre kam auch vor dem Internationalen Militärgerichtshof in Nürnberg zur Sprache, als dort am 12. April 1946 der Nachfolger Heydrichs in der Leitung des Reichssicherheitshauptamtes, Ernst Kaltenbrunner, aussagte. Von seinem Verteidiger Dr. Kurt Kauffmann auf das Vorgehen gegen die Bibelforscher angesprochen, nahm Kaltenbrunner die Gelegenheit wahr, sich zum Retter der Glaubensverfolgten zu stilisieren. Nachdem er einleitend festgestellt hatte, zwar hätten Militär- und Zivilgerichte Todesurteile gegen Bibelforscher ausgesprochen, durch die Geheime Staatspolizei aber seien Todesurteile ,natürlich nicht erfolgt“, wählte er würdevolle Begriffe und sprach von einer ,unbilligen Härte gegenüber glaubensbedingter Einstellung dieser Sektenangehörigen" ${ }^{121}$. Nun suggerierte er, daß ihm das rigorose Vorgehen der Gerichte seinerzeit keine Ruhe gelassen habe: „Ich habe sowohl an die Parteikanzlei, als an das Justizministerium, als an Himmler, als in meiner Nachrichtenerstattung an Hitler, auf diesen Umstand hingewiesen, und habe in mehreren Besprechungen bei Thierack verlangt, daß diese Art Rechtsprechung eingestellt werde."

Kaltenbrunner beließ es aber nicht bei dieser Apologie, sondern ging noch einen Schritt weiter, indem er dem in dieser Frage anscheinend nicht besonders gut informierten Auditorium erklärte, seine Bemühungen hätten schließlich zum „Erfolg“ geführt. Er schwadronierte über eine Weisung an die Oberstaatsanwaltschaften, nach der „bereits ausgesprochene Urteile zu inhibieren“ gewesen wären, und behauptete ohne Umschweife, in einem weiteren Schritt sei erreicht worden, „daß Bibelforscher nicht mehr vor Gericht gestellt wurden“. Kaltenbrunner verkündete abschließend zu diesem Thema: „Ich halte es für einen ausgesprochenen Erfolg meiner persönlichen Intervention bei Thierack, [...] daß diese Rechtsprechungsart gegen diese Sekten restlos beseitigt worden ist." ${ }^{122}$

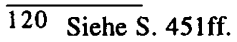

121

Der Prozeß gegen die Hauptkriegsverbrecher, Band XI, S. 323.

122 Die von Kaltenbrunner angeführte Weisung des Reichsjustizministers Thierack konnte nicht ermittelt werden. Wenn es sie wirklich gegeben haben sollte, so könnte sie allenfalls in den letzten Kriegsmonaten ergangen sein. Angesichts der gerade für diese Zeit äußerst lückenhaften Überlieferung läßt sich allerdings auch anhand der Gerichtsakten nur schwer beurteilen, ob eine solche Weisung jemals erteilt worden sein mag. Für das zweite Halbjahr 1944 sind jedenfalls noch mindestens 19 aufgrund eines justitiellen Verfahrens vollzogene Hinrichtungen von Zeugen Jehovas belegbar. Die letzte nachgewiesene Vollstreckung eines vom VGH in einem Bibelforscherverfahren gefältten Todesurteils wurde für den 12.1.1945 angeordnet (Hinrichtung der 32jährigen Mathilde Hengeveld in Plötzensee, vgl. BA, R 60 II/108-4, VGH, 7 J. 58/44, Urteil vom 4.8.1944; Ehrenbuch Plötzensee, S. 104). Für die Militärjustiz ist einem Schreiben des OKW an den Chef des Hauptamtes SS-Gericht vom 8.3.1945 zufolge davon auszugehen, daß zumindest Anfang März 1945 die in den ein halbes Jahr zuvor 
Daß eine solche Apologie überhaupt so dreist versucht werden konnte, wie es bereits ein Jahr nach Ende des Nazi-Regimes in Nürnberg geschah, zeugt davon, daß die - auch 1945 überdauernde - Randständigkeit der Zeugen Jehovas und die sie betreffende allgemeine Uninformiertheit ein geradezu ideales Terrain für Falschdarstellungen und Manipulationen boten.

\section{Kriegsdienstverweigerung der Zeugen Jehovas}

Als Adolf Hitler am 16. März 1935 die Wiedereinführung der allgemeinen Wehrpflicht ankündigte, kamen auf die Zeugen Jehovas neue, schwere Belastungen zu. Während in den Jahren seit dem Ende des Ersten Weltkrieges eine Ablehnung des Militärdienstes dem einzelnen staatlicherseits keine Probleme bereitete, sahen sich die Angehörigen der Bibelforschervereinigung nun direkt mit der Frage der Rekrutierung zum Soldatendienst konfrontiert, denn mit Erlaß des Wehrgesetzes vom 21. Mai 1935 unterlag ,jeder deutsche Mann“ zwischen dem vollendeten 18. und dem 45. Lebensjahr der Wehrpflicht ${ }^{123}$. Eine Ausnahmeregelung für Kriegsdienstverweigerer aus religiösen oder anderen Gewissensgründen war nicht vorgesehen; eine derartige Bestimmung lag dem nationalsozialistischen Denken vollkommen

erlassenen „Richtlinien für Strafverfahren gegen ernste Bibelforscher usw.“ (IfZ, MA 333, 657686; siehe S. 392f.) enthaltenen Bestimmungen - wonach bei unwiderrufener Kriegsdienstverweigerung ohne Ausnahme die Todesstrafe zu verhängen war - noch in Kraft waren. Das letzte bekannte - allerdings standrechtlich ergangene - Todesurteil gegen einen Zeugen Jehovas ist wenige Tage vor Kriegsende im Bereich des Oberbefehlshabers der Heeresgruppe Mitte, Generalfeldmarschall Ferdinand Schörner, durch ein Standgericht gesprochen und anschließend vollstreckt worden (EB Johannes Rauthe, Geschichtsbericht, S. 40).

Für Kaltenbrunners Angabe spricht allenfalls - neben einigen in den letzten Kriegsmonaten gegen kriegsdienstverweigernde Zeugen Jehovas ausgesprochene Zeitstrafen (vgl. beispielsweise Kammler, Kasseler Soldaten, S. 55) - eine gegen Kriegsende allem Anschein nach großzügiger gehandhabte Gnadenpraxis. So wurde z. B. ein vom Sondergericht für die Operationszone Alpenvorland am 9.4.1945 wegen „Verweigerung der Einberufung zum Volkssturm" verhängtes Todesurteil auf fünf Jahre Zuchthaus gemildert (vgl. Hartmann, Kriegsdienstverweigerung [1986], S. 60). Auch wird vereinzelt von Verfahrenseinstellungen in den letzten Kriegsmonaten berichtet (vgl. Maislinger, Andere religiöse Gruppen, S. 331). In einem beim Hanseatischen Sondergericht ebenfalls wegen der Verweigerung des Volkssturmes geführten Verfahren nach § 5 Abs. 1 Zif. $3 \mathrm{KSSVO}$ wurde die für den 26.1.1945 angesetzte Gerichtsverhandlung aufgehoben, weil - so die angegebene Begründung - „die Akte vom Reichsjustizministerium angefordert wurde" (SLG HH, HSG 11 Js. P. Sond. 464/44, B1. 16). Der Angeschuldigte blieb noch drei weitere Monate in Haft, ohne daß es noch zu einem Prozeß gekommen ist (AfW HH, 080789). Ob dieser zuletzt genannte Vorgang ein Beleg für die Angabe Kaltenbrunners ist, läßt sich ohne weitere Aktenkenntnis nicht beurteilen. Nach wie vor bleiben aber große Zweifel am Wahrheitsgehalt seiner Aussage bestehen; von generell eingestellten Gerichtsverfahren gegen Zeugen Jehovas kann jedenfalls überhaupt nicht die Rede sein.

$123 \S \S 1$ Abs. 2 und 4 des Wehrgesetzes vom 21.5.1935, RGB1. 1935 I, S. 609. Das Wehrgesetz (§ 14) kannte nur zwei Wehrpflichtausnahmen: Neben den ,völlig untauglichen Dienstpflichtigen“, die nach der Ausmusterung aus dem Wehrpflichtverhältnis ausschieden, waren nur die „Dienstpflichtigen römisch-katholischen Bekenntnisses, die die Subdiakonatsweihe erhalten haben" im Frieden von der Heranziehung zum aktiven Wehrdienst befreit. (,Juden, Zigeuner und Wehrunwürdige" waren zum Wehrdienst nicht zugelassen.) 
fern ${ }^{124}$. Im „Dritten Reich“ galt der Wehrdienst als „Ehrendienst am deutschen Volk“125, und nach nationalsozialistischer Auffassung entsprach die ,erneut errungene“ allgemeine Wehrpflicht „der Treupflicht des Volksgenossen zu seinem Volk“126.

Für die Zeugen Jehovas gab es hingegen eine andersgeartete „Treupflicht“, diejenige zu Gott und den biblischen Geboten. Sowohl die Treue zu dem einen Herrn, dem allein Christen zu dienen hätten, als auch die Pflicht, sich ,in den Dingen der vergehenden Welt neutral“" zu verhalten ${ }^{127}$, schloß für sie jegliche Teilnahme am Militärdienst aus ${ }^{128}$. Als „Soldaten Jesu Christi“ hatten sie sich von allen politi-

124 Es konnte lediglich ein einziger Hinweis darauf gefunden werden, da $B$ die Frage einer solchen Ausnahmeregelung überhaupt thematisiert wurde. Im Zusammenhang mit der Verkündigung des Wehrgesetzes hatte der stellvertretende Vorsitzende der „Deutschen Vereinigung des Weltbundes für internationale Freundschaftsarbeit der Kirchen", Superintendent Max Diestel aus Berlin, Verhandlungen „mit dem betreffenden Referenten im Kriegsministerium“ über die Frage der religiös motivierten Kriegsdienstverweigerung ,namentlich im Hinblick auf Quäker und Mennoniten" geführt. Ihm sei im Reichskriegsministerium zugesagt worden, da $\mathrm{B}$ man ,in der praktischen Behandlung solcher Fälle [...] nachsichtig verfahren wolle“ (Max Diestel, Schreiben vom 19.10.1939 an das Gericht des 2. Admirals der Ostseestation, zit. nach Röhm, Sterben für den Frieden, S. 147). Nach Röhm handelt es sich bei diesem Schreiben um ,die einzige bekannt gewordene Äußerung zur Kriegsdienstverweigerung eines leitenden Kirchenmannes im Zweiten Weltkrieg" (ebenda, S. 206).

125 So der Wortlaut der einleitenden Formel des Wehrgesetzes ( $\$ 1$ Abs. 1).

126 Heckel, Wehrverfassung, S. 96.

127 Die prinzipielle Haltung der Zeugen Jehovas zur Wehrpflicht hat sich auch im Nachkriegsdeutschland nicht verändert. Obgleich in der Bundesrepublik Deutschland das Recht auf Kriegsdienstverweigerung verfassungsmäßig garantiert ist (Art. 4 Abs. $3 \mathrm{GG}$ ), gerieten die Angehörigen der Glaubensgemeinschaft hier ebenfalls in Konflikt mit dem Staat. Da durch die von anerkannten Kriegsdienstverweigerern geforderte Ableistung des Zivildienstes der Wehrpflicht nachgekommen wird, lehnten die Zeugen Jehovas auch den Zivildienst ab, denn die Erfüllung eines Wehrersatzdienstes erkenne dem - nach ihrem Verständnis dazu nicht legitimierten - Staat das Recht zu, die zur "Neutralität" in der „vergehenden Welt" verpflichteten Zeugen Jehovas der Wehrpflicht zu unterwerfen (vgl. Burski, Die Zeugen Jehovas, S. 33-35; Hannover, Ersatzdienstverweigerung, S. 33ff.). In den fünfziger und sechziger Jahren saßen daraufhin hunderte Zeugen Jehovas als „Totalverweigerer" in bundesdeutschen Gefängnissen ein. Durch eine Änderung des Gesetzes über den zivilen Ersatzdienst im August 1969 trug der Gesetzgeber den Gewissensbedenken der Zeugen Jehovas Rechnung. Die „nach Rücksprache mit der Wachtturm-Gesellschaft“ (Krölls, Kriegsdienstverweigerung, S. 211) - neu eingefügte Vorschrift des $\S 15 a$ Ersatzdienstgesetz regelte, da $\$$ bei einem anerkannten Kriegsdienstverweigerer, ,der aus Gewissensgründen gehindert ist, Ersatzdienst zu leisten“, von der Heranziehung zum Ersatzdienst abgesehen wird, falls er vor Vollendung des 23. Lebensjahres für die Mindestdauer von zweieinhalb Jahren freiwillig in einem Arbeitsverhältnis in einer Kranken- oder Heil- und Pflegeanstalt tätig war. Im Zusammenhang mit dem sich in jüngster Zeit schrittweise vollziehenden Veränderungsprozeß (siehe auch S. 544f.) hat die WTG die prinzipielle Verwerfung der Zivildienstpflicht aufgegeben und es nunmehr in das Ermessen der einzelnen Gläubigen gestellt, ob sie Zivildienst leisten oder die (aufgrund der Arbeitsmarktsituation zunehmend schwierigere) Alternativmöglichkeit wählen. Vgl. Der Wachtturm, 1.5.1996, S. 19f.

128 Zur Begründung der Kriegsdienstverweigerung durch die Zeugen Jehovas vgl. Gott bleibt wahrhaftig, S. 245ff.; Cole, Jehovas Zeugen, S. 95ff.; Lichtenegger, Wiens Bibelforscherinnen, S. 36-42. Von Außenstehenden werden die Zeugen Jehovas nicht selten als „Pazifisten“ bezeichnet. Sie selbst verstehen sich jedoch als „Kriegsdienstverweigerer aus Gewissensgründen, aber nicht Pazifisten" (Cole, Jehovas Zeugen, S. 128f.) und wünschen nicht, daß jene IBV-Angehörigen, die im „Dritten Reich“ in großer Zahl den Kriegsdienst verweigert haben, heute in der Rückschau zu „Vorläufern der Friedensbewegung“" erklärt werden. Nicht nur die Achtung vor den Motiven der Zeugen Jehovas, die für ihre Überzeugung in den Tod gingen, sondern auch objektive Gesichtspunkte fordern diese Unterscheidung. Den Zeugen Jehovas ging es nicht um weltliche Dinge. Es ging ihnen also nicht etwa um die Ver- 
schen und nationalistischen Bestrebungen fernzuhalten. Nach ihrer Glaubensüberzeugung war jeder Krieg zudem Ausdruck der unsichtbaren Herrschaft des Teufels in dieser Welt. Das neutestamentliche Gebot der Gewaltlosigkeit verbot ihnen ebenso wie das alttestamentliche Gebot „Du sollst nicht töten“ jeden Waffengebrauch gegen Mitmenschen oder andere Völker. Der Kriegsdienst stellte für die Zeugen Jehovas die totale Negation ihres christlichen Glaubens dar; über ihre Beweggründe heißt es in einem Bericht: „Unser Gewissen war an der Bibel orientiert und deswegen international. Es wäre für uns undenkbar gewesen, zur Waffe zu greifen und auf andere Menschen zu schießen, nur weil der Staat sie zu Feinden erklärt. Das waren für uns keine Feinde. [...] Wir fühlten uns nicht als Deutsche, und deshalb war es uns auch nicht um die deutsche Ehre, um den deutschen Ruhm und um das deutsche Vaterland zu tun. Für uns ist der andere einfach der Bruder, selbst der Feind ist es für uns wert, geliebt zu werden."129

Der von den Angehörigen der Wehrmacht bei Dienstantritt zu leistende Fahneneid stellte für die Zeugen Jehovas eine zusätzliche Gewissensnötigung dar, denn der auf die Person Hitlers zu leistende Eid verband das Gelöbnis zur Erfüllung der Pflichten des soldatischen Dienstverhältnisses mit einer Anrufung Gottes. Die Eidesformel lautete: „Ich schwöre bei Gott diesen heiligen Eid, daß ich dem Führer des Deutschen Reiches und Volkes Adolf Hitler, dem Obersten Befehlshaber der Wehrmacht, unbedingten Gehorsam leisten und als tapferer Soldat bereit sein will, jederzeit für diesen Eid mein Leben einzusetzen." 130

Die Eidesverweigerung und mehr noch die gegenüber den Wehrmeldeämtern oder den Kompanieführern abgegebene Erklärung, der Aufforderung zum Militärdienst nicht Folge leisten zu wollen, brachte die Zeugen Jehovas in Konflikt mit dem Wehrstrafrecht, denn $\S 48$ des Militärstrafgesetzbuches sah ausdrücklich die volle Strafbarkeit auch bei Handlungen aus religiösen Motiven vor ${ }^{131}$. Diese Gesetzesbestimmung, die sich nach den Worten des führenden Kommentarwerkes „,insbesondere gegen Sekten und Pazifisten“132 richtete, räumte der militärischen Gehorsamspflicht den ,unbedingten Vorrang" vor einer „Gewissenspflicht“ und anderen persönlichen Erwägungen ein. Der ministerielle Gesetzeskommentar von Ministerialrat Georg Dörken und Oberkriegsgerichtsrat Dr. Werner Scherer beschränkte die Erläuterung zu diesem Paragraphen auf einen bezeichnenden Satz:

werfung von Gewalt als Mittel der politischen Auseinandersetzung, auch nicht um die Herstellung einer internationalen Friedensordnung oder um radikale Abrüstung. Ihre Zielsetzung hatte demnach nichts mit Pazifismus im Sinne eines aktiven Eintretens für Gewaltfreiheit zu tun, sondern die Kriegsdienstverweigerung wurde mit der Christenpflicht zur ,politischen Neutralität" begründetet (siehe S. 55). Sie verstand sich somit als ein Zeichen der Treue gegenüber Gott und nicht vordergründig als ein Zeichen für die Welt. Vgl. Der Wachtturm, 15.2.1979, S. 12 („Warum Jehovas Zeugen keine Pazifisten sind“).

129 Knöller, Erinnerungen, S. $21 \mathrm{f}$.

130 Eidesformel nach der am 20.7.1935 erlassenen Fassung, RGB1. 1935 I, S. 1035. Der Reichskriegsminister unterstrich mit Erlaß vom 29.3.1936, daß es sich bei dem Fahneneid der Wehrmacht um einen ,religiösen Eid“" handele, dieser aber nicht ein christliches Bekenntnis voraussetze (RKM, Erlaß vom 29.3.1936; zit. nach Dade, Fahneneid, S. 50).

$131 \S 48$ MStGB: „Die Strafbarkeit einer Handlung oder Unterlassung ist dadurch nicht ausgeschlossen, daß der Täter nach seinem Gewissen oder den Vorschriften seiner Religion sein Verhalten für geboten erachtet hat.“

132 Militärstrafgesetzbuch/Schwinge ${ }^{1} 1936$, S. $115 f$. 
„Die Vorschrift, daß Religions- oder Gewissensüberzeugungen nicht von der Einhaltung der staatlichen Normen befreien, dient nur der Belehrung; sie versteht sich bei dem Totalitätsanspruch des Staates von selbst."133

Verstöße gegen das Militärstrafrecht wurden im „Dritten Reich“ von den Kriegsgerichten geahndet. Die im Anschluß an den Ersten Weltkrieg abgeschaffte Militärgerichtsbarkeit war nur wenige Monate nach der nationalsozialistischen Machtübernahme, am 12. Mai 1933, wieder eingeführt worden ${ }^{134}$. Am 1. Januar 1934 nahmen die erstinstanzlichen Kriegsgerichte und die Oberkriegsgerichte als zweite Instanz ihre Tätigkeit auf. Mit Verordnung vom 5. September 1936 wurde als höchstes Wehrmachtsgericht das „Reichskriegsgericht“ geschaffen ${ }^{135}$.

Auf wehrrechtlichem Gebiet wurde durch Novellierungen vom 23. November 1934 und vom 16. Juli 1935 das Militärstrafgesetzbuch (MStGB) von 1872 den ,neuen Erfordernissen“ angepaßt ${ }^{136}$, wobei auch die meisten Milderungen, die in das MStGB seit dem Ersten Weltkrieg Eingang gefunden hatten, beseitigt wurden. Das Militärstrafgesetzbuch ${ }^{137}$ kannte aber auch danach weder den Begriff der „Kriegsdienstverweigerung“138 noch eine besondere Strafsanktion für die „Eides-

133 Dörken/Scherer, Militärstrafgesetzbuch, S. 40.

134 Gesetz zur Wiedereinführung der Militärgerichtsbarkeit vom 12.5.1933, RGB1. 1933 I, S. 264.

135 RGBl. 1936 I, S. 517. Nach Kater hat das Reichskriegsgericht bereits seit 1935 Zeugen Jehovas wegen Eidesverweigerung abgeurteilt (vgl. Kater, Bibelforscher, S. 199). Dies ist nicht zutreffend; nach der Militärstrafgerichtsordnung fielen diese Fälle in die Zuständigkeit der Kriegs- bzw. im Berufungsverfahren der Oberkriegsgerichte und nicht in diejenige des (ohnehin erst 1936 geschaffenen) Reichskriegsgerichtes. Erst nach dem - am Tag der Mobilmachung verfügten - Inkrafttreten der „,Kriegsstrafverfahrensordnung“, die die Zuständigkeit des RKG für den mit der KSSVO neu geschaffenen Tatbestand der „Zersetzung der Wehrkraft“ begründete ( $\$ 14$ Abs. 1 Zif. 9 KStVO), waren die Verfahren gegen Zeugen Jehovas Angelegenheit des obersten Wehrmachtgerichts (siehe auch S. 366f.).

136 RGBl. 1934 I, S. 1165; RGB1. 1935 I, S. 1021. Im Zweiten Weltkrieg wurde das MStGB durch VO vom 10.10.1940 (RGBI. 1940 I, S. 1347) nochmals in zahlreichen Punkten geändert und verschärft.

137 Auch in dem Entwurf für ein neues „Wehrmachtstrafgesetzbuch“ - parallel zum „Deutschen Strafgesetzbuch" vorbereitet und ebenfalls nie verabschiedet - waren keine speziellen Regelungen über die Wehrdienstverweigerung vorgesehen (vgl. BA, R 43 II/1284, Bl. 18ff.; Zur Neugestaltung des Militärstrafgesetzbuches, Bericht des Wehrrechtsausschusses): Der im Dezember 1936 von Reichskriegsminister Blomberg vorgelegte verabschiedungsreife „,Entwurf eines Strafgesetzbuches für die deutsche Wehrmacht" nennt als Straftatbestände bei den Entziehungsdelikten ausschließlich „Fahnenflucht“ (§ 52-54), „Herbeiführung der Dienstuntauglichkeit“ (§55) und „Wehrdienstentziehung durch Täuschung“ (§ 56). Vermutlich lag die Vorstellung, da $B$ Wehrpflichtige unter Berufung auf Gewissensgründe - ohne Anstalten zu treffen, sich der Strafverfolgung zu entziehen - den Waffendienst a priori zu verweigern und die Folgen ihres Tuns bewußt in Kauf zu nehmen bereit waren, so weit außerhalb des Blickfeldes jener mit den Entwürfen befaßten juristischen und militärischen Fachleute, daß sie diesen ,Tatbestand“ unberücksichtigt ließen. Die Frage der Kriegsdienstverweigerung blieb in den Vorkriegsjahren gesetzlich ungeregelt.

138 Unter dem Begriff der „Kriegsdienstverweigerung“, so wie er im folgenden gebraucht wird, ist die offen demonstrierte persönliche Weigerung zu verstehen, einer bereits ergangenen oder $\mathrm{zu}$ erwartenden Aufforderung zur Kriegsteilnahme bzw. zum Waffendienst Folge zu leisten: „Kriegsdienstverweigerung ist die dem Staat gegenüber offen ausgesprochene oder auf andere Weise offen zum Ausdruck gebrachte Verweigerung aller militärischen Handlungen oder der Ausbildung zu diesen Handlungen." (Hartmann, Kriegsdienstverweigerung [1986], S. 4; vgl. auch Bredemeier, Kriegsdienstverweigerung, S. 79) In diesem eingeschränkten Sinne kann zum einen eine „Kriegsdienstverweigerung“ nur von jenen praktiziert werden, von denen realiter ein „Kriegsdienst“ verlangt wird, in der Regel also von den „Dienstpflichtigen“, und zum anderen fallen andere Verweigerungshandlungen nicht unter diese Definition. Wenngleich 
verweigerung“. Ein Erlaß des Reichskriegsministers vom 14. Oktober 1936 bestimmte aber, daß die Verweigerung des Fahneneides gesetzlich unzulässig und als „militärischer Ungehorsam“ ( $92 \mathrm{MStGB}$ ) disziplinarisch und strafrechtlich zu verfolgen sei, denn jeder, der die Eidesleistung in dem ,vorgeschriebenen Wortlaut" verweigere, lehne sich gegen den „Führer" auf ${ }^{139}$. Die Ablehnung der Wehrdienstleistung wurde nach den Strafbestimmungen für „Fahnenflucht“ ( $\$ \$ 69,70$ MStGB) abgeurteilt, da in der Verweigerung die Absicht zu erkennen sei, ,sich der Verpflichtung zum Dienst in der Wehrmacht dauernd zu entziehen"140. In den Jahren vor Beginn des Zweiten Weltkrieges erfolgte bei wehrdienstverweigernden Zeugen Jehovas in den meisten Fällen eine kriegsgerichtliche Bestrafung wegen beider Delikte - Gehorsamsverweigerung und Fahnenflucht -, wobei sich die Strafen zumeist zwischen ein und zwei Jahren Gefängnis bewegten.

Gegen Personen, die nicht oder noch nicht der Militärgerichtsbarkeit unterlagen, fanden bei „Wehrflucht" die Bestimmungen des (allgemeinen) Strafgesetzbuches Anwendung ( $\S 140-143$ StGB). Nach Einführung der allgemeinen Wehrpflicht wurden mit „Gesetz zur Änderung des Strafgesetzbuches“141 vom 28. Juni 1935 diese Paragraphen im Blick auf die nun in Betracht zu ziehenden Fälle von Dienstpflichtentziehung neu gefaßt und - so meldete es Oberlandesgerichtsrat Dr. Karl Schäfer dem juristischen Fachpublikum - „durchweg mit schwereren Strafandrohungen ausgestattet"142. Danach konnten Wehrpflichtige, die vor Erhalt des Gestellungsbefehles 143 in der Absicht handelten, sich der Verpflichtung zum Dienst zum Beispiel durch Verlassen des Reichsgebietes - dauernd zu entziehen, aufgrund des $\S 140 \mathrm{StGB}$ wegen Wehrpflichtentziehung mit mehrjährigen Gefängnisstrafen belegt werden ${ }^{144}$. Wer Soldaten zur „Fahnenflucht" verleitete oder diese dabei unterstützte, konnte nach $\S 141$ StGB in ,besonders schweren Fällen“ zu Zuchthaus bis zu zehn Jahren verurteilt werden ${ }^{145}$.

um der definitorischen Klarheit willen bzw. aus Gründen der Subsumtion dieses eingrenzende Verständnis von „Kriegsdienstverweigerung“ in den folgenden Ausführungen zugrunde gelegt wird, so soll zumindest darauf hingewiesen werden, daß unter diesem Begriff in einem weiteren Sinne sämtliche Handlungen zu fassen sind, die eine Verweigerung von Leistungen darstellten, die der Kriegsführung dienten. Von diesem weiter gefaßten Verständnis ausgehend, wäre zum Beispiel die von Bibelforschern wie Bibelforscherinnen praktizierte Ablehnung von Rüstungsarbeiten (siehe S. 429ff.) ebenfalls als „Kriegsdienstverweigerung“ zu bezeichnen.

139 BA-MA, RW 15/76, Der Reichskriegsminister, RdS vom 14.10.1936.

$140 \S 69$ MStGB. Der Strafrahmen für Fahnenflucht sah in Friedenszeiten eine Gefängnishaft von 6 Monaten bis zu 2 Jahren, bei erneuter Fahnenflucht von 1 bis zu 5 Jahren und im Wiederholungsfalle (,wiederholter Rückfall") eine Zuchthausstrafe von 5 bis zu 10 Jahren vor.

141 Gesetz zur Änderung des Strafgesetzbuches vom 28.6.1935, RGB1. 1935 I, S. 839. Die in der Strafandrohung deutlich verschärften Bestimmungen galten der Ahndung folgender Delikte: Wehrdienstentziehung durch Verlassen des Reichsgebietes $(\S 140)$, Verleitung oder Beihilfe zur Fahnenflucht (§141), Selbstverstümmelung (§142), Wehrdienstentziehung durch Täuschung (\$143).

142 Schäfer, Änderung des Strafgesetzbuchs, S. 2478f.

143 Vom Gestellungstag 0.00 Uhr an waren die Einberufenen Soldaten ( $\$ 21 \mathrm{WG)}$. Damit unterlagen sie den für die Angehörigen der Wehrmacht gültigen Gesetzen und der Zuständigkeit der Militärjustiz.

144 Zuvor betrug die Strafandrohung Geldstrafe oder Gefängnis bis zu einem Jahr.

145 Friedrich Zipfel hat die Vermutung geäußert, daß der nationalsozialistische Staat mit der Verschärfung dieser strafrechtlichen Bestimmungen der „ernsten Gefahr“ zu begegnen suchte, die er bei den Bibelforschern meinte annehmen zu müssen (vgl. Zipfel, Kirchenkampf, S. 198). 


\section{Nischen beseitigt, Auswege verbaut}

Schon wenige Wochen nach der Einführung der allgemeinen Wehrpflicht wurden die Polizeibehörden um Berichterstattung ersucht, „ob Fälle bekannt geworden sind, daß Anhänger der ,Internationalen Bibelforscher-Vereinigung ' ihre Teilnahme am Heeresdienst [...] verweigert haben"146. Der von den Zeugen Jehovas bekundeten Ablehnung des Waffendienstes galt fortan das besondere Interesse der Gestapo. Die Bayerische Politische Polizei teilte Anfang 1936 den ihr unterstellten Dienststellen mit, „daß abgesehen von der Propaganda gegen den Militär- und Kriegsdienst, sogar versucht worden“ sei, „,bei Militärpersonen für die Ideen der Ernsten Bibelforscher zu werben“. Dies zeige, ,um welche gefährlichen Elemente es sich bei den Ernsten Bibelforschern handelt"147.

Die Wehrmachtführung warnte ebenfalls vor der Werbetätigkeit der Zeugen Jehovas und forderte die militärischen Dienststellen zu gesteigerter Wachsamkeit auf. Diesem Zweck diente auch ein Rundschreiben des Reichskriegsministers vom 18. Januar 1937, das zur Verwendung im Abwehrunterricht, ,einige Fälle kommunistischer Zersetzungsversuche als besonders lehrreiche Beispiele" aufführte, die „zum Gegenstand der Belehrung für Offiziere und Unteroffiziere und in geeigneter Form auch für Mannschaften zu machen " waren ${ }^{148}$. Einer der sieben Fälle, anhand derer ,richtiges Verhalten gegenüber Zersetzungsversuchen durch Personen außerhalb der Wehrmacht" aufgezeigt werden sollte, beschäftigte sich mit den Aktivitäten der IBV: „Dem Schützen T. wurde am 2.1.36 auf der Straße eine Zersetzungsschrift der Internationalen Bibelforscher-Vereinigung zugesteckt. Auf die sofortige Meldung und nähere Bezeichnung der Persönlichkeit des Unbekannten hin konnte durch die Polizei als Täter der Ausgeher Otto M. in München ermittelt werden. M. wurde zu 1 Jahr 9 Monaten Gefängnis verurteilt.“

In der Gestapa-Denkschrift des Jahres 1936 wurde sogar davon berichtet, daß die Bibelforschervereinigung den Versuch unternehme, ,alle Wehrpflichtigen zur Verweigerung des Wehrdienstes zu verleiten"149. Zu diesem Zweck würden Formulare verteilt, deren erste Worte lauteten: „Ich sehe mich leider genötigt, Ihnen mitzuteilen, daß ich der Aufforderung, mich an militärischen Übungen zu beteiligen, als Zeuge Jehovas aus Glaubens- und Gewissensgründen nicht Folge leisten

Die $\$ \S 140-143$ StGB zielten jedoch nicht auf die von den meisten Zeugen Jehovas vollzogene offene Form der Kriegsdienstverweigerung, sondern auf andere Formen der Dienstpflichtentziehung. Gegen Gestellungspflichtige, die mit dem Tag der Einberufung der Militärgerichtsbarkeit unterlagen, kamen diese Strafvorschriften nicht zur Anwendung. Ein direkter Zusammenhang zwischen der Strafverschärfung der $\S \S 140-143$ StGB und dem Vorgehen gegen die Zeugen Jehovas liegt nicht vor; bei den Beratungen hat die Wehrdienstverweigerung durch Zeugen Jehovas nach Aktenlage keine Rolle gespielt (vgl. BA, R 22/962; sowie die von Franz Gürtner 1935/36 herausgegebenen Veröffentlichungen der Strafrechtskommission).

Der Politische Polizeikommandeur der Länder, Schreiben vom 13.5.1935 an die Gestapo Frankfurt, zit. nach Diamant, Frankfurt, S. 84; vgl. auch BHStA, Reichsstatthalter 638, BPP, RdErl. vom 24.5.1935. als Anlage zum RdS der Staatspolizeileitstelle München vom 24.12.1936. 
kann. Mein Leben ist dem großen ,Jehova Gott" geweiht."150 Wie schon der Text dieser Erklärung - die so oder in einem ähnlichen Wortlaut tatsächlich abgegeben wurden - vermuten läßt, beschränkte sich die von der Gestapo als allgemeine Gefahr dargestellte „Werbung für Kriegsdienstverweigerung“ jedoch im wesentlichen auf die Angehörigen der eigenen Glaubensgemeinschaft.

Ferner wußte die Gestapa-Denkschrift davon zu berichten, daß Bibelforscher in einigen Fällen absichtlich auf offener Straße verbotene Schriften in auffälliger Weise verteilten, um eine Festnahme und eine anschließende gerichtliche Aburteilung zu provozieren: „Wenn sie dann mit Gefängnis bestraft wurden, so erklärten sie nach ihrer Entlassung, daß sie keinen Wehrdienst ausüben dürften, da sie wehrunwürdig im Sinne des Gesetzes seien, weil sie wegen staatsfeindlicher Betätigung mit Gefängnis bestraft seien.“151

Zeugen Jehovas, die so argumentierten ${ }^{152}$, versuchten eine Bestimmung des Wehrgesetzes sich zunutze zu machen, nach der als „Wehrunwürdiger" von der Erfüllung der Wehrpflicht auch derjenige ausgeschlossen wurde, der ,wegen staatsfeindlicher Betätigung gerichtlich bestraft" 153 worden war. Als die NS- und Wehrmachtführung auf den ,Zweischneidigen Charakter“ des aus ideologischen wie aus pragmatischen Gründen angeordneten ,unehrenhaften" Ausschlusses der Regimegegner von der Erfüllung der Wehrpflicht aufmerksam wurde, schränkte sie die Möglichkeit, sich auf dem Wege einer politischen Vorstrafe der Wehrdienstleistung entziehen zu können, stark ein ${ }^{154}$. Nachdem bereits die „Richtlinien des Reichskriegsministeriums zur Frage der Wehrunwürdigkeit bei gerichtlicher Bestrafung wegen staatsfeindlicher Betätigung“155 vom 6. Mai 1936 festgelegt hatten, daß eine

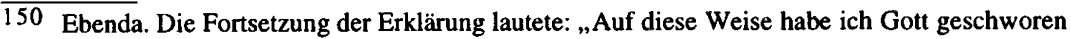
unter allen Umständen und in jeden Prüfungen ihm Treue und Gehorsam nach seinen Worten zu erweisen. Ungehorsam wäre für mich Eidbruch und würde den Tod und zwar die ewige Vernichtung zur Folge haben." (BA, R 58/779, Bl. 145)

151 IfZ, MA 554, 936280. Zur absichtlichen Herbeiführung der „Wehrunwürdigkeit“ vgl. Klausch, Bewährungsbataillone, S. 23; Zipfel, Kirchenkampf, S. 197, Anm. 54.

152 Vgl. Heuzeroth/Wille, Lila Winkel, S. 203 (Bericht über J. Harms). Nicht nur gerichtlich Bestrafte, sondern auch entlassene KZ-Häftlinge versuchten, auf diese Weise der Rekrutierung zu entgehen. So schickte ein Zeuge Jehovas, der Mitte der dreißiger Jahre in Esterwegen inhaftiert war, seinen bei Kriegsbeginn erhaltenen Gestellungsbefehl mit dem Vermerk zurück, er denke, ehemalige KZ-Insassen seien „wehrunwürdig“. Vgl. Fahle, Verweigern, S. 157.

$153 \S 13$ Abs. le WG. Als „wehrunwürdig“ und damit ausgeschlossen von der Erfüllung der Wehrpflicht galt ferner, wer entweder mit Zuchthaus bestraft oder durch militärgerichtliches Urteil die Wehrwürdigkeit verloren hatte. Gleiches galt für Personen, die nicht im Besitze der bürgerlichen Ehrenrechte oder den Maßregeln der Sicherung und Besserung nach § 42a StGB unterworfen waren.

154 Den Wehrmachtjuristen war die Bestimmung im § 13 WG, wonach „Wehrunwürdigkeit“ zum Ausschluß von der „Erfüllung der Wehrpflicht" führe, von Anfang an ein Ärgernis. Der Nestor der deutschen Militärjustiz, Heinrich Dietz, erklärte 1936, daß den „Wehrunwürdigen“ zwar ein „Recht“ versagt, aber nicht eine Pflicht genommen werde: „Die Wehrpflicht bleibt, wenn auch ihre Ausflüsse ruhen, dauernd lebendig und kann - im Kriege und bei Notständen des Staates, also auch im Frieden - dazu führen, daß Wehrunwürdige zum Dienst in der Wehrmacht herangezogen werden, ohne von der Wehrunwürdigkeit befreit zu sein." (Dietz, Wehrunwürdigkeit, S. 174) Damit war bereits der Grundstein für die ab 1942 erfolgende Rekrutierung von „Wehrunwürdigen“" in die „Bewährungseinheiten“ gelegt.

155 Zit. nach Entscheidungen des Reichskriegsgerichts, Band II, 1. Heft, S. 33. Durch AV des RJM vom 21.7.1936 (DJ 98 [1936], S. 1168) wurden diese Richtlinien auch für die Justizbehörden für verbindlich erklärt. 
„Wehrunwürdigkeit“ nur bei Freiheitsstrafen von mindestens neun Monaten bejaht werden könne, grenzte die im April 1937 erlassene amtliche „Erläuterung“ dann den Begriff der ,staatsfeindlichen Betätigung“ ein. Nach dieser Präzisierung hatte als solche nur die Tat zu gelten, ,die geeignet und nach dem Willen des Täters dazu bestimmt war, den Bestand und die Sicherheit des nationalsozialistischen Staates zu untergraben oder zu gefährden“156. Verurteilte nach $\$ 4$ der „Reichspräsidentenverordnung zum Schutze von Volk und Staat" vom 28. Februar 1933 - also der Strafvorschrift, nach der die Zeugen Jehovas in den Vorkriegsjahren in aller Regel abgeurteilt worden waren - fielen selbst bei einer Strafe von über neun Monaten Gefängnis nicht mehr grundsätzlich unter die „Wehrunwürdigkeit“157. Die Möglichkeit, auf ,gesetzlicher Grundlage“ der Einberufung zum Waffendienst entgehen zu können, war damit für die IBV-Angehörigen faktisch beseitigt; nur sehr wenige von ihnen erhielten einen Ausschließungsschein 158 .

Außer der jeweils kleinen Zahl von Zeugen Jehovas, die den Jahrgängen angehörten, die gerade einberufen wurden - im Herbst 1935 zog man als erste Dienstpflichtige die des Jahrgangs 1914 zum Wehrdienst heran -, waren in einem ständig steigenden $\mathrm{Maß}$ durch die Einberufung von älteren Jahrgängen zu Wehrübungen und kurzfristigen militärischen Ausbildungsgängen weitere Zeugen Jehovas betroffen ${ }^{159}$. Die Mehrzahl von ihnen wartete zunächst den Gestellungsbefehl $a b$, teilte dann beispielsweise dem betreffenden Wehrbezirkskommando schriftlich ihre Verweigerungsabsicht mit oder fuhr am Einberufungstag - wie angeordnet - zu dem genannten Truppenteil respektive zu den Sammelstellen und gab dort die Verweigerungsabsicht den diensthabenden Offizieren bekannt. Einige IBV-Angehörige verweigerten auch bereits bei Zustellung des Fragebogens über Erfassung zum Wehrdienst dessen Ausfüllung oder gaben im Vorwege - zum Beispiel bei der Musterung - den Wehrmeldebehörden gegenüber eine Erklärung $a b$, daß sie einer Einberufung zum Militärdienst aus Glaubensgründen keine Folge leisten würden. Gegen diese Wehrdienstverweigerer, die noch nicht der Militärgerichtsbarkeit unterstanden und auch keine „Wehrflucht“ im Sinne der §§ 140-143 StGB begangen hatten, schritt die Gestapo, sofern sie von den Vorgängen Kenntnis erhielt, direkt über die Musterung und Aushebung vom 17.4.1937), RGBI. 1937 I, S. 469; vgl. auch Otto/ Güldenpfennig, Ersatzwesen, S. 131. Zur Zweckbestimmung war in der „Erläuterung“ ausgeführt, mit der Präzisierung solle ,den Bestrebungen solcher Personen begegnet werden, die sich durch leichtere politische Delikte der Wehrpflicht zu entziehen suchen".

157 Bei der Aufzählung der Straftaten, die zur „Wehrunwürdigkeit“ führten bzw. führen konnten, waren Vergehen gegen die VOSchVuS nicht genannt. Hingegen wurden beispielsweise Zeugen Jehovas, die wegen Vergehens gegen das „Heimtückegesetz“ zu einer Gefängnisstrafe von mehr als neun Monaten verurteilt worden waren, im Regelfall als „wehrunwürdig“ eingestuft. Nach Inkrafttreten der „Wehrkraftschutzverordnung“ vom 25.11.1939 hatten ferner jene Zeugen Jehovas als ,wehrunwürdig“ zu gelten, die wegen „Teilnahme an einer wehrfeindlichen Verbindung " $z u$ einer Zuchthausstrafe verurteilt worden waren.

Vgl. beispielsweise Hetkamp, Du sollst nicht töten, S. 188; VVN HH, Komiteeakten Z 4.

159 Nach der Verordnung über die Einberufung zu Übungen der Wehrmacht vom 25.11.1935 (RGBI. 1935 I, S. 1358, neue Fassung vom 28.3.1936, RGB1. 1936 I, S. 326) konnten Wehrpflichtige des Beurlaubtenstandes (also auch jene der Geburtsjahrgänge 1913 und älter) zu militärischen Übungen beordert werden. Aus diesem Grund war auch die Zahl der in den Vorkriegsjahren gegen wehrdienstverweigernde Zeugen Jehovas geführten Verfahren größer, als bisher in der Literatur (vgl. Zipfel, Kirchenkampf, S. 198) angenommen wurde. 
ein. So wurden beispielsweise im März 1937 in Bad Kissingen zwei Bibelforscher in Schutzhaft genommen, weil sie sich geweigert hatten, den Fragebogen über die Erfassung zu unterschreiben ${ }^{160}$. In derartigen Fällen erfolgte eine Einlieferung in die Konzentrationslager, aus denen es für diese Gefangenen allenfalls dann noch eine Chance auf Entlassung gab, wenn sie sich vorbehaltlos zur Ableistung des Wehr- bzw. Kriegsdienstes bereit fanden.

Die Gestapo mußte andererseits respektieren, daß vom Einberufungstermin an die Strafverfolgung von Kriegsdienstverweigerern in die alleinige Zuständigkeit der Wehrmachtjustiz fiel. Dieser Kompetenzabgrenzung trug ein Erlaß des Politischen Polizeikommandeurs der Länder vom 14. November 1935 Rechnung:

„Nachdem die neue Militärstrafgerichtsordnung und die neue Disziplinarordnung für die Wehrmacht erlassen worden sind, ist es unzulässig, gegen Wehrpflichtige Schutzhaft zu verhängen, die sich weigern, dem an sie ergangenen Gestellungsbefehl Folge zu leisten. [...] Es ist nunmehr ausschließlich Sache der Militärbehörden, gegen derartige renitente Gestellungspflichtige im Wege des Disziplinarverfahrens oder militärischen Strafverfahrens vorzugehen. Hiervon unberührt bleiben naturgemäß die Fälle, in denen Gestellungspflichtige sich in staatsfeindlicher Weise vor ihrer Einberufung zur Wehrmacht betätigt haben. Insoweit ist es nach wie vor Aufgabe der Politischen Polizei, die ihr zur Bekämpfung von Staatsfeinden zur Verfügung stehenden Mittel, insbesondere also auch die Schutzhaft, anzuwenden." 161

Ein halbes Jahr später erließ Gestapo-Chef Heydrich dann Richtlinien, die den eigenen Anspruch beim Vorgehen gegen Wehr- und Dienstpflichtige erneut unterstrichen. Da diese erst mit dem Tage der Einberufung der Militärgerichtsbarkeit unterliegen würden, könnten sie, so ließ Heydrich die Staatspolizeistellen wissen, „allen etwa erforderlichen polizeilichen Maßnahmen unterworfen werden“162. Sofern ein Anlaß gegeben war, versuchten die Gestapodienststellen nach Möglichkeit bereits im Vorwege gegen potentielle Wehrdienstverweigerer einzuschreiten, offenbar in der Auffassung, daß die ,unbelehrbaren“ Zeugen Jehovas für die nach der Einberufung zu erwartende Verweigerung mit dem dann fälligen Strafmaß der Militärgerichte (wohlgemerkt in der Vorkriegszeit !) nicht hart genug bestraft würden.

Wie es denjenigen wehrpflichtigen Zeugen Jehovas erging, die nach der Einberufung die Ableistung des Militärdienstes verweigerten, soll an einigen Beispielen verdeutlich werden. Der 38jährige Johannes Rauthe aus Bad Warmbrunn (Schlesien) wurde im Frühjahr 1937 zu einer vierwöchigen Übung einberufen ${ }^{163}$. Nach-

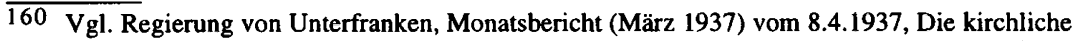
Lage in Bayern/Unterfranken, S. 110. Im Unterschied zu der Gestapo-Praxis sah § 8 Abs. 5 der VO über die Musterung und Aushebung vom 17.4.1937 (RGBl. 1937 I, S. 469) vor, daß in Fällen, in denen Dienstpflichtige , sich zur Erfassung, Musterung oder Aushebung schuldhaft nicht gestellt haben“, diese „nach ihrer Aufgreifung von der Polizeibehörde dem örtlich zuständigen Wehrbezirkskommando zuzuführen" seien. Diese Dienstpflichtigen sollten dann, ,,soweit sie ihrer Arbeitsdienstpflicht bereits genügt haben, sofort für eine Sonderabteilung der Wehrmacht" ausgehoben werden.

161 BA, R 58/264, Bl. 178, Der Politische Polizeikommandeur der Länder, RdErl. vom 14.11. 1935, zit. in: BPP, RdV vom 26.11.1935.

162 BA, R 58/267, B1. 43-50 (45), Preußische Geheime Staatspolizei, Richtlinien betr. „Polizeiliche Maßnahmen gegen Wehrmachtsangehörige und Wehrpflichtige" vom 28.5.1936.

163 EB Johannes Rauthe, Geschichtsbericht, S. 40-55. 
dem er dem Hauptmann der betreffenden Einheit mitgeteilt hatte, daß er aus Glaubensgründen an der Militärübung nicht teilnehmen könne, wurde er in Haft genommen. Ende April 1937 fand die Verhandlung vor dem Kriegsgericht der Division Nr. 18 in Liegnitz statt. Johannes Rauthe wurde zu sechs Monaten Gefängnis verurteilt. Nach einigen Wochen Haft in der Arrestzelle der Liegnitzer Funkerkaserne erfolgte im Juni 1937 die Überstellung ins Militärgefängnis Torgau, in dem damals eine kleinere Gruppe Zeugen Jehovas inhaftiert gehalten wurde. Nach Verbüßung seiner kriegsgerichtlich verhängten Strafe wurde er jedoch nicht nach Hause entlassen, sondern von der Gestapo in Schutzhaft genommen. Diese habe ihn mit dem Argument reklamiert, daß wegen der Kürze der Haft keine Änderung der Gesinnung eingetreten sein könne. Am 4. November 1937 wurde der Wehrdienstverweigerer ins $\mathrm{KZ}$ Buchenwald eingeliefert ${ }^{164}$.

Gegen den 32jährigen Ernst Wilhelm Zehender, der zusammen mit zwei Glaubensbrüdern aus seinem Heimatort Gemmrigheim (bei Heilbronn) das Einrücken zu einer Landwehrübung abgelehnt hatte, die sie gemeinsam vom 7. Februar bis zum 6. März 1938 bei einem Pionierbataillon in Rosenheim absolvieren sollten, griff die Wehrmachtjustiz zu härteren Strafen ${ }^{165}$. Zunächst verurteilte ihn am 29 . März 1938 das Gericht des V. Armeekorps in Stuttgart wegen „Fahnenflucht“ zu einer Gefängnisstrafe von einem Jahr. Da Zehender während des Strafvollzuges einem Befehl zur Teilnahme am Exerzierdienst nicht nachkam, wurde er ein Vierteljahr darauf, dieses Mal vom Kriegsgericht der Division Nr. 33 in Mannheim, wegen „Gehorsamsverweigerung vor versammelter Mannschaft“ (\$95 MStGB) zu zwei Jahren Gefängnis verurteilt ${ }^{166}$.

In der Strafhöhe unterschieden sich die Urteile gegen Wehrdienstverweigerer nicht von den Strafaussprüchen gegen diejenigen Zeugen Jehovas, die sich in den Vorkriegsjahren zwar zur Teilnahme am Militärdienst bereit erklärten, aber dann die Eidesleistung ablehnten. Zu dieser kleineren Zahl von IBV-Angehörigen gehörte ein 23jähriger kaufmännischer Angestellter, der am 1. September 1936 im Rahmen einer achtwöchigen Wehrmachtübung eine militärische Grundausbildung in Neustettin antreten mußte ${ }^{167}$. Obgleich der Hamburger Zeuge Jehovas sich der Waffen-

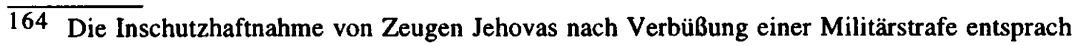
dem analogen Vorgehen der Gestapo bei Haftentlassung nach Strafen der allgemeinen Gerichtsbarkeit. Selbst nach Kriegsbeginn ging die Gestapo noch auf diese Weise gegen wehrpflichtige Zeugen Jehovas vor. So wurde ein Ludwigsburger IBV-Angehöriger im Frühjahr 1940 nach Verbüßung einer gegen ihn im Sommer des Vorjahres vom Luftwaffengericht in München verhängten neunmonatigen Gefängnisstrafe von der Gestapo in das KZ Sachsenhausen eingeliefert (EB Otto Wulle, 7.6.1984). Gewissermaßen bedeutete die KZ-Einweisung für diesen Mann die „Lebensrettung“, denn sie bewahrte ihn vor einer erneuten Einberufung und damit vor dem bei fortgesetzter Kriegsdienstverweigerung nahezu unausweichlichen Todesurteil.

165 Die Darstellung beruht auf Unterlagen der betreffenden Kriegsgerichtsverfahren, die sich im Besitz des Sohnes befinden (UaP Rolf Zehender).

166 Drei Monate nach seiner am 15.3.1941 erfolgten Haftentlassung wurde Zehender erneut einberufen. Da er dem Gestellungsbefehl keine Folge leistete, wurde er vom RKG am 10.12. 1941 wegen „Zersetzung der Wehrkraft“ zum Tode verurteilt. Im Alter von 36 Jahren wurde Zehender am 17.1.1942 im Zuchthaus Brandenburg-Görden guillotiniert. Das RKG-Urteil vom 10.12.1941 ist abgedruckt in: Hartmann, Kriegsdienstverweigerung (1986), S. 74-77.

167 Die Darstellung beruht auf: AfW HH, 130313; VVN HH, Komiteeakten K 1; SLG HH, HSG 11 Js. Sond. 1617d/34. Der 1935 wegen Zuwiderhandlung gegen das IBV-Verbot mit 
ausbildung bis zu ihrem Ende am 24. Oktober unterzogen hatte, verurteilte ihn das Gericht der 20. Division in Wandsbek zu sechs Monaten Gefängnis. Da auf Anraten des Anklägers Berufung eingelegt wurde, verhandelte am 4. Dezember 1936 das Oberkriegsgericht des X. Armeekorps erneut über den Fall. Dieses Mal folgte das Gericht dem Antrag des Anklagevertreters und verurteilte den 23jährigen Zeugen Jehovas wegen ,erschwerter Gehorsamsverweigerung mit nachteiligen Folgen“ ( $§ 92$ u. 95 MStGB) zu zwei Jahren Gefängnis, die der Mann in der Strafanstalt Wolfenbüttel und den emsländischen Strafgefangenenlagern Oberlangen und Neusustrum verbüßen mußte ${ }^{168}$.

Während die direkt zur Wehrmacht Einberufenen und damit in erster Linie die älteren, $\mathrm{zu}$ Wehrübungen eingezogenen Zeugen Jehovas mit den Kriegsgerichten konfrontiert waren, erging es den Angehörigen derjenigen Geburtsjahrgänge, die vor der Heranziehung zum regulären Wehrdienst noch der Arbeitsdienstpflicht Genüge tun mußten ${ }^{169}$, im Verweigerungsfalle anders. Zwar sahen nicht alle der in der Regel 18- bis 20jährigen Zeugen Jehovas, die zum Reichsarbeitsdienst (RAD) einberufen wurden, durch eine Eingliederung in dessen Reihen das ihnen auferlegte „Neutralitätsgebot“" verletzt und erklärten sich daher zur einer Teilnahme am ,reinen" Arbeitsdienst bereit ${ }^{170}$. Doch in der Frage des von ihnen auch beim RAD geforderten Eides ${ }^{171}$ verhielten sie sich genauso kompromißlos wie die „Totalverweigerer" unter den Zeugen Jehovas, die jede Form der Beteiligung an dem vormilitärischen RAD grundsätzlich ablehnten. Verweigerten nun die Zeugen Jehovas, nachdem sie zum Arbeitsdienst eingerückt waren, aus Glaubensgründen die ihnen nicht mögliche Eidesabgabe, wurden sie zunächst beim RAD in Zellenarrest genommen. Wenn ihre Haltung nicht gebrochen werden konnte, wurden sie im Anschluß an die Ausstoßung aus dem Arbeitsdienst der Gestapo übergeben, die sie in ein $\mathrm{KZ}$ überstellte.

Beispielsweise wurde gegen einen 1915 geborenen Zeugen Jehovas aus Leutenbach (Kreis Waiblingen), der im November 1937 beim Arbeitsdienst den Eid auf Hitler und das Anlegen der Uniform verweigerte, zunächst eine 21 tägige Arrest-

zwei Monaten Gefängnis vorbestrafte Mann gehörte dem Geburtsjahrgang 1913 an; er wurde als Wehrpflichtiger des Beurlaubtenstandes nicht mehr zum regulären Wehrdienst, sondern lediglich zu einer militärischen Kurzausbildung herangezogen.

168 In diesem Fall erfolgte nach der Haftentlassung keine Inschutzhaftnahme durch die Gestapo. Nach fünfjähriger „Freiheit“" wurde der Zeuge Jehovas am 28.7.1943 erneut zur Wehrmacht eingezogen. Unter dem Druck der Verhältnisse nahm er von seiner Verweigerungshaltung Abstand und leistete der Einberufung Folge.

169 Durch das Reichsarbeitsdienstgesetz vom 26.6.1935 (RGB1. 1935 I, S. 769) war die allgemeine Arbeitsdienstpflicht für Männer eingeführt worden. In der ersten Zeit nach Einführung der Wehrpflicht - innerhalb der für den Aufbau der Wehrmacht als Wehrpflichtarmee erforderlichen Übergangszeit - wurden jedoch Dienstpflichtige unter Befreiung von der Arbeitsdienstpflicht direkt zum Militärdienst eingezogen. Bei Kriegsbeginn wurde ähnlich verfahren. So wurden z. B. Angehörige des Geburtsjahrganges 1921 sogleich zur Wehrmacht einberufen, ohne zuvor zum Dienst im RAD herangezogen worden zu sein.

170 So erinnert sich ein damals 20jähriger Zeuge Jehovas, der 1935 zum RAD einberufen wurde, $\mathrm{da} \beta$ er den Dienst deshalb nicht verweigern wollte, weil er ihn als einen Dienst an der Gesellschaft empfand. Vgl. John, Wewelsburg (1996), S. 159.

171 Im Art. 13 Abs. 1 der Zweiten Verordnung zur Durchführung und Ergänzung des Reichsarbeitsdienstgesetzes vom 1.10.1935 (RGB1. 1935 I, S. 1215) war die Pflicht zur Ableistung eines Eides festgeschrieben. 
strafe ausgesprochen ${ }^{172}$. Nachdem er diese verbüßt hatte, wurde er - vermutlich auf Anordnung einer ärztlichen Untersuchungsstelle des Arbeitsdienstes - zur psychiatrischen Begutachtung in eine Klinik eingeliefert. Im Anschluß an die 14tägige Beobachtungszeit, in der der 22jährige ,als völlig ,normal “ befunden“ wurde, nahm die Gestapo ihn in Haft. Nachdem der Mann es abgelehnt hatte, seinem Glauben abzuschwören und die „Verpflichtungserklärung“ zu unterschreiben, wurde er Anfang 1938 in das KZ Dachau eingeliefert.

Ein anderer, ebenfalls 22jähriger Zeugen Jehovas, der 1936 bei seiner Einberufung zum RAD den Eid auf den „Führer“ verweigerte, allerdings - wie vermerkt wurde - ,den ihm aufgetragenen Arbeitsdienst [...] stets auf das Peinlichste“173 erfüllte, zeigte sich gleichwohl in der Eidesfrage unbeugsam. Die Gutachter der Psychiatrischen und Nervenklinik der Universität Breslau berichten davon, daß man ihn beim RAD ,mit Güte und Strenge“ behandelt habe, ,ohne etwas zu erreichen“. Seine „Gediegenheit" sei der Grund dafür gewesen, „daß man sich sehr um ihn bemüht" habe. Weiter heißt es in dem psychiatrischen Gutachten: „Arreststrafen haben ihn keineswegs irre gemacht."174

Dies war anders im Fall eines 21 jährigen Klempners aus Hamburg, der am 1. April 1936 zum Arbeitsdienst nach Elmshorn eingezogen wurde. Die Leitung der dortigen RAD-Abteilung 5/71 „General von Bonin“ versuchte, ihn durch ,alle erdenklichen Drillformen “ und mehrfachen Arrest von der Eides- und Grußverweigerung abzubringen ${ }^{175}$. Am 24. Dezember des Jahres wurde er zur Verbüßung von 150 Tagen Zellenarrest in das Gerichtsgefängnis Altona überstellt. Drei Wochen vor Haftende, am 4. Mai 1937, wurde „die Strafzeit unterbrochen“, weil der Zeuge Jehovas sich nach weiteren Drohungen jetzt zur Ablegung des Eides bereit erklärte. Die Gestapo griff nicht ein, da der junge Mann sowohl die Restzeit beim Arbeitsdienst als später auch den Wehrdienst absolvierte.

Auch während des Krieges ging die Gestapo mit dem Instrument der Schutzhaft gegen dienstpflichtige Zeugen Jehovas vor ${ }^{176}$. Wegen Eidesverweigerung beim Reichsarbeitsdienst wurden beispielsweise 1940 ein 19jähriger Zeuge Jehovas in das KZ Dachau177 und 1943 ein knapp 18jähriger in das KZ Schirmeck eingeliefert ${ }^{178}$. Ebenfalls aus dem gleichen Grunde kam 1943 der 17jährige Jonathan Stark aus Ulm in das KZ Sachsenhausen. Dort wurde er in die Strafkompanie ein-

172 Die Darstellung beruht auf: EB Erwin Rinker, Juni 1984; EB Erwin Knöller, 28.2.1985; UaP Norbert Weiss, Landesstelle für die Betreuung der Opfer des Nationalsozialismus, Bescheinigung vom 29.1.1949.

173 Sollmann/Wagner, Bibelforscher, S. 437.

174 Ebenda.

175 VVN HH, Komiteeakten K 12, Angabe im Lebenslauf vom 3.4.1946.

176 Unter Berufung auf den $\$ 3$ der Verordnung zum Schutze des Reichsarbeitsdienstes vom 12.3.1940 (RGB1. 1940 I, S. 485), der die Dienstpflichtentziehung vom RAD ahndete, wurden auch gerichtliche Strafen verhängt. Beispielsweise wurde der 20jährige Kurt Auschner wegen Arbeitsdienstverweigerung im Jahre 1940 zu 8 Monaten Gefängnis verurteilt. Kurze Zeit nach seiner Haftentlassung wurde er im Oktober 1941 zur Wehrmacht einberufen. Da er auch dort die Eidesleistung sowie die Kriegsdienstteilnahme verweigerte, wurde er vom RKG am 27.1.1942 zum Tode verurteilt und einen Monat später, am 28.2.1942, in BrandenburgGörden hingerichtet (VVN HH, Komiteeakten A 11, vgl. auch Jahrbuch 1989, S. 118).

177 Vgl. Knaut, Propheten, S. 134.

178 EB Egon Knöller, 30.4.1983. 
gewiesen und nach mehrfachen Einvernahmen durch die Lagerkommandantur, bei denen er auf seiner Verweigerungshaltung beharrte, im Lager erhängt ${ }^{179}$.

Mit Sanktionen hatten jedoch nicht nur Dienstpflichtige zu rechnen, die die von ihnen geforderte Eides- und Wehrdienstleistung verweigerten oder bereits im Vorwege den Entschluß zur Verweigerung von sich aus bekundet hatten. Seit 1935 wurden Zeugen Jehovas, die im wehrfähigen Alter waren, in Vernehmungen vor der Gestapo, aber auch in Einvernahmen durch den Haftrichter regelmäßig auf ihre Stellung zum Kriegsdienst hin befragt, und zwar zumeist auch ganz direkt danach, ob sie im Fall einer möglichen Einberufung dem Gestellungsbefehl Folge leisten würden oder nicht. Bekannten sie sich offen zur Kriegsdienstverweigerung, so konnte dies sowohl für die staatspolizeiliche Entscheidung über eine Inschutzhaftnahme den Ausschlag geben, als auch bei gerichtlicher Aburteilung straferschwerend in Anschlag gebracht werden.

Die präventive Bekämpfung der Kriegsdienstverweigerung wurde auch auf solche Zeugen Jehovas, die sich nicht mehr für die IBV betätigten, sowie auf die Söhne aus Bibelforscherfamilien ausgeweitet. Beispielsweise wurde der 1918 geborene Hans Joachim H. aus Kassel, nachdem seine Eltern 1936 wegen Zuwiderhandlung gegen das IBV-Verbot ins Gefängnis gekommen waren, öfters zur Gestapo vorgeladen. Dort wurde er geschlagen und zur Abgabe einer Bereitschaftserklärung für den Wehrdienst gezwungen: „Nachdem man mich gezwungen hatte, ein Schriftstück zu unterschreiben, zufolge dessen ich der Wehrpflicht genüge tun sollte, ließ man mich in Ruhe, und erst nach Ausbruch des Krieges trat die Gestapo wieder in Erscheinung, um mich zu warnen, damit ich ja dem Gestellungsbefehl Folge leisten würde." 180

\section{... mit dem Tode bestraft}

Mit Kriegsbeginn veränderte sich die Situation für die wehrdienstverweigernden Zeugen Jehovas entscheidend. Die am Mobilmachungstag in Kraft gesetzte „Kriegssonderstrafrechtsverordnung“ faßte unter dem neu eingeführten Straftatbestand der ,Wehrkraftzersetzung" auch die Kriegsdienstverweigerung ${ }^{181}$. 5 Abs. 1 Zif. 3 bestimmte, daß wegen „Zersetzung der Wehrkraft“ mit dem Tode

179 Vgl. Leber, Lebensbilder, S. 20; Jahrbuch 1974, S. 183. Gut dokumentiert ist der ähnlich gelagerte Fall des 17jährigen Walter Appel, der nach Einberufung zum RAD im Oktober 1944 von der SS in Königsberg „wegen Verweigerung des Arbeits- und Wehrdienstes“ hingerichtet wurde. Vgl. Garbe, Gott mehr gehorchen, S. 210; Imberger, Widerstand, S. 372f.; Jahrbuch 1974, S. 189f.; Philipsen, Für den Glauben in den Tod, S. 43; Verfolgung der Zeugen Jehovas in Kiel, S. 50.

180 Hans Joachim H., Lebenslauf vom 8.3.1948, abgedruckt in: Kammler, Kasseler Soldaten, S. 55f. H., der sich gegen seine innere Überzeugung zum Kriegsdienst hatte pressen lassen, nutzte im Sommer 1944 an der Ostfront eine Gelegenheit zur ,Fahnenflucht“. Er schlug sich bis in seine Heimatstadt Kassel durch. Dort wurde er von einer Heeresstreife ergriffen. Im Januar 1945 wurde H. kriegsgerichtlich zu vier Jahren und vier Monaten Zuchthaus verurteilt.

181 Siehe S. 344f. Da die KSSVO kein „Militärgesetz“, sondern ,allgemeines Strafrecht“" war, das ,für alle dem deutschen Strafrecht unterworfenen Personen, Militärpersonen wie Zivilisten" galt, war Kriegsdienstverweigerung nunmehr in jeder Hinsicht justitiabel. Der $\S 5$ Abs. 1 Zif. 3 ersetzte damit zugleich die auf bestimmte Fälle der Wehrdienstentziehung beschränkten Strafvorschriften der $\S \S 140-143$ StGB. Vgl. Heyne, KSSVO, S. 258-260. 
bestraft wird, „wer es unternimmt, sich oder einen anderen durch Selbstverstümmelung, durch ein auf Täuschung berechnetes Mittel oder auf andere Weise der Erfüllung des Wehrdienstes ganz, teilweise oder zeitweise zu entziehen“. Die amtlichen Erläuterungen zur „Kriegssonderstrafrechtsverordnung“ führten zu diesem Paragraphen unter anderem aus:

„Darüber hinaus erweitert er den Täterkreis, indem er auch den mit Strafe bedroht, der es unternimmt, sich , auf andere Weise' dem Wehrdienst zu entziehen: Es soll jede andere Art von Kriegsdienstverweigerung erfaßt werden $[\ldots] \S 5$ Abs. 1 Nr. 3 richtet sich mithin auch gegen Kriegsdienstverweigerer, die sich auf die in $\S 48 \mathrm{MStGB}$ angeführten Gründe berufen. " 182

Noch deutlicher wurde die Reichskriegsanwaltschaft in den Grundsätzen für die „Behandlung von Zersetzung der Wehrkraft“, die betonten, daß es für eine Anwendung dieser Strafvorschrift nicht von Belang sei, ob durch die einzelne Handlung auch tatsächlich eine Beeinträchtigung der Wehrkraft herbeigeführt oder angestrebt wurde, und daß es folglich für die Strafbarkeit auch unerheblich sei, ob überhaupt deren ,Zersetzung“ beabsichtigt wurde:

„Bei allen Verstößen gegen Abs. $1 \mathrm{Nr} .3$ ist nicht ein über die Tat selbst hinausgehender, auf Zersetzung der Wehrkraft gerichteter Vorsatz Voraussetzung. Die Vorstellung des Täters kann sich auf die Auswirkung der Straftat auf seine eigene Person beschränken; eine Auswirkung auf andere, insbesondere den Geist der Wehrmacht, wird hier nicht verlangt. [...] Unter Abs. 1 Nr. 3 fallen vor allem die Überzeugungstäter (Bibelforscher u. dgl.).“183

Die mit dem $\S 5$ Abs. 1 Zif. 3 KSSVO geschaffene Strafvorschrift bestimmte die Todesstrafe als Regelstrafe für Kriegsdienstverweigerung. Zwar ermöglichte der Absatz 2 die Annahme eines ,minder schweren Falles“ und damit die Zuerkennung einer Zuchthaus- oder Gefängnisstrafe, aber nach den „Grundsätzen“ der Reichskriegsanwaltschaft waren die Voraussetzungen für eine Absenkung des Strafmaßes in Kriegsdienstverweigerungsfällen regelmäßig nicht gegeben: „Gegen den hartnäckigen Überzeugungstäter (Bibelforscher) wird wegen der propagandistischen Wirkung seines Verhaltens im Normalfall nur die Todesstrafe angezeigt sein."184

Dieses Strafinstrument wurde von der Wehrmachtjustiz gegen Zeugen Jehovas und andere Kriegsdienstverweigerer rigoros angewandt. Wer nach dem 26. August 1939, dem Tag, an dem die „Kriegssonderstrafrechtsverordnung“ Gesetzeskraft erlangte, der Einberufung zur Wehrmacht keine Folge leistete, hatte - sofern diese Gewissensentscheidung nicht doch noch zurückgenommen wurde - mit dem Todesurteil und der Vollstreckung zu rechnen. Das Datum des Gestellungsbefehles markierte die eingetretene Veränderung: Wer die Aufforderung zum Militärdienst vor dem 26. August erhalten hatte, beging seine Tat nach den wehrrechtlichen Bestimmungen noch nicht ,im Felde“ und unterlag somit nicht den im Mobilmachungs- bzw. Kriegszustand geltenden erhöhten Strafandrohungen. So wurde ein

182 OKW (Wehrmachtrechtsabteilung), Erläuterungen zur Verordnung über das Sonderstrafrecht im Kriege und bei besonderem Einsatz vom 17.8.1938, abgedruckt in: Absolon, Wehrmachtstrafrecht, S. 51-56 (54). Zum § 48 MStGB siehe S. 354f.

183 Rechtsgrundsätze des Reichskriegsgerichts, S. 4.

184 Ebenda, S. 5. 
Kriegsdienstverweigerer, der zum 22. August zur Marine einberufen worden war, von dem Gericht des 2. Admirals der Ostseestation in einem Urteil vom 1. November 1939 unter Zugrundelegung der „friedensrechtlichen“ Bestimmungen des Militärstrafgesetzbuches zunächst noch wegen „Fahnenflucht“ mit einem Jahr Gefängnis bestraft ${ }^{185}$. Paul Frick, ein 40 jähriger Zeuge Jehovas, der vier Tage später den Gestellungsbefehl ausgehändigt bekommen und gleich beim Empfang die Verweigerung erklärt hatte, wurde hingegen bereits nach $\S 5$ KSSVO durch Urteil des Reichskriegsgerichtes vom 23. Oktober 1939 zum Tode verurteilt. Zwei Wochen darauf wurde der Vater von vier Kindern in Berlin-Plötzensee enthauptet ${ }^{186}$.

Die Prozesse gegen Zeugen Jehovas, die den Kriegsdienst verweigerten, wurden seit Kriegsbeginn ${ }^{187}$ zentral vor dem obersten Wehrmachtsgericht, dem in Berlin-Charlottenburg amtierenden Reichskriegsgericht, geführt. Gemäß der gleichzeitig mit der „Kriegssonderstrafrechtsverordnung“ in Kraft getretenen „Kriegsstrafverfahrensordnung "188 fielen zunächst sämtliche Verfahren wegen ,Zersetzung der Wehrkraft", unabhängig davon, ob es sich bei dem Beschuldigten um einen Wehrmachtsangehörigen oder um eine Zivilperson handelte, in die Zuständigkeit dieses Gerichtes, dem seit dem 12. September 1939 als Präsident und Gerichtsherr ${ }^{189}$ der Admiral Max Bastian vorstand.

Eine Neuregelung erfolgte durch die „siebente Durchführungsverordnung“ vom 18. Mai 1940, die einerseits die ausschließliche Zuständigkeit der Kriegsgerichtsbarkeit für Verfahren nach $\S 5$ KSSVO aufhob - womit diese berüchtigte Strafnorm nun auch von den Gerichten der allgemeinen Justiz angewendet werden konnte und andererseits die Zuständigkeiten für die Aburteilung von ,Wehrkraftzerset-

$\overline{185}$ Das Urteil wurde gegen den ehemaligen Sekretär des Internationalen Versöhnungsbundes Dr. Hermann Stöhr verhängt. Da er anschließend die von ihm noch während seiner Haftzeit geforderte Eidesleistung verweigerte, wurde gegen ihn ein erneutes kriegsgerichtliches Verfahren, dieses Mal wegen „Verbrechens nach § 5 Abs. 1 Zif. 3 KSSVO“, angestrengt. Das RKG verurteilte ihn am 16.3.1940 zum Tode; das Urteil wurde am 21.6.1940 vollstreckt. Stöhr ist der einzige Christ aus der evangelischen Kirche, von dem bekannt ist, daß er wegen glaubensbedingter Kriegsdienstverweigerung zum Tode verurteilt wurde. Vgl. Röhm, Sterben für den Frieden; zu den Kriegsgerichtsverfahren ebenda, S. $186 \mathrm{ff}$.

186 BA, R 60 II/131, „Totenregister“ des Generalstaatsanwaltes beim Kammergericht; vgl. ferner Hartmann, Kriegsdienstverweigerung (1982), S. 87-89.

187 In der ersten Zeit nach Inkrafttreten der kriegsrechtlichen Bestimmungen kamen noch einige Verfahren vor anderen Kriegsgerichten zur Verhandlung, da anscheinend noch Unklarheit über die „Rechtslage“ bei der Strafverfolgung von Kriegsdienstverweigerern herrschte. Vgl. Jahrbuch 1989, S. 119; Poliakov/Wulf, Das Dritte Reich, S. 195; RzW 15 (1964), S. 501-505.

188 Verordnung über das militärische Strafverfahren im Kriege und bei besonderem Einsatz (Kriegsstrafverfahrensordnung) vom 17.8.1938, RGBI. 1939 I, S. 1457. Nach den Bestimmungen der KStVO gab es nur noch eine kriegsgerichtliche Instanz; besonders schwerwiegende Fälle waren dem Reichskriegsgericht vorbehalten, in dessen Zuständigkeit auch alle Fälle der „Wehrkraftzersetzung“ nach § 5 KSSVO fielen ( $\$ 14$ Abs. 1 Zif. 9 KStVO).

189 Mit der KStVO wurde die beinahe unbegrenzte Autorität des militärischen Gerichtsherrn festgeschrieben; die mit den Aufgaben des Gerichtsherrn vom jeweiligen Oberkommando betrauten Befehlshaber waren für die Anordnung des Ermittlungsverfahrens, die Anklageverfügung und die Urteilsbestätigung zuständig. Beim Reichskriegsgericht nahm dessen Präsident neben der allgemeinen Geschäftsleitung auch die Aufgaben des militärischen Gerichtsherrn wahr. Damit übte er - außer bei Todesurteilen gegen Offiziere, bei denen Hitler selbst als „oberster Gerichtsherr" fungierte - das Recht zur Bestätigung oder Aufhebung von Urteilen aus ( $\$ 80 \mathrm{KStVO}$ ). Die Vorsitzenden der einzelnen Senate des RKG waren dagegen Juristen. 
zungsfällen“ im Bereich der Wehrmachtjustiz neu regelte ${ }^{190}$. Danach verblieben beim Reichskriegsgericht die Fälle „öffentlicher Zersetzung des Wehrwillens“ ( 5 Nr. 1), während die Deliktgruppen „Untergraben der Mannszucht“ ( 5 Nr. 2) und die „Wehrdienstentziehung“ ( $\$ 5$ Nr. 3) den (unteren) Kriegsgerichten zur Aburteilung zugewiesen wurden. Abweichend von dieser allgemeinen Regelung der ,siebenten Durchführungsverordnung" blieben die Verfahren gegen Zeugen Jehovas und andere Kriegsdienstverweigerer jedoch grundsätzlich in der Zuständigkeit des obersten Wehrmachtgerichtes. Zu diesem Zweck ordnete das Oberkommando der Wehrmacht durch Erlaß vom gleichen Tage an, daß die Gerichtsherrn Strafverfahren wegen Zersetzung der Wehrkraft nach $\S 5$ Abs. 1 Zif. 2 und 3 KSSVO dann an den Präsidenten des Reichskriegsgerichts zur Übernahme der Untersuchung und Aburteilung abzugeben haben, wenn „,der Täter nach seinem Gewissen oder den Vorschriften seiner Religion sein Verhalten für geboten erachtet hat (\$ $48 \mathrm{MStGB}$. Beispiele: Ernster Bibelforscher, Jünger Jehovas, Adventist usw.)“191.

Unter der Gesamtzahl der Fälle von „Wehrkraftzersetzung“, die in den ersten Kriegsmonaten vor dem Reichskriegsgericht zur Verhandlung kamen, nahmen die Verfahren gegen kriegsdienstverweigernde Zeugen Jehovas einen großen Anteil ein; mindestens jeder vierte Angeklagte gehörte zu den Bibelforschern ${ }^{192}$. Die Reichskriegsgerichtsräte sahen sich mit dem Auftreten von religiösen Dienstverweigerern einem „Phänomen“ gegenüber, daß sie aus ihrer bisherigen Spruchpraxis nicht kannten. Gegen diese glaubensfrommen Menschen schrieb die von den Wehrmachtjuristen wegen ihrer scharfen Strafsätze und wegen der weiten Fassung der Tatbestände seit langem als durchgreifendes Instrument einer „wirksamen Abschreckungsjustiz" herbeigewünschte ${ }^{193}$ Kriegssonderstrafrechtsverordnung im Regelfall das Todesurteil vor. Bereits in den ersten Kriegswochen fällten die Senate des Reichskriegsgerichtes etliche Entscheidungen, mit denen Zeugen Jehovas - wie die Urteilsformel stereotyp lautete - ,zum Tode, zum dauernden Verlust der bürgerlichen Ehrenrechte und zum Verlust der Wehrwürdigkeit" verurteilt wurden ${ }^{194}$. Im

190 Siebente VO zur Durchführung und Ergänzung der Verordnung über das militärische Strafverfahren im Kriege und bei besonderem Einsatz vom 18.5.1940, RGB1. 1940 I, S. 787; vgl. Hülle, Kriegsstrafverfahrensordnung, S. 153ff.; siehe auch S. 344, Anm. 95.

191 BA, R 22/2296, Bl. 442, OKW, ErlaB vom 18.5.1940. Die Bezeichnung „Jünger Jehovas“ findet sich in mehreren OKW-Erlassen der ersten Kriegsjahre. Eine Glaubensgemeinschaft dieses Namens gab es nicht. Entweder waren damit die von der IBV abgespaltenen „Engel Jehovas“ (Menschenfreundliche Versammlung) gemeint oder es lag eine aufgrund des mangelnden sektenkundlichen Sachverstandes der Wehrmachtrechtsabteilung erfolgte Verwechselung mit dem Namen „Zeugen Jehovas“ vor.

192 Die Kriegs-Kriminalstatistik für die Wehrmacht weist für die ersten vier Kriegsmonate (26.8.-31.12.1939) 159 wegen „Zersetzung der Wehrkraft“ (bezogen auf alle Deliktgruppen des § 5 KSSVO) geführte Verfahren aus, von denen 40 mit einem Todesurteil endeten (vgl. BA-MA, RW 6/v.129 D). Mindestens 39 der Todesurteile (und damit nahezu jedes) wurden gegen Zeugen Jehovas gefällt. Siehe auch S. 373, Anm. 216.

193 Vgl. Garbe, Einzelfall, S. 47ff.; Messerschmidt/Wüllner, Wehrmachtjustiz, S. 26ff., 133ff.; siehe auch S. 345.

194 Die über die Verurteilung zum Tode gemäß $\S 31$ und 32 MStGB hinausgehende Verurteilung zum „Verlust der bürgerlichen Ehrenrechte“ sollte die besondere „Unehrenhaftigkeit“ der begangenen Tat zum Ausdruck bringen. Mit der Aberkennung der „,bürgerlichen Ehrenrechte“ war nach § 13 Abs. 1 WG regelmäßig "die Straffolge der Wehrunwürdigkeit" verbunden. Dies bedeutete zugleich die Ausstoßung aus der Wehrmacht. Aus diesem Grunde wurde gegen die wegen Kriegsdienstverweigerung „zum Tode und zum Verlust der bürgerlichen Ehren- 
Anschluß an die Urteilsbestätigung durch den Gerichtsherrn des Reichskriegsgerichtes erfolgte - zumeist zwei bis vier Wochen nach dem Richterspruch - die Vollstreckung durch Enthauptung 195 in einer Richtstätte der Reichsjustizverwaltung (anfangs ausschließlich in der Strafanstalt Berlin-Plötzensee ${ }^{196}$ ). So wurde am 13. September 1939 der 37jährige Adolf Bultmeyer aus Rethorn (bei Delmenhorst) wegen Kriegsdienstverweigerung zum Tode verurteilt, am 13. Oktober wurde er in Plötzensee hingerichtet ${ }^{197}$. Mit ihm zusammen wurde am gleichen Tag ein 42 jähriger Zeuge Jehovas aus Boizenburg guillotiniert, der am 26. September durch das Reichskriegsgericht abgeurteilt worden war ${ }^{198}$.

Während ansonsten die Wehrmachtjustiz um der von ihr angestrebten $\mathrm{Ab}$ schreckungswirkung willen darauf bedacht war, daß die verhängten Urteile regelmäßig öffentlich bekanntgegeben wurden - um durch die ständige Propagierung und Allgegenwärtigkeit der Strafandrohung die Gefolgschaft aller zu erzwingen 199 -, kamen schon bald Bedenken auf, ob eine solche Vorgehensweise auch im Fall der Aburteilung von religiösen Dienstverweigerern angebracht und zweckmäßig sei. Der Präsident des Reichskriegsgerichtes verwies darauf, daß eine Urteilsveröffentlichung in diesen Fällen nur der ,feindlichen Propaganda“ nütze und darüber hinaus die Verweigerer ,in ihrem Fanatismus als Märtyrer"200 stärke. Einem Geheimerlaß des Oberkommandos des Heeres/Befehlshaber des Ersatzheeres vom 17. Oktober 1939 ist zu entnehmen, daß die oberste Wehrmachtführung derartige Bedenken teilte:

„Das Oberkommando der Wehrmacht nimmt zur Frage der Bekanntmachung von Todesurteilen gegen ,Ernste Bibelforscher', die den Fahneneid und jeglichen Kriegsdienst verweigert haben, im

rechte" Verurteilten nicht - wie in § $103 \mathrm{KStVO}$ vorgeschrieben - die Strafe durch ErschieBen (dem „Tod aus der Kameradenhand") vollstreckt, sondern durch die "unehrenvolle“ und "schändliche" Hinrichtungsart des Enthauptens (vgl. Schmidt, Straftat, S. 28).

195 Erinnerungsberichten zufolge sind gegen Zeugen Jehovas in Einzelfällen nach vorangegangenem Kriegsgerichtsurteil auch Erschießungen vorgenommen worden (vgl. Jahrbuch 1989, S. 121; Der Wachtturm, 1.9.1985, S. 14). In etwas größerer Zahl sind Zeugen Jehovas auf dem Truppenübungsplatz Heuberg (Angehörige der Bewährungsbataillone 999) sowie im Militärgefängnis Torgau von Exekutionskommandos hingerichtet worden. Vgl. Haase, Deserteure, S. 101; Klausch, Bewährungsbataillone, S. 234.

196 Im Jahre 1939 war nahezu jedes zweite Opfer von Plötzensee ein Zeuge Jehovas: Bei 94 registrierten Vollstreckungen (BA, R 22/1315, B1. 229) waren unter den 47 nach RKG-Urteil Hingerichteten mindestens 39 Zeugen Jehovas (siehe S. 367, Anm. 192). Insgesamt werden in Plötzensee ungefähr 100 vom RKG wegen Kriegsdienstverweigerung zum Tode verurteilte Zeugen Jehovas hingerichtet worden sein. Am 3.7.1940 ordnete das RJM an, daß zukünftig die vom RKG erlassenen Todesurteile in der neueingerichteten „,Richtstätte“ im Zuchthaus Brandenburg-Görden zu vollstrecken seien (BA, R 22/1315, Bl. 234). Die ersten nachweisbaren Hinrichtungen von Zeugen Jehovas in Brandenburg fanden im September 1940 statt. Die Gesamtzahl der dort hingerichteten Zeugen Jehovas ist von Walter Hammer auf 50 bis 60 geschätzt worden (Hammer, Brandenburg, S. 2; Weisenborn, Aufstand, S. 87); sie wird jedoch noch höher liegen. Nachdem das RKG im Herbst 1943 seinen Amtssitz von Berlin nach Torgau verlegt hatte, ließ es die Urteile fortan zumeist im näher gelegenen Halle vollstrecken. Wie viele Zeugen Jehovas dort 1944/45 enthauptet worden sind, ist unbekannt.

197 Vgl. Heuzeroth/Wille, Lila Winkel, S. 199ff.

198 BA, R 60 IV/131, „Totenregister“ des Generalstaatsanwaltes beim Kammergericht; DCB, Unterlagen Gefängnis Berlin-Plötzensee und Gesundheitsamt Charlottenburg.

199 Vgl. Garbe, Im Namen des Volkes, S. 104ff.

200 Max Bastian, Tätigkeitsbericht vom 30.5.1940, zit. nach Haase, Praxis des Reichskriegsgerichts, S. 391. 
Einvernehmen mit dem Generalstab des Heeres folgende Stellung ein: Nachrichten über Vollstreckungen derartiger Todesurteile sollen nicht plakatiert werden. Eine Mitteilung hierüber soll in den Zeitungen nicht erfolgen. Die Angehörigen der zum Tode Verurteilten können [!] von der Vollstreckung verständigt werden.“201

Als die Zahl der Bibelforscherverfahren in den folgenden Wochen weiter anstieg und in nur einem Monat, im November 1939, allein gegen Zeugen Jehovas wegen glaubensbedingter Kriegsdienstverweigerung etwa genauso viele Todesurteile gefällt wurden, wie sie das Reichskriegsgericht im gesamten Vorjahr in allen dort zur Verhandlung gekommenen Verfahren ausgesprochen hatte ${ }^{202}$, wuchs bei den Richtern ein gewisses Gefühl des Unbehagens. Nun sahen sich die Reichskriegsgerichtsräte, von denen nicht wenige einem eher konservativen Rechtstraditionen verhafteten Denken verpflichtet waren und daher oftmals von einer deutschnationalen Grundposition aus zu einem gewissen Grade in Distanz zur NS-Ideologie standen $^{203}$, mit den Konsequenzen ihrer eigenen „Rechtsanschauung“ konfrontiert.

$\mathrm{Zu}$ Vorkriegszeiten hatte das Reichskriegsgericht beispielsweise in einem Grundsatzurteil vom 20. Januar 1938 die Rechtsauffassung vertreten, daß bereits in der Verweigerung lediglich eines einzelnen eine Beeinträchtigung der Wehrkraft des gesamten Reiches zu erblicken sei: „Der ungestörte Ablauf einer Mobilmachung setzt voraus, daß jeder Wehrpflichtige widerspruchslos das tut, was ihm vorher befohlen worden ist. [...] Es bedeutet also eine Schädigung der Schlagfertigkeit der Truppe und der Sicherheit des Reiches, wenn auch nur ein einzelner Wehrpflichtiger seine Verpflichtung nicht erfüllt, damit bereits eine Gefahr für diese Schlagfertigkeit und Sicherheit, wenn nur die Möglichkeit besteht, daß ein Wehrpflichtiger sich seiner Pflicht entzieht." 204 Der absolute Vorrang der Interessen des Staates galt den Militärjuristen als oberstes Gebot, wobei die bedingungslose Ausrichtung an

201 BA-MA, RH 53-6/76, Bl. 139, OKH/BdE, Erlaß vom 17.10.1939.

202 Im Jahr 1938 sind vom RKG 15 Todesurteile (wegen Landesverrat u. a.) gefällt worden, von denen 12 vollstreckt wurden (vgl. BA-MA, RW 2/v. 258, Wehrstrafrechtsstatistik 1938; BA, R 22/1315, B1. 229). Nach einer unvollständigen Zusammenstellung des Verf., die Angaben zu 130 Zeugen Jehovas enthält, die während des Zweiten Weltkrieges wehrmachtgerichtlich abgeurteilt wurden, sind im November 1939 nachweisbar mindestens 13 Zeugen Jehovas durch das RKG zum Tode verurteilt worden (davon vollstreckt: 12); es kann mit ziemlicher Sicherheit davon ausgegangen werden, daß die tatsächliche Zahl der in jenem Monat gegen Zeugen Jehovas verhängten Todesurteile deutlich über den insgesamt 15 des Vorjahres liegt.

203 Vgl. Schorn, Richter, S. 170ff.; Schweling, Militärjustiz, S. 117ff., 212ff.; Schwinge, Wehrmachtgerichtsbarkeit, S. 57ff. Nach Schorn, Richter, S. 170, stellte die Wehrmachtjustiz insbesondere in den Jahren ihres Aufbaus (1934 bis 1938), geradezu ein Sammelbecken für Juristen“ dar, , die mit der Partei Schwierigkeiten hatten oder wegen ihrer Haltung befürchten mußten". Auch wenn der Arbeit Schorns und insbesondere den Werken der ehemaligen Wehrmachtjuristen Schweling und Schwinge wegen der offenkundig apologetischen Zielrichtung mit größter Skepsis zu begegnen ist, so ist weder in Abrede zu stellen, daß etliche Juristen, die zur NSDAP in einer gewissen Distanz standen, sich aus diesem Grund in den Mitte der dreißiger Jahre noch weitgehend parteifreien Raum der Wehrmacht begaben, noch daß diese dem „,neuen Rechtsdenken“ gegenüber mit Vorbehalten behaftet waren. In der kriegsgerichtlichen Spruchpraxis haben jene weltanschaulichen Unterschiede, von wenigen Ausnahmen abgesehen, allerdings keinen Niederschlag gefunden (vgl. auch Haase, Praxis des Reichskriegsgerichts, S. 411).

204 RKG, Rev. L. 158/37 I, Urteil vom 20.1.1938, Entscheidungen des Reichskriegsgerichts, Band I, S. 123-128 (127). Es handelte sich in diesem Fall nicht um ein Bibelforscherverfahren. 
den militärischen „Notwendigkeiten“ zur alles bestimmenden Leitlinie geworden war. Die Formel ,in Zeiten staatlicher und völkischer Not darf nicht die Rücksicht auf den einzelnen entscheiden, sondern muß das geschehen, was das Wohl der Gemeinschaft verlangt" ${ }^{\prime 205}$ war zum Credo der Wehrmachtjuristen geworden. Die von ihnen betriebene Beugung des Rechtes unter das militärische Zweckdenken ließ sie nach Erlaß der „Kriegssonderstrafrechtsverordnung“ und anderer NS-Kriegsgesetze zu den Exekutoren einer mörderischen Justiz werden ${ }^{206}$.

Obgleich die Tötung von Menschen, deren einziges „Verbrechen“ darin bestand, aus Glaubensgründen keinen Waffendienst leisten zu können, sich als Konsequenz der eigenen „Rechtsvorstellungen“ darstellte, erschreckten die Reichskriegsgerichtsräte vor dem Ergebnis ihres Tuns. Die Bibelforscherverfahren schufen für sie „ein Problem, an dem man einfach nicht so ohne weiteres vorübergehen kann"; der Präsident des Reichskriegsgerichtes, Admiral Max Bastian, bekundete später, daß die Todesurteile gegen Zeugen Jehovas seinem ,inneren Empfinden“ widersprochen hätten ${ }^{207}$. Bereits in den ersten Tagen nach Kriegsbeginn war man in dieser Frage beim „Führer" vorstellig geworden. Der Oberreichskriegsanwalt Dr. Walter Rehdans übermittelte am 11. September der verunsicherten Richterschaft die Entscheidung des Obersten Befehishabers. Rehdans berichtete, so die Aufzeichnungen Bastians, daß Hitler es abgelehnt habe, den Zeugen Jehovas eine "Sonderstellung“" einzuräumen. Er habe die Auffassung vertreten, daß „,die Sektierer [...] im Kriegsfalle, also in einer Notzeit des Vaterlandes, ihre persönliche Überzeugung einem höheren ethischen Zweck gegenüber zurückstellen" 208 müßten.

Wie einem Schreiben des Chefs des Oberkommandos der Wehrmacht, Generaloberst Wilhelm Keitel, zu entnehmen ist, fanden auch in den folgenden Wochen und Monaten noch weitere Vorsprachen beim „Führer“ in dieser Angelegenheit statt. Am 1. Dezember 1939 teilte Keitel unter dem Betreff „Behandlung der Bibelforscher" und unter dem Vermerk "Geheim" dem Chef der Heeresriustung und Befehlshaber des Ersatzheeres mit:

$\overline{205}$ Schwinge, Mannszucht, S. 54.

206 Vgl. Garbe, Im Namen des Volkes, S. 101ff.; Messerschmidt/Wüllner, Wehrmachtjustiz, S. 63ff,; Wüllner, NS-Militärjustiz, S. $192 \mathrm{ff}$.

207 BA-MA, N 192/1, Max Bastian, Lebenserinnerungen (1956), S. 55f. (Die Ausführungen in den Lebenserinnerungen zum „Problem" der Bibelforscherverfahren sind nur unwesentlich gekürzt abgedruckt im Anhang bei Schweling, Militärjustiz, S. 399-402.) Bastian konnte sich allerdings erst am 1.10.1944 - einen Monat vor seiner aus Altersgründen erfolgten Demission - dazu durchringen, an das OKW mit einem Vorschlag „betr. die Aussetzung des Vollzugs der Todesstrafe gegen sogenannte Bibelforscher" heranzutreten (vgl. Haase, Torgau und das Reichskriegsgericht, S. 55).

Auch von unverdächtiger Seite wird die durch die Bibelforscherverfahren hervorgerufene Verunsicherung der Richterschaft am RKG bezeugt. So berichtet der Gefängnispfarrer von Plötzensee und Widerständler Harald Poelchau, daß das Reichskriegsgericht „sich in den ersten Jahren des Krieges, 1939 bis 1940, nur schwer [habe] entschließen können, die Todesurteile an Bibelforschern vollstrecken zu lassen" (Poelchau, Die letzten Stunden, S. 34). Auch Kurt Scharf, wie Poelchau der Bekennenden Kirche zugehörig und in den sechziger Jahren Ratsvorsitzender der Evangelischen Kirche in Deutschland, berichtet davon, da $B$ die über Kriegsdienstverweigerer urteilenden Militärrichter „im allgemeinen menschlich empfindende, zum großen Teil sogar christlich geprägte Persönlichkeiten" gewesen seien (Gespräche mit Kurt Scharf, S. 24).

208 BA-MA, N 192/1, S. 56; vgl. auch Haase, Praxis des Reichskriegsgerichts, S. 392. 
„Das Reichskriegsgericht hat in größerer Anzahl sog. ernste Bibelforscher, die die Erfüllung des Wehrdienstes ablehnten, nach $\S 5 \mathrm{Nr} .3$ der Kriegssonderstrafrechtsverordnung zum Tode verurteilt. Die Urteile sind vollstreckt worden. Einige neue Urteile haben mir Veranlassung gegeben, das Problem der Behandlung der ernsten Bibelforscher dem Führer wiederum eingehend vorzutragen.

Der Führer hat entschieden:

Allein in Polen seien mehr als zehntausend anständige Soldaten gefallen, viele tausend Soldaten seien schwer verwundet worden. Wenn er von jedem deutschen Mann, der wehrfähig ist, dieses Opfer fordern müsse, sehe er sich nicht in der Lage, bei ernsthafter Wehrdienstverweigerung Gnade walten zu lassen. Dabei könne kein Unterschied danach gemacht werden, aus welchen Beweggründen der einzelne den Wehrdienst verweigere. Auch Umstände, die sonst strafmildernd in Betracht gezogen würden oder die bei einer Gnadenentscheidung eine Rolle spielten, könnten hier keine Berücksichtigung finden. Wenn also der Wille des Mannes, der den Wehrdienst verweigere, nicht gebrochen werden könne, müsse das Urteil vollstreckt werden.

Ich bitte, die Entscheidung des Führers den Gerichtsherrn und den Gerichten mitzuteilen. “209

Mit diesem „Führerwort" war die allgemeine Richtung für die „Handhabung“ der Verweigererfälle vorgegeben. Im Januar 1940 unterrichtete der Präsident des Reichskriegsgerichtes bei einer Besprechung seine Senatspräsidenten von der Auffassung der politischen und militärischen Führung zum Problem der „Ernsten Bibelforscher“. In den folgenden Jahren folgte das Reichskriegsgericht der ausgegebenen Grundlinie - wenn vielleicht auch bei einigen Richtern mit innerem Widerstreben - gewissenhaft, wobei es sich die tödliche „Logik“, daß den „unbeirrbaren“ Kriegsdienstverweigerer stets das Fallbeil treffen müsse, vermutlich nicht zuletzt deshalb zu eigen machte, weil diese sozusagen zur eigenen „Gewissensentlastung“ beitrug: Wenn trotz aller Einwirkungsversuche die Angeklagten nicht bereit waren, ihre Haltung aufzugeben, so trugen sie in den Augen ihrer Richter auch allein die Verantwortung für die auf sie dadurch zukommenden Folgen.

Während die Reichskriegsgerichtsräte unter Hinweis auf die „höheren Staatsnotwendigkeiten" und das ,geschriebene Recht“ die Zeugen Jehovas und andere Kriegsdienstverweigerer formal und ,leidenschaftslos" mit den Mitteln der Justiz in den Tod schickten, scheint die Meinung ihres ,obersten Gerichtsherrn“ zumindest in den späteren Jahren nicht allein davon bestimmt gewesen zu sein, daß angesichts des von allen Soldaten geforderten Kriegseinsatzes und der ihm eigenen Gefahren Verweigerer auf Schonung nicht hoffen dürften, sondern seine Sicht war anscheinend auch von ,leidenschaftlichem“ Haß getragen. Am 7. Juni 1942 soll Hitler bei einem seiner langatmigen Monologe, die er in der Wolfsschanze bei Tisch zu halten pflegte, auf die Bibelforscher zu sprechen gekommen sein, als er wieder einmal über die Verzagtheit und mangelnde Entschlußkraft der Justiz Klage führte. Landesverrat aus idealistischer Gesinnung gebe es nicht, mit diesem Argument habe er immer wieder die bei der Justiz bestehenden Widerstände gegen ein rücksichtsloses Vorgehen im Fall von Landesverrätern auszuräumen versucht. Wenn überhaupt ein landesverräterisches Delikt auf idealistische Beweggründe zurückgeführt werden könne, dann die sich auf den Glauben berufende Kriegsdienstverweigerung. Danach soll Hitler seine Ansprache wie folgt fortgesetzt haben: 
„Diesen Elementen, die aus religiöser Überzeugung nicht kämpfen wollten, müsse man aber entgegenhalten, daß sie offenbar aber essen wollten, was andere erkämpfen, daß das im Sinne einer höheren Gerechtigkeit aber nicht angehe und man sie deshalb verhungern lassen müsse. Wenn man davon Abstand genommen und sie, die sogenannten Bibelforscher, 130 an der Zahl, erschossen habe, so sei das seiner besonderen Milde zu verdanken. Übrigens hätten sich diese 130 Erschießungen wie ein die Atmosphäre reinigendes Gewitter ausgewirkt. Tausenden ähnlich Gesinnter sei bei der Nachricht von den Erschießungen der Mut vergangen, sich unter Hinweis auf irgendwelche Bibelstellen ebenfalls um den Kriegsdienst herumzudrücken zu suchen. Wer einen Krieg erfolgreich führen wolle und wer überhaupt ein Volk über schwere Zeiten hinwegbringen wolle, dürfe über eines keinen Zweifel aufkommen lassen: daß in diesen Zeiten jeder, der sich aktiv oder passiv aus der Volksgemeinschaft ausschließe, von der Volksgemeinschaft liquidiert werde." 210

Acht Wochen später, am 1. August 1942, kam der „Führer“ erneut auf das Thema Zeugen Jehovas zu sprechen. Nach den Aufzeichnungen von Heinrich Heim, dem Adjutanten des Reichsleiters Martin Bormann, erklärte Hitler, daß man die Bibelforscher ,ausrotten“ müsse. Dabei rekurrierte er wiederum auf sozialdarwinistische Vorstellungen: Wenn eine Gesellschaft vor derartigen ,asozialen Tendenzen" kapituliere, gebe sie sich selbst auf. Auch in der Tierwelt sei es schließlich der Fall, daß ,asoziale Elemente ausgemerzt“" würden ${ }^{211}$.

\section{Verurteilt vom Reichskriegsgericht}

Die im „Führerwort“ geforderte Unerbittlichkeit prägte die Spruchpraxis des Reichskriegsgerichts, die zuvor geäußerten Zweifel fanden in den Gerichtsverfahren selbst jedenfalls keinen Niederschlag. Der Sicherheitsdienst der SS, der um die Jahreswende 1939/40 in den für den inneren Führungskreis (ReichsführerSS, Staatsführung, Parteileitung) bestimmten „Meldungen aus dem Reich“ mehrfach über Urteile des Reichskriegsgerichtes gegen Zeugen Jehovas berichtete ${ }^{212}$, meldete am 7. Februar 1940, daß seit Kriegsbeginn „bereits über 55 Bibelforscher wegen Kriegsdienstverweigerung zum Tode verurteilt wurden“213. Admiral Bastian sah in einem am 30. Mai 1940 dem Chef des OKW erstatteten Tätigkeitsbericht Anzeichen einer seit Kriegsbeginn anhaltenden „Massendienstverweigerung" der Bibelforscher, wobei allerdings zumeist älterer Jahrgänge in Erscheinung getreten seien ${ }^{214}$. In einem vom Oberkommando der Wehrmacht (OKW) für den internen Gebrauch herausgegebenen Sonderheft, in dem die kriminalstatistischen Ergebnisse des ersten Kriegsjahres vertraulich mitgeteilt wurden, hieß es betreffs der Deliktgruppe „Zersetzung der Wehrkraft", daß diese Straftaten ,eine

$\overline{210}$ Picker, Hitlers Tischgespräche, S. 360. Die Angabe, daß es sich um „Erschießungen“ gehandelt habe, ist unzutreffend; die angegebene Zahl von „130“ bis Mitte 1942 hingerichteten Zeugen Jehovas ist zu niedrig angesetzt.

211 Jochmann, Hitler-Monologe, S. 320.

212 Vgl. Sicherheitsdienst der SS, Meldungen Nr. 30 vom 18.12.1939, Nr. 43 vom 22.1.1940, Nr. 44 vom 24.1.1940, Nr. 46 vom 29.1.1940, Nr. 57 vom 23.2.1940, Meldungen aus dem Reich, Band 3, S. 581f., 669, 679, 700, 797.

213 Sicherheitsdienst der SS, Meldung Nr. 50 vom 7.2.1940, Meldungen aus dem Reich, Band 3, S. 732.

214 Vgl. Haase, Praxis des Reichskriegsgerichts, S. 390f. 
stark ansteigende Kurve“ aufwiesen, wobei das Anwachsen der Fälle ,auch trotz schwerster gerichtlicher Strafen nicht wirksam" hätte verhindert werden können. Diese „gewaltige Zunahme der Straftaten nach § 5 KSSVO“ sei jedoch nicht etwa auf „Zersetzungserscheinungen in der Truppe“ zurückzuführen: „Ursache für das Ansteigen der Fälle der Zersetzung der Wehrkraft ist im wesentlichen die Häufung der Fälle, in denen Ernste Bibelforscher nach ihrer Einberufung die Leistung des Dienstes mit der Waffe verweigert haben. So wurden vom Reichskriegsgericht in der Zeit vom 26. August 1939 bis 30. September 1940 in der Heimat allein 152 Verfahren gegen Ernste Bibelforscher wegen Zersetzung der Wehrkraft durchgeführt."215 Der Statistik ließ sich ferner entnehmen, daß 112 Todesurteile ,in der Heimat gegen Ernste Bibelforscher gefällt" worden waren.

Eine Auswertung des Zahlenmaterials zeigt den Umfang, den die Prozesse gegen kriegsdienstverweigernde Zeugen Jehovas vor dem obersten Wehrmachtgericht im ersten Jahr des Krieges einnahmen. Von den 1.087 Verfahren wegen ,Zersetzung der Wehrkraft“ ( $\$ 5 \mathrm{KSSVO}$ ) waren 152 Bibelforscherverfahren (14\%); von den insgesamt 117 wegen „Wehrkraftzersetzung“ gefällten Todesurteilen ergingen 112 gegen Zeugen Jehovas $(95,7 \%)^{216}$. Dieses bedeutet, daß in nur 40 der 152 Bibelforscherprozesse kein Todesurteil erging (26,3\%), während 73,7 \%. der Verfahren mit der Verurteilung zum Tode endeten: Damit wurden Zeugen Jehovas vom Reichskriegsgericht im ersten Kriegsjahr in drei von vier Verfahren zum Tode verurteilt.

Im Laufe des Jahres 1940 verschärfte sich, wie dem Tätigkeitsbericht von Admiral Bastian zu entnehmen ist, der Kurs des Reichskriegsgerichts weiter. Da die Bibelforscher einen ihnen auch noch nach der Urteilsverkündigung ermöglichten Widerruf oftmals anschließend doch wieder zurückgenommen hätten und erneut auf ihrer Verweigerungshaltung beharrten, seien die RKG-Senate nunmehr dazu übergegangen, bei wiederholter Sinnesänderung Wiederaufnahmeanträge abzulehnen 217 .

Generaloberst Keitel würdigte in einer Stellungnahme vom 10. Juni 1940, in der er noch einmal sein Verständnis für die seelischen Belastungen des Justizpersonals bekundete, die Spruchpraxis des Reichskriegsgerichtes in Bibelforscherverfahren. Unter Verweis auf das allmähliche Absinken der Strafsachen gegen Kriegsdienstverweigerer stellte er mit Genugtuung fest, ,daß die Weisungen, die der Führer gegeben hat, auch hier zum gewünschten Erfolg geführt haben“. Zur Belobigung und Bestärkung der Richter in ihrer unnachgiebigen Haltung fand der Chef des Oberkommandos der Wehrmacht die folgenden Worte: „Das Gericht hat durch sein

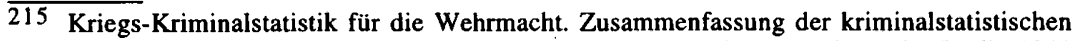
Ergebnisse des ersten Kriegsjahres. Hrsg. v. Oberkommando der Wehrmacht. Berlin 1941 (Sonderheft), S. 9 (archiviert in: BA-MA, RW 6/v. 129 D, Teil 1).

216 Von den fünf nicht gegen Zeugen Jehovas ausgesprochenen Urteilen ergingen mindestens vier ebenfalls gegen Kriegsdienstverweigerer (d.h. nahezu alle Todesurteile wurden nach Zif. 3 des § 5 KSSVO gefällt), und zwar gegen den Adventisten Gustav Psyrembel (RKG-Urteil Anfang März 1940; † 30.3.1940), den evangelischen Christen Dr. Hermann Stöhr (RKG-Urteil 16.3.1940; $†$ 21.6.1940) und die Angehörigen der katholischen Christkönigsgesellschaft Michael Lerpscher (RKG-Urteil 2.8.1940; † 5.9.1940) und Josef Ruf (RKG-Urteil 14.9. $1940 ; \dagger 10.10 .1940)$.

217 Vgl. Haase, Praxis des Reichskriegsgerichts, S. 390 f. 
scharfes Zupacken viele andere Wehrpflichtige vor der Begehung so schwerer Taten bewahrt. Damit hat sich das Reichskriegsgericht um den Erhalt der Wehrkraft des Volkes ein Verdienst erworben und zugleich - bewahrend und verhütend menschlich viel Gutes getan." 218

Ende 1940 ordnete das Oberkommando der Wehrmacht die unverzïgliche Einberufung derjenigen Wehrpflichtigen an, ,die bei der Musterung, auf einer Wehrversammlung oder im sonstigen Verkehr mit den Wehrersatzdienststellen die Absicht äußern, keinen Wehrdienst zu leisten“, und dabei - wie es in dem diesbezüglichen Erlaß vom 8. November 1940 hieß - ,ihr Verhalten nach ihrem Gewissen oder den Vorschriften ihrer Religion für geboten erachten (Beispiele: Ernste Bibelforscher, Jünger Jehovas, Adventisten usw.)“219. Nach diesen Sondereinberufungen nahm in den folgenden Jahren die Zahl der vor dem Reichskriegsgericht verhandelten Bibelforscherprozesse $a^{220}$. Zugleich scheint im Vergleich zum

$\overline{218}$ Der Chef des OKW, Schreiben vom 1.6.1940, zit. nach Haase, Praxis des Reichskriegsgerichts, S. 392.

219 BA-MA, RH 15/221, Bl. 27, OKW, Erlaß vom 8.11.1940. In einem bei Hartmann, Kriegsdienstverweigerung (1982), S. 88, abgedruckten Bescheid des Landesamtes für Wiedergutmachung des Landes Württemberg-Hohenzollern vom 15.1.1952 ist von einer bereits bei Kriegsbeginn durch die Gestapo bei den Wehrmeldeämtern veranlaßten „Sondereinberufungsaktion für vermutliche Kriegsdienstverweigerer, insbesondere Bibelforscher" die Rede. Für eine derartige zu Kriegsbeginn durchgeführte Aktion konnte ein weiterer Beleg jedoch nicht aufgefunden werden. Ob die vergleichsweise hohe Zahl der im Herbst 1939 vor dem RKG zur Verhandlung gekommenen KDV-Fälle die Annahme einer solchen speziellen Rekrutierungsaktion rechtfertigt, läßt sich angesichts der bei der Mobilmachung insgesamt stark ausgeweiteten Einberufenenzahl nicht verläßlich beantworten. Bei der zuweilen in der Literatur erwähnten, gegen die Bibelforscher gerichteten „Sonderaktion zu Beginn des 2. Weltkrieges“ (vgl. Billstein, Krefeld, S. 302) handelte es sich hingegen um eine andersgeartete, nicht der Rekrutierung zur Wehrmacht dienende Gestapo-Maßnahme (siehe näher S. 403, Anm. 336).

220 Obgleich spätere Wehrmacht-Statistiken keine gesonderten Angaben mehr über die Bibelforscherverfahren enthalten, läßt sich ihnen entnehmen, daß in den folgenden Jahren die Zahl der gegen kriegsdienstverweigernde Zeugen Jehovas gefällten Todesurteile jeweils deutlich unter der des ersten Kriegsjahres gelegen haben wird:

Im zweiten Kriegsjahr (1.10.1940 bis 30.9.1941) war die Zahl der nach § 5 KSSVO verhängten Todesstrafen auf insgesamt 54 gefallen. Danach stieg sie allerdings wieder stark an. So betrug die Zahl der in der Zeit vom 1.10.1941 bis 30.6.1942 (für das III. Quartal 1942 gibt es keine Angaben) nach $\S 5$ KSSVO ausgesprochenen Todesurteile 167. Doch dieser, sich in der folgenden Zeit noch weit stärker fortsetzende Anstieg ist ausschließlich auf eine Zunahme der Todesurteile in den anderen Deliktgruppen des $\$ 5$ - und zwar hauptsächlich auf andere Wehrdienstentziehungsdelikte - zurückzuführen. So zeigt die (erstmalige) Aufschlüsselung nach den einzelnen Tatbeständen im Heft 13 der „Kriegs-Kriminalstatistik“, daß von den im IV. Quartal 1942 (1.10.1942-31.12.1942) wegen „Zersetzung der Wehrkraft“ gefällten 171 Todesurteilen die größte Zahl auf Fälle von „Selbstverstümmelung“ (112) entfällt sowie ferner auf Dienstpflichtentziehung durch Täuschung (35). Die Zahl der Todesurteile ist für die anderen Deliktgruppen nicht gesondert ausgewiesen; sie wurde unter der Bezeichnung ,andere Straftaten, Abs. 1 Nr. 1-3" pauschal zusammengefaßt. Demnach betrug im IV. Quartal 1942 die Zahl der Todesurteile für „Zersetzungsäußerungen“, für Fälle des Abs. 1 Nr. 2 (Aufforderung zur Dienstpflichtverweigerung, zum Ungehorsam etc.) und bei Kriegsdienstverweigerung zusammen 24 . Von diesen insgesamt 24 Urteilen wurden wiederum zehn gegen ,Legionäre" gefällt. Die Statistiken für die späteren Jahre, soweit erhalten, zeigen bei den wegen $\S 5$ KSSVO geführten Verfahren eine entsprechende Entwicklung. (Angaben nach BA-MA, RW 6/v.129 D und v.130 D, H 25/39, H 25/40; Hennicke, Wehrmachtkriminalstatistik, S. 444). Gegenüber dem Kriegsbeginn ist folglich eine deutliche Verschiebung feststellbar: Fiel im ersten Kriegsjahr bei den wegen „Zersetzung der Wehrkraft" verhängten Todesurteilen die weitaus größte Zahl auf Kriegsdienstverweigerer-Fälle (mindestens 116 von 117); so gingen diese in den folgenden Kriegsjahren in Relation zu anderen Wehrdienstentziehungsdelikten stark zurück. Auch der für diese Arbeit erstellten Zusammenstellung von 130 quellen- 
ersten Kriegsjahr der Anteil der Verfahren, die mit der Verhängung einer Zeitstrafe endeten, leicht angestiegen $z u \operatorname{sein}^{221}$. Jedoch blieb die Todesstrafe die Regel; die Quote der Bibelforscherverfahren, die vor dem obersten Wehrmachtgericht mit der schärfsten Strafe beschlossen wurden, lag auch später weit über 50 Prozent $^{222}$. Von den gefällten Todesurteilen wurde lediglich etwa jedes fünfte nicht bestätigt oder im Gnadenwege aufgehoben 223 . Es kann davon ausgegangen werden, daß insgesamt während des Zweiten Weltkrieges ungefähr 250 (deutsche und österreichische) Zeugen Jehovas nach kriegsgerichtlichem Urteil hingerichtet wurden $^{224}$. Damit stellten die Zeugen Jehovas 225 unter den im Dritten Reich von der

mäßig belegten Fällen wehrmachtgerichtlich abgeurteilter Zeugen Jehovas läßt sich tendenziell diese Entwicklung der Bibelforscherverfahren entnehmen. Demnach kamen von den Verfahren, für die das Urteilsdatum und Strafmaß ermittelt werden konnte, zur Verhandlung: 36 Fälle im Jahre 1939, 1940 (30), 1941 (14), 1942 (10), 1943 (13), 1944 (12), 1945 (3).

221 Bezogen auf die gesamte Kriegsdauer lag - nach den 1993 von Seidler veröffentlichten Zahlen - der Anteil der in den Kriegsdienstverweigererverfahren verhängten Todesurteilen bei $62 \%$, so daß im Vergleich zum ersten Kriegsjahr $(73,7 \%$ ) von einer tendenziellen Zunahme der nicht mit einer Todesstrafe beschlossenen KDV-Verfahren auszugehen ist. Vgl. Seidler, Fahnenflucht, S. $128 f$.

222 Zur Urteilspraxis des RKG in Bibelforscherverfahren haben sich in der Literatur lange unzutreffende Annahmen gehalten. In dem apologetischen Werk von Schweling und Schwinge ist die Rede von einer ,, humaneren Lösung“, zu der das RKG dadurch gefunden habe, daß es in Prozessen gegen Zeugen Jehovas auf die Möglichkeit der Strafmilderungsklausel des § 5 Abs. 2 KSSVO rekurriert hätte: „Durch diese Urteile war von den ,Ernsten Bibelforschern ‘ für den Regelfall die Todesstrafe abgewendet worden. Sie wurden deshalb meist auch nur zu Freiheitsstrafen verurteilt." (Schweling, Militärjustiz, S. 193) Doch nicht nur von ehemaligen Kriegsrichtern und ihnen ideologisch nicht allzu fern stehenden Nachkriegsautoren - in vorderster Front der Vorsitzende des Verbandes Deutscher Soldaten, Generalmajor Dr. Jürgen Schreiber (vgl. Schreiber, Wehrmachtjustiz und Kriegsdienstverweigerung, S. 145f.) -, sondern auch von wissenschaftlich unverdächtiger Seite ist zuweilen geäußert worden, die Rechtsprechung des RKG habe sich durch Umsicht und eine geringe Bereitschaft zur Verhängung von Todesurteilen ausgezeichnet. So befand Zipfel, daß das RKG „auch noch in den Kriegsjahren die Todesstrafen für Bibelforscher nach Möglichkeit zu umgehen versucht" habe (Zipfel, Kirchenkampf, S. 198f.; ähnlich Hellmund, Zeugen Jehovas, o. S., Kapitel IV, 3). Aufgrund einer irrtümlichen Berufung auf ein Dokument, das auf ein andersgeartetes Problem Bezug nimmt (nämlich auf die Behandlung von Eidesverweigerern aus den besetzten Westgebieten), nahm Fauck an, „daß es - zumindest in vielen Fällen - den Wehrmachtsstellen gelungen ist, von der Verhängung der Todesstrafe abzusehen" (Fauck, Fahneneid, S. 473).

223 Aus den von der WTG veröffentlichten Zahlen kann eine Begnadigungsquote von 19,8\% errechnet werden (Jahrbuch 1974, S. 212); da die Zahlen auch die durch die allgemeine Gerichtsbarkeit Verurteilten umfassen (zur Gnadenpraxis nach VGH-Urteilen siehe S. 350, Anm. 119), dürfte die Quote allein auf die kriegsgerichtlich Abgeurteilten bezogen eher noch zu hoch sein. Nach der „Kriegs-Kriminalstatistik“ für das II. Quartal 1942 betrug die Begnadigungsquote bei sämtlichen Verfahren nach § 5 KSSVO 23,2 \%. Vgl. BA-MA, H 25/39.

Die 1991 von Norbert Haase aufgrund der Auswertung der im Militärhistorischen Archiv Prag aufgefundenen (allerdings nicht vollständigen) Strafverfahrens- und Vollstreckungslisten des RKG veröffentlichte „Übersicht über die in der Zeit vom 26.8.1939 bis 7.2.1945 beim Reichskriegsgericht ergangenen und vollstreckten Todesurteile“ (Haase, Praxis des Reichskriegsgerichts, S. 390) beziffert bei einer Gesamtzahl von 1.189 die wegen ,Zersetzung der Wehrkraft" ausgesprochenen Todesurteile auf 251, die zu einem sehr großen Teil gegen kriegsdienstverweigernde Zeugen Jehovas verhängt und vollstreckt wurden. Franz W Seidler nennt in einer 1993 erschienenen Veröffentlichung unter Berufung auf den gleichen Aktenbestand eine Zahl von 196 RKG-Todesurteilen gegen Kriegsdienstverweigerer (Seidler, Fahnenflucht, S. 128f.). Unter Berücksichtigung der hohen Vollstreckungsquote sowie der nicht in die genannte Übersicht mit eingegangenen RKG-Urteile und der (zu Kriegsbeginn und -ende) von anderen Wehrmachtgerichten verhängten Todesurteile gegen Zeugen Jehovas stützen die von Haase und Seidler veröffentlichten Zahlen die vom Verf. vorgenommene quantitaive Einschätzung. Bestätigung findet diese auch durch einen 1992 erschienenen 
Wehrmachtjustiz abgeurteilten Kriegsdienstverweigerern - deren Zahl verglichen mit anderen Entzugsdelikten (Fahnenflucht, ,Selbstverstümmelung“ etc.) insgesamt gering war 226 - die weitaus meisten Opfer 227.

In den Verfahren gegen religiöse Dienstverweigerer dominierte eindeutig das vermeintliche „Staatswohl“" vor dem so oft beschworenen „Mitgefühl“228, die „Kriegsnotwendigkeiten“ rückten in das Zentrum aller rechtlichen Überlegungen. Bereits bei Kriegsausbruch befanden die Reichskriegsgerichtsräte und die als Laienrichter fungierenden Offiziere, daß dem im „Existenzkampf“ stehenden Reich ein „Notwehrrecht“ zustehe, wonach es ,in der gegenwärtigen Lage Deutschlands“ von jedem Soldaten unbedingte Pflichterfüllung und völlige Aufopferung verlangen könne. In einem Urteil vom 3. Mai 1940 erklärte das oberste Wehrmachtgericht, daß vor ,allen anderen Erwägungen“ den „Kriegsnotwendigkeiten“ der Vorrang

Ausstellungskatalog, in dem Bezug genommen wird auf ,unvollständige Erhebungen des Jahres 1948“, nach denen „,das Reichskriegsgericht 236 Zeugen Jehovas als Kriegsdienstverweigerer" zum Tode verurteilt und hingerichtet hat (vgl. „Das Recht wurzelt im Volk“, S. 59, 73). Die 1991 von Fritz Wüllner (unter Falschzitierung des Verf.) genannte Zahl von ,etwa 1.000 Hinrichtungen von Ernsten Bibelforschern" (Wüllner, NS-Militärjustiz, S. 517) ist durch Quellen nicht gestützt und muß als weit überhöht bezeichnet werden. Das gilt erst recht hinsichtlich der fehlerhaften Hochrechnung, die Karsten Bredemeier in seiner - auch 1991 veröffentlichten - Dissertation vorgenommen hat. Seine Schätzung geht von „10.500 Kriegsdienstverweigerungsverfahren“ aus, da Bredemeier unter Berufung auf die KriegsKriminalstatistik fälschlich von $152 \mathrm{im}$ Zeitraum vom 26.8.1940 (tatsächlich 26.8.1939!) bis 28.9.1940 - und damit monatlich - geführten Bibelforscherverfahren ausgeht; diese Zahl hat er dann einfach mit 69 Kriegsmonaten multipliziert. Vgl. Bredemeier, Kriegsdienstverweigerung, S. 84f.

225 Bei einer Angabe der Gesamtzahl der Kriegsdienstverweigerer aus dem Kreis der Zeugen Jehovas ist zu bedenken, daß diese bedeutend größer gewesen ist als die der wehrmachtgerichtlich Abgeurteilten, da auch die bis zu 1.500 männlichen Bibelforscher-Häftlinge mit einzubeziehen sind, die sich in den Konzentrationslagern der nach Kriegsbeginn erfolgten Aufforderung zum Militärdienst versagten. Angaben über 6.000 bis 7.000 kriegsdienstverweigernde Zeugen Jehovas im Zweiten Weltkrieg (Röhm: Sterben für den Frieden, S. 213; Hartmann, Kriegsdienstverweigerung [1982], S. 78) bedeuten hingegen eine Ausdehnung auf sämtliche verfolgte Zeugen Jehovas einschließlich der großen Zahl jener, die sich - zumeist Mitte der dreißiger Jahre - , nur ' vorübergehend in Haft befunden haben. Diese mit einzubeziehen, läßt sich objektiv nicht rechtfertigen, jedenfalls wenn der Begriff der Kriegsdienstverweigerung nicht völlig konturenlos werden soll.

226 Unter den Opfern der Wehrmachtjustiz stellen diejenigen, die dem Einberufungsbefehl keine Folge leisteten und den Fahneneid verweigerten, einen vergleichsweise kleinen Anteil. Weit größer war die Zahl derjenigen Soldaten, die sich auf andere Weise dem (weiteren) Kriegsdienst versagten. Nach neueren Schätzungen wurden wegen „Fahnenflucht" 22.750 Todesurteile und wegen „Wehrkraftzersetzung“ - zumeist „Selbstverstümmelung“ und „Dienstpflichtentziehung durch Täuschung“" - ungefähr 5.000 bis 6.000 Todesurteile verhängt, wobei von einer Vollstreckungsquote von 60 bis $70 \%$ ausgegangen wird (Messerschmidt/Wüllner, Wehrmachtjustiz, S. 91 und S. 138).

227 Die Gesamtzahl aller im „Dritten Reich“ nach militärgerichtlichem Urteil hingerichteten Kriegsdienstverweigerer wird nicht wesentlich über der für die Zeugen Jehovas genannten Zahl liegen (vgl. Garbe, „Du sollst nicht töten“, S. 93ff.). Die Verweigerung war in nahezu allen Fällen (rein) religiös motiviert; nur in wenigen Fällen waren die Gewissensentscheidungen auch von pazifistischen und politischen Erwägungen geprägt. Die einschlägige biographisch orientierte Literatur berichtet von sechs katholischen Kriegsdienstverweigerern, fünf Mitgliedern der Siebenten-Tags-Adventisten-Reformationsbewegung, einem Baptisten und einem bekennenden evangelischen Christen, die kriegsgerichtlich abgeurteilt wurden und für ihre Überzeugung das Leben ließen. Vgl. Bredemeier, Kriegsdienstverweigerung, S. 109ff.; Hartmann, Kriegsdienstverweigerung; Röhm, Sterben für den Frieden, S. $212 \mathrm{f}$.

228 Vgl. Schreiber, Wehrmachtjustiz und Kriegsdienstverweigerung, S. 145f. 
eingeräumt werden müsse: „Diese erfordern aber, daß ein Deutscher, der in einem Augenblick schwerster Not für Volk und Reich die Wehrdienstleistung, gleichgültig aus welchen Gründen, abgelehnt [hat] und bei dieser Ablehnung trotz eindringlichster Belehrung verbleibt, keine Milde findet. Nur die Todesstrafe vermag die erforderliche abschreckende Wirkung auszuüben. Sie ist in dem Abwehrkampf Deutschlands ein Gebot der Notwehr."229

Generalpräventive Gesichtspunkte bestimmten den Urteilstenor; Beweggründe des einzelnen fanden keine Berücksichtigung: „Die Tatsache, daß er aus religiöser Überzeugung handelt, ist für seine Schuld strafrechtlich ohne Bedeutung." Zwar habe der Angeklagte „nicht aus Feigheit gehandelt. Mit Rücksicht auf die von ihm gezeigte Hartnäckigkeit und Unbelehrbarkeit ist aber eine milde Beurteilung ausgeschlossen. Derart hartnäckige Wehrdienstverweigerungen sind wegen der ihnen innewohnenden Werbekraft besonders geeignet, den Wehrwillen anderer zu zersetzen. Deshalb muß auf die Todesstrafe erkannt werden." 230

Das zuletzt zitierte Urteil erging gegen Ernst Wilhelm Zehender, einen Zeugen Jehovas, der bereits 1938 kriegsgerichtlich zu insgesamt drei Jahren Gefängnis wegen „Fahnenflucht" und „Gehorsamsverweigerung“" verurteilt worden war. Ein knappes Vierteljahr nach seiner am 15. März 1941 erfolgten Haftentlassung wurde Zehender vom Wehrbezirkskommando Stuttgart erneut zur Wehrmacht einberufen. Am 5. Juni, dem ersten Tag seines Dienstes bei der 5. Kompanie des L.S. Rekrutenausbildungskommandos II (Fliegerhorst Mühldorf), weigerte sich der 36jährige Mann - wie es in der Anklageverfügung vom 31. Juli 1941 heißt -, „Uniform anzuziehen und ein Gewehr anzufassen mit der Begründung, die Vorschriften der Bibel verböten dies“231. Eine „eingehende“ Belehrung durch den zuständigen Hauptmann blieb ohne Wirkung. Auch am folgenden Tag erklärte der Soldat wider Willen ,auf erneutes Befragen seines Kompaniechefs, er werde keinen Wehrdienst leisten". Daraufhin wurde er festgenommen und nach Berlin in das Wehrmachtuntersuchungsgefängnis Alt Moabit überstellt. Auf das am 10. Dezember 1941 vom Reichskriegsgericht gefällte Urteil gegen den „Flieger Zehender“, der standhaft bei seiner glaubensbedingten Kriegsdienstverweigerung blieb, ,obwohl er in wiederholten Vernehmungen und auch in der Hauptverhandlung eingehend über die Folgen seines Verhaltens belehrt worden" war, folgte am 17. Januar 1942 die Enthauptung im Zuchthaus Brandenburg-Görden.

Das Reichskriegsgericht wandte die „Kriegssonderstrafrechtsverordnung“ exzessiv an. So bekannte es sich zu der Ansicht, daß auch vor der Einberufung zur Wehrmacht eine Bestrafung nach $\S 5$ Abs. 1 Zif. $3 \mathrm{KSSVO}$ regelmäßig dann angebracht sei, wenn der Wehrpflichtige im Vorwege eine Erklärung abgebe, daß er die Teilnahme am Waffendienst zu verweigern beabsichtige. Die Handlung eines 18jährigen, der bei der Musterung die Unterschrift auf dem Wehrpaß ablehnte, weil er glaubte, damit sonst sein Einverständnis mit der Wehrdienstleistung zu bekun-

$\overline{229}$ Entscheidungen des Reichskriegsgerichts, Band II, 1. Heft, S. 63f., RKG, StPL (HLS) III 25/40, Urteil v. 3.5.1940.

230 RKG, StPL (HLS) III 79/41, Urteil vom 10.12.1941, abgedruckt in: Hartmann, Kriegsdienstverweigerung (1986), S. 74-77 (76).

231 RKG, StPL (RKA) III 349/41, Anklageverf. vom 31.7.1941, ebenda, S. 72f. 
den, wertete das Reichskriegsgericht in einer Entscheidung vom 6. Dezember 1939 als „Wehrdienstentziehung", obgleich eine Heranziehung zum Wehrdienst vom Wehrbezirkskommando vorläufig noch überhaupt nicht beabsichtigt war ${ }^{232}$.

Nach der Rechtsprechung des Reichskriegsgerichtes schützte auch eine etwaige krankheitsbedingte Dienstunfähigkeit nicht vor einer Bestrafung. Am 20. Februar 1940 urteilten die Richter über einen Angeklagten, der der Musterungskommission gegenüber erklärt hatte, daß er einem Gestellungsbefehl keine Folge leisten werde. Obwohl sich bei der ärztlichen Untersuchung herausgestellt hatte, daß der Mann „,nicht kriegsverwendungsfähig“ war, hielt das Reichskriegsgericht eine Aburteilung für geboten: „Für die Frage, ob sich der Angeklagte eines Verbrechens der Wehrdienstverweigerung nach $\S 5$ Abs. $1 \mathrm{Nr}$. 3 KSSVO schuldig gemacht hat, ist es ohne Bedeutung, daß er, wie durch die militärärztliche Untersuchung festgestellt wurde, wehrdienstuntauglich ist und nach $\S 14 \mathrm{Nr}$. 1 WG zum Wehrdienst nicht herangezogen werden darf. Mit Strafe bedroht ist schon das ,Unternehmen ' der Wehrdienstentziehung. " 233 Als höchstrichterlicher Leitsatz wurde verkündet, daß „Wehrpflichtige, die für den Wehrdienst untauglich befunden worden sind, [...] wegen (untauglichen) Versuchs der Wehrdienstentziehung nach $\S 5$ Abs. 1 Nr. 3 bestraft werden" 234 können.

Die zunehmende Verschärfung der Spruchpraxis des Reichskriegsgerichtes in Verfahren gegen religiöse Dienstverweigerer und damit die schrittweise Entfernung von den ursprünglich geäußerten Bedenken zeigte sich insbesondere auch an der Frage, inwieweit Strafmilderungsgründe zu berücksichtigen seien. Neben der gesetzlich möglichen Abweichung von der als Regelstrafe vorgesehenen Todesstrafe durch Heranziehung der Bestimmung über den ,minder schweren Fall“ ( 5 Abs. 2 KSSVO) - die Entscheidung hierüber lag allein im richterlichen Ermessen ${ }^{235}$ - kam gegebenenfalls auch ein Strafausschluß oder eine Strafmilderung aufgrund $\S 51$ Abs. 1 StGB (Unzurechnungsfähigkeit) respektive $\S 51$ Abs. 2 StGB (verminderte Zurechnungsfähigkeit) in Betracht. In den Verfahren wegen glaubensbedingter Kriegsdienstverweigerung spielte dies nicht zuletzt deshalb eine größere Rolle, weil die Verteidigung unter Hinweis auf das aus einer Gewissensnot erwachsene Handeln und die dadurch eingeschränkte „Bestimmbarkeit des Willens“ oftmals die Herbeiziehung eines psychiatrischen Gutachtens beantragte, um auf diese Weise ihre Mandanten vor der drohenden Hinrichtung zu bewahren ${ }^{236}$.

$\overline{232}$ Entscheidungen des Reichskriegsgerichts, Band II, 1. Heft, S. 44f., RKG, StPL (HLS) II 63/39, Urteil vom 6.12.1939; vgl. auch ZWR 5 (1940/41), S. 290.

233 Entscheidungen des Reichskriegsgerichts, Band II, 1. Heft, S. 58f., RKG, StPL (HLS) II $18 / 40$, Urteil vom 20.2.1940.

234 Rechtsgrundsätze des Reichskriegsgerichts, S. 13.

235 Der Absatz 2 des § 5 KSSVO nannte für die Annahme eines „,minder schweren Falles“ keine Voraussetzungen. Die Richter hatten somit nach der Schwere des Unrechts und nach Maßgabe der persönlichen Schuld über die Frage einer möglichen Heranziehung dieser Milderungsklausel zu befinden. Auch bei Schweling/Schwinge wird eingeräumt, daß die Richter am RKG bei Verfahren gegen Zeugen Jehovas und andere Kriegsdienstverweigerer "natürlich immer die Möglichkeit gehabt [hätten], auf den Abs. 2 des §5 KSSVO auszuweichen und einen, minder schweren Fall' anzunehmen. Aus Abschreckungsgründen hielten das aber die Senate nicht für tragbar." (Schweling, Militärjustiz, S. 195)

236 Diese Praxis wird oftmals dem RKG als Ganzem zugeschrieben (vgl. Schweling, Militärjustiz, S. 194; Schreiber, Wehrmachtjustiz und Kriegsdienstverweigerung, S. 146). Tatsächlich 
Obgleich aus der Sicht der Juristen und Psychiater religiöse Überzeugungen, die in der Kriegführung etwas Verabscheuenswertes und zutiefst Verwerfliches erblickten, an Geisteskrankheit grenzten und ,religiöse Dienstverweigerer" neben den „Friedensaposteln und Freiheitsschwärmern“ zu den ,wirklichkeitsfremden und verschrobenen Psychopathen" 237 gerechnet wurden, plädierten die Gutachter vergleichsweise selten auf Zubilligung des $\S 51$. Bereits in der Vorkriegszeit hatte Professor Johannes Lange, Direktor der Psychiatrischen und Nervenklinik der Universität Breslau und anerkannte Kapazität auf dem Gebiete der Psychiatrie, nach Durchführung einer klinischen Untersuchungsreihe an IBV-Angehörigen befunden, daß diese Personen in aller Regel unter medizinischen Aspekten nicht als geisteskrank gelten könnten ${ }^{238}$. Der Spezialist erklärte, daß die Frage, ,wie man dem Übel dieser Art von Dienstverweigerung zu begegnen“ habe, vorwiegend Angelegenheit der Juristen sei, die mit der Härte des Gesetzes vorzugehen hätten. Professor Lange erkannte zwar an, daß es unter den religiösen Dienstverweigerern auch solche aus ,echtem Glauben“ gebe, aber sie seien selten. Vielmehr lauere hinter dem Bekenntnis in den meisten Fällen lediglich „die Angst, die dem männlichen Tode nicht ins Auge zu sehen vermag, lauert die Feigheit, die sich das falsche Gewand einer echten Gesinnung überzieht, oder es liegt geduckt hinter ihr die Sucht nach Aufsehen, nach Geltung um jeden Preis“239. Unter dieser Annahme gelangte Lange zu der Schlußfolgerung: „Es erscheint uns keine Möglichkeit gegeben, die Dienstverweigerung aus religiösen Gründen anders zu behandeln als andere Formen von Dienstverweigerung auch. Die etwaigen, sicherlich wenig zahlreichen, echten Märtyrer aber werden sich durch jede Art der Bestrafung vor ihrem Gotte ausgezeichnet sehen.“

Die ihre Mitwirkung an Militärdienst und Kriegseinsatz verweigernden Zeugen Jehovas wurden in der Regel für ,strafrechtlich voll verantwortlich“ erklärt und dementsprechend unerbittlich von der Wehrmachtjustiz abgeurteilt. Ganz generell drängte das Reichskriegsgericht die Möglichkeiten einer Strafmilderung durch Zuerkennung des $\S 51$ StGB sukzessive und zunehmend stärker zurück. Dies hatte zur Folge, daß im Unterschied zum Ersten Weltkrieg im Zweiten Weltkrieg nur sehr wenige religiös motivierte Kriegsdienstverweigerer in euphemistisch als „Heilanstalten" bezeichnete Institutionen eingewiesen wurden 240 .

\section{Grundsätzlich keine ,minder schweren“ Fälle}

Stück um Stück wurden die letzten Milderungsmöglichkeiten beschnitten. Wichtige Bedeutung kam dabei einem Bibelforscherverfahren zu, das am 24. Januar 1940 vor dem 2. Senat des Reichskriegsgerichtes stattfand ${ }^{241}$. Aufgrund der Herkunft

hat es wohl auch Fälle gegeben, wo Richter auf die Einholung von § 51-Gutachten drangen; von einer generellen „Linie" des RKG kann aber nicht die Rede sein.

237 Ziemann, Psychopathen, S. 41.

238 Vgl. Lange, Dienstverweigerung; siehe auch S. 243f.

239 Lange, Dienstverweigerung, S. 15.

240 Vgl. Zipfel, Kirchenkampf, S. 199; Garbe, Gott mehr gehorchen, S. 208f.

241 Entscheidungen des Reichskriegsgerichts, Band II, 2. Heft, S. 65f., RKG, StPL (HLS) II 4/40, Urteil vom 24.1.1940; vgl. auch DJ 102 (1940), S. 939. 
aus einer „erblich außerordentlich schwer belasteten Familie“ und weiteren „Auffälligkeiten", zu denen der vom Gericht zu Rate gezogene psychiatrische Sachverständige insbesondere „die außerordentliche Starrheit und Verbissenheit“ rechnete, ,mit der der Angeklagte an seiner Weigerung und den für sie ursächlichen Vorstellungen und Gedankengängen“ festhalte, nahm das Gericht „zugunsten des Angeklagten" an, daß er in einem Zustande der verminderten Zurechnungsfähigkeit im Sinne des $\S 51$ Abs. 2 StGB gehandelt habe.

Der Senat hielt es gleichwohl für angebracht, mit Nachdruck darauf hinzuweisen, ,daß die besonderen Verhältnisse der Wehrmacht und die Notwendigkeiten des Kriegs dazu zwingen, vermindert zurechnungsfähige Täter grundsätzlich nicht anders zu behandeln als strafrechtlich voll verantwortliche [!] und die Strafmilderung des $\S 51$ Abs. 2 auf besondere Ausnahmefälle zu beschränken“. Da jedoch von einem solchen Ausnahmefall ausgegangen werden könne, erkannte das Reichskriegsgericht auf eine Strafe von 3 Jahren Zuchthaus.

Gleichzeitig betonte der 2. Senat - wohl um den Eindruck einer „Milde“ im Umgang mit Kriegsdienstverweigerern erst gar nicht aufkommen zu lassen -, da $B$ lediglich aufgrund der besonderen Umstände des Einzelfalles von der Regelstrafe abgegangen worden sei, während das Vorliegen eines "minder schweren Falles“ allgemein bei derartig unbeirrbaren „Tätern“ zu verneinen sei. So erklärten die Richter, ,daß grundsätzlich die Kriegsdienstverweigerung nicht als minder schwer beurteilt werden kann, solange sich nicht der Täter ernsthaft und ohne Vorbehalt zur Leistung des Kriegsdienstes bereit erklärt hat". Diese höchstrichterliche Entscheidung erklärte damit den Willen des „Führers“, daß ausschließlich bei Aufgabe der Verweigerungshaltung von der Todesstrafe abzusehen sei, zur verbindlichen Leitlinie in der Rechtsprechung der Wehrmachtjustiz.

Ein Vierteljahr später bekräftigte das oberste Wehrmachtgericht seine Auffassung, daß bei ,hartnäckigen“ Dienstverweigerern ,nur die Verhängung der härtesten Strafe“ imstande sei, ,den Strafzweck zu erreichen“242. Milderungsgründe seien in solchen Fällen grundsätzlich nicht angebracht, wobei durch die vom Gericht angeführte Begründung der Milderungsklausel jeder Sinn entzogen wurde: „Die Frage, ob ein minder schwerer Fall anzunehmen ist, ist nicht von der Person des einzelnen Täters aus, sondern in erster Reihe vom Standpunkt der Allgemeinheit, vor allem von den Kriegsnotwendigkeiten aus, zu beurteilen." Selbst wenn „beim Angeklagten die Voraussetzungen des § 51 Abs. 2 StGB. vorlägen“, so bekundeten die Richter, würde man ,von der gesetzlichen Möglichkeit, die Strafe nach dieser Vorschrift zu mildern, keinen Gebrauch machen “.

Diese Ausführungen des Reichskriegsgerichtes lösten in der rechtswissenschaftlichen Fachpresse eine Auseindersetzung über die Frage des „minder schweren Falles" aus, womit implizit zugleich die Frage, ob jeder Kriegsdienstverweigerer unabhängig von den Gegebenheiten des Einzelfalles stets die Todesstrafe zu erwarten habe, zur Debatte stand. Der Strafrechtsprofessor und Oberkriegsgerichtsrat der Reserve Eberhard Schmidt kritisierte die im Widerspruch zu der überlieferten Rechtsprechung des früheren Reichsmilitärgerichtes stehende Auffassung, nach der

242 Entscheidungen des Reichskriegsgerichts, Band II, 1. Heft, S. 63f., RKG, StPL (HLS) III 25/40, Urteil vom 3.5.1940. 
die gerichtliche Prüfung strafmildernder Aspekte allein unter Zugrundelegung objektiver Überlegungen, wie den vom Reichskriegsgericht im Urteil angeführten Erfordernissen der Kriegslage, und damit ohne Berücksichtigung subjektiver, sich aus der Person des Beschuldigten ergebender Momente vorzunehmen sei. Wenn die Entscheidung über die „Schwere des Falles“ sich an objektiven (Wehrdienstentziehung) wie subjektiven (Hartnäckigkeit des Täters) Umständen ausrichte, so müsse dies umgekehrt auch für die Frage des ,minder schweren Falles“ gelten. Für Schmidt war darum ,diese Frage sehr wohl ,von der Person des einzelnen Täters“ aus zu beurteilen" 243 . Die gebotene Beachtung der persönlichen Schuldfrage respektive der subjektiven Schuldmomente verbiete es zugleich auch, den $\S 51$ Abs. 2 StGB von vornherein für belanglos zu erklären. Schmidt hielt mit seinen Einwänden gegen die Rechtsprechung des Reichskriegsgerichtes somit an dem klassischen Strafrechtsgedanken fest, daß die Strafhöhe in dem vom Gesetz vorgegebenen Rahmen sich nicht nur am begangenen „Unrecht“ zu orientieren habe, sondern auch nach Maßgabe der „Schuld“ erfolgen müsse.

Dieser „konservative Einspruch“ wider eine Spruchpraxis, die eine Grundregel richterlicher Urteilsfindung preiszugeben bereit war, wurde von seiten des Reichskriegsgerichtes zurückgewiesen. Nachdrücklich wandte sich der Senatspräsident beim Reichskriegsgericht Dr. Karl Schmauser gegen die „Irrtümer und Mißverständnisse Schmidts“, wobei Schmauser in seiner Replik einschränkend darauf hinwies, daß die Urteilsausführungen keine Allgemeingültigkeit beanspruchten und von daher die diesbezüglichen Erwägungen des Reichskriegsgerichtes zur Frage des minder schweren Falles ,nur auf wenigstens wesensgleiche Fälle einer nicht widerrufenen Auflehnung gegen die Wehrpflicht“ zu beziehen seien ${ }^{244}$. Denn es wäre bei der Frage, ,ob ein Wehrdienstverweigerer überhaupt als vermindert zurechnungsfähig i. S. des $§ 51$ Abs. 2 StGB. zu erachten ist, [...] von grundsätzlich anderen Voraussetzungen als in der Regel sonst auszugehen“. Da es sich bei der Kriegsdienstverweigerung um keinen einmaligen Tatvorgang handele, sondern um ein sogenanntes Dauerdelikt, könne nicht eine rückblickende Betrachtung über die Zurechnungsfähigkeit zum Tatzeitpunkt erfolgen. Vielmehr setze sich der Verweigerer über einen längeren Zeitraum mit den Folgen seiner Haltung auseinander, die zwischen Festnahme und Hauptverhandlung ihm auch ,immer wieder eindeutig vor Augen geführt" würden. Wenn er trotzdem den Wehrdienst weiter verweigere, so wisse er genau um die Gesetzeswidrigkeit und kenne darüber hinaus „Art und Höhe der angedrohten Strafe“. Zwar könne bei ,Tätern der hier fraglichen Art“ die Fähigkeit vermindert sein, ,einzusehen, warum der Staat von jedem einzelnen ohne Rücksicht auf seine persönliche Weltanschauung u. dgl. ( $\$ 48 \mathrm{MStGB}$.) Gehorsam, d. h. hier Wehrdienst, fordert, und warum er die Wehrdienstverweigerung bestraft", aber es sei kaum denkbar, daß jene nicht zu erfassen vermögen, „daß die Wehrdienstverweigerung durch das Gesetz verboten ist“. Für die „volle Einsichtsfähigkeit“ im rechtlichen Sinne würde es genügen, „wenn sie nach ihren geistigen

243 Schmidt, Entscheidungen, S. 325; zur Beurteilung der oftmals überschätzten Kritik Schmidts an der Rechtsprechung des RKG vgl. die Rezension des Werkes von Messerschmidt/Wüllner durch den Verf. in: Kritische Justiz 21 (1988), S. 352-358, hier S. $356 f$.

244 Schmauser, Minder schwerer Fall, S. 132-141 (133). 
Fähigkeiten diese Tatsache und ihre Bedeutung voll zu erkennen imstande sind“ 245 . Wenn in diesem Sinne in den allermeisten Fällen die Einsichtsfähigkeit vorausgesetzt werden könne, so gelte dies erst recht hinsichtlich der Entscheidungsfähigkeit. Denn ein Wehrdienstverweigerer, der ,trotz Kenntnis der ihm drohenden Todesstrafe u. U. monatelang unbeirrbar an seiner Weigerung " festhalte, bekunde damit eine „so außergewöhnliche Bestimmtheit des Willens“, daß von einer erheblichen Minderung der „Bestimmbarkeit seines Willens“ nicht ausgegangen werden könne. Wer verstandesmäßig begreift, daß es bei der Kriegsdienstverweigerung um seinen Kopf geht und trotzdem auf seiner Haltung beharrt, begeht seine „Tat" bewußt; er entscheidet sich gewissermaßen , freiwillig' für das Fallbeil - so darf man wohl die Erwägungen des Senatspräsidenten deuten.

Aber selbst dann wenn psychiatrische Gutachter bei einem Kriegsdienstverweigerer zu der Überzeugung gelangten, daß eine verminderte Zurechnungsfähigkeit zu attestieren und die Voraussetzungen des $§ 51$ Abs. 2 StGB gegeben seien, sollte das Gericht nach Ansicht Schmausers grundsätzlich nicht von der Möglichkeit einer Strafmilderung Gebrauch machen. Zur Begründung verwies der Senatspräsident auf die Gefahren, die von der „Werbekraft" einer Verweigerung des Wehrdienstes ausgingen. Im Einklang mit dem in der Wehrmachtjustiz vorherrschenden Rechtsdenken befand Schmauser, daß die Motive des einzelnen für die Entscheidung keinerlei Bedeutung hätten:

„Ein Wehrdienstverweigerer mag in einem bestimmten Fall aus an sich nicht ehrlosen Gründen handeln. Es wird aber immer Ehrvergessene geben, die, besonders in Erwartung von Begnadigungen oder irgendwelchen Veränderungen nach Kriegsende, lieber eine noch so schwere Freiheitsstrafe auf sich nehmen, bevor sie als Soldat ihr Leben für das Vaterland einsetzen wollen. Dieser Gefahr muß mit allen Mitteln vorgebeugt werden." 246

Schmausers Ausführungen bedeuteten nicht weniger als die Stellung der Kriegsdienstverweigerer unter ein - durch die faktische Suspendierung der gesetzlichen Strafmilderungsmöglichkeiten gekennzeichnetes - Ausnahmerecht. Mit einer Grundsatzentscheidung ${ }^{247}$ vom 10. März 1942 unterstrich das Reichskriegsgericht, daß es seine Spruchpraxis an einer solchen Sichtweise voll und ganz auszurichten gewillt war. Der in dem betreffenden Verfahren angeklagte Zeuge Jehovas war am 14. Mai 1941 zur Wehrmacht eingezogen worden. Er leistete zunächst der Einberufung Folge. Nach drei Wochen beim Militär weigerte er sich, die Gasmaske aufzusetzen. Zwei Tage danach gab er dem Hauptfeldwebel in seiner Einheit bekannt, daß er den Fahneneid nicht leisten werde. Daraufhin erfolgte die Festnahme. In wiederholten Vernehmungen erklärte der Mann, daß sein Gewissen ihm die weitere Teilnahme am Waffendienst verbiete. Am 23. August 1941 verurteilte ihn das oberste Wehrmachtgericht wegen ,Zersetzung der Wehrkraft“ zum Tode. Als man ihn vor der Urteilsbestätigung nochmals befragte, ob er in Anbetracht des Strafmaßes nicht zu einer Revidierung seiner Haltung bereit sei, erklärte der Zeuge

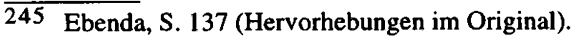

246 Schmauser, Minder schwerer Fall, S. 139 (Hervorhebungen im Original).

247 Entscheidungen des Reichskriegsgerichts, Band II, 3. Heft, S. 144-155 (155), RKG, StPI (HLS) III 122/41, Urteil vom 10.3.1942. 
Jehovas, daß er „gern Arbeit leisten und auch als Sanitäter Dienst tun wolle. Er könne aber keinen Fahneneid leisten und nicht von der Waffe Gebrauch machen“.

Doch die erklärte Bereitschaft zum waffenlosen Dienst war nicht dazu angetan, den Präsidenten des Reichskriegsgerichtes umzustimmen ${ }^{248}$. Die Vollstreckung sollte am Morgen des 27. September stattfinden: „Wenige Stunden vor ihr erklärte der Angeklagte, daß er nunmehr bedingungslos zum Wehrdienst in jeder Form bereit sei. Daraufhin wurde die Vollstreckung aufgehoben. Das Verfahren wurde auf einen Antrag des Angeklagten entsprechend der in solchen Fällen üblichen Handhabung des Reichskriegsgerichts wieder aufgenommen." Drei Wochen später, am 16. Oktober 1941, fand die erneute Hauptverhandlung statt. Wie in dem späteren Urteil vermerkt ist, habe in ihr der Angeklagte erklärt, „daß er gern Wehrdienst leisten möchte, daß er aber nicht so könne, wie er wolle, weil ihn sein Gewissen quäle“. Der Senat setzte die Verhandlung aus und ordnete zur Frage der Zurechnungsfähigkeit „die Beobachtung des Angeklagten auf seinen Geisteszustand in einer Heilanstalt" an. Am 10. März 1942 wurde zum dritten Mal über den 39jährigen Mann im Gerichtsgebäude am Lietzensee verhandelt ${ }^{249}$. Jetzt gab der Angeklagte zu Protokoll, daß er ,,auf Grund reiflicher Überlegung“ zu der Überzeugung gelangt sei, keinen Wehrdienst leisten zu können. Dabei sei er - wie die Urteilsschrift betont - ,trotz eingehendster Vorhaltungen“" geblieben.

Während in der ersten Hauptverhandlung der Sachverständige, der - wie das Gericht vermerkte - ,in der Beurteilung ähnlicher Fälle geschulte“ Oberfeldarzt Dr. $\mathrm{X}^{250}$, bei dem Angeklagten die Voraussetzungen des $\S 51$ Abs. 2 StGB für nicht gegeben ansah, attestierte ihm ein Psychiater aufgrund der Ergebnisse der Beobachtung während des angeordneten sechswöchigen Aufenthalts in der Heilanstalt ,eine solche unzulängliche Intelligenz, daß man bei ihm von einem angeborenen Schwachsinn mäßigen Grades sprechen könne. Dieser Schwachsinn zusammen mit der kritikschwachen Übernahme und der weitgehenden Aneignung fanatisierter Anschauungen habe bei dem Angeklagten eine erhebliche Verminderung der Zurechnungsfähigkeit insofern bewirkt, als sowohl die Einsicht in das Strafbare der Handlung als auch insbesondere das Vermögen, nach einer solchen Einsicht zu handeln, erheblich vermindert worden sei.“

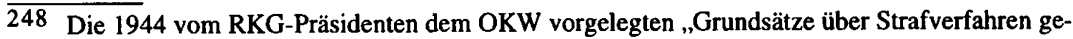
gen ,Ernste Bibelforscher ““ bestimmten unmißverständlich, daß es für die Erfüllung des Tatbestandes des § 5 Abs. 1 Zif. 3 ,keinen Unterschied“" mache, ,ob der Angeklagte sich weigert, den Wehrdienst in jeder Form zu leisten, oder ob er erklärt, lediglich den Wehrdienst mit der Waffe nicht leisten zu wollen, im übrigen aber bereit zu sein, jeden von ihm verlangten Wehrdienst zu tun". Auch in diesen Fällen sei auf Todesurteil zu erkennen. Ebenso käme eine Nicht-Bestätigung eines bereits ergangenen Todesurteils nur für den Fall in Betracht, wenn der Wehrdienstverweigerer seine Bereitschaft zu erkennen gebe, , in vollem Umfang Wehrdienst zu leisten“ (IfZ, MA 333, 657694-96, Der Präsident des RKG, Schreiben vom 3.8. 1944 an das OKW).

249 Es kam nicht selten vor, daß Zeugen Jehovas ihre Entscheidung erneut korrigierten und abermals verweigerten - ein Zeichen für die Gewissenszweifel und die inneren Kämpfe, denen sie ausgesetzt waren. Schweling, Militärjustiz, S. 194f., berichtet von einem Bibelforscherverfahren, in dem es aufgrund mehrfachen Widerrufes ebenfalls zu drei Verhandlungen kam.

250 Entscheidungen des Reichskriegsgerichts, Band II, 3. Heft, S. 147 (Anonymisierung bereits in der Vorlage). 
Doch obgleich das medizinische Gutachten in diesem Fall auf Zuerkennung des $\S 51$ Abs. 2 StGB plädierte und damit die Möglichkeit zu einer Strafmilderung offenstand, hielt der 3. Senat des Reichskriegsgerichtes es für ,notwendig, das auf Tod, Verlust der Wehrwürdigkeit und dauernden Verlust der bürgerlichen Ehrenrechte lautende erste Urteil des Senats vom 23. August 1941 aufrechtzuerhalten“. Zur Begründung beriefen sich die Richter des 3. Senates, an dem Dr. Schmauser Präsident war, darauf, daß im Krieg ,nicht so sehr die Persönlichkeit des Täters als die Gefährlichkeit der Tat für die Volksgemeinschaft den Ausschlag geben" müsse: „Diese Gefährlichkeit wird aber nicht davon beeinflußt, ob der Täter voll oder vermindert zurechnungsfähig ist. Die Tat eines vermindert zurechnungsfähigen Angeklagten kann u. U. sogar kriegsgefährlicher sein als die eines voll Verantwortlichen." Auch in diesem Fall gelte es an dem in der „Rechtsprechung des Reichskriegsgerichts stets vertretenen Standpunkt festzuhalten, daß eine Wehrdienstverweigerung grundsätzlich so lange nicht als minder schwer bewertet werden kann, als sich der Täter nicht ernstlich und vorbehaltlos bereit erklärt hat, seine Pflicht dem deutschen Volk gegenüber zu erfüllen“".

\section{Keine Milde ohne Widerruf}

Mit Nachsicht konnte ein Zeuge Jehovas bei den Richtern am Reichskriegsgericht nur dann rechnen, wenn er seine Verweigerungshaltung vollkommen aufgab und sich bedingungslos zum Kriegsdienst bereit erklärte. Nachhaltig versuchten die Richter bei den Angeklagten einen solchen Entschluß herbeizuführen, wobei die Motive für die zumeist intensiven Bemühungen vielschichtig gewesen sein mögen. Neben dem Bestreben, auf diese Weise Angeklagte ,,vor dem Todesurteil bewahren" zu können, stand wohl auch das Verlangen nach Gewissensberuhigung, um den Strafausspruch schließlich in dem Bewußtsein fällen zu können, nichts unversucht gelassen zu haben. Es ging also auch darum, ,dieser Fälle menschlich Herr zu werden" 251 .

Im August 1942 teilte der Präsident des Reichskriegsgerichtes seinen Senatspräsidenten mit, daß er eine formale Lockerung der Richtlinien erwäge, um den Zeugen Jehovas einen Ausweg zu ermöglichen, fügte aber zugleich hinzu, daß dieses unter keinen Umständen zu einer Milderung der sachlichen Beurteilung der Kriegsdienstverweigerer und ihres ,,vom Standpunkt der Kriegsführung aus durchaus verbrecherischen Verhaltens" führen dürfte. Auch hielt Admiral Bastian es offenbar zur Vermeidung von Mißverständnissen für erforderlich, darauf hinzu-

$\overline{251}$ Schweling, Militärjustiz, S. 194. Da die zahlreichen Todesurteile gegen religiöse Kriegsdienstverweigerer das von ehemaligen Wehrmachtrichtern bis in die Gegenwart propagierte Selbstbild einer zwar harten, aber „maßvollen“ Militärjustiz beeinträchtigen, sind verschiedene Wege beschritten worden, um jene Urteile zu rechtfertigen beziehungsweise zu entschuldigen. Als Entlastungsargumente wurden unter anderem genannt: das stete Bemühen der Richter, die „Angeklagten umzustimmen“, die den Verweigerern noch unmittelbar vor der Urteilsvollstreckung eingeräumte „Gelegenheit, ihre Haltung zu revidieren", die Machtlosigkeit gegen eine „Führerentscheidung" und der Verweis darauf, daß Kriegsdienstverweiger auch im demokratischen Ausland seinerzeit kriegsgerichtlich abgeurteilt worden seien, wobei beim letzten Argument verschwiegen wird, daß sich das Strafmaß dort durchweg auf Freiheitsstrafen beschränkte. Vgl. auch Haase, Praxis des Reichskriegsgerichts, S. 381, 392f. 
weisen, daß es keineswegs Sentimentalitäten seien, die seinen Standpunkt bestimmten, sondern er nach einer Möglichkeit suche, „der Wehrmacht in ernstester Kriegszeit auch noch in letzter Stunde einen brauchbaren Kämpfer zuzuführen bzw. zu erhalten" 252 .

Daß auch noch nach der Hauptverhandlung und dem Urteilsspruch diese Bemühungen fortgeführt wurden und den Verweigerern bis zum - nicht selten aus diesem Grunde herausgezögerten - Vollstreckungstermin die Möglichkeit eingeräumt wurde, durch einen Widerruf ein Wiederaufnahmeverfahren zu erwirken ${ }^{253}$, zeigt die Janusköpfigkeit einer Richterschaft, bei der die kalkulierte, kaltblütige Verhängung eines drakonischen Urteils und gleichzeitig die Absicht, das Opfer doch noch „zur Besinnung“ zu bringen, nicht im Widerspruch standen. Der Unbeirrbarkeit der meisten kriegsdienstverweigernden Zeugen Jehovas, die, vor die Wahl zwischen Tod und Soldatendienst gestellt ${ }^{254}$, darin für sich keine Alternative zu erkennen vermochten, begegneten viele der Richter mit völligem Unverständnis. Fassungslos wirkten sie daran mit, daß die Betreffenden um ihres Glaubens willen, wie es hieß, ,ins eigene Unglück liefen“.

Um Verweigerer dennoch zu einem Sinneswandel zu bewegen, wandten die Angehörigen des Reichskriegsgerichtes zahlreiche Methoden an. Neben „Zuspruchsversuchen“, bei denen sich die Untersuchungsrichter - wie Gerichtspräsident Bastian berichtete - „die denkbar größte Mühe“ gaben, und Belehrungen durch Offiziere über ,die Verpflichtung jedes wehrfähigen Deutschen dem eigenen Volke, der eigenen Familie, kurz dem Vaterland gegenüber" wurden vor allem Gefängnispfarrer beider Konfessionen gebeten, die Zeugen Jehovas mitzubetreuen und ,ihnen zu zeigen, daß der Wehrdienst mit den Vorschriften, Weisungen und Tatsachen der Bibel nicht im Widerspruch“ 255 stünde. Allerdings wiesen nicht wenige Zeugen Jehovas deren Gesprächsangebote spontan zurück, weil ihnen die Geistlichen „,von vornherein als verdächtig“ 256 galten.

Der evangelische Gefängnispfarrer in Berlin-Plötzensee Dr. Harald Poelchau, der mit Widerstandskreisen in Verbindung stand, empfand das vom Reichskriegsgericht an seinen Berufsstand herangetragene Ansinnen, ,diese Leute theologisch für den Kriegsdienst zu überzeugen, um sie zu retten“, als „eine unmögliche Forderung" für jemanden, der wie er ,den Dienst im Kriege und besonders in diesem

252 Der Präsident des Reichskriegsgerichts, Schreiben vom 17.8.1942 an die Senatspräsidenten, zit. nach Haase, Praxis des Reichskriegsgerichts, S. 393 (Hervorhebung im Original).

253 Vgl. Schweling, Militärjustiz, S. 195; Weisenborn, Aufstand, S. 88; BA-MA, N 192/1, S. 39, 57f. Nach §91 Abs. 1 KStVO war die Wiederaufnahme eines durch Urteil und nach Bestätigung des Gerichtsherrn rechtskräftig geschlossenen Verfahrens dann möglich, wenn „neue Tatsachen oder Beweismittel" beigebracht wurden. Die über die Zulassung des Antrages erkennenden Senate des RKG werteten regelmäßig einen Widerruf als hinreichenden Beleg für eine neue Tatsachenlage und ordneten in diesen Fällen ein neues Verfahren an. Diese „erweiterte Auslegung der Vorschriften“ wurde in den 1944 vom OKW erlassenen „Richtlinien für Strafverfahren gegen ernste Bibelforscher usw." (IfZ, MA 333, 657687-89) festgeschrieben.

254 Das Angebot von Zeugen Jehovas, ersatzweise außerhalb des Verbandes der Wehrmacht Arbeiten zu verrichten, wurde von den Kriegsgerichten regelmäßig zurückgewiesen. Vgl. Entscheidungen des Reichskriegsgerichts, Band II, 1. Heft, S. 36-38; Entscheidungen des Reichskriegsgerichts, Band II, 3. Heft, S. 145.

255 BA-MA, N 192/1, Max Bastian, Lebenserinnerungen (1956), S. 57. 
Kriege auch für ein Verbrechen gegen das 5. Gebot hielt“257. Nach Poelchaus Erinnerungen führten die Bemühungen der Geistlichen, soweit ihm bekannt wurde, in keinem Fall ,zu einem ,positiven“ Ergebnis“258. Vielmehr trat - an den Intentionen des Reichskriegsgerichtes gemessen - eher ein gegenteiliger „Erfolg“ ein, insofern die Zeugen Jehovas durch die Gespräche bestärkt ,ihren harten Weg gewisser gingen" ${ }^{\circ 59}$.

Bei den Theologen, die oftmals auf diese Weise überhaupt zum ersten Mal mit Bibelforschern in persönlichen Kontakt kamen, hinterließen die Begegnungen einen tiefen Eindruck, und sie gewannen, auch wenn sie deren Überzeugung nicht teilten, Achtung vor der glaubensstarken und gottesfürchtigen Haltung der Zeugen Jehovas $^{260}$. Davon zeugt eindrucksvoll der Bericht des Stuttgarter Stadtpfarrers Rudolf Daur, der Anfang 1942 mehrfach den Zeugen Jehovas Gustav Stange, einen Schuhmacher aus Stammheim, in der Haft besuchte. Daur, der - was keineswegs selbstverständlich gewesen zu sein scheint - sich auch darum bemühte, der Witwe des am 20. Februar 1942 Hingerichteten Trost zuzusprechen, und ihr in einem am gleichen Tag abgefaßten Schreiben gegenüber bekannte, daß er zwar die Anschauungen ihres Mannes ,nicht in allen Stücken teilen“ könne, gleichwohl sich aber mit ihm, der nun ,allen Dunkelheiten und Wirrnissen dieser bösen Welt entronnen und in Gottes Händen“ sei, „im tiefsten Innern verbunden“261 fühle, schrieb über seine Begegnung mit Stange:

„Er lehnte aus Gewissensgründen den Kriegsdienst radikal ab, lehnte insbesondere ab, einen Eid auf Adolf Hitler zu leisten. Ich versuchte ihm alles zu sagen, was ihm etwa eine andere Stellungnahme ermöglichen könnte. Es lag mir so viel daran, das Leben dieses tüchtigen Menschen [...] zu retten. Aber er war seiner Meinung völlig gewiB. Bei der Kriegsgerichtsverhandlung sagte ihm der Hauptmann: ,Was würde denn, wenn es alle Menschen so machen wie Sie?', worauf er die Antwort gab: ,Dann wäre der Krieg gleich zu Ende. “'262

Die besondere Tragik des Auftrages und Tuns der Seelsorger spiegelt sich darin, daß sie das Leben von Bibelforschern, zu denen man sie in die Zellen schickte, nur dann zu retten vermochten, wenn sie deren Glaubensüberzeugung brachen. Die nervenaufreibende Zwangssituation, in der diese Gespräche stattfanden, verdeutlicht ein Bericht des Standortpfarrers Dr. Werner Jentsch über seine Begegnung mit einem 19jährigen Todeskandidaten im Zuchthaus Brandenburg-Görden. Jentsch

257 Poelchau, Ordnung der Bedrängten, S. 76f.

258 Poelchau, Die letzten Stunden, S. 35.

259 Poelchau, Ordnung der Bedrängten, S. 77.

260 Berichte über Begegnungen von Gefängnispfarrern mit kriegsdienstverweigernden Zeugen Jehovas finden sich z. B. bei Müller/Weckerling, Protestantismus, S. 297; Scharf, Widerstehen, S. 42-45; Gespräche mit Kurt Scharf, S. 24f. Aber nicht alle zur seelsorgerischen Begleitung bei Hinrichtungen herbeigezogenen Geistlichen zählten den Beistand oder die Fürsprache für die „Delinquenten“ zu ihren pastoralen Aufgaben. Ein anderes Amtsverständnis zeigen zum Beispiel die Ausführungen von Dr. Max Schultz, seinerzeit Pfarrer an der als Richtstätte genutzten Breslauer Untersuchungshaftanstalt. Vgl. Schultz, Seelsorge, S. 52ff. 
suchte den jungen Zeugen Jehovas ${ }^{263}$ in der Nacht vor der für den 21 . August 1942 anberaumten Hinrichtung in dessen Zelle auf:

„Laut kriegsgerichtlicher Maßnahme durfte er, noch notfalls in der letzten Nacht, einen Zettel schreiben und darauf seine Bereitschaft zum Kriegsdienst und zur Eidesleistung bekunden. Er hätte sein Leben retten können, und unser Gespräch war praktisch die letzte Chance, ihn umzustimmen. Wir haben Text um Text in der Heiligen Schrift ernstlich durchgenommen. Er wollte sich alles noch einmal überlegen. Dann ließ ich ihn allein mit seinem Herrn. Als ich in den frühen Morgenstunden wiederkam, war er ganz reif und klar, er unterschrieb den Zettel nicht. Was blieb mir nun anderes übrig, als seine Entscheidung im Angesichte Jesu zu achten und ihn jetzt zum letzten Gang zu rüsten." 264

Auf Fürsprache des Jentsch verbundenen Reichskriegsgerichtsrates Dr. HansUlrich Rottka, der im September 1940 - als Senatsrichter unerwünscht - zur Reichskriegsanwaltschaft versetzt worden war ${ }^{265}$, vermittelte Senatspräsident Kraell einen Gesprächstermin bei Admiral Bastian, so daß sich für Jentsch kurze Zeit nach der für ihn so tief bewegenden Begegnung die Möglichkeit bot, dem Gerichtspräsidenten das Problem der Kriegsdienstverweigerung aus theologischer Sicht vorzutragen ${ }^{266}$. Jentsch unterbreitete den Vorschlag, sowohl den religiösen Kriegsdienstverweigerern als auch den mit deren Aburteilung befaßten Juristen eine kirchlich-dogmatische Abhandlung über die biblischen Texte zum Themenkreis Krieg und Frieden in die Hand zu geben. Nachdem Bastian sich einverstanden erklärt hatte, verfaßte Jentsch 1943 auf ausdrücklichen Wunsch des im gleichen Jahr zum Oberreichskriegsanwalt ernannten Dr. Alexander Kraell den Entwurf einer Broschüre für die geistliche Betreuung der „Kriegsdienst- und Eidverweigerer“267.

263 Im Unterschied zu dem 1952 verfaßten Bericht nimmt Jentsch in seiner 1992 verfaßten Autobiographie irrtümlich an, der „Delinquent“, der den Vornamen Bernhard trug, sei kein Bibelforscher, sondern ein evangelischer Christen gewesen (Jentsch, Ernstfälle, S. 183 u. S. 557, Anm. 12). Die ursprüngliche Angabe ist jedoch zutreffend; es handelte sich um einen am 14.5.1923 geborenen Zeugen Jehovas namens Bernhard Grimm, der am 14.7.1942 vom RKG wegen Wehrdienstverweigerung zum Tode verurteilt und am 21.8.1942, u.a. zusammen mit Pater Franz Reinisch, im Zuchthaus Brandenburg-Görden enthauptet wurde. Vgl. Ehrenbuch Brandenburg-Görden, Band 2, S. 106. Jentsch, Wehrdienstfrage, S. 182.

265 Rottka wurde am 26.9.1942 auf Veranlassung Hitlers in den Ruhestand versetzt, offenbar weil er - besonders hinsichtlich der Bibelforscherverfahren - „eine humanere Auffassung“ vertrat, als von ihm verlangt wurde (vgl. Haase, Praxis des Reichskriegsgerichts, S. 411; Haase, Reichskriegsgericht, S. 72). Rottka gehört damit zu der sehr kleinen Minderheit von Richtern, die im „Dritten Reich“ aus Gewissensgründen ihre Mitwirkung an einer zunehmend verbrecherischen Justiz aufkündigten.

266 Vgl. Jentsch, Ernstfälle, S. 19lff.; Bredemeier, Kriegsdienstverweigerung, S. 165f.

267 Nach dem Bericht von Jentsch hatte die Anfertigung der Broschüre ,,mehr oder weniger getarnt zu geschehen, da die ganze Sache ja praktisch als eine Auflehnung gegen den ,Führerbefehl " verstanden werden mußte" (Jentsch, Wehrdienstfrage, S. 13). Nachdem die Schrift im zweiten Entwurf im Sommer 1944 fertiggestellt war, sei sie „heimlich in den Kellern des Gefängnisses von Zelle zu Zelle gewandert". Das bei Jentsch sehr positiv gezeichnete Bild von den Richtern am RKG („Männer, die nicht mit ruhigem Gewissen zusehen konnten“) und die Darstellung einer demnach beinahe als Widerstandshandlung anmutenden Tat haben dazu geführt, daß dieser Vorgang in der einschlägigen Literatur immer wieder zu Entlastungszwecken benutzt worden ist. So hat sich beispielsweise Jürgen Schreiber 1988 auf den Bericht von Jentsch gestützt, um „den Behauptungen von Messerschmidt-Wüllner von der 
Diese in Briefform gehaltene Schrift, deren zweiter Entwurf 1944 zur Verbreitung gelangte, nachdem er ,von Beamten des Reichskriegsgerichts, dienstlich' gelesen und abgezeichnet“ 268 worden war, sollte dem ,Angefochtenen helfen, vom Studium des Wortes Gottes her eine gründliche Überprüfung seines Standpunktes vorzunehmen“269. Das „,bedrückende Bild“, so urteilte Admiral Bastian im Rückblick, habe jedoch auch diese Denkschrift ,nicht zu ändern“ vermocht ${ }^{270}$.

Neben seelische Torturen (längere Unterbringung in „Todeszellen“) 271 und Drohungen beispielsweise mit dem Vollzug juristischer Sanktionen gegen die Familie des jeweils Betroffenen (Wegnahme der Kinder durch Sorgerechtsentzug ${ }^{272}$ ) traten noch subtilere Formen der „Einwirkung“. So wurde versucht, bereits Verurteilte durch Hinzuziehen von Familienangehörigen noch zu einem Sinneswandel zu bewegen $^{273}$. Dies geschah in der Hoffnung, daß in der direkten Konfrontation mit den Ehefrauen, Kindern oder anderen Verwandten und in Situationen, die letzten Abschiedsszenen gleichkamen, die Betreffenden sich ,erweichen" lassen würden. Zwar ging dieses Kalkül insofern auf, daß insbesondere die Verwandten, die nicht den Zeugen Jehovas angehörten, häufig von sich aus mit massivem Bitten und Flehen, aber auch mit Vorwürfen auf die Inhaftierten einzuwirken versuchten und tatsächlich in Einzelfällen „die Todeskandidaten“ diesem Druck dann nachgaben, aber andererseits wurden - wie Gerichtspräsident Bastian vermerkte - damit auch „,seltsame Erfahrungen“ gemacht: „Es kam nicht selten vor, daß die Angehörigen die Beschuldigten ermahnten, unter allen Umständen fest zu bleiben, sich nicht weich machen zu lassen und lieber den Tod hinzunehmen als ,umzufallen“" 274

Eine derartige Haltung beruhte darauf, daß es für die Zeugen Jehovas etwas noch Schlimmeres als den Tod auf Erden gab: nämlich den als Folge der Untreue zu erleidenden ,wirklichen“ Tod. Elise Harms, deren Mann Johannes im Alter von 30 Jahren am 8. Januar 1941 in Brandenburg-Görden enthauptet wurde, erinnerte sich der Eindrücke, als sie die Todesbenachrichtigung erreichte: „Ich war mir darüber im klaren, was für eine schwere Zeit er durchgemacht hatte, in der ich ihm

Brutalität und Gnadenlosigkeit der Kriegsgerichte" entgegenzutreten (Schreiber, Wehrmachtjustiz - Anmerkungen, S. 104).

269 Ebenda. Vgl. die kommentierte Wiedergabe von Textauszügen in Jentsch, Ernstfälle, S. $240 f f$. Die 1943 abgefaßte Broschüre bildete die Grundlage für eine Abhandlung über „,Die Wehrfrage im Neuen Testament", die der spätere Professor für Praktische Theologie Werner Jentsch 1952 in seinem Buch über die „Wehrdienstfrage“ auf den Seiten 17 bis 84 veröffentlicht hat. Dort zeigt sich, daß Jentsch, der auf diese Weise die kriegsdienstverweigernden Zeugen Jehovas vor dem Tode zu retten versuchte, noch wesentlich in der kirchlichen Tradition verankert war, nach der es die Pflicht des Christen sei, dem Ruf der Obrigkeit zu den Waffen zu folgen.

BA-MA, N 192/1, Max Bastian, Lebenserinnerungen (1956), S. 57.

271 Vgl. Zipfel, Kirchenkampf, S. 199, Anm. 58.

272 Vgl. den in Kap. 3 (siehe S. 208f.) geschilderten Fall der Süderbraruper Familie Appel.

273 Berichte über derartige Einwirkungsversuche sind beispielsweise veröffentlicht in: Jahrbuch 1974, S. 122; Jahrbuch 1989, S. 119; Der Wachtturm, 1.3.1987, S. 22.

274 BA-MA, N 192/1, Max Bastian, Lebenserinnerungen (1956), S. 57. Die Inhaftierten in ihrem Entschluß zu bestärken, konnte eine Bestrafung wegen „Wehrkraftzersetzung“" zur Folge haben. Beispielsweise wurde Wilhelm Blaschek vom SG Wien am 11.8.1941 zu vier Jahren Haft verurteilt, weil er sechs Tage vor der RKG-Verhandlung gegen seinen Freund Franz Zeiner diesen mit einem Brief ermunterte, „stark im Glauben“ $\mathrm{zu}$ sein und „auf den Herrn Jesu“" zu vertrauen. Das Sondergericht sah darin eine Beihilfe zur Wehrdienstverweigerung. Vgl. Neugebauer, Wien, S. 182; Jahrbuch 1989, S. 122 f. 
nur wenig helfen konnte. Als ich daher die Nachricht von seiner Hinrichtung erhielt, war ich erleichtert zu wissen, daß es jetzt vorbei war. [...] Mein einziger Gedanke war nur: Jetzt können sie ihn nicht mehr umstimmen. Es gibt keine Gefahr mehr, daß er untreu werden könnte. Er ist bis zum Tode treu geblieben." 275

Die Verweigerungshaltung beizubehalten und keinen „Kompromiß“ zu schließen - in einigen Fällen wurde den Todeskandidaten von den Kriegsrichtern noch im Bestätigungsverfahren das Angebot unterbreitet, bei Widerruf für eine Truppenverwendung im waffenlosen Dienst Sorge tragen zu wollen ${ }^{276}$-, wurde von den Zeugen Jehovas als Sieg über die satanischen Mächte empfunden, da sie durch die Bewahrung ihrer „Lauterkeit" auch in schwierigsten Zeiten ein Zeichen dafür setzen wollten, daß die Gewalt Satans die Kraft des Glaubens nicht zu brechen vermag 277. Ihr ganzes Streben zielte deshalb darauf, durch ihre Standhaftigkeit ,zur Rechtfertigung des Namens Jehovas beizutragen“. Die Bemühungen der Richter, sie zur Kriegsteilnahme zu bewegen, galten ihnen somit als Versuch, ,die treuen Zeugen Gottes in die Falle zu locken"278.

Von der Schwere des inneren Kampfes, dem sich die Zeugen Jehovas stellten, legen die Briefe Zeugnis ab, die sie im Angesicht des Todes an ihre Angehörigen richteten. Im letzten Brief von Johannes Harms, den er an seinen im KZ Sachsenhausen einsitzenden Vater richtete, heißt es:

„Und nun ist auch mir Gelegenheit gegeben, dem Herrn gegenüber die Treue zu beweisen, ja die Treue nicht nur bis an den Tod, sondern bis in den Tod. Schon jetzt ist das Todesurteil gegen mich ausgesprochen, ich liege Tag und Nacht in Fesseln [...], aber ich habe noch nicht bis aufs Blut widerstanden. Das [Wider-]Stehen wird einem Zeugen Jehovas nicht so leicht gemacht. So ist auch mir immer noch die Möglichkeit gegeben, mein irdisches Leben zu retten, um das wirkliche Leben zu verlieren. Ja sogar angesichts des Schafotts wird dem Zeugen Jehovas nochmals Gelegenheit gegeben, seinen Bund zu brechen. Darum bleibt auch der Kampf für mich noch bestehen, und auch ich habe noch viele Siege zu erringen, um sagen zu können: ,Ich habe den Kampf gekämpft, ich habe den Glauben bewahrt, fortan liegt mir bereit die Krone der Gerechtigkeit, welche Gott, der Gerechte, geben wird. ' Der Kampf ist zweifelsohne schwer, ich bin aber dem Herrn von ganzem Herzen dankbar, daß er mir auch jetzt angesichts des Todes, eine Freudigkeit gegeben hat, die ich gern mit allen meinen Lieben teilen möchte. [...] Mein lieber Vater, im Geiste rufe ich Dir zu, bleibe auch Du treu, wie ich mich bemühe, treu zu sein, dann werden wir uns wiedersehen."279

$\overline{275}$ Elise Harms: Nach einem tragischen Verlust ausharren, in: Der Wachtturm, 15.1.1982, S. 26-30 (27). Zur gut dokumentierten Biographie des aus Wilhelmshaven gebürtigen Johannes Harms vgl. Fahle, Verweigern, S. 154f.; Heuzeroth/Wille, Lila Winkel, S. 203-207.

276 Vgl. Hartmann, Kriegsdienstverweigerung (1986), S. 79; Heuzeroth/Wille, Lila Winkel, S. 203; Scharf, Widerstehen, S. 42f. Derartige von Kriegsrichtern in einzelnen Fällen geäußerte „Angebote“ standen im Widerspruch zu den vom OKW erlassenen ,Richtlinien für Strafverfahren gegen ernste Bibelforscher usw." (IfZ, MA 333, 657687-89), die bestimmten, daß für eine Wiederaufnahme die Abgabe einer „glaubhaften“ Erklärung Voraussetzung sei, in der sich der Betreffende verpflichte, , in vollem Umfange Wehrdienst zu leisten“.

277 Zu den Beweggründen vgl. Jahrbuch 1974, S. 182-191 (Berichte deutscher Kriegsdienstverweigerer); Jahrbuch 1989, S. 119-123 (Berichte österreichischer Kriegsdienstverweigerer).

278 „Beantwortung einiger Fragen. Mitteilungsblatt der deutschen Verbreitungsstelle des W.T.“, Juli 1942 (Kopie in Besitz des Verf.). Siehe auch S. 332f.

279 Johannes Harms, Schreiben vom 9.11.1940 an seinen Vater Martin Harms, zit. nach Heuzeroth/Wille, Lila Winkel, S. 204f. 
Für viele kriegsdienstverweigernde Zeugen Jehovas bedeutete die Hinrichtung eine Art Erlösung, denn nun war der ungeheure seelische Druck genommen; auf ihnen lastete nicht mehr die Frage, ob sie standhaft bleiben und die „Prüfung“ bestehen würden. Die inneren Kämpfe und Anfechtungen, vor allem hervorgerufen durch die Gedanken an die Familie und die Not, die man seinen Liebsten bereiten würde, hatten nun ein Ende. Der 24jährige Franz Mattischek aus Wolfsegg (Oberösterreich) schrieb am 1. Dezember 1939, wenige Stunden vor der für den Morgen des nächsten Tages angesetzten Hinrichtung, an seine Familie: „Ihr werdet ja auch erleichtert aufatmen, wenn ich zur göttlichen Ruhe gelangt bin. Denn ich habe mich ja einerseits schon danach gesehnt, denn viel habe ich erlebt, besonders die letzten Monate. Aber wenn ich nun vor Jehova Gnade gefunden habe, so ist alles gut."280 Ein Glaubensbruder faßte seine Empfindungen in die Worte: „Ach, könnte ich aber in dieser Welt nach der Verleugnung unseres Herm Jesus Christus noch einmal glücklich werden? - Nie! Aber so habt Ihr die Gewißheit, daß ich glücklich und in Frieden von dieser Welt scheide [...]. Die Entscheidung ist gefallen. Alles Schwere, alles Leid ist überwunden!" 281

Der durchgestandene Kampf und die Auferstehungshoffnung gaben den Zeugen Jehovas die Kraft zu jener aufrechten Haltung, die gleichermaßen bei ihren Mitgefangenen wie bei den Wehrmachtrichtern einen tiefen Eindruck hinterließ und von der auch die Berichte der sie auf den letzten Weg begleitenden Seelsorger zeugen $^{282}$. Sie starben in der Gewißheit, daß der Tod bald überwunden sein werde, und in der Erwartung der Wiedervereinigung mit den Angehörigen in dem ihnen bereits vor Augen stehenden tausendjährigen Friedensreich Gottes.

Diejenigen Zeugen Jehovas aber, die dem auf sie lastenden Druck nachgaben und sich schließlich zum Wehrdienst bereit erklärten, wurden unter Zubilligung eines „minder schweren Falles“ der „Wehrkraftzersetzung“ in der Regel ,lediglich“ zu Gefängnisstrafen von ein bis drei Jahren verurteilt, wobei die Strafvollstreckung bis zur Beendigung des Krieges ausgesetzt wurde. Auf eine Gefängnisstrafe erkannten die Wehrmachtrichter, da diese die Aussetzung zur „Feindbewährung" und damit die Überstellung des Kriegsdienstverweigerers zur "tätigen Reue“ in eine frontnahe Strafformation der Wehrmacht ermöglichte ${ }^{283}$. Die harten Bedingungen und die gefahrvollen Kriegseinsätze, denen die Straf- und Bewährungsbataillone

$\overline{280}$ Der Abschiedsbrief ist veröffentlicht bei Steiner, Österreich, S. 127-130. Zum Schicksal des am 10.11.1939 vom RKG zum Tode verurteilten Franz Mattischek vgl. Vogl, Widerstand, S. 172; Zinnhobler, Oberösterreich, S. 202f.

281 Zit. nach „Du hast mich heimgesucht“, S. 342.

282 Hanns Lilje, der mit Zeugen Jehovas während seiner Haft Ende 1944 im Berliner GestapoGefängnis in Kontakt kam, spricht davon, daß sie ,wahrhaft unbekümmert in den Tod gingen“ (Lilje, Im finstern Tal, S. 59). Werner Jentsch befand: „Sterben war hier wirklicher Tod. Und gerade deswegen meine innere Achtung! Hätten die Hunderte von Bibelforschern, die in jenen Jahren starben, nur plumpe Angst gehabt, sie wären bald umgefallen. $\mathrm{Da} B$ sie aber angesichts des Schafotts noch geradestanden und strahlend in den Tod gingen, war und ist mir ein Zeichen, daß es sich hier um Leute handelte, die nicht ohne Jesus waren." (Jentsch, Wehrdienstfrage, S. 183)

283 In einem Schreiben vom 15.8.1944 erklärte der Chef des OKW unter Verweis auf die wehrmachtgerichtliche Praxis, bei Widerruf der Kriegsdienstverweigerung die Vollstreckung der Strafe regelmäßig „zur Feindbewährung“ auszusetzen, daß bei Bibelforschern „die Erfahrung mit der Strafaussetzung gut" sei (IfZ, MA 333-657692). 
ausgesetzt wurden, führten dazu, daß die Zahl der Opfer auch unter jenen Zeugen Jehovas hoch war, die unter dem Druck der Kriegsgerichte ihre Verweigerungshaltung aufgegeben und sich schließlich zum Militärdienst bereit gefunden hatten.

Mit der Verhängung einer Zuchthausstrafe wäre hingegen die Ausstoßung aus der Wehrmacht wegen „Wehrunwürdigkeit“ verbunden gewesen. Wehrmachtgerichtlich zu Zuchthausstrafen Verurteilte wurden zur „Freiheitsentziehung auf unbestimmte Zeit" an die Reichsjustizverwaltung überstellt ${ }^{284}$, die die Betreffenden zumeist in den emsländischen Straflagern unterbrachte ${ }^{285}$. Da diese an sich härtere Strafzuerkennung zugleich die Verschonung vom Wehrdienst bedeutete ${ }^{286}$, wurde sie als dem „Strafzweck“ zuwiderlaufend bei „widerrufener Wehrdienstverweigerung" grundsätzlich nicht ausgesprochen.

Von daher erkannte das Reichskriegsgericht bei Zeugen Jehovas überhaupt nur in wenigen Fällen auf eine Zuchthausstrafe. Dieses war zunächst bei der kleinen Zahl der Kriegsdienstverweigerer der Fall, denen - beispielsweise aufgrund des $\S 51$ Abs. 2 StGB - auch ohne Widerruf Strafmilderung zuteil wurde. Ebenfalls wurde in einigen besonders gelagerten Verfahren, in denen bei Wehrdienstverweigerung, ohne daß ein Widerruf vorlag, ein Gnadenerweis erfolgte, eine Umwandlung der Todesurteile auf langjährige Zuchthaustrafen verfügt.

Die Zahl der nach wehrmachtgerichtlichem Urteil in den Emslandlagern inhaftierten Zeugen Jehovas war aus den genannten Gründen recht klein. Doch diejenigen Kriegsdienstverweigerer, die in diesen harten Straflagern für kriegsgerichtlich Abgeurteilte einsaßen, wurden von den Wachmannschaften besonders schikaniert und geschunden 287 .

\section{Strafeinsatz, Fahnenflucht, Wehrmachtdienst}

Erst gegen Kriegsende wurde die alleinige Zuständigkeit des Reichskriegsgerichtes für Verfahren gegen Zeugen Jehovas und andere religiöse Dienstverweigerer aufge-

$\overline{284}$ Die vom OKW am 30.9.1939 erlassenen „Richtlinien für die Strafvollstreckung im Kriege und bei besonderem Einsatz" (BA-MA, RH 14/22, Bl. 70f.) bestimmten, daß auf wehrmachtgerichtlich verhängte Zuchthausstrafen die in die Zeit des Kriegszustands fallende Vollzugszeit nicht anzurechnen war, da die Strafverbüßung erst nach Kriegsende erfolgen sollte. Gemäß der Ausführungsbestimmungen vom 3.11.1939 waren die Betroffenen deshalb von den Behörden der Reichsjustizverwaltung zur „Verwahrung ohne Anrechnung auf die Freiheitsstrafe" in besondere Straflager einzuweisen. Vgl. Wüllner, NS-Militärjustiz, S. $780 f$.

Ab Herbst 1939 wurde Esterwegen von der Reichsjustizverwaltung zum Zweck der Unterbringung kriegsgerichtlich Verurteilter benutzt. Im Sommer 1940 kamen weitere Gefangenenlager des Emslandes und ab 1942 die neu erbauten Lager Bernau (Oberbayern), Elberegulierung (Coswig), Rodgau (Dieburg) und Zweibrücken hinzu (vgl. Ausländer, Militärstrafgefangene, S. 165ff.; Kosthorst/Walter, Konzentrations- und Strafgefangenenlager, S. 234-240; Suhr, Emslandlager, S. 50-54, 167f.).

286 Wenn auch durch die mögliche Einbeziehung in die Bewährungstruppe 500 (mit „Führererlaß" vom 21.12.1940 für straffällig gewordene Soldaten gebildet) und durch die im Herbst 1944 gebildeten Zuchthauskompanien der Feldstrafgefangenenabteilungen zahlreiche aus der Wehrmacht ausgestoßene ,wehrunwürdige“ Soldaten nach Verleihung des Status der , bedingten Wehrwürdigkeit" erneut zum Kriegsdienst herangezogen wurden, so bedeutete doch für wehrmachtgerichtlich abgeurteilte Zeugen Jehovas eine Zuchthausstrafe und damit die Straflagerverwahrung die einzige Möglichkeit, den Krieg zu überstehen, ohne in der Truppe dienen zu müssen.

287 Vgl. Frese, Bremsklötze, S. $79 f$. 
hoben. In einem Bericht vom 7. Juni 1944 teilte der Präsident des Reichskriegsgerichtes dem Chef des Oberkommandos der Wehrmacht mit, daß sich beim obersten Wehrmachtgericht in der Frage der Strafverfahren gegen „Ernste Bibelforscher“ eine feststehende Rechtsprechung herausgebildet habe, die es möglich erscheinen lasse, das Reichskriegsgericht von der Durchführung derartiger Verfahren in $\mathrm{Zu}$ kunft zu entlasten. Zwei Monate später übersandte er eine detaillierte Auflistung, die die Grundsätze darstellte, nach denen diese Verfahren beim Reichskriegsgericht behandelt wurden ${ }^{288}$. Mit Schreiben vom 15. August 1944 ersuchte der Chef des Oberkommandos der Wehrmacht unter abschriftlicher Beifügung der Grundsätze des Reichskriegsgerichtes die Oberkommandos der drei Wehrmachtteile (Heer, Kriegsmarine, Luftwaffe) sowie den Chef des Hauptamtes SS-Gericht und den SSRichter beim Reichsführer-SS um Stellungnahme zu der Frage, ob Bedenken gegen eine Abgabe der gegen Bibelforscher und andere religiöse Dienstverweigerer gerichteten Verfahren an die Feldkriegsgerichte unter der Voraussetzung bestünden, daß für diese die beim Reichskriegsgericht entwickelten Grundsätze zum verbindlichen Maßstaß erklärt werden würden. Das Oberkommando der Wehrmacht sei geneigt, dem Wunsch des Reichskriegsgerichtes zu entsprechen und ,den Obersten Gerichtshof der Wehrmacht von der weiteren Verfolgung und Aburteilung der Bibelforscher zu entlasten“, zumal mit dieser „Dezentralisation“ zugleich eine Vereinfachung der Verwaltung verbunden wäre 289.

Nachdem bis zum angegebenen Stichtag (31.8.1944) keine Bedenken vorgebracht worden waren 290 - auch das Reichssicherheitshauptamt stimmte den Verfahrensrichtlinien ohne Einwände $\mathrm{zu}^{291}$-, verfügte das Oberkommando der Wehrmacht Anfang September 1944 eine entsprechende Regelung. Damit war der Erlaß vom 18. Mai 1940 aufgehoben, der die ausschließliche Zuständigkeit des Reichskriegsgerichtes in Fällen, in denen Kriegsdienstverweigerer nach ihrem Gewissen oder religiösen Vorschriften handelten, begründet hatte. Nun konnten alle Verweigerungsfälle von den Feldkriegsgerichten bei den Wehrmachtkommandanturen oder den betreffenden Divisionen abgeurteilt werden. Den Gerichten wurde zur Sicherstellung der Einheitlichkeit der Rechtsprechung ein Merkblatt „Richtlinien für Strafverfahren gegen ernste Bibelforscher usw.“ zugestellt, das im Wortlaut nur unwesentlich von den Grundsätzen des Reichskriegsgerichtes abwich. Im Merkblatt, das die Verfahren in acht verschiedene Fallgruppen gliederte und in der Verfahrensweise beispielsweise zwischen einem Widerruf vor der Hauptverhandlung, vor der Urteilsbestätigung und vor der Vollstreckung genau unterschied, heißt es unter anderem:

„1.) Hat der Wehrpflichtige dem Einberufungsbefehl Folge geleistet, weigert er sich jedoch, den Fahneneid und Wehrdienst zu leisten, so wird gegen ihn, falls er trotz aller Belehrungen bis zum Schluß der Hauptverhandlung dabei verbleibt, gemäß $\S 5$ Abs. 1 Ziff. 3 KSSVO auf Todesstrafe

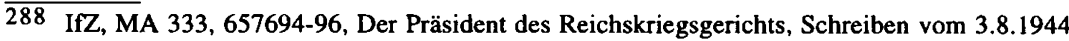
an den Chef des OKW.

289 IfZ, MA 333, 657692, Der Chef des OKW, Schreiben vom 15.8.1944.

290 Vgl. Bredemeier, Kriegsdienstverweigerung, S. 78.

291 IfZ, MA 333, 657690, RSHA, Fernschreiben vom 30.9.1944 an den SS-Richter beim Reichsführer-SS. 
und ferner auf Verlust der Wehrwürdigkeit und dauernden Verlust der bürgerlichen Ehrenrechte erkannt. [...] 7.) Erklärt der Wehrpflichtige vor der Bestätigung des Todesurteils, er sei nunmehr bereit, in vollem Umfange Wehrdienst zu leisten, und erscheint dieser Widerruf glaubhaft, so wird das Urteil aufgehoben. Zuvor wird er in der Regel nochmals richterlich gehört, um festzustellen, ob der Widerruf auf einer wirklich inneren Umstellung beruht oder nur aus Angst vor der Vollstreckung des Todesurteils erklärt wurde. Das neue Urteil lautet dann in der Regel auf eine Gefängnisstrafe von 1 bis 3 Jahren." 292

Den Richtern der Feldkriegsgerichte waren mit diesen durch das Reichskriegsgericht entwickelten Grundsätzen klare Handlungsvorgaben gesetzt. Ihre „Rechtsfindung“" konnte sich im Grunde auf die Frage beschränken, welcher Fallgruppe der Angeklagte zuzuordnen sei. Selbst die Urteilsbegründung war ihnen vorformuliert worden:

„Die Verurteilung zur Todesstrafe wird meist damit begründet, daß ein Wehrpflichtiger, der hartnäckig an seinem ablehnenden Standpunkt festhalte, die ihm seinem Volke gegenüber obliegende Treuepflicht aufs schwerste verletze, wodurch er sich aus der Volksgemeinschaft selbst ausschließe; zudem sei sein Verhalten wegen der ihm innewohnenden gefährlichen Werbekraft besonders geeignet, auf andere zersetzend zu wirken."

Auch die vergleichsweise wenigen Zeugen Jehovas, die nach einem Strafgerichtsurteil als „Wehrunwürdige“ vom „Ehrendienst" in der Wehrmacht ausgeschlossen worden waren, blieben nicht von der Einberufung zum Kriegsdienst verschont. Die Wehrmachtführung, die seit spätestens Anfang 1942 aus ihrem Interesse an dringend benötigten neuen Reserven auch die Heranziehung von ,Wehrunwürdigen" erwogen hatte, ordnete mit Verfügung vom 2. Oktober 1942 die Aufstellung der „Bewährungstruppe 999 “ an. Den zu dieser Truppe einberufenen Personen wurde bei Erhalt des Gestellungsbefehles mitgeteilt, daß sie für die Dauer des Krieges als ,wehrwürdig (bedingt wehrwürdig)“ gelten würden; man zog ihren „Ausschließungsschein" ein und händigte ihnen an seiner Statt einen Wehrpaß aus $^{293}$. Noch im Oktober 1942 erfolgten die ersten Einberufungen zum auf dem Truppenübungsplatz Heuberg bei Stetten (Schwäbische Alb) stationierten Ersatzund Ausbildungsbataillon 999.

Der österreichische Zeuge Jehovas Franz Oswald, der am 26. September 1940 wegen „Teilnahme an einer wehrfeindlichen Verbindung“ durch Urteil des Sondergerichtes St. Pölten zu zwei Jahren Zuchthaus verurteilt und anschließend zur „Verwahrung“ ins Straflager „Elberegulierung“ in Griebo (bei Coswig) eingeliefert worden war, erhielt dort am 15. November 1942 nach Wiederverleihung der ,Wehrwürdigkeit" den Einberufungsbefehl zum Bewährungsbataillon ${ }^{294}$. Auf dem Übungsplatz Heuberg erklärte er, daß er ,aus Glaubensgründen nicht Soldat werden könne“. Der Untersuchungsrichter des Gerichtes der Afrikabrigade 999, vor

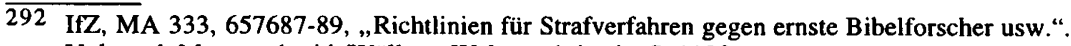
Vgl. auch Messerschmidt/Wüllner, Wehrmachtjustiz, S. $110 \mathrm{f}$.

293 Vgl. Klausch, Bewährungsbataillone, S. 67ff.; Die Sondereinheiten, S. 29-32.

294 Vgl. Die mit dem blauen Schein, S. 50f.; Hartmann, Kriegsdienstverweigerung (1986), S. 64-67; Vogl, Widerstand, S. 160f. 
dem Oswald auf seiner Ablehnung des Kriegsdienstes beharrte, gab das sofort eingeleitete Verfahren an das Reichskriegsgericht ab, das den 34jährigen Zeugen Jehovas am 6. April 1943 wegen ,Zersetzung der Wehrkraft" zum Tode verurteilte.

Urteilsvollstreckungen gegen Zeugen Jehovas, die nach Einberufung zur Bewährungseinheit dort den Waffengebrauch verweigerten, fanden vielfach nicht in einer Richtstätte, sondern - vermutlich zu Abschreckungszwecken - ,im Angesicht der Truppe“ durch Erschießungen auf dem Heuberg statt ${ }^{295}$. Der Hamburger Kommunist Herbert Baade, der nach einer Verurteilung wegen „Vorbereitung zum Hochverrat“ als ,,wehrunwürdig“" galt, wurde Ende 1942 einberufen. In der Gruppe von Neuankömmlingen, mit denen er gemeinsam die Ausbildung auf dem Truppenübungsplatz Heuberg/Stetten absolvieren sollte, befand sich damals auch ein Zeuge Jehovas. Dieser weigerte sich bereits beim Kleiderempfang, auch nur die Uniform entgegenzunehmen. Er erklärte, daß er als „Christ“ so etwas nicht anziehen werde. Daraufhin sei er weggeholt worden. Nach kurzer Zeit sei verkündet worden, daß der Zeuge Jehovas zusammen mit noch zwei anderen Glaubensgenossen zum Tode verurteilt worden sei, weil sie ,das Ehrenkleid der Nation“ abgelehnt hatten. Über die Vollstreckung berichtet Herbert Baade: „Die drei Bibelforscher sind erschossen worden, wir mußten da zugucken, wie die erschossen worden sind. Und die haben dann ein Lied gesungen: ,Ziehen wir nun nach Kapernaum hinein.““296

Doch nicht alle wehrpflichtigen Zeugen Jehovas, die noch in „Freiheit“ waren, praktizierten die Kriegsdienstverweigerung als einen gegenüber den Militärbehörden offen demonstrierten Bekenntnisakt, bei dem unbeugsamen Verweigerern das Todesurteil gewiß sein konnte, sondern sie suchten - verständlicherweise nach Möglichkeiten, ihren Glauben zu wahren, sich der Kriegsteilnahme zu entziehen und gleichzeitig dem ,sicheren Todesurteil“" aus dem Weg zu gehen, wobei ihr Verhalten ebenfalls großen Mut erforderte und ein hohes Risiko barg. Zwar war diese Handlungsweise innerhalb der Bibelforschervereinigung nicht unumstritten, da nach Überzeugung zumindest der radikaleren Kräfte von einem Zeugen Jehovas die offene und öffentlich gegenüber dem „Cäsar“ bekundete Verweigerung gefordert war ${ }^{297}$, während andere Formen der Kriegsdienstentziehung als ,fauler Kom-

295 Die genaue Zahl der bei der Bewährungstruppe 999 erschossenen Bibelforscher ist nicht bekannt. Eine Liste der auf dem Truppenübungsplatz Heuberg vom 12.12.1942 bis 17.11.1943 Hingerichteten weist insgesamt 37 Personen aus (Klausch, Bewährungsbataillone, S. 220). Hans-Peter Klausch geht davon aus, ,, daß während der Ausbildung in Deutschland zumindest im ersten Jahr des Bestehens der 999er Einheiten von den weltanschaulichen Gegnern des Nationalsozialismus die Bibelforscher die meisten Opfer an Menschenleben lassen mußten" (ebenda, S. 234). Dabei ist jedoch zu berücksichtigen, daß unter den Erschossenen „weltanschaulich" Motivierte die Minderzahl gestellt haben dürften. Die Zahl der Zeugen Jehovas, die auf dem Heuberg exekutiert wurden, wird insgesamt nicht sehr groß gewesen sein.

296 EB Herbert Baade, 26.1.1986. Nach der Evangelienüberlieferung hat Jesus während seines Auftretens in Kapernaum die eschatologische Verheißung kundgetan, daß die Gläubigen im Gottesreich mit den Erzvätern Israels zu Tisch sitzen werden. Vgl. Mt 8, $11 \mathrm{f}$.

297 Diese Haltung konnte sogar so weit gehen, daß einzelne Zeugen Jehovas den Wehrdienst selbst dann verweigerten, wenn er von ihnen gar nicht gefordert wurde: Obgleich bei der Musterung für untauglich erklärt und von daher von der Wehrdienstleistung befreit, bekannte sich z. B. der wegen Betätigung für die IBV verhaftete Johann Oswald aus Thürnthal, der jüngere Bruder von Franz Oswald, vor dem Ermittlungsrichter zur Kriegsdienstverweigerung. Bei seiner Aburteilung durch das SG St. Pölten im Herbst 1940 zu zwei Jahren Zuchthaus wirkte dieses Bekenntnis strafverschärfend. Vgl. Mitterrutzner, Niederösterreich, S. 276, $285 f$. 
promiß“ und Ausdruck von „Furchtsamkeit“ verworfen wurden ${ }^{298}$, doch gleichwohl wurden beispielsweise jene, die untertauchten, von vielen Glaubensgeschwistern nach Kräften unterstützt.

Vom Einberufungstage an, an dem diese sich dem Dienst entziehenden Zeugen Jehovas nicht bei der Truppe erschienen, galten sie als „Fahnenflüchtige“; wer ihnen half, machte sich der „Beihilfe zur Fahnenflucht" schuldig. So wurde beispielsweise Heinrich Finke aus Wulferdingsen (Westfalen), der eine Zeitlang seinen Glaubensbruder Hans Baumgart verbarg und erst entdeckt wurde, als er Baumgart in ein anderes Versteck bringen wollte, vom Sondergericht Bielefeld wegen Beihilfe zu drei Jahren Zuchthaus verurteilt ${ }^{299}$. Die österreichische Bibelforscherin Andrea Haas versuchte ihren Mann bei Erhalt des Gestellungsbefehls Ende Mai 1940 dadurch zu schützen, daß sie dem Wehrmeldeamt falsche Angaben über seinen Aufenthaltsort übermittelte. Aus diesem Grunde und weil sie für ihren Mann ein Versteck in einer Schrebergartenhütte besorgt hatte, wurde sie im Dezember 1941 wegen Beihilfe zur Wehrdienstentziehung vom Sondergericht Wien abgeurteilt. Ihre Bemühungen waren jedoch vergeblich geblieben, denn ihr Mann wurde gefaßt und am 5. März 1942 vom Reichskriegsgericht zum Tode verurteilt ${ }^{300}$. Der auf der Nordseeinsel Norderney wohnhafte Harm Buß, der sich 1935 im Alter von 31 Jahren den Zeugen Jehovas angeschlossen hatte und einige Monate in Esterwegen inhaftiert gewesen war, erhielt den Einberufungsbefehl 1939301. Er schickte ihn mit dem Bemerken zurück, er denke, daß ehemalige KZ-Insassen wehrunwürdig seien. Der Einberufung leistete er dann zunächst Folge, erklärte aber, daß er einen Eid auf Hitler nicht leisten könne und werde. Noch bevor die Vereidigung stattfand, wurde er mit seiner Pioniereinheit an die Weichsel südlich von Warschau verlegt. Am achten Tag seiner Wehrmachtzugehörigkeit sollte er dort den Fahneneid leisten. Wenige Stunden vor dem angesetzten Vereidigungstermin setzte sich Harm Buß über den Kasernenzaun ab. Von Polen aus schlug er sich zu Fuß bis in seine oldenburgische Heimat durch. Unterwegs verhalfen ihm einige Polen zu etwas Zivilkleidung. Nachts marschierte er, tagsüber hielt er sich verborgen. Schließlich erreichte er seinen Geburtsort Nesse (Landkreis Oldenburg). Dort verbarg er sich fünf Jahre lang auf dem Dachboden des Elternhauses. Zwar suchten die Polizei und die Feldgendarmerie bei seiner Frau auf Norderney, in Nesse geschah dem Mann jedoch nichts.

$\mathrm{Zu}$ den Untergetauchten zählten auch einige, die nach vorangegangener Entlassung aus der KZ-Haft zur Wehrmacht einberufen worden waren ${ }^{302}$. Der 36jäh-

298 Siehe S. 332f.

299 Struckmeier, Eickhorst, S. 23.

300 Vgl. Lichtenegger, Bibelforscher, S. 188; Neugebauer, Wien, S. 183.

301 Vgl. Fahle, Verweigern, S. 156-158.

302 Vgl. Hartmann, Kriegsdienstverweigerung (1986), S. 60; BA, Z Sg. 134/28, o. B1. (zu Horst H.). Es ist auch ein Fall bekanntgeworden, in dem ein Zeuge Jehovas, der im Jahre 1941 bei der Gestapo die „,Verpflichtungserklärung" unterzeichnet hatte und daraufhin aus der Schutzhaft entlassen worden war, dennoch anschließend den Kriegsdienst offen verweigerte. Nach seiner Einberufung im September 1943 meldete er sich befehlsgemäß bei der zuständigen Einheit. Dort gab er eine schriftliche Erklärung ab, daß er die Militärdienstpflicht verweigere, da er sich verpflichtet habe, „die göttlichen Gesetze zu respektieren“ und sich „vor der Welt 
rige Bremer Kraftfahrer Albert Trey, der als IBV-Zellenleiter zu zwei Jahren Gefängnis verurteilt und anschließend in den KZ Sachsenhausen, Neuengamme und Dachau inhaftiert worden war, entzog sich sofort nach seiner im Juli 1941 erfolgten Entlassung aus der KZ-Haft der Einberufung durch Untertauchen bei Glaubensgeschwistern in Bremen, wo er sich hauptsächlich auf deren Parzellen verbarg ${ }^{303}$.

Gegen Kriegsende mehrte sich die Zahl der Zeugen Jehovas, die untertauchten, um sich auf diese Weise dem Zugriff der Wehrmacht zu entziehen. Bruno Knöller zum Beispiel, der nach wiederholten Musterungen aufgrund einer Krankheit als ,zeitlich untauglich zurückgestellt bis 31.12.44“ galt, erhielt Ende 1944 ohne erneute Nachmusterung einen Gestellungsbefehl ${ }^{304}$. Nachdem er sich daraufhin auf Anraten einer Ärztin zum Wehrbezirkskommando in Heilbronn begeben hatte, um selbst eine Nachmusterung zu beantragen, wurde ihm dort von einem wohlgesonnenen Wehrmachtsbeamten ein Schreiben des Ortsgruppenleiters seines Heimatortes Simmozheim (bei Pforzheim) gezeigt, in dem ausgeführt stand, daß die Bevölkerung sich darüber empören würde, daß der 22jährige Bibelforscher ,noch im Land sei, während andere fürs Vaterland kämpfen und sterben". Der Beamte habe jedoch die erneute Nachmusterung angeordnet und ihm noch einen Rat gegeben. Er solle zunächst die Musterungsaufforderung abwarten und sich acht Tage später in Heilbronn abmelden. Bevor er sich dann, wie bei der Abmeldung angegeben, an einem anderen Wohnort wieder anmelde, solle er sich einige Tage Zeit lassen. Nach weiteren vierzehn Tagen solle er sich anschließend wieder zurück nach Heilbronn melden. Bruno Knöller befolgte den Rat und gewann auf diese Weise etwas Zeit, bis auch dieses Ausweichen nicht mehr ausreichte: „Dann bin ich untergetaucht. Ich habe mich versteckt gehalten, teils in Heilbronn, teils bei uns zu Hause bei meinen Eltern. Dies war nirgends lange möglich, weil ja die Bevölkerung im allgemeinen irgendwie dafür eine Nase hatte und vor allem kolossal aufgebracht war, der Krieg stand auf dem Höhepunkt.“ Bruno Knöller wechselte häufig seine Unterkunft. Eine Zeitlang konnte er sich im Frühjahr 1945 bei einem Heilbronner Fabrikanten verbergen, der ihm Schutz bot, obwohl er selbst kein Zeuge Jehovas war.

Ein anderer Zeuge Jehovas, der zunächst ebenfalls durch wiederholtes Ummelden und Eingaben (sein aus der Ukraine gebürtiger Vater war Staatenloser) Zeit zu gewinnen versuchte, entschloß sich im März 1945 unterzutauchen und ,in den Wald" zu flüchten. Dort hauste er in einer Höhle und ging nur ins Dorf, um Essen zu holen. In seinem Versteck wartete er das Kriegsende $a^{305}$.

Als das Regime durch die Bildung des „Volkssturmes“ aus älteren Männern, kaum dem Kindesalter entwachsenen Jugendlichen und Versehrten ,das letzte Aufgebot" rekrutierte, um doch noch eine Kriegswende herbeizuführen, verweigerten sich Zeugen Jehovas auch diesem Ansinnen. In Ostfriesland versteckten sich zwei Zeugen Jehovas in Scheunen beziehungsweise auf dem Heuboden; ein Zeuge

neutral zu verhalten“. Am 4.1.1944 wurde der 44jährige Bergmann vom RKG zum Tode verurteilt. Vgl. BA-MA, RW 11 II/v.27, RKG, StPL (RKA) I 359/43, Urteil vom 4.1.1944.

303 Vgl. Marssolek/Ott, Bremen, S. 308, FGN, NHS, 13-7-9-8.

304 EB Bruno Knöller, 6.5.1981, 23.11.1987; Knöller, Erinnerungen, S. 21.

305 AfW HH, 070319, Bl. 33. 
Jehovas hielt sich vier Monate lang in Berlin verborgen ${ }^{306}$. Ins $\mathrm{KZ}$ Buchenwald wurden in den letzten Kriegsmonaten sieben Bibelforscher eingeliefert, weil sie der Heranziehung zum Volkssturm keine Folge geleistet hatten ${ }^{307}$. Ein 55jähriger Hamburger Autoschlosser, der am 22. Oktober 1944 den Heranziehungsbescheid zum Volkssturm erhielt, teilte noch am gleichen Tag dem Einsatzführer brieflich mit: ,Sende Ihnen anbei gesandte Papiere unausgefüllt zurück. Ich kann mich in den Volkssturm Hamburg nicht einreihen. Ich bin ein überzeugter Christ und ein freier Mensch. Meine Überzeugung gestattet mir nicht, daß ich mich politisch oder militärisch beteilige. Möchte auch noch bemerken, daß ich als Bibelforscher $2 \mathrm{mal}$ vorbestraft bin.“308 Wenige Tage später erreichte ihn eine „Vorladung“ der Gestapo. Nachdem ihm dort vorgehalten wurde, daß sein Verhalten eine ,vaterlandslose Gesinnung“ offenbare, gab er zu Protokoll: „Wenn mir vorgehalten wird, $\mathrm{da} \beta$ ich der Obrigkeit untertan sein soll, so verstehe ich hierunter keine weltliche Obrigkeit, sondern nur die göttliche, denn letztere besagt, wir sollen Gottes Gebote achten. "309 Die Gestapo nahm ihn daraufhin sogleich in Haft.

Bereits am 25. November erhob der Oberstaatsanwalt beim Hanseatischen Sondergericht Anklage wegen „Verbrechens gegen $§ 5$ Abs. 1 Ziff. 3 Kriegssonderstrafrechtsverordnung“. Ganz sicher war sich der Anklagevertreter über die Rechtslage und die Justizzuständigkeiten jedoch nicht, zumal es sich „um den ersten Fall der Dienstverweigerung im Volkssturm im hiesigen Bezirk“ handelte. So übermittelte er noch am gleichen Tag dem Reichsjustizminister eine Abschrift der Anklage mit dem Bemerken, seines Erachtens sei „die Zuständigkeit des Sondergerichts und nicht des Kriegsgerichts gegeben, weil der Beschuldigte nicht bei Ausübung des Dienstes im Volkssturm gehandelt hat “310. Nach Anforderung der Akte durch das Ministerium wurde die für den 26. Januar 1945 angesetzte Gerichtsverhandlung aufgehoben. Der Zeuge Jehovas blieb noch drei weitere Monate in Hamburg in Haft, ohne daß es zu einem Prozeß kam. Am 25. April 1945 wurde er aus dem Untersuchungsgefängnis entlassen 311 .

Das „Sondergericht für die Operationszone Alpenvorland“ verurteilte hingegen noch am 9. April 1945 den österreichischen Bibelforscher Johann Haslinger aus Straßwalchen (bei Salzburg) zum Tode. Haslinger, der nach Haft in den Konzentrationslagern Sachsenhausen und Wewelsburg am 24. September 1941 entlassen worden war, hatte die an ihn gerichtete Aufforderung, sich am 11. März 1945 in

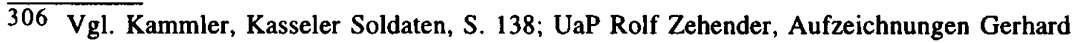
Oltmanns über Zeugen Jehovas aus dem Raum Unterweser/Ems, die wegen Kriegsdienstverweigerung hingerichtet wurden.

307 Vgl. Grünewald, Geschichte der Kriegsdienstverweigerung, S. 33.

308 SLG HH, HSG 11 Js. P. Sond. 464/44, B1. 4, Schreiben vom 22.10.1944.

309 SLG HH, HSG 11 Js. P. Sond. 464/44, Bl. 8, Vernehmungsprotokoll vom 9.11.1944.

310 SLG HH, HSG 11 Js. P. Sond. 464/44, Berichtsheft, Bl. 2, Der Oberstaatsanwalt beim Hanseatischen Sondergericht, Schreiben vom 25.11.1944 an den RJM.

311 Über die Gründe, weshalb es zu keinem ProzeB mehr kam, gibt die eingesehene Akte keine Auskunft. Der letzte Aktenvermerk stammt vom 8.11.1945 [!]: „Eingestellt, da gegenstandslos geworden“" (SLG HH, HSG 11 Js. P. Sond. 464/44, Bl. 23). Zur Frage, ob es gegen Kriegsende eine von der Justiz in Bibelforscherverfahren vorgenommene Kurskorrektur gegeben hat, siehe S. 351, Anm. 122. 
den Volkssturm eingliedern zu lassen, mit dem Bemerken beantwortet, daß er „unter keinen Umständen gewillt sei, Wehrdienst zu tun“312.

Neben den Zeugen Jehovas, die verweigerten oder sich auf andere Weise, zum Beispiel durch Flucht ins Ausland, dem Wehrdienst entzogen ${ }^{313}$, gab es auch IBVAngehörige, die der Einberufung - wenn wohl auch unter großen Gewissensqualen - Folge leisteten ${ }^{314}$. Beispielsweise rückte im April 1940 ein 31jähriger Hamburger Bibelforscher und vierfacher Familienvater zur Wehrmacht ein, der sich in den Jahren zuvor zur Kriegsdienstverweigerung bekannt hatte. Seinen Berichten ist zu entnehmen, wie stark der ihn ,aus Rücksicht auf die Familie“ gefaßte Entschluß belastete. Seinen Idealen versuchte er - so weit wie es möglich war - nicht untreu zu werden und Menschlichkeit und Anstand auch im Krieg zu bewahren. Bei seiner Einheit wurde er in Haft genommen, als er sich an der Ostfront weigerte, einen Befehl auszuführen: „Ich war dazu beauftragt, Häuser in Brand zu stecken, in denen sich Frauen und Kinder befanden. Ich sollte erschossen werden; es wurde aus mir unbekannten Gründen unterlassen. [...] Ich habe in den ganzen Kriegsjahren keinen Menschen getötet.“315

In einigen anderen Fällen setzten wohlmeinende Offiziere die Zeugen Jehovas für Dienste ein, die ohne Waffengebrauch erledigt werden konnten. Der Leiter der IBV-Gruppe Itzehoe, der ab dem 10. Februar 1940 seinen Soldatendienst leistete, berichtete davon, daß ihm sein Kompanieführer auf seine Erklärung hin, daß er den Waffeneinsatz gegen Menschen verweigere, erklärt habe, er könne ,in militärischen Diensten bleiben und brauche keinen zu töten“"316. Teilweise dienten auch IBVAktivisten bei der Wehrmacht. So stellte ein etwas älterer Unterbezirksdiener, der im ersten Weltkrieg den Offiziersrang erworben hatte, seine Bedenken zurück und diente als Hauptmann; allerdings nicht im Fronteinsatz, sondern bei einer Wehrmachtsbehörde in der Heimat ${ }^{317}$. Einem Zeugen Jehovas, der in den Jahren 1934 bis 1936 führend am Schriftenschmuggel über die deutsch-tschechische Grenze beteiligt war, wurde im Gefängnis, wie ein Glaubensbruder von ihm berichtete, „von den Wärtern derart zugesetzt, indem ihm immer wieder vorgehalten wurde, er solle doch an seine Familie denken und dabei scheint er derart mit den Nerven

312 Anklageschrift des SG für die Operationszone Alpenvorland vom 4.4.1945, zit. in: Maislinger, Andere religiöse Gruppen, S. 349. Das Todesurteil wurde nicht vollstreckt, da die Strafe auf dem Gnadenwege in fünf Jahre Zuchthaus umgewandelt wurde. Vgl. Hartmann, Kriegsdienstverweigerung (1986), S. 60.

313 Vgl. Zipfel, Kirchenkampf, S. 197, Anm. 53; Erwachet!, 22.11.1992, S. 19. Vereinzelt gibt es auch Hinweise auf Selbstbeschädigungen (vgl. Hartmann, Kriegsdienstverweigerung [1982], S. 75, 126). In der vermutlich Ende 1936 verfaßten Gestapa-Denkschrift über die IBV ist davon die Rede, daß ,einige Anhänger der Irrlehre [...] sich in ihrem Fanatismus selbst verstümmelt [haben], um auf diese Weise der Wehrpflicht zu entgehen“ (IfZ, MA 554, 936280). Klausch berichtet von einem 1942/43 auf dem Truppenübungsplatz Heuberg nach Todesurteil wegen „Zersetzung der Wehrkraft" hingerichteten Angehörigen des Bewährungsbataillons 999, bei dem es sich ,mit einiger Wahrscheinlichkeit“ um einen Bibelforscher gehandelt habe, der „Reißzwecken - nach einem anderen Bericht einen Löffel - schluckte, um so vom Militärdienst loszukommen“ (Klausch, Bewährungsbataillone, S. 234).

314 Vgl. Minninger, Bielefeld, S. 67f.; Kammler, Kasseler Soldaten, S. 138, 141.

315 VVN HH, Komiteeakten B 15, Lebenslauf vom 12.9.1946.

316 VVN HH, Komiteeakten L 27, Lebenslauf vom 27.2.1946; vgl. auch Möller, Steinburg, S. 217.

317 EB Bruno Knöller, 23.11.1987. 
fertiggewesen zu sein, daß er Soldat wurde“318. In einigen wenigen Einzelfällen erklärten sich auch in den Konzentrationslagern inhaftierte Bibelforscher zum Wehrdienst bereit. Sie wurden, wenn die Gestapo ihre Erklärung für ,glaubhaft“ hielt und die Schutzhaftverhängung dann auch aufhob ${ }^{319}$, aus den Konzentrationslagern entlassen und zur Wehrmacht überstellt.

Von den heranwachsenden Söhnen aus Bibelforscherfamilien sowie anderen IBV-Angehörigen, die noch nicht getauft waren, haben etliche der Einberufung zum Wehrdienst Folge geleistet ${ }^{320}$. In diesen Fällen stellte sich die Situation nach Überzeugung vieler Bibelforscher anders dar; man könne von ihnen nicht das gleiche fordern, was von einem Zeugen Jehovas, der sich in der Taufe ganz Gott geweiht habe, zu verlangen sei. In diesem Sinne lautete zum Beispiel die Antwort an eine Zeugin Jehovas, die in einem ins $\mathrm{KZ}$ Neuengamme eingeschmuggelten Brief an ihren dort inhaftierten Ehemann berichtete, daß der 19jährige Sohn den Wehrdienst verweigern wolle. Der Vater des Jungen beriet sich daraufhin mit den Wortführern der Bibelforscher-Häftlinge in Neuengamme. Diese rieten aus mehreren Gründen ab: Die Mutter bedürfe ihres einzigen Sohnes, er sei im Glauben noch nicht gefestigt genug und außerdem noch nicht getauft, so daß er gegenüber Jehova nicht wortbrüchig werden könne. Er solle statt dessen versuchen, sich vom Waffendienst soweit wie irgend möglich fernzuhalten, also sich etwa zu einer technischen Einheit melden. Diese Antwort wurde Frau und Sohn in einem aus dem Lager geschmuggelten Brief übermittelt ${ }^{321}$.

Welche Gewissensqualen Zeugen Jehovas zu durchleiden hatten, die sich schließlich zum Militärdienst bereit fanden, veranschaulicht ein Bericht über einen IBV-Angehörigen, der Anfang 1943 zum Dienst im Bewährungsbataillon 999 herangezogen wurde. Karl Schild, der als Regimegegner (Sozialistische Arbeiterjugend) den Ausschließungsschein erhalten und nach Wiederverleihung der ,Wehrwürdigkeit" zum 4. Februar 1943 zum BB 999 einberufen worden war, lernte jenen Zeugen Jehovas bei seiner Ankunft auf dem Truppenübungsplatz Heuberg kennen:

„Uns fiel ein älterer Stubenkamerad mit dem Namen Fuchs auf. Wir konnten ihn schwer einordnen, weil er sehr kontaktscheu und verschlossen war. Nur langsam kamen wir mit ihm ins Gespräch und erfuhren, daß er in einem schweren Glaubens- und Gewissenskonflikt war. Er war Bibelforscher und auch deswegen verurteilt worden. Jetzt wollte er sich weigern, an der Ausbildung mit der Waffe teilzunehmen. Auch den Eid wollte er nicht leisten. Wir wußten damals schon: das bedeutet Tod durch Erschießen. Wir drei sprachen sehr viel mit ihm. Er kam aus der Pfalz und hatte drei oder vier Kinder. Immer wieder versuchten wir ihm klar zu machen, daß die Situation nicht mit dem Zuchthaus zu vergleichen war, weil es jetzt um sein Leben ging. Immer wieder sagten wir ihm, daß er auch an seine Familie denken müsse und er im Einsatz ja absichtlich vorbeischießen könne. Es dauerte eine ganze Zeit, bis er das einsah. Schließlich machte er bei der Ausbildung mit und wir merkten, wie sehr er dabei mit sich kämpfte. Aber er behielt die Nerven. Als dann ein

318 EB Johannes Rauthe, Geschichtsbericht, S. 39.

319 Siehe S. 313, Anm. 357.

320 Vgl. Das Schicksal der Freiburger Zeugen Jehovas, o. S.; EB Wilhelm Molsich, Juni 1984; EB Elise Kühnle, 23.11.1987; VVN HH, Komiteeakten, S. 37.

321

EB Richard Rudolph, 31.5.1986. 
,Putzer' für irgendeinen Hauptwachtmeister gesucht wurde, redeten wir ihm zu, sich dafür zu melden. Es klappte, und so verbesserte sich seine Lage etwas, zumal er bei der Ausbildung schon des öfteren bei den Vorgesetzten als ,Flasche oder ,Blindgänger' aufgefallen war.

Aber nach kurzer Zeit kam er in einen zweiten Konflikt, die Vereidigung stand bevor. Er wollte nicht mitmachen. Sein ,oberster Führer' war Gott, ihm alleine habe er zu gehorchen, auf den ,Führer' könne er keinen Eid leisten. [...] Emil Schäfer und ich kamen dann auf die Idee, ihm zu empfehlen, daß er sich bei der Vereidigung so verhalten solle, wie es die Sinti bei einem erzwungenen Eid machten: während sie die rechte Hand mit den drei gespreizten Fingern zum Schwur erhoben, legten sie die linke Hand mit den drei gespreizten Fingern auf den Rücken, so daß nach einem alten Aberglauben der Eid durch den Körper ,hindurchglitt' und so unwirksam wurde. Beim Nachsprechen der Eidesformel sollte er dann nur die Lippen bewegen. Noch heute sehe ich ihn vor mir, wie er bei der Vereidigung mit der Hand auf dem Rücken dastand. [...] Nach diesen beiden schweren Belastungsproben kam unser Freund mit auf die Insel Rhodos. Er war bis zum Schluß ein guter Kamerad und hat unserer Widerstandsgruppe als Bursche des Oberleutnants der Stabsbatterie manche wichtige Information mitteilen können, die er bei Gesprächen der Offiziere aufgeschnappt hatte.“322

War in der Vorkriegszeit die Rechtsprechung der Militärgerichte gegen Wehrdienstverweigerer noch vergleichsweise milde und stellte im Vergleich dazu die Verfolgung durch die Gestapo die weit größere Gefahr dar, so hatte sich dieses Bild mit Kriegsbeginn völlig verändert. Während jenen wehrpflichtigen Zeugen Jehovas, die nach der Mobilmachung am 26. August 1939 den Gestellungsbefehl erhielten, es aber ablehnten, der Einberufung Folge zu leisten, das kriegsgerichtliche Todesurteil und die Hinrichtung drohten, unterlagen diejenigen, die von der Gestapo bereits in früheren Jahren in die KZs verbracht worden waren, nicht dem Zugriff der Wehrmachtjustiz. Für diese kriegsdienstverweigernden Zeugen Jehovas stellte sich im nachhinein die Verschleppung in die Lager gegenüber einer ihnen im Verweigerungsfalle drohenden justitiellen Verfolgung gewissermaßen als ,das kleinere Übel“" heraus. Paul Marszalek, der nach Verbüßung der Justizhaft die Unterschrift unter die „Verpflichtungserklärung“ verweigerte und daraufhin vor Kriegsbeginn in das Konzentrationslager Buchenwald überstellt wurde, wertete dies deshalb als seine „Rettung“: „Wäre ich bis dahin in Freiheit geblieben, wäre es wahrscheinlich für mich viel schmerzlicher gewesen: wegen Verweigerung die Todesstrafe!“"323 Alois Moser, der am 4. April 1939 verhaftet und nach Unterschriftsverweigerung direkt durch die Gestapo in das KZ Dachau eingewiesen wurde, urteilt im Rückblick: „Wenn ich in einen Kompromiß getreten wäre, so hätte diese vermeintliche Freiheit fünf Monate gedauert. Warum? Weil am 1. September 1939 der Krieg ausgebrochen ist, und ich hätte mich wieder entscheiden müssen zum Militär oder erschießen lassen um Christi willen. [...] Vier Monate später hätte es nicht mehr ,Schutzhaft' gegeben, sondern nur mehr das Kriegsrecht, den ,Tod" durch Erschießen. “324

$\overline{322}$ Bericht von Karl Schild, zit. nach Klausch, Bewährungsbataillone, S. 235f. Zum Dienst einiger weiterer Zeugen Jehovas in den Bewährungsbataillonen vgl. Die mit dem blauen Schein, S. 239; Schmiedgen, Partisanen, S. 145f. 
Die Grundlage für diese Nicht-Heranziehung von KZ-Häftlingen zum Wehrdienst bildete die vom Reichskriegsministerium nach Abstimmung mit der Gestapo verfügte Regelung, nach der Dienstpflichtige bis „zum Abschluß des Verfahrens der Schutzhaft von der Ableistung der Arbeitsdienstpflicht und der aktiven Dienstpflicht zurückzustellen“ waren ${ }^{325}$. Die ,in Schutzhaft genommenen Dienstpflichtigen" blieben bei dem zuletzt zuständigen Wehrmeldeamt in Wehrüberwachung gemeldet, das die KZ-Häftlinge wie andere zurückgestellte Dienstpflichtige verwaltungsmäßig behandelte ${ }^{326}$. Von daher wurden auch Schutzhäftlinge entweder zur Musterung „vorgeführt“ oder im Lager gemustert ${ }^{327}$. Nach Kriegsbeginn kamen in die Gefängnisse und Konzentrationslager Musterungskommissionen der Wehrbezirkskommandos, um die noch nicht gemusterten wehrpflichtigen Häftlinge auf ihre Kriegstauglichkeit hin zu untersuchen ${ }^{328}$. Da das Gestapa die „Freistellung zum Wehrdienst" bei Bibelforschern jedoch nur verfügte, wenn diese sich zuvor vorbehaltlos und ,glaubhaft" zur Wehrdienstleistung bereit erklärt hatten, verblieben die kriegsdienstverweigernden Zeugen Jehovas in der Gewalt der Gestapo. Versuche, Bibelforscher-Häftlinge auch ohne Bereitschaftserklärung an die Wehrmacht zu überstellen, bewiesen die Sinnlosigkeit dieses Unterfangens: Wegen der von den Überstellten eingenommenen kompromißlosen Verweigerungshaltung konnte man der Wehrmacht auf diese Weise nur Fälle für ihre Gerichtsbarkeit, aber keine Soldaten zuführen.

Dieses Ergebnis stellte sich auch ein, als im Februar 1941 aus dem KZ Niederhagen 27 Bibelforscher-Häftlinge zur Wehrmacht eingezogen wurden, obwohl sie es abgelehnt hatten, ihre Bereitschaft zum Wehrdienst zu erklären ${ }^{329}$. Ihre Musterung war im November des Vorjahres erfolgt; den Gestellungsbefehl hatten sie im Januar erhalten. Nachdem sie zu verschiedenen Truppenteilen in die Garnisonen Paderborn und Gütersloh (Fliegerhorst), Minden (Infanterieeinheit) und Iserlohn (Sanitätseinheit) verlegt worden waren, verweigerten sie dort bis auf einen sämtlich unter Berufung auf ihren Glauben die Ableistung des Kriegsdienstes. Obgleich sie als Eingezogene der Militärjustiz unterlagen, unterblieb jedoch die Durchführung

$\overline{325}$ BA-MA, RH 15/209, BI. 100, Reichskriegsministerium, Erlaß vom 27.3 .1936 betr. „Heranziehung der politischen Schutzhäftlinge zum aktiven Wehrdienst".

326 Die Wehrmeldeämter fragten bei den Lagerkommandanturen in gewissen Zeitabständen an, ob mit einer Aufhebung der Schutzhaft zu rechnen sei (vgl. auch Kammler, Kasseler Soldaten, S. 144-146). Anläßlich dieser Anfragen wurden die betreffenden Bibelforscher-Häftlinge vom Schutzhaftlagerführer oder anderen SS-Verantwortlichen jeweils danach befragt, ob sie sich zur Leistung des Wehrdienstes vorbehaltlos bereit erklären würden. Für eine mögliche Entlassung aus dem $\mathrm{KZ}$ war - sieht man von Ausnahmen ab - die Abgabe einer derartigen Bereitschaftserklärung ebenso wie die Unterzeichnung des „Revers“ die Voraussetzung. Oftmals endeten derartige Befragungen nach der Wehrdienstbereitschaft mit Schlägen; zuweilen auch mit Strafmeldungen oder etwa der Einweisung in die Strafkompanie. Vgl. beispielsweise Poel, Neuengamme, S. $107 \mathrm{ff}$.

327 Vgl. § 2 Abs. 4 der VO über die Musterung und Aushebung vom 17.4.1937, RGBI. 1937 I, S. 469.

328 Im Jahre 1941 wurde die Einstellung der „Musterung von Schutzhäftlingen“ verfügt. Mit Erlaß vom 30.8.1941 ordnete das $O K W$ an, daß zukünftig KZ-Häftlinge „bis zum AbschluB des Verfahrens der Schutzhaft nicht zu mustern sind" (BA-MA, RH 15/226, B1. 41).

329 Die Schilderung beruht auf: KmW, Ermittlungsergebnisse des 1971 vor dem Schwurgericht Paderborn geführten Wewelsburg-Prozesses; KmW, KW D 87, Buder, Wewelsburg; Hüser, Wewelsburg, S. 88f.; EB Klingenberg, 16.5.1992; EB Alois Moser, 23.5.1986. 
von Kriegsgerichtsverhandlungen, in denen die Aburteilung wegen ,Zersetzung der Wehrkraft" die erwartungsgemäße Folge gewesen wäre. Statt dessen erfolgte die Rücküberstellung der 26 Wehrdienstverweigerer an die Gestapo, die mit ihrem Versuch, Bibelforscher auch ohne Abgabe einer Bereitschaftserklärung zwangsweise zum Wehrdienst zu rekrutieren, gescheitert war ${ }^{330}$.

Aufgrund dieser und ähnlicher Erfahrungen wurde von einer Überstellung von Bibelforscher-Häftlingen zur Wehrmacht, soweit diese sich nicht selbst zum Wehrdienst meldeten, Abstand genommen. An einer anderen Verfahrensweise, die letztlich nur zur Zuführung von KZ-Häftlingen zur Militärjustiz geführt hätte, hatten anscheinend weder Wehrmacht noch Gestapo noch SS ein Interesse, zumal letztere mittlerweile die Arbeitsleistung der Bibelforscher-Häftlinge zu schätzen gelernt hatte. Auch als gegen Kriegsende in den Konzentrationslagern verstärkt Rekrutierungen von deutschen Schutzhäftlingen stattfanden und Tausende zunächst freiwillig, später zwangsweise in die kämpfenden Verbände, etwa die berüchtigte SSEinheit Dirlewanger ${ }^{331}$, eingegliedert wurden, blieben die Bibelforscher-Häftlinge in den Lagern. Im subjektiven Erleben empfanden viele von ihnen - so befremdlich dies klingen mag - das Konzentrationslager damals als den sichereren Ort, der zumindest die Aussicht bot, unter Umständen überleben zu können. Sie zogen deshalb das ungewisse Lagerschicksal trotz all der Qualen, der barbarischen Martern und Entbehrungen einem vorbestimmten Schicksal außerhalb vor ${ }^{332}$.

\section{Die Häftlinge mit dem ,lila Winkel“: Jehovas Zeugen in den Konzentrationslagern}

Seit 1935, dem Jahr, in dem erstmals in größerem Stil viele Hunderte von Zeugen Jehovas in die Konzentrationslager eingewiesen wurden, bildeten die Bibel-

$\overline{330}$ Nach ihrer im Laufe der Monate März und April 1941 erfolgten Rücküberstellung ins KZ Wewelsburg wurden die 26 Bibelforscher fortwährend schwer mißhandelt. Ehemalige Häftlinge berichten davon, daß die SS geäußert habe, nun werde sie nachholen, „wozu die Wehrmacht zu feige ist". Seitens der Kommandantur soll beim RFSS Antrag auf Exekution gestellt worden sein, wider Erwarten sei dem jedoch nicht entsprochen worden. Daraufhin faßte die SS in Wewelsburg die Wehrdienstverweigerer in einer besonderen Strafkompanie zusammen. Dort mußten die Häftlinge zunächst sämtliche Arbeiten im Laufschritt verrichten, die Verpflegungsrationen wurden gekürzt, ärztliche Hilfe wurde ihnen während dieser Zeit generell verwehrt. Als besondere Schikane ließen SS-Leute die Gruppe unter schrecklichen Bedingungen auf dem Appellplatz bis zur völligen Erschöpfung „Sport“ treiben. Die Häftlinge mußten exerzieren, rollen, robben und hüpfen. Wenn es der SS nicht schnell genug ging, wurden die Häftlinge mit Knüppeln und Stiefeltritten traktiert. Gerade in dieser für ihre Glaubensbrüder so beschwerlichen Situation bewährte sich die Solidarität unter den Bibelforschern. Trotz Verbotes halfen die anderen Häftlinge, soweit es irgendwie möglich war. Erst nach einigen Monaten besserten sich die Zustände, bis schließlich im August die Sonderbehandlung ganz eingestellt wurde.

331 Bei der im Herbst 1944 erfolgten Ausweitung der Rekrutierungen für die SS-Sonderformation Dirlewanger, zu der schon seit dem Sommer 1943 ,asoziale“ und ,kriminelle“ KZ-Häftlinge deutscher Nationalität herangezogen worden waren, auch auf die Gruppe der erklärten Regimegegner unter den KZ-Gefangenen, sind - soweit bislang bekannt - keine Zeugen Jehovas erfaßt worden. Vgl. Auerbach, Konzentrationslagerhäftlinge; Jahrbuch 1974, S. 204.

332 Vgl. Bredemeier, Kriegsdienstverweigerung, S. 86. 
forscher-Häftlinge innerhalb der Lagergemeinschaft - neben Kommunisten, Sozialisten, Gewerkschaftern, Zentrumsangehörigen und Mitgliedern anderer bürgerlichdemokratischer Parteien sowie den anfangs noch vergleichsweise wenigen ,nichtpolitischen“ KZ-Gefangenen - eine eigene, gesonderte Gruppe. Das enge Zusammengehörigkeitsgefühl, der eigene Gruppenkodex und nicht zuletzt die weltanschauliche Distanz der Zeugen Jehovas zu den „Politischen“ führten dazu, daß sie eine geschlossene Gemeinschaft darstellten, die sich von den anderen Häftlingsgruppen deutlich unterschied ${ }^{333}$. In den Vorkriegsjahren, als die Belegungszahl in den Konzentrationslagern noch relativ gering war - im Winter 1936/37 war die Gesamtzahl der "Schutzhäftlinge“ in den KZs mit ungefähr 7.500 auf den insgesamt niedrigsten Stand gesunken ${ }^{334}$-, stellten die Bibelforscher-Häftlinge zahlenmäßig eine nicht unerhebliche Gruppe. In der Regel betrug ihr Anteil an der jeweiligen Belegstärke der KZs zwischen fünf und zehn Prozent; im KZ Buchenwald waren im Mai 1938 zwölf Prozent der Häftlinge Zeugen Jehovas, und im Schloß Lichtenburg, vom Dezember 1937 bis Mai 1939 das zentrale Frauen-KZ und somit Vorläufer von Ravensbrück, stellten im Mai 1939 die Bibelforscherinnen über $40 \%$ der Gefangenen ${ }^{335}$. Ihr Anteil lag damit deutlich über dem der Kommunistinnen und Sozialdemokratinnen (zusammen etwas über $10 \%$ ).

Nach Kriegsbeginn ${ }^{336}$ bildeten die Zeugen Jehovas hingegen im Verhältnis zu der Häftlingsgesamtzahl, die sich rasch durch die Verschleppung von Hunderttausenden von Ausländern vervielfachte ${ }^{337}$, nur noch eine sehr kleine Minderheit:

333 Vgl. Garbe, Der lila Winkel; John, Wewelsburg (1996), S. 136ff.

334 Vgl. Broszat, Konzentrationslager, S. 64.

335 Anhand der Häftlingsnummern-Zuteilung ist davon auszugehen, daß ins KZ Lichtenburg in den eineinhalb Jahren seines Bestehens insgesamt 1.416 Frauen eingewiesen wurden. Die Gefangenenzahl schwankte sehr. Bei der Auflösung des Lagers im Mai 1939 betrug sie knapp 1.000; die Statistik nennt 386 Bibelforscherinnen (40,3\%), 240 als „Asoziale“ $(25,1 \%)$ und 119 als „Kriminelle“ $(12,4 \%)$ Bezeichnete, 114 ,politische Schutzhäftlinge“ $(11,9 \%)$ und 98 wegen sogenannter „Rasseschande“ Verfolgte (10,2\%). Angaben nach Arndt, Ravensbrück, S. 100; Drobisch, Frauenkonzentrationslager, S. 103 sowie ders., Frauen-KZ Lichtenburg, Referat/Maschinenschrift, Berlin 1993.

336 Die in der Literatur erwähnte, gegen die Zeugen Jehovas gerichtete „Sonderaktion zu Beginn des 2. Weltkrieges" (vgl. Billstein, Krefeld, S. 302) führte zu einem nur sehr begrenzten Anstieg der Bibelforscher-Häftlinge. Diese Sonderaktion, von der jedoch nicht speziell die IBV, sondern alle Regimegegnergruppen betroffen waren, beruhte auf einer bereits Anfang 1936 erfolgten Anweisung Heydrichs an die Staatspolizeistellen. Danach waren ,karteimäßig (= A Kartei) umgehend alle Staatsfeinde" zu erfassen, die „im Kriegsfalle unbedingt in Schutzhaft genommen werden müssen“. Zu den „Staatsfeinden im Sinne dieser Anordnung“ rechnete Heydrich neben ,allen linksradikalen Elementen“, den „Führern oppositioneller oder reaktionärer Bewegungen" auch ,alle maßgeblichen Mitglieder der Bibelforschervereinigung“ (BA, R 58/264, Bl. 195-197, Preußische Geheime Staatspolizei, RdErl. vom 5.2.1936). Während zahlreiche Angehörige der Linksparteien bei Kriegsbeginn aufgrund der vorbereiteten Listen in die KZs eingewiesen wurden, sind verstärkte Einlieferungen von Bibelforschern im Herbst 1939 jedoch kaum festzustellen - vermutlich aus dem Grunde, weil die Mehrzahl der „maßgeblichen Mitglieder" bereits in den Vorjahren in Haft genommen worden waren. Während im Konzentrationslager Buchenwald beispielsweise in dem Zeitraum vom 1.9.1939 bis zum 1.1.1940 die Gesamtzahl der Häftlinge (von 5.397) um 6.377 auf 11.774 (Zunahme von $118 \%$ ) stieg, erhöhte sich die Zahl der Bibelforscher im gleichen Zeitraum lediglich von 386 auf 405 (Zunahme von $5 \%$ ). Vgl. BA, NS 4 Bu/vorl. 137.

337 Vor allem durch die hohe Zunahme bei den Einlieferungen ,nichtpolitischer“ KZ-Gefangener (,Asozialen“-Aktionen im April und Juni 1938, ,Juden-Aktion“" im November 1938) sowie von Regimegegnern aus den „eingegliederten“ Gebieten (Österreich, Sudetenland) war die Ge- 
So stellten die IBV-Angehörigen im Dezember 1939 in Mauthausen 5,2 \% aller Gefangenen, in Buchenwald betrug ihr Anteil zum gleichen Zeitpunkt 3,3\%. Ende 1944 verzeichnen die Statistiken für Mauthausen 0,12 \% Bibelforscher-Häftlinge und für Buchenwald ungefähr $0,3 \% 338$.

Abbildung 3: Prozentualer Anteil der Bibelforscher am Gesamthäftlingsbestand des KZ Buchenwald

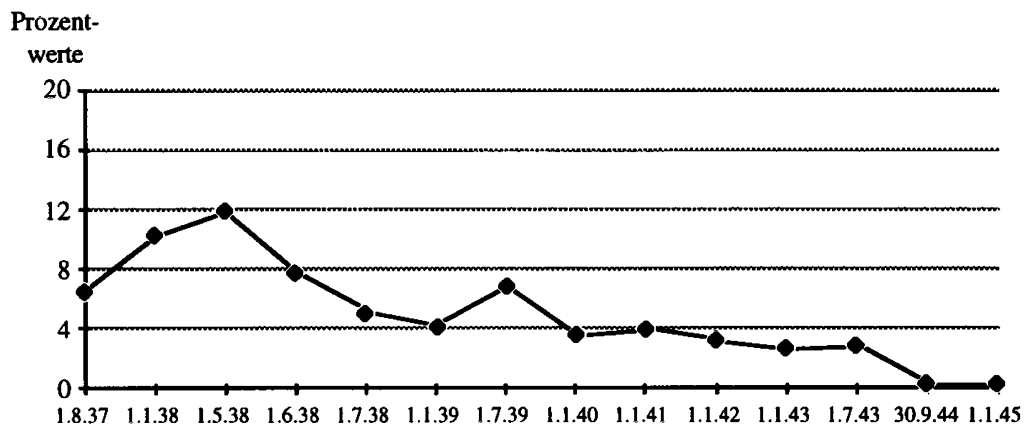

Schon früh begann die SS, die Bibelforscher in den Konzentrationslagern, soweit es Lagerunterbringung und Arbeitseinteilung zuließen, zu separieren, um auf diese Weise deren rege Missonsaktivitäten zu unterbinden und die Möglichkeiten zur Kontaktaufnahme mit anderen Gefangenen einzuschränken ${ }^{339}$. Mit Kommandanturbefehl vom 9. Dezember 1935 ordnete der Lagerführer des KZ Sachsenburg (bei Chemnitz) an: „Die Posten haben vor allen Dingen darauf zu achten, daß vor

samtbelegungszahl aller Konzentrationslager bis Kriegsbeginn auf ungefähr 25.000 gestiegen. Während des Krieges vergrößerte sie sich aufgrund der Einweisungen von Häftlingen ausländischer Nationalität - bei gleichzeitigem starken Anstieg der Todesrate - um ein Vielfaches (Dezember 1942: 88.000, August 1943: 224.000, August 1944: 524.000, Mitte Januar 1945: 718.000; Angaben nach Broszat, Konzentrationslager, S. 80f.; Pingel, Häftlinge, S. 129f.; BA, NS 3/439).

338 Die absoluten Werte lauten für Mauthausen am 1.12.1939: 143 Bibelforscher bei einer Gesamtbelegstärke von 2.772 Gefangenen, am 31.12.1944: 85 Bibelforscher bei einer Belegstärke von 72.426; für Buchenwald am 1.12.1939: 405 Bibelforscher bei einer Belegstärke von 12.341, im September 1944: ungefähr 260 Bibelforscher bei einer Belegstärke von 82.239 Häftlingen. Zahlenangaben nach Chêne, Mauthausen, S. 178-190; Pingel, Häftlinge, S. 282, Anm. 47; BA, NS 4 Bu/vorl. 143, Schutzhaftlagerrapport Buchenwald. Der Graphik liegen zudem die „täglichen Stärke-Meldungen“ des KZ Buchenwald zugrunde, die im Bundesarchiv für die Zeit vom 29.7.1937 bis zum 31.12.1942 überliefert sind (BA, NS 4 Bu/vorl. 137-139).

339 In den Konzentrationslagern erfolgte zwar zumeist ohnehin - soweit möglich - eine Belegung der Häftlingsunterkünfte (,Blocks“) nach der Gruppenzugehörigkeit. Da man die Zeugen Jehovas aber von den anderen Gefangenen zu isolieren beabsichtigte, wurde auf ihre getrennte Unterbringung besonders geachtet. Im Provinzialwerkhaus Moringen, das seit Oktober 1933 als zentrales Frauenkonzentrationslager für Preußen diente und in das im Januar 1935 die ersten IBV-Angehörigen eingeliefert wurden, gab es z. B. bereits 1936/37 einen eigenen „Bibelforschersaal“. Vgl. Distel, Schatten, S. 30; Deutschland-Berichte 4 (1937), S. 713. 
allem die Bibelforscher sich in ihrer freien Zeit nicht mit anderen Häftlingen in Gespräche einlassen, um eine Verbreitung des Bibelforschertums zu verhindern. "340

Seit 1935/36 ging die SS dazu über, die Häftlinge nach ihren Einlieferungsmerkmalen sichtbar an der Kleidung zu kennzeichnen. Dazu wurden - anfangs noch nicht einheitlich ausgeprägt - unterschiedliche Farben benutzt. In Sachsenburg erhielten die „Asozialen“ einen schwarzen, die „Kriminellen“ einen grünen und die Bibelforscher einen blauen Fleck. Im KZ Lichtenburg, Mitte der dreißiger Jahre noch mit männlichen Gefangenen belegt, hatten die Zeugen Jehovas einen blauen Kreis auf der Brust zu tragen. Die jüdischen Häftlinge waren ebenfalls mit einem (gelben) Kreis markiert, während für die anderen Kategorien andersartige Markierungen gewählt wurden ${ }^{341}$. Auch im KZ Sachsenhausen und im Mitte 1937 eingerichteten $\mathrm{KZ}$ Buchenwald trugen die Zeugen Jehovas anfangs blaue Markierungen $^{342}$. 1938 wurde für alle Konzentrationslager ein einheitliches System von festgelegten Farbcodes eingeführt. Die Häftlinge hatten nun auf der linken Brustseite ein farbiges Dreieck zu tragen, darunter auf weißem Rechteck eine schwarze Häftlingsnummer. Für die Zeugen Jehovas trat an die Stelle des „Blau“ das „Violett“343. Die politischen Gefangenen, die zunächst als Stammkategorie noch ohne Kennzeichnung geblieben waren, erhielten das rote Dreieck.

Die Eingruppierung der Bibelforscher als eigenständige Kategorie ${ }^{344}$ neben den „Politischen“ (rot), den „Asozialen“ (schwarz), den „Homosexuellen“ (rosa) und den mit grünen Winkeln versehenen „Sicherungsverwahrten“ (SV) und „Befristeten Vorbeugungshäftlingen“ (BV - im SS-Jargon bürgerte sich die Bezeichnung „Berufsverbrecher“ ein) erfolgte aus dem Interesse der SS, die von den anderen Gefangenen zu separierenden Zeugen Jehovas sichtbar kenntlich zu machen, und trug zugleich der tatsächlichen ,Sonderstellung“ dieser sich im Verhalten von den anderen Häftlingskategorien unterscheidenden Gruppe Rechnung ${ }^{345}$. Mit der Kate-

$\overline{340}$ Zit. nach Pingel, Häftlinge, S. 90 (bei der dortigen Nennung des Lagers Sachsenhausen statt Sachsenburg liegt ein Schreibfehler vor; vgl. hingegen die zutreffende Angabe ebenda, S. 76). Vgl. Drobisch, Konzentrationslager, S. 36.

342 Nach einem Bericht von Otto Horn, einem österreichischen Gewerkschaftsfunktionär, wurden die Bibelforscher-Häftlinge zu dieser Zeit in Buchenwald, wo sie große, blaue Punkte (ca. $10 \mathrm{~cm}$ Durchmesser) als Markierung trugen, aus diesem Grunde auch „Blaupunkte“ genannt (DÖW, Nr. 1458, Otto Horn, Bericht über das Konzentrationslager Buchenwald).

343 Da die Gruppen der Bibelforscher-Häftlinge zu dieser Zeit in den Lagern den Strafkompanien zugewiesen waren (siehe S. 41 lff.), kam noch der Strafpunkt für alle Angehörigen der Strafkompanie hinzu. Die Bibelforscher-Häftlinge jüdischer Herkunft mußten zudem wie andere Juden unter dem Winkel ihrer Kategorie noch ein nach oben ausgerichtetes gelbes Dreieck tragen, so daß sich aus den beiden Dreiecken zusammen ein Davidstern ergab. Die Zahl der ,jüidischen Bibelforscher-Häftlinge“ (in den SS-Akten zumeist „Bibelforscher, Jude“" genannt) war recht klein. Vgl. Chêne, Mauthausen, S. 40; Kautsky, Teufel und Verdammte, S. 125; Kogon, SS-Staat, S. 51.

344 Daneben gab es noch weitere Sonderkategorien, die teilweise erst in den späteren Jahren hinzukamen (z. B. Sonderabteilung Wehrmacht), und Einteilungen, die mit den Stammkategorien verbunden wurden (Juden, , Rasseschänder“", ,Rückfällige“).

345 Auch in einzelnen Haftstätten der Justiz erfolgte eine gesonderte Kennzeichnung der Zeugen Jehovas. So wurden sie (zumindest 1938/39) in den emsländischen Strafgefangenenlagern mit weißen Armbinden gekennzeichnet. Auf diese Weise konnte das Bewachungspersonal Kontaktaufnahmen von Bibelforschern zu einzelnen Mitgefangenen leicht erkennen. Das Zusammenfinden mehrerer Häftlinge mit Armbinde zu einem Gespräch signalisierte den Wachtmeistern, daß es sich um eine Predigtgruppe handeln könnte, gegen die es laut Anweisung sofort einzuschreiten galt (EB Willi Lehmbecker, 15.4.1971). 
gorie „Bibelforscher“ war eine Zuordnung gewählt, die speziell und einzig für die Angehörigen einer Weltanschauungsgemeinschaft galt. Während Kommunisten und Sozialdemokraten, Anarchisten und bürgerliche Demokraten, Geistliche und christliche Widerständler der großen Konfessionen, oppositionelle oder in Ungnade gefallene Nationalsozialisten (z. B. die „Schwarze Front“ Otto Strassers) und sich selbst nicht als Regimegegner verstehende Unzufriedene (,Meckerer und Querulanten“") alle gemeinsam mit dem roten Winkel der „Politischen“ markiert wurden, waren die Bibelforscher-Häftlinge mit einer exklusiven Kennzeichnung versehen. Außer den IBV-Angehörigen sowie einigen Mitgliedern von Bibelforschergruppen, die sich von der Wachtturm-Gesellschaft getrennt hatten ${ }^{346}$, trugen lediglich noch Adventisten $^{347}$, deren Zahl allerdings sehr klein war und bei denen die SS keine Unterschiede zu den Bibelforschern zu erkennen vermochte, den violetten Winkel.

Die in vielerlei Hinsicht besondere Stellung der Zeugen Jehovas innerhalb der KZ-Lagergesellschaft wurzelte in ihrer nahezu unerschütterlichen Glaubenszuversicht, ihrem Gemeinschaftsgeist und Bekennermut. Ein aus Deutschland herausgeschmuggelten Bericht über die Verhältnisse im KZ Sachsenburg, der im Mai 1937 in den von der Exil-SPD in Prag herausgegebenen „Deutschland-Berichten“ erschien, gibt zu erkennen, worin jene „Eigenart“ der Bibelforscher bestand, die die SS veranlaßte, sie als eine eigene Kategorie zu führen:

„Ganz erstaunlich ist das Verhalten der Ernsten Bibelforscher. Diese [...] Leute bewiesen unerschütterlichen Oppositionsgeist, sie zeigten Märtyrergesinnung und waren unbeugsam wie keine andere Gruppe im Lager. Wir politischen Gefangenen hatten von Anfang an die Losung unter uns ausgegeben, nicht zu rebellieren und uns allen Anordnungen der Lagerleitung zu fügen, da die SSLeute mit uns wenig Federlesen gemacht hätten und nur darauf warteten, daß wir ihnen Anlaß zum Einschreiten gaben. Wir leisteten also vorschriftsmäßig den Gruß usw. Die Ernsten Bibelforscher waren dagegen unter keinen Umständen dazu zu bewegen. Ihre Jehova-Gläubigkeit verbot es ihnen, und sie hielten sich strikte daran. Eine Anzahl von ihnen weigerte sich auch, die Freilassung aus dem Konzentrationslager anzunehmen. Einige erklärten, sie wollten solange im Lager bleiben, bis man ihnen die Ausübung ihrer Religionstätigkeit wieder erlaube. “348

In der gleichen Ausgabe der „Deutschland-Berichte“ heißt es über die im Frauenkonzentrationslager Moringen inhaftierten weiblichen IBV-Angehörigen: „Die alten Bibelforscherinnen machen den Aufseherinnen viel zu schaffen. Sie leisten weder

346 In Erinnerungsberichten von IBV-Angehörigen wird bei Häftlingen, die den violetten Winkel als „Bibelforscher" trugen, genau unterschieden zwischen den „wahren Zeugen Jehovas" und den „falschen Brüdern“ (während der Haft „Abgefallene“), den „Abtrünnigen“ (Angehörige anderer Bibelforschergruppen, z. B. „Engel Jehovas“) sowie den Adventisten.

347 Die Zahl der in die Konzentrationslager eingelieferten Siebenten-Tags-Adventisten (Reformationsbewegung) wird schätzungsweise um 50 liegen, von denen - soweit bekannt - zwölf Personen in KZ-Haft umkamen. Vgl. Fleschutz, Gedenkbuch, S. 8f.

348 Deutschland-Berichte 4 (1937), S. 707. Die Bemerkung, daß Zeugen Jehovas die Entlassung aus der KZ-Haft ablehnten, hebt vermutlich darauf ab, daß diese sich bei den Haftprüfungsterminen weigerten, eine als Voraussetzung der Entlassung vorgelegte Erklärung (der einheitliche ,Revers“" wurde erst zwei Jahre später eingeführt) zu unterschreiben, mit der sie sich zur Nicht-Betätigung für die IBV verpflichten sollten und die damit eine Anerkenntnis der „Rechtmäßigkeit“ des IBV-Verbots implizierte. 
einen Hitlergruß, noch lassen sie sich von ihren Andachten abhalten."349 In den Akten der SS finden sich zahlreiche Belege für diese resistente Haltung, die frei von jedem taktischen Kalkül von den Zeugen Jehovas um der Wahrung ihrer Glaubensüberzeugung willen geleistet wurde und von der sie auch in der Gewalt der SS nicht abzulassen bereit waren. Viele Beispiele dokumentieren dies. So reichte am 24. April 1935 ein SS-Oberscharführer bei der Kommandantur des KZ Sachsenburg eine „Meldung“ ein und beantragte, einen 36jährigen Bibelforscher-Häftling mit acht Tagen ,strengen Arrestes“ sowie jeweils 25 Stockhieben zu Beginn und am Ende zu bestrafen ${ }^{350}$. Zur Begründung seines Strafantrages führte der SSOberscharführer an, der Zeuge Jehovas habe „die vorgeschriebene Ehrenbezeugung [!] absichtlich unterlassen“ und damit zu erkennen gegeben, daß ,er sich der Zucht und Ordnung nicht fügen will". Auch weigere sich der Bibelforscher, beim Einrücken die in der Marschkolonne angestimmten Lieder zu singen. Mehrmalige Verwarnungen hätten ihn nicht dazu bewegen können, seine Haltung aufzugeben: „Auf mein Vorhalten hin, sagte er in einer frechen Art und Weise: ,Er würde die Lieder nicht kennen', obwohl er sich schon seit dem 5.3.35 im Lager befindet. Weiter weigerte er sich Grundstellung mir gegenüber einzunehmen." Als er daraufhin zur Wache gebracht wurde, hielt er es beim Passieren des Postens - so voll Empörung der berichtende SS-Mann - ,abermals nicht für nötig in Haltung vorbeizugehen. Als ihn der Posten zurück rief und ihn dazu aufforderte, antwortete er frech: ,Als Zeuge Jehovas hätte er es nicht nötig!““

Diese Meldung veranlaßte den Lagerkommandanten, umgehend bei der Inspektion der Konzentrationslager in Berlin um Genehmigung nachzusuchen, den Bibelforscher-Häftling sowie einen weiteren Zeugen Jehovas, der sich ebenfalls weigere, ,den üblichen Anweisungen“ im Lager Folge zu leisten, ,nach § 6 Abs. I der Disziplinar- und Lagerordnung zu bestrafen " 351 . Zum Sachverhalt führte der Kommandant aus: „Unter dem Hinweis, sie seien Zeugen Jehovas, lehnen sie alles Militärische ab, und behaupten, keinen Menschen, sondern nur Gott Achtung schuldig zu sein. Sie weigern sich vor Führern und Wachvorgesetzten Haltung anzunehmen, zu grüßen und auch die üblichen Lieder mit den anderen Häftlingen beim Ein- und Ausrücken zu singen.“

\section{Besonderes Haßobjekt der SS}

Wenn die Zeugen Jehovas ansonsten auch die Lagerordnung peinlichst genau befolgten und insbesondere die ihnen aufgetragenen Arbeiten gewissenhaft ausführten, so zeigten sie sich dort unbeugsam, wo von ihnen Handlungen gefordert wurden, die sie mit ihrem Gewissen nicht vereinbaren konnten. Dabei herrschten über die Frage, welchen Forderungen der SS sich ein Zeuge Jehovas zu versagen hatte, unter den Bibelforscher-Häftlingen durchaus unterschiedliche Ansichten. So lehn-

349 Deutschland-Berichte 4 (1937), S. 714.

$350 \mathrm{GBu}, 36-1 / 2$, KZ Sachsenburg, Meldung vom 24.4.1935.

351 GBu, 36-1/2, Der Lagerkommandant des Konzentrationslagers Sachsenburg, Schreiben vom 25.4.1935 an die Inspektion der KL. 
ten nur einige von ihnen die ,vorgeschriebene Ehrenbezeigung“ $a b^{352}$, während die große Mehrheit vorschriftsmäßig die Mütze zog und Haltung einnahm. Die kleine Zahl derer, die im Grüßen der SS eine Art Götzendienst sahen, argumentierten damit, daß ein solcher Achtungserweis einer Huldigung der Diener Satans gleichkäme. Wie deren Verhalten auf die SS wirkte, kann den Erinnerungen von Rudolf Höß entnommen werden, der im KZ Sachsenhausen vom August 1938 bis Mai 1940 zunächst als Adjutant des Kommandanten und dann als Schutzhaftlagerführer „Dienst“ tat und dort zwei - wie er schreibt - „,besonders fanatischen Bibelforschern" begegnete: „Sie standen nicht still, also sie nahmen nicht die Absätze zusammen, legten die Hände nicht an die Hosennaht, nahmen die Mütze nicht ab. Sie sagten, diese Ehrenbezeigung gebühre nur Jehova, aber nicht den Menschen. Es gäbe für sie keine Vorgesetzten, sie würden nur Jehova als Vorgesetzten anerkennen. Man mußte die beiden aus dem Block der Bibelforscher entfernen und im Zellenbau verwahren, da sie die anderen Bibelforscher auch fortgesetzt zu ähnlichem Verhalten aufforderten."353

Die Bibelforscher Weiß und Zibold ${ }^{354}$, die über lange Zeit im Arrest waren, wurden nach Aussage von SS-Hauptscharführer Kurt Eccarius, dem Leiter des Lagergefängnisses in Sachsenhausen, ,auf persönlichen Befehl Himmlers“ hin erschossen, ,weil sie, als der Reichsführer Himmler den Zellenbau besuchte, nicht aufstanden und ihn nicht grüßten, sondern auf den Knien liegenblieben und das begonnene Gebet fortsetzten“"355.

Die große Mehrheit der Bibelforscher-Häftlinge sah jedoch im vorschriftsgemäßen Grüßen der SS-Bewacher keine ihnen durch ihren Glauben verbotene Handlung, sondern betrachtete dies als einen Bestandteil der Lagerordnung, mithin als eine Forderung, der man notgedrungen nachkommen müsse und ohne Verleugnung seines Glaubens auch könne ${ }^{356}$. Dabei kam es den Zeugen Jehovas insgesamt sehr zunutze, daß die SS - im Unterschied zu den Verhältnissen in den frühen Konzentrationslagern ${ }^{357}$ - zu der Auffassung gelangte, daß den KZ-Häftlingen als

$\overline{352}$ In der Literatur finden sich, aus Einzelvorkommnissen abgeleitet, teilweise unzutreffende Verallgemeinerungen, beispielsweise wenn Erika Weinzierl über die Bibelforscherinnen generell feststellt: „Sie verweigerten der SS jede Ehrenbezeigung, zu Zählappellen konnte man sie nur mit Gewalt bringen." (Weinzierl, Österreichische Frauen, S. 182)

353 Kommandant in Auschwitz, S. 75; die beiden Zeugen Jehovas wurden später wegen der Weigerung, sich der Musterungskommission zu stellen, hingerichtet (siehe S. 422, Anm. 414).

354 Schreibweise nicht gesichert.

355 Todeslager Sachsenhausen, S. 42.

356 Richard Rudolph, der im Januar 1939 ins KZ Sachsenhausen eingeliefert wurde, berichtet, daß die dortige (,gemäßigte") Bibelforschergemeinde Glaubensbrüdern abgeraten habe, eine rigorose Haltung einzunehmen. Man habe ihm, als er die Verweigerung erwog, erklärt, dieses sei nicht notwendig und auch biblisch nicht gefordert, man betreibe dadurch keinen Götzendienst. Ein solches Verhalten wäre eine überflüssige und unnötige Herausforderung der SS. Die Sachsenhausener Zeugen Jehovas verurteilten diejenigen Glaubensbrüder nicht, die sich - weil sie glaubten, dadurch am besten ihrem Gewissen zu folgen - so verhielten, aber ein solches Verhalten wurde als nicht nachahmenswert dargestellt (EB Richard Rudolph, 31.5. 1986, 9.9.1986).

357 Wolfgang Langhoff beschreibt in seinem bekannten, 1935 nach seiner Flucht in der Schweiz erschienenen Bericht „Die Moorsoldaten“, wie ein Bibelforscher-Häftling im KZ Lichtenburg von der SS fortwährend mißhandelt wurde, weil er den „Hitler-Gruß" verweigerte. Dem Bericht zufolge war der Mann, dem die politischen Mitgefangenen zu einem taktischen Verhal- 
notorischen „Volksfeinden“ generell das „Recht“ zur Erweisung des „Deutschen Grußes“ nicht zukäme. Folglich wurde den „Schutzhäftlingen“ dieser mit dem Ausspruch „Heil Hitler“ verbundene „Ehrengruß“ untersagt.

Mit nationalsozialistischem Liedgut sahen die Gefangenen sich hingegen weiter konfrontiert. Welche Konflikte für die Zeugen Jehovas daraus erwuchsen, benennt ein Bericht aus dem KZ Dachau:

„Der Bibelforscher Edelmann sollte wie alle anderen Häftlinge singen. Er sang nicht. Andere Häftlinge redeten ihm gut $\mathrm{zu}$, zu singen. Er antwortete: ,Wenn es der Wille Jehovas ist, werde ich sterben. " - Eines Tages sagte ein Posten zu ihm: Du damischer Zeuge Jehovas! In der Bibel weißt Du gut Bescheid, warum bist Du so blöd und kannst nicht einmal singen? - , Wer sagt denn, daß ich nicht singen kann? Singen kann ich auch.' Die Abteilung mußte halten und er wurde gefragt: ,Was Du kannst singen? Warum hast Du Schwein uns bisher angelogen?' - Ich singe nur christliche Lieder!' war seine Antwort. Er sang ein christliches Kampflied. Dann marschierte die Abteilung weiter. Edelmann mußte allein singen. Wir hatten Ruhe. Die SS brüllte vor Lachen. “358

Durch derartige Handlungsweisen, die im allgemeinen nicht glimpflich auszugehen pflegten, sondern oftmals mit Schlägen - zumeist ohne gesonderte „Strafmeldung" - verbunden waren, und ihren offen demonstrierten Glauben an Jehova wurden die Bibelforscher-Häftlinge zum besonderen Haßobjekt der SS.

Herabwürdigende Beschimpfungen und Verhöhnungen ihres Glaubens waren an der Tagesordnung. Die SS legte sich ein ganzes Arsenal von Bezeichnungen zu, mit denen sie die „lila Winkel“-Häftlinge bedachte; „Himmelskomiker“, „Paradiesvögel“, ,Jordanscheiche“, „Gethsemane-Soldaten“ und „Bibelwürmer“ lauteten einige von ihnen. In Dachau mußten sich Zeugen Jehovas auf einen Haufen Kies stellen und laut rufen: „Ich bin der größte Idiot des 20. Jahrhunderts.“359 Immer wieder verspotteten die SS-Leute den Glauben der IBV-Angehörigen an die Allmacht Gottes. Der Journalist und politische Gefangene Edgar Kupfer-Koberwitz hat in seinen heimlich im $\mathrm{KZ}$ Dachau angefertigten Aufzeichnungen einen derartigen „Auftritt“ eines SS-Mannes gegenüber einem Bibelforscher festgehalten: „Du mit deinem Herrgott! Warum kommt er nicht herab, warum hilft er dir nicht? Weil er ein Rindvieh ist, dein Herrgott! Weil er nicht kann, das Stück Scheiße!“ Dabei habe der SS-Mann gelacht und mit der Faust zum Himmel gedroht: „Herrgott Herrgott - dein Herrgott bin ich, verstehst du mich, du Himmelskomiker?"360 Und nach diesen Worten - gewissermaßen zur Bekräftigung - habe er dem Zeugen Jehovas einen Faustschlag versetzt.

Besonders schlimme Folgen konnten kollektive Verweigerungsaktionen haben. Dieses war zum Beispiel im KZ Lichtenburg der Fall, als dort am 6. Oktober 1938, sechs Tage nach dem Einmarsch der Wehrmacht in das Sudetenland, von der SS der „Gemeinschaftsempfang“ einer „Führeransprache“ im Hof der Schloßanlage

ten rieten (,Wir tun doch auch nur so"), nach wochenlangen Qualen so geschwächt, daß er seinen Widerstand schließlich doch aufgeben mußte. Vgl. Langhoff, Moorsoldaten, S. $311 \mathrm{ff}$.

360 Kupfer-Koberwitz, Mächtigen, S. 215, vgl. auch ebenda, S. 243. 
angeordnet wurde ${ }^{361}$. Die Bibelforscherinnen beschlossen jedoch, an dieser „Feierstunde" nicht teilzunehmen und statt dessen auf ihrem Saal zu bleiben. Die Hamburger Kommunistin Charlotte Groß, der zufolge die politischen Häftlinge - weil sie hofften, anhand der Ansprache gewisse Rückschlüsse über die politische Lage ziehen zu können - durchaus mit einer Teilnahme einverstanden waren, erinnert sich an die Gespräche mit den Bibelforscherinnen: „Wir versuchten sie davon zu überzeugen, daß die Weigerung zweck- und sinnlos sei, daß man sie bestimmt dazu zwingen würde. Sie erklärten uns jedoch, sie hätten nur einen Führer, und das wäre Jehova. Das Anhören einer anderen Führerrede wäre Verrat! An politischen Informationen [...] waren sie durchaus interessiert."362

Als am Abend mit der Übertragung der Rede begonnen werden sollte und die Bibelforscherinnen nicht im Burghof erschienen, versuchten weibliche und männliche SS-Angehörige sie aus dem in der obersten Etage gelegenen Saal herauszuprügeln. Da das nicht gelang, schlossen SS-Leute kurzerhand Feuerwehrschläuche an einen Hydranten an, richteten den eiskalten Wasserstrahl auf die Bibelforscherinnen und spülten sie die Steintreppen bis in den Hof hinab. Die Worte der Kommunistin Gertrud Geßmann lassen die Situation erahnen: „Eine entsetzliche Panik entstand, in höchster Angst rennende Frauen, fallende Menschenleiber, Schmerzensschreie, übertönt vom Gebrüll und den Kommandos der SS und der Aufseherinnen.“363 Die Bibelforscherinnen riefen, so erinnern sich die Mitgefangenen, „Bibelworte gegen den Krieg“" und „Es gibt Krieg!“. Draußen wurden sie mit Stockschlägen weitergetrieben. Die vollkommen durchnäßten Frauen mußten stehend über eine Stunde die Rede Hitlers über sich ergehen lassen.

Die SS machte anschließend die angedrohte Warnung, daß die Bibelforscherinnen die Folgen ihrer Weigerung nachhaltig zu spüren bekämen, wahr. Diejenigen, die sich erkältet hatten, durften sich nicht zum Arzt melden. Für die nächsten zwei oder drei Tage wurde ihnen das Essen entzogen. Außerdem bekamen sie keine Post ausgehändigt und Schreibverbot auferlegt. Die „Rädelsführerinnen“ wurden in Dunkelarrest eingewiesen; die Bedingungen im feuchten Verlies des Schloßkellers ließen dies zu einer fürchterlichen Tortur werden. Trotz Hilfen von seiten politischer Gefangener ${ }^{364}$ haben - so die Kommunistin Maria Zeh - viele der Bibelforscherinnen ,,sich niemals erholt" ${ }^{\text {"365. }}$.

Die SS versuchte mit fortwährender Steigerung des Terrors die außergewöhnliche Resistenz der Bibelforscher zu brechen. Mit den Konzentrationslagerhäftlingen standen ihnen allerdings die Aktivisten aus den Reihen der IBV gegenüber, von denen der Großteil bereits in einer vorangegangenen Gefängnishaft und der anschließenden ,Schutzhaftprüfung“ durch die Gestapo Entschlossenheit und Wider-

$\overline{361}$ Die Schilderung beruht auf: Drobisch, Frauenkonzentrationslager, S. 107f.; Elling, Frauen, S. 30; Haag, Staub, S. 151f.; MGRa, RA, Bd. 25, Nr. 332, Berta Hartmann: Erlebnisse der Zeugen Jehovas in den Frauen-Konzentrationslagern. Unveröffentlichtes Manuskript, 1948.

362 Bericht Charlotte Groß, in: Elling, Frauen, S. 104.

363 Zit. nach Maur, Lichtenburg, S. 26.

364 Bei Drobisch, Frauenkonzentrationslager, S. 112, heißt es: „Die Kommunistinnen versorgten auch die Bibelforscherinnen mit Brot, als ihnen wegen der Weigerung, Hitlers Rede anzuhören, die Verpflegung entzogen wurde - und das, obwohl die erfahrenen Kämpferinnen, diese Demonstration" für , unnötig und die Opfer für sinnlos" hielten."

Bericht Maria Zeh, in: Elling, Frauen, S. 171. 
standsbereitschaft unter Beweis gestellt hatte. Gelang es auch der Gestapo und der Justiz, zahlreiche Zeugen Jehovas so sehr unter Druck zu setzen, daß sie von einer weiteren Betätigung für die Bibelforschervereinigung abließen - bei ihren Glaubensgeschwistern innerhalb des Stacheldrahtes konnte die SS derartige „Erfolge“ nur äußerst selten erringen.

Im Jahre 1937 hatte die SS in den Männerkonzentrationslagern begonnen, die Bibelforscher in die im Vorjahr für „Rückfällige“ (Häftlinge, die zum zweiten Mal in einem $\mathrm{KZ}$ einsaßen) erlassenen Bestimmungen (Bildung „besonderer Abteilungen“"366) einzubeziehen. In den Sonderabteilungen wurden die Gefangenen zu Schwerstarbeiten herangezogen. Nur alle drei Monate durfte ein Brief empfangen und abgesandt werden; Pakete durften sie überhaupt nicht erhalten.

Im KZ Buchenwald wurden die ersten Zeugen Jehovas im August 1937 in die berüchtigte „Strafkompanie“ eingewiesen, zu der neben den politisch „Rückfälligen" strafweise auch andere Häftlinge für eine bestimmte Dauer abkommandiert wurden. Fortan teilte die SS sämtliche neu angekommenen Bibelforscher als „Zugänge“ dieser Strafeinheit zu, in der sie in der Regel drei, zum Teil aber auch bis zu neun Monate verblieben ${ }^{367}$. Aufgrund der langen Aufenthaltsdauer stellten die Zeugen Jehovas innerhalb der Strafkompanie ein großes Häftlingskontingent ${ }^{368}$. Die Strafkompanie mußte die schwersten und schmutzigsten Arbeiten verrichten (Steine- und Lastentragen, Ausschachten, Jaucheentsorgung etc.), die auf zehn bis zwölf Stunden täglich und auch auf den Sonntag ausgedehnt wurden. Die Kapos, und zwar „Berufsverbrecher wie Politische“ - so formulierte es wenige Tage nach seiner Befreiung aus dem KZ Buchenwald der IBV-Bezirksdiener Karl Siebeneichler -, ,taten ihr möglichstes“, um den Bibelforschern ,das Leben schwer zu machen“369. Den Häftlingen in der Strafkompanie wurde ,nicht die geringste Vergünstigung "370 gewährt. Sie durften weder Pullover noch warme Unterkleidung tragen, und wenn Sonntag nachmittags nicht gearbeitet wurde, mußten sie geschlossen am Tor stehen.

Im KZ Dachau sollen im Oktober 1937 genau 144 Bibelforscher in die Strafkompanie gekommen sein ${ }^{371}$. Zugleich wurden die Bibelforscher geschlossen in der „Isolierung“ einquartiert, die sich durch einen Drahtzaun vom übrigen Lager

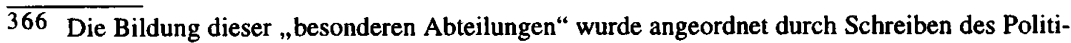
schen Polizeikommandeurs der Länder vom 23.3.1936 an den Inspekteur der Konzentrationslager, SS-Gruppenführer Theodor Eicke, abgedruckt in: Rürup, Topographie, S. 98.

367 Vgl. Kogon, SS-Staat, S. 264; Konzentrationslager Buchenwald, Post Weimar, S. 34f.; Zahnwetzer, Buchenwald, S. 27f. Von der generellen Einweisung der neuankommenden Bibelforscher in die Strafkompanie waren nur wenige besonders qualifizierte Fachkräfte, die die SS in anderen Kommandos einzusetzen wünschte, ausgenommen.

368 Nach Angabe des österreichischen Gewerkschaftsfunktionärs Otto Horn setzte sich die Strafkompanie in Buchenwald über lange Zeit ,hauptsächlich aus ,Blaupunkten " zusammen“ (DÖW, Nr. 1458, Otto Horn, Bericht über das Konzentrationslager Buchenwald).

369 Karl Siebeneichler, Bericht vom 24.4.1945, GBu, 31-826; der Bericht hat in einer überarbeiteten Fassung auch im sog. „Buchenwald-Report“ Aufnahme gefunden, allerdings unter Auslassung der oben zitierten Passage (vgl. Hackett, Buchenwald-Report, S. 214f.).

370 USHRI, RG-32.008.01, Franz Josef Seitz: Meine Erlebnisse im Dritten Reich, S. 5f.

371 Vgl. Gostner, 1000 Tage im KZ, S. 40; Matthias Lex, Eidesstattliche Versicherung, Der Prozeß gegen die Hauptkriegsverbrecher, Band 31, S. 300, Dokument 2928-PS; EB Alois Moser, 23.5.1986. 
abgetrennt befand. In den Isolierblocks verblieben auch jene Zeugen Jehovas, die nach dem Ende der Zugehörigkeit zur Strafkompanie in andere Arbeitskommandos versetzt wurden.

Das Dachauer Modell der „Isolierung“ wurde auch im KZ Sachsenhausen übernommen. Am 20. März 1938 ordnete der kurz zuvor zum Lagerkommandanten ernannte SS-Standartenführer Hermann Baranowski ${ }^{372}$, der zuvor seit Herbst 1936 Schutzhaftlagerführer in Dachau gewesen war, an, die Bibelforscher, die ,rückfällig Politischen" und die Strafkompanie in einem Sonderlager zu internieren ${ }^{373}$. $\mathrm{Zu}$ diesem Zweck wurden die Baracken 11 und 12 im ersten sowie 35 und 36 im zweiten Barackenring durch einen Stacheldrahtzaun von dem übrigen Häftlingslager abgetrennt. Der Zugang zum größeren Lager und den Mitgefangenen dort war den „Isolierten“ genommen; nur zum Arbeitseinsatz konnten sie das kleine Areal verlassen. Über die Arbeitsbedingungen berichtet Erich Mundt, der nach Verbüßung einer 18monatigen Gefängnisstrafe im August 1937 durch die Stettiner Gestapo in das KZ Sachsenhausen überstellt wurde: „Dieser Aufenthalt bedeutete schwerste körperliche Arbeit, d. h. Erdbewegungsarbeit. Die Erdmasse mußte in $3 / 4 \mathrm{cbm}$ Loren über einen Kilometer weit im Laufschritt transportiert werden, wobei einzelne Blockführer entweder auf den Loren standen, oder auf einem Fahrrad neben den Loren herfuhren und mit einem Knüppel auf die Häftlinge einschlugen, um diese zu immer stärkerem Tempo zu veranlassen. “374

Über die harten Belastungen hinaus, die für alle Gefangenen der Isolierung galten, wurden für die Bibelforscher-Häftlinge die Bestimmungen noch zusätzlich verschärft; für sie kamen nach und nach weitere Auflagen und Schikanen hinzu. Noch im März 1938, als Baranowski die „Isolierung“ anordnete, wurde es den Bibelforscher-Häftlingen völlig verboten, Briefe zu schreiben. Diese totale Postsperre, die die SS auch in anderen Lagern verfügte, wurde in Sachsenhausen neun Monate lang aufrechterhalten ${ }^{375}$. Nachdem Anfang 1939 das Schreibverbot wieder aufgehoben wurde, durften die Gefangenen zwar jeden Monat einmal nach Hause schreiben, jedoch wurde nicht erlaubt, daß die von Bibelforschern abgefaßten

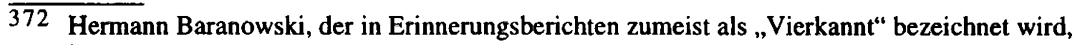
jenem Namen, den die Gefangenen ihm wegen seines groben Benehmens und seiner dickleibigen Erscheinung gaben, hatte sich bereits in Dachau die Bibelforscher - wie Alfred Hübsch schreibt - zu seinen speziellen „Freunden“ auserkoren (FGN, NHS 13-4-2-1, Aufzeichnungen von Alfred Hübsch, S. 6; vgl. auch Jahrbuch 1974, S. 169).

373 Vgl. Graffard/Tristan, Bibelforscher, S. 69. Die sogenannte „SK-Isolierung“ wurde nach Abschluß des Barackenbaus am 1.6.1938 eingerichtet; den Bibelforschern wurden die Baracken 35 und 36 zugewiesen. In den folgenden Jahren wurden in Sachsenhausen noch weitere der SS ebenfalls besonders verhaßte Gruppen in die Isolierung eingeschlossen: die Homosexuellen, die „Sonderabteilung Wehrmacht“ und zeitweilig die sogenannten „Rasseschänder“ (zu den Zuständen in der SK-Isolierung in Sachsenhausen und den dort verübten bestialischen Greueltaten vgl. KZ-Verbrechen vor deutschen Gerichten, S. 295ff.; Lienau, Zwölf Jahre Nacht, S. $110 \mathrm{ff}$; Naujoks, Sachsenhausen, S. 109f., 179ff.). Die Isolierung in Sachsenhausen wurde im Herbst 1941 aufgehoben. Nicht alle Zeugen Jehovas waren bis zum Auflösungszeitpunkt in der Isolierung; eine kleinere Zahl, ungefähr 40 bis 50 , war bereits in den Jahren zuvor nach und nach in das große Lager verlegt worden. Vgl. DdW, AN 707, Herbert Baron: Jahre des Grauens.

374 ETG, Biographie des Bibelforschers Erich Mundt, o. D.

375 Vgl. Jahrbuch 1974, S. 165; EB Johannes Rauthe, Geschichtsbericht, S. 56. 
Briefe mehr als fünfundzwanzig Worte enthielten ${ }^{376}$. Diese besondere Regelung für Zeugen Jehovas, die in allen Konzentrationslagern praktiziert wurde, blieb für ungefähr dreieinhalb Jahre bestehen. In Buchenwald wurde sie sogar bis zum Kriegsende nicht aufgehoben. Um die Beschränkung im Briefverkehr kenntlich zu machen und die Anfragen der Angehörigen nicht einzeln beantworten zu müssen, ließ die SS in der Postzensurstelle auf die Briefbögen stempeln: „Der Schutzhäftling ist nach wie vor hartnäckiger Bibelforscher und weigert sich, von der Irrlehre der Bibelforscher abzulassen. Aus diesem Grunde ist ihm lediglich die Erleichterung, den sonst zulässigen Briefverkehr zu pflegen, genommen worden.“377 Dieser Stempel galt den Zeugen Jehovas daheim, sobald sie Post aus dem Lager bekamen, als „Beweis“ dafür, daß der Schreiber beziehungsweise die Schreiberin „treu geblieben“ war. Rückblickend erklärte ein Zeuge Jehovas: „So waren wir weniger an dem Inhalt des Briefes interessiert, denn was konnte man schon in fünf Zeilen zum Ausdruck bringen, aber der Stempel bereitete uns immer Freude. “378

Neben der ebenfalls verfügten Einkaufssperre ${ }^{379}$, dem zeitweiligen Ausschluß von jeder Krankenbehandlung im Revier ${ }^{380}$ sowie den dauernden Schikanen und Mißhandlungen wurde insbesondere der Essensentzug als Mittel eingesetzt, um den Widerstand der Zeugen Jehovas zu brechen. So wurden beispielsweise im KZ Dachau den Bibelforscher-Häftlingen über eine lange Zeit noch geringere Essensrationen als den anderen Häftlingen zugeteilt, wobei ihnen in Aussicht gestellt wurde, daß sie bei Widerruf ihres Glaubens sofort die Normalrationen erhalten würden.

Auch im KZ Neuengamme wurde den Zeugen Jehovas 1940 die Brotzulage gestrichen. Der Verzicht auf täglich 200 Gramm Brot war überaus schmerzlich. Am Abend mußten die Bibelforscher an der Brotkiste, aus der vom „Lagerältesten“ oder einem von ihm beauftragten Häftling die Zulage ausgeteilt wurde, vorbeigehen. Neben der Kiste stand zumeist der im Lager sehr gefürchtete SS-Hauptscharführer Franz Xaver Trenkle. Jedes Mal, wenn nun ein „lila Winkel“-Häftling vor ihm stand, fragte Trenkle: „Bist du noch Bibelforscher?“ Wenn die Antwort „Ja“ lautete, gab es kein Brot, sondern einen Hieb mit dem Ochsenziemer ${ }^{381}$.

$\overline{376}$ Der Text war in der Anfangszeit im wesentlichen vorgegeben und lautete in der Regel: „Meine Lieben, habe Euren Brief erhalten, herzlichen Dank dafür. Es geht mir gut. Bin gesund und munter. Herzliche Grüße“. Vgl. Garbe, Gott mehr gehorchen, S. 172.

377 Während in den meisten Konzentrationslagern Stempel zu diesem Zweck benutzt wurden, gebrauchte man im KZ Buchenwald ein hektographiertes Schreiben mit dem gleichen Wortlaut. Noch im April 1945 wurden von der Buchenwalder Kommandantur derartige Schreiben an die Angehörigen von Zeugen Jehovas versandt (BA, NS $4 \mathrm{Bu} / 32$ ). Vermutlich läßt sich die Tatsache, daß die Briefbeschränkung für Zeugen Jehovas im KZ Buchenwald nicht aufgehoben wurde, darauf zurückführen, daß die dortige Bibelforschergemeinde mehrheitlich zum „radikalen Flügel" der IBV zählte (siehe S. 430f.).

378 Jehovas Zeugen in Gottes Vorhaben, S. 168.

379 Vgl. Kogon, SS-Staat, S. 264; Zahnwetzer, Buchenwald, S. 28.

380 Vgl. DÖW, Nr. 1458, Otto Horn, Bericht über das Konzentrationslager Buchenwald; USHRI, RG-32.008.01, Franz Josef Seitz: Meine Erlebnisse im Dritten Reich, S. 12; EB Alois Moser, 23.5.1986.

381 EB Richard Rudolph, 31.5.1986; EB Alfred Knegendorf, 29.1.1985. Trenkle hatte 1940 in Neuengamme zeitweilig die Funktion des Rapportführers inne. 


\section{Terrorisiert durch die SS}

Insbesondere in den Jahren 1939 und 1940 wütete der SS-Terror gegen die Bibelforscher-Häftlinge. Auf welche Weise die SS den Widerstand der Zeugen Jehovas zu brechen versuchte, soll im folgenden am Beispiel des KZ Sachsenhausen aufgezeigt werden. In der dortigen „SK-Isolierung“ führten unter dem SSHauptscharführer Richard Bugdalle die Blockführer Fritz Fickert, Martin Knittler, Wilhelm Schubert und Gustav Sorge ein Schreckensregiment. Den nicht von ihrem Glauben lassenden Zeugen Jehovas galt ihr $\mathrm{Ha}$ in besonderer Weise.

Die Torturen begannen am Tag der Einlieferung - für „Neuzugänge“ hatte die SS sich besondere „Einlieferungszeremonien“ erdacht. Wenn die Zeugen Jehovas beim „Empfang“ auf die allen „Zugängen“ gestellte Frage, welcher Art „Verbrecher" sie denn seien, den SS-Männern widersprachen und als Antwort ihren Glauben an die Bibel und Jesus Christus anführten, nahm diese „Prozedur“ regelmäßig ihren Lauf. Entweder setzte es sofort Prügel, oder man nahm den ,exotischen Vogel" weiter ins Kreuzverhör. Der am 20. April 1940 eingelieferte Willi Lehmbecker berichtet: „Alle Fragen, die man mir gestellt hatte, habe ich versucht, biblisch zu beantworten. Bei der Frage, wer der Führer ist, wollten sie von mir die Antwort hören: Adolf Hitler. Aber ich schwieg." 382 Daraufhin wurde der 36jährige Zeuge Jehovas blutig geschlagen.

An diesen ,widerspenstigen Bibelwürmern“ glaubten die SS-Männer, ,ihrem sadistischen Verlangen frönen " 383 zu können. Die Drangsalierungen hielten den ganzen Tag über an. Bei jeder Station, etwa der Einkleidung, wiederholte sich das schändliche Schauspiel. Gerhard Oltmanns, der nach einer eineinhalbjährigen Haftstrafe am 27. Januar 1940 ins KZ Sachsenhausen überstellt wurde, erinnert sich an seinen Einlieferungstag: „Mit 101 Zugängen von Berlin war ich der einzige Zeuge Jehovas. Kaum im Lager war als erstes: ,Bibelforscher vortreten'. Schon hagelten Boxhiebe und Tritte. Umringt von 20 SS-Führern: ,Würden Sie den Wehrpaß unterschreiben?' Ich verneinte. Als geducktes Huhn saß ich in Kniebeuge. Ein Ungewitter brach über mich hinein, ein Brüllen. Minutenlang wurde ich deren Fußball, bis einer mir den Revolver auf die Brust setzte. ,Der Lump wird umgelegt!' Sodann mimten die Herren der SS ein Schnellgerichtsverfahren mit dem Urteil: ,Der Häftling wird sofort standrechtlich erschossen!'“384 Die Androhung der Exekution gehörte in der „SK-Isolierung“ des KZ Sachsenhausen zum psychischen Folterarsenal. Regelmäßig wurde den Neueingelieferten prophezeit, daß man schon dafür sorgen werde, daß sie keine Zeugen Jehovas blieben, wobei die „Kraftproben“ nicht selten schon am ersten Tag zu den bestialischsten Mißhandlungen führten konnten. Eine solche Szene beschreibt Alexander Joseph, der im September 1939 wegen „Rundfunkvergehens“ (Abhören von Auslandssendern) ins KZ Sachsenhausen eingeliefert wurde: „Ein Bibelforscher brach unter den Mißhandlungen durch Schubert zusammen. Dabei wurde er von einem SS-Mann gefragt: ,Glaubst du noch an Jehova?' Als der Bibelforscher bejahte, trat Schubert ihn weiter und

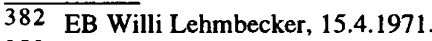

383 Ebenda. Weitere Berichte über die Einlieferungszeremonien und -rituale sind veröffentlicht in: Jehovas Zeugen in Gottes Vorhaben, S. 166f.

384 UaP Rolf Zehender, Aufzeichnungen Gerhard Oltmanns. 
fragte abermals. Das wiederholte sich 4 bis 5 Male. Schließlich hauchte der Bibelforscher nur noch , $\mathrm{Ja}^{\mathrm{a}}$ '“"385

Um die Standhaftigkeit der Bibelforschergemeinde zu erschüttern, griffen die SS-Schergen einzelne heraus, an denen sie ein Exempel zu statuieren beabsichtigten. So verkündete im Frühjahr 1939 ein SS-Blockführer in Sachsenhausen, daß er es den Bibelforschern und ihrem Gott Jehova beweisen werde, wer der Stärkere sei. Er erklärte seinen „Gesinnungsgenossen“ von der SS, ihm werde es gelingen, zwei junge, ungefähr 20jährige Bibelforscher innerhalb von zehn Tagen soweit zu haben, daß sie abschwüren ${ }^{386}$. Dieser SS-Blockführer, im Lager als ,der Windhund" bekannt, schikanierte und quälte die beiden Betroffenen von Tag zu Tag mehr. DaB sie das Ende des zehnten Tages überhaupt überleben konnten, verdankten sie einer von Mitgefangenen bewerkstelligten Hilfsaktion. Diesen gelang es, mit einer geschickten Inszenierung den Blockführer, der sich hin und wieder in der Lagerschreinerei etwas für seine Privatzwecke herstellen ließ, bei der Lagerleitung als Groß-Schieber auffliegen zu lassen ${ }^{387}$.

In einem Fall, der im Lager Sachsenhausen großes Aufsehen erregte, zog sich die „Kraftprobe“ über Jahre hin. Dr. Werner Koch, der als evangelischer Pfarrer vom 13. Februar 1937 bis zum 1. Dezember 1938 Häftling des KZ Sachsenhausen war, berichtet in seiner Autobiographie: ,Einer von ihnen - er heißt Rachuba - weigert sich, seine Mütze herunterzureißen und stramme Haltung anzunehmen, wenn die Hakenkreuzfahne gehißt wird. ,Das ist Götzendienst', sagt er, womit er ja recht hat! Immer wieder wird er über den Bock gespannt und in Dunkelarrest gesperrt. Aber er beugt sich nicht. Seine körperliche Widerstandsfähigkeit ist ein Phänomen, das von uns ebenso bestaunt wird wie von der SS." 388 Der ehemalige Gefangene Willy Henschel erklärte, daß der „Bibelforscher Rachuba“, der „,on Sorge immer wieder gepeinigt worden" sei, obgleich er nur noch kriechen konnte, trotz seines Zustandes ,eine große Überlegenheit über seine Peiniger ausgestrahlt" habe ${ }^{389}$.

Bei diesem Mann, der als "Seele des Widerstandes" der inhaftierten Bibelforscher galt, handelte es sich um den Bergmann Johann Ludwig Rachuba, der im Alter von 39 Jahren am 28. Juni 1935 verhaftet und von der Gestapo direkt in das Lager Esterwegen eingewiesen worden war ${ }^{390}$. Bei der Auflösung dieses emsländischen Lagers im September 1936 war er zusammen mit den anderen dortigen Gefangenen in das an dessen Stelle tretende KZ Sachsenhausen verlegt worden. Der dreifache Familienvater, der bereits in Esterwegen schwere Mißhandlungen erleiden mußte, war von einer Willensstärke und Kühnheit, die für die SS offensichtlich eine Herausforderung darstellte. Die SS-Schergen in der Sachsenhausener Isolierung setzten alles daran, diesen Mann, der sich standhaft weigerte, beim Ab-

385 Alexander Joseph, Aussage vom 24.11.1958 vor dem Landgericht Bonn im Verfahren gegen Schubert und Sorge (KZ Sachsenhausen), KZ-Verbrechen vor deutschen Gerichten, S. 209.

386 SS-Leute sollen im Fall solcher „Kraftproben“ mit Zeugen Jehovas sogar Wetten über deren Ausgang abschlossen haben. Vgl. Langhoff, Moorsoldaten, S. 313.

387 EB Richard Rudolph, 31.5.1986, 9.9.1986.

388 Koch, W., Leben im Widerstand, S. 218.

389 Willy Henschel, Aussage vom 23.11.1958 vor dem Landgericht Bonn im Verfahren gegen Schubert und Sorge (KZ Sachsenhausen), KZ-Verbrechen vor deutschen Gerichten, S. 197.

390 Zur Biographie Rachubas vgl. auch John, Wewelsburg (1996), S. 141-143. 
spielen des „Horst-Wessel-Liedes“ die Mütze abzunehmen, zum Abfall von seinem Glauben zu bringen. In der Urteilsschrift des 1958/59 vor dem Landgericht Bonn gegen Sorge und Schubert geführten Verfahrens heißt es dazu: „Die Lagerführung war der Ansicht, daß sich viele Bibelforscher zur Wehrmacht melden würden, wenn entweder Rachuba die Wehrdienstverpflichtungserklärung unterschreiben oder getötet sein würde, so daß sein tägliches Beispiel des Widerstandes seinen Glaubensgenossen nicht mehr vor Augen war. Den geringen Erfolg, den die Lagerführung bei der Verpflichtungserklärung zum Wehrdienst der Bibelforscher hatte, kam ihr sehr ungelegen, weil sich Himmler bei jedem Lagerbesuch ausdrücklich nach der Zahl der abgegebenen Erklärungen der Bibelforscher erkundigte. "391

Um den Willen des Bibelforschers zu brechen - dies und nicht die Tötung versprach in den Augen der SS einzig den gewünschten „Erfolg“ -, reihte die SS Mißhandlung an Mißhandlung. Neben den offiziellen „Lagerstrafen“, die sich bei Rachuba laut „Strafkarte“ auf insgesamt zwölf summierten ${ }^{392}$, traten willkürliche Folterungen. So mußte Johann Rachuba eine mit Sand vollbeladene Holzkarre, auf Knieen und Händen kriechend und mit dem Nacken vorwärts stoßend, im Sand weiterschieben. Dabei, so berichtete sein Glaubensbruder Paul Buder, ,wurde er mit den Stiefeln getreten, wohin es gerade beliebte“393. Doch der Bergmann blieb unbeugsam und im Willen ungebrochen. Seine Zähigkeit zeigte allen anderen Gefangenen, daß auch die Gewalt der SS ihre Grenzen hatte und gegen eine schier unerschütterliche Glaubenskraft nichts auszurichten vermochte. Dies hinterließ auch bei Häftlingen der anderen Kategorien einen tiefen Eindruck: „Rachuba, nachdem er 25 Stockhiebe ohne Stöhnen hingenommen hatte, stand auf und ging in seinen Block, was nur selten geschah." 394

$\mathrm{Zu}$ welchen Bestialitäten die SS-Schergen griffen, zeigt eine Begebenheit aus dem Jahre 1938. Dazu sagte vor dem vom 23. Oktober bis 1. November 1947 in

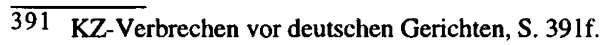

Himmler lieB sich Berichten zufolge bei Lagerinspektionen oftmals Bibelforscher-Häftlinge vorführen, um diese persönlich aufzufordern, ihrem Glauben abzuschwören. Vgl. Jahrbuch 1974, S. 174; Langbein, Widerstand, S. 188; Der Prozeß gegen die Hauptkriegsverbrecher, Band XI, S. 563; MGRa, RA, Bd. 25, Nr. 332, Berta Hartmann: Erlebnisse der Zeugen Jehovas in den Frauen-Konzentrationslagern. Unveröffentlichtes Manuskript, 1948, S. 3.

392 Die bei Buder in Abschrift wiedergegebene „Strafkarte“ weist folgende Eintragungen auf: „13.8.35: Krummschließen, weil er keinem Befehl nachkam; 1.7.36: 10 Tage strengen Arrest und 25 Stockhiebe, weil er die Arbeit verweigerte; 5.11.36: 10 Tage Arrest und 25 Stockhiebe, weil er Reklame für Jehova im Lager machte; 11.1.37: 21 Tage strengen Arrest, weil er wiederholt die Arbeit verweigerte; 1.5.37: 18 Tage strengen Arrest, weil er die Arbeit verweigerte und sich disziplinlos benahm; 3.5.37: 21 Tage strengen Arrest, 3 Monate Strafkompanie, weil er während eines Gemeinschaftsempfangs die anderen Häftlinge aufhetzte und gegen die Regierung schimpfte; 7.3.38: 30 Tage verschärften Arrest und 25 Stockhiebe, weil er den ersten Schutzhaftlagerführer bei einer Belehrung auslachte; 6.4.38: 5 Tage strengen Arrest und 15 Stockhiebe, weil er sich weigerte, die verschärfte Haft zu unterschreiben; 12.8.38: 8 Tage strengen Arrest und 15 Stockhiebe, weil er während des Singens des Deutschlandliedes sitzen blieb und die Mütze nicht abnahm; 12.10.38: 2 mal 2 Stunden Pfahl wegen Faulheit; 18.10.38: 8 Tage Torstehen ohne Abendbrot; 13.9.40: 4 Stunden strafexerzieren, weil er sich während der Arbeit längere Zeit mit anderen Häftlingen unterhalten und nicht gearbeitet hat; 3.9.42: Verstorben an Körperschwäche." (KmW, KW D 87, Buder, Wewelsburg, S. 91) KmW, KW D 87, Buder, Wewelsburg, S. 92.

394 Karl Block, Aussage vom 23.11.1958 vor dem Landgericht Bonn im Verfahren gegen Schubert und Sorge (KZ Sachsenhausen), KZ-Verbrechen vor deutschen Gerichten, S. 197. 
Berlin-Pankow durchgeführten sowjetischen Militärtribunal über die im KZ Sachsenhausen verübten Verbrechen als Zeuge der ehemalige Häftling Otto Gede aus:

„Im Herbst 1938 arbeitete ich als Maurer beim Bau eines Sägewerkes. Dort waren auch Sträflinge, die Sektierer waren, eingesetzt. Eines Tages kamen Sorge und der Blockführer Bugdalle zur Arbeitsstelle und befahlen einer Gruppe von Häftlingen, eine Grube von Menschenhöhe zu graben. Als die Grube fertig war, stellten Sorge und Bugdalle einen Bibelforscher namens Rachuba hinein und schütteten ihn bis zum Hals mit Erde zu. Dann, als über der Erde nur noch der Kopf von Rachuba zu sehen war, spotteten Sorge und Bugdalla über ihn und begannen lachend, ihm auf den Kopf und ins Gesicht ihre Notdurft zu verrichten. Danach blieb Rachuba noch etwa eine Stunde in der Grube begraben. Als er ausgegraben und an die Oberfläche geholt wurde, war er noch am Leben, aber er konnte sich nicht mehr auf den Beinen halten. “395

Johann Rachuba wurde 1940 in das Außenlager Wewelsburg überstellt. Die ihm in Sachsenhausen zugefügten Mißhandlungen hatten ihre Spuren hinterlassen: „Sein Körper war voller Narben; normal gehen konnte er nicht mehr. Beide Beine zog er steif nach; denn die Muskeln waren zerschlagen. Aber immer war er glücklich ..."396 Am 3. September 1942 verstarb Johann Rachuba im Alter von 46 Jahren an „Körperschwäche“. Die SS hatte ihn töten können; seinen Willen konnte sie nicht zerstören.

In besonderer Weise trafen die mannigfachen Schikanen der SS die älteren und kranken Bibelforscher. Häftlinge, die nicht arbeiten konnten und nicht zum Arbeitseinsatz eingeteilt waren, durften nicht in der Häftlingsunterkunft, dem „Block“, bleiben. In Sachsenhausen, wie in den meisten anderen Konzentrationslagern, existierten für nicht zur Arbeit eingesetzte Gefangene sogenannte „Stehkommandos“; zeitweilig umfaßten die Stehkommandos in Sachsenhausen ungefähr $2.000 \mathrm{Häft-}$ linge ${ }^{397}$. Die Gefangenen mußten den ganzen Tag außerhalb der Baracken stehen. Für die Invaliden - unter den Bibelforschern in Sachsenhausen gab es etliche Kriegsversehrte des Ersten Weltkrieges, die zum Teil Prothesenträger waren - war das eine furchtbare Qual: „Den ganzen Tag auf einer Stelle stehen, den ganzen Tag, bei Hitze und Kälte, bei Wind und Regen. Die sind da eingegangen wie die Flie-

$\overline{395}$ Otto Gede, Aussage vor dem vom 23.10. bis 1.11.1947 in Berlin-Pankow durchgeführten sowjetischen Militärtribunal, Todeslager Sachsenhausen, S. 43 (die Schreibweise der Namen Rachuba und Bugdalle wurde korrigiert; zur Bezeichnung der Bibelforscher als „Sektierer“ in dieser Prozeßdokumentation siehe S. 22, Anm. 50). Der gleiche Vorgang kam in dem vom 13.10.1958 bis 6.2.1959 vor dem Landgericht Bonn gegen Schubert und Sorge geführten Prozeß erneut zur Verhandlung (vgl. KZ-Verbrechen vor deutschen Gerichten, S. 196f.). Während Zeugenaussagen und die staatsanwaltschaftlichen Ermittlungen den Vorgang bestätigten, erklärte der Angeklagte Sorge, der vor dem sowjetischen Militärtribunal 1947 noch zugegeben hatte, daß im Herbst 1938 beim Waldstubbenroden ,einer der Sektierer auf meinen persönlichen Befehl in die Erde eingegraben" wurde (Todeslager Sachsenhausen, S. 43; Sorge weiter: „So verfuhren wir mit Sektierern“), nunmehr, daß der Befehl zur Eingrabung von der "Lagerleitung" veranlaßt worden sei. Auch bestritt er vor der bundesdeutschen Justiz mit Entschiedenheit, ,seine Notdurft über den Kopf des Eingegrabenen verrichtet“ zu haben (KZ-Verbrechen vor deutschen Gerichten, S. 392f.). Das Bonner Landgericht, das Sorge des Mordes in 67 Fällen für schuldig befand und ihn zu lebenslangem Zuchthaus verurteilte, erkannte für „die versuchte gemeinschaftliche Ermordung des Bibelforschers Rachuba“ unter Berücksichtigung der „,besonderen Intensität des Vorgehens" auf zwölf Jahre Zuchthaus.

397 Vgl. Naujoks, Sachsenhausen, S. 166; Pingel, Häftlinge, S. 260, Anm. 81. 
gen.“398 Hatten die Zeugen Jehovas diese Qualen auch mit ihren Mitgefangenen gemeinsam, so nutzte die SS dennoch auch diese Stehkommandos gerade zur Verhöhnung der Bibelforscher. Sie bekamen Schilder in die Hand gedrückt, auf denen Sprüche standen wie „Wir sind Jehovas Idioten“, „Wir sind Himmelskomiker“ etc. Den Bibelforschern wurde befohlen, mit diesen Schildern im Kreise zu gehen. SSLeute und auch einige „Funktionshäftlinge“399 standen oft feixend dabei und machten sich über die alten, humpelnden Gestalten lustig.

Auch in den Blocks wurden die Bibelforscher terrorisiert. Nicht selten kamen Blockführer mitten in der Nacht - und zumeist alkoholisiert -, um ihren „Mut“ an den „Himmelskomikern“ zu kühlen. Dann mußten die Gefangenen beispielsweise raus aus den dreistöckigen Holzpritschen und mehrere Runden um die Baracke drehen. Oder es wurde befohlen, daß sie unter die wenigen Tische zu kriechen hatten, wobei bei keinem eine Hand oder ein Fuß herausschauen durfte, da sonst von den SS-Schergen drauf getreten wurde. Die sich auf engstem Raum drängelnden Häftlinge mußten dann ein Lied anstimmen ${ }^{400}$. Die Zeugen Jehovas waren in den Isolierblocks dauernden Schikanierungen in bezug auf die Spindordnung und den Bettenbau ausgesetzt, an denen sich auch „Funktionshäftlinge“ - teils auf Geheiß der SS, teils aus eigenem Antrieb - beteiligten ${ }^{401}$. Für Nichtigkeiten wurde Strafexerzieren, von der SS auch „Sport“ genannt, angeordnet: „Das war kein Sport im Sinne des Wortes, sondern eher Mord; denn manch ein Häftling, der herzkrank

398 EB Richard Rudolph, 9.9.1986.

399 Als Hilfsmittel bei der Organisierung des Lagerbetriebes errichtete die SS eine „Häftlingsselbstverwaltung“, die sich im Aufbau sowohl an überlieferte Formen aus dem Gefängniswesen als auch an militärische Strukturen anlehnte. „Lagerälteste“, „Blockälteste" und „Stubenälteste" waren für den reibungslosen Ablauf des Lagerlebens gegenüber der SS verantwortlich. Für die Arbeitskommandos wurden „Kapos“ und „Vorarbeiter" eingesetzt, die die Aufsichtsfunktion der Wachmannschaften unterstützen sollten. Durch Besserstellung dieser sogenannten „Funktionshäftlinge“ versuchte die SS Zwietracht und Mißgunst unter den KZ-Gefangenen zu säen und hoffte, in ihnen willige Werkzeuge zu haben. Die Einflußmöglichkeiten der Funktionshäftlinge waren beträchtlich, und je nach Persönlichkeit konnten sie diese zum Nutzen oder zum Nachteil der anderen Häftlinge einsetzen.

400 Vgl. Jahrbuch 1974, S. 164f.; EB Richard Rudolph, 31.5.1986; EB Alois Moser, 23.5. 1986; VVN, Komiteeakten H 34, Emil Horn, Bericht vom 28.8.1949.

401 Berichten von Zeugen Jehovas zufolge haben sich in der Isolierung in Sachsenhausen einige der zumeist politischen „Funktionshäftlinge“ gegenüber der SS durch ihren Elan beim Vorgehen gegen „bibelforscherische Aktivitäten“ zu profilieren versucht bzw. sich bemüht, die Aufmerksamkeit der SS auf jene abzulenken. Von daher ist das Urteil in manchen Berichten der Zeugen Jehovas über die „Häftlingsfunktionäre“ mit Bitternis erfüllt. Doch nicht über alle politischen „Funktionshäftlinge“ wird in dieser Weise berichtet. Einige werden vielmehr ausdrücklich wegen ihrer gruppenübergreifenden solidarischen Haltung gewürdigt. Zu ihnen gehört Albin Lüdke, der als Kommunist seit 1933 im KZ Esterwegen und später als „politisch Rückfälliger" in Sachsenhausen und Neuengamme inhaftiert war. Über ihn schreibt Paul Buder in seinen Erinnerungen: „Eines Abends, 10.00 Uhr. Alles raus aus den Betten! Nackt ausziehen! Raus in den Schnee! Der Schnee war rot vom Blut der Geschlagenen! - Albin Lüdke aber schlug auch! Was ist denn mit dem los?, denke ich. Man suchte die Bibel bei uns! Und fand sie nicht! Denn Lüdke hatte sie in der Tasche! Ja, Paul, damit ich nicht auffiel, mußte ich auch etwas schlagen. “” (KmW, KW D 87, Buder, Wewelsburg, S. 97) Ein ähnlicher Akt des Beistandes hatte für Lüdke in Sachsenhausen die Ablösung als Blockältester zur Folge. Seine Solidarität haben ihm die Zeugen Jehovas nie vergessen. Einer der ihren, Alfons Kupka, dankte 1949 schriftlich dem ,lieben Kameraden Albin“ für die den Bibelforschern erwiesene Kameradschaft, insbesondere für den Einsatz in Sachsenhausen, „wo Du vieles auf Dein Konto nahmest, um uns zu schützen“ (VVN HH, Komiteeakten K 41, Alfons Kupka, Schreiben vom 30.11.1949). 
war, blieb tot liegen. Drei SS-Männer kommandierten: ,Auf, nieder, hinlegen, rollen!', bis zum Erbrechen, und dies alles auf einem Platz, der aus staubiger, schwarzer Kohlenschlacke bestand. “402

Im Winter 1939/40, der mit Minustemperaturen bis zu $30 \mathrm{Grad}$ Celsius besonders streng war und in dem es in Sachsenhausen eine große Zahl von Todesopfern gab - zwischen Januar und Mai 1940 wurden insgesamt 2.184 Tote registriert ${ }^{403}$-, erreichten die Leiden der Zeugen Jehovas in der „Isolierung“ ihr größtes Ausmaß. Viele wurden damals regelrecht zugrunde gerichtet. Dutzende starben infolge von Hunger und Entbehrungen, durch völlige Entkräftung beim stundenlangen Appellstehen und in den Stehkommandos.

Mindestens einmal, nach anderen Angaben drei- bis viermal, wurden Anfang 1940 in Sachsenhausen Bibelforscher-Häftlinge erstickt. Zu diesem Zweck sperrte die SS ungefähr 25 Gefangene in die Besenkammer. Diese war sehr schmal, ungefähr einen Meter breit und circa drei bis dreieinhalb Meter lang, oben war nur ein kleines Fenster. Die Schlüssellöcher wurden von außen mit Papier verstopft, Fenster und Türen mit Schlafdecken abgedichtet. Die Tür wurde für zwölf Stunden geschlossen gehalten. Nach den Angaben von Paul Wauer haben 15 Zeugen Jehovas diese Tortur nicht überlebt ${ }^{404}$. Im Bericht seines Glaubensbruders Willi Lehmbecker heißt es: „Man hörte die Menschen schreien und niemand konnte helfen." 405

Um die Abkehr vom Bibelforscherglauben zu erzwingen und die Gefangenen zu veranlassen, Jehova zu verleugnen ${ }^{406}$, wüteten Bugdalle, Sorge und die anderen SS-Schergen mit einer unbeschreiblichen Brutalität. Zu ihrem Folterarsenal gehörten: Ertränken, Spießrutenlaufen, einen Häftling vom Baum schütteln, der zuvor gezwungen wurde, hinaufzuklettern, Häftlingen bis zum Eintritt des Todes mit einem Wasserschlauch auf die Herzgegend spritzen, Einführen von Schläuchen in Körperöffnungen, Durchnäßte bei Frost im Freien stehen lassen, bis sie erfroren.

Insgesamt sind, soweit bekannt, im Winter 1939/40 in Sachsenhausen 130 Zeugen Jehovas - und damit ungefähr jeder vierte Bibelforscher-Häftling - ums

$\overline{402}$ Jehovas Zeugen in Gottes Vorhaben, S. 167; vgl. auch Geschonneck, Meine unruhigen Jahre, S. 90; Sachsenhausen, Dokumente, S. 51.

403 Vgl. Wolff, Sachsenhausen, S. 17.

404 BHStA, OMGUS, Dachauer KriegsverbrecherprozeB, Mikrofilm 1a/1, Nr. 182f., Paul Wauer, Aussage vom 21.5.1945.

405 EB Willi Lehmbecker, 15.4.1971.

406 Vgl. Kater, Bibelforscher, S. 210. Zahlreiche Grausamkeiten waren darauf gerichtet, die Taufe zu verhöhnen. Johann Wrobel, der als Häftlings-Vorabeiter im Kommando Garagenbau in Sachsenhausen eingesetzt worden war, berichtete, daß SS-Oberscharführer Wilhelm Schubert einmal die Zeugen Jehovas auf dieser Arbeitsstelle aufgefordert habe, einen alten jüdischen Häftling, den er über eine Lore mit Wasser hielt, zu „taufen“. In dieser Zwangslage waren die Bibelforscher bereit, dem ihren Glauben verspottenden Wunsch nachzukommen, zur Mißhandlung des Mitgefangenen gaben sie sich aber nicht her: „Wir bestrichen ihm die Stirn symbolisch mit Wasser. Schubert, ergrimmt über unsere Resistenz, hielt ihn ganz ins Wasser, und als er losließ, fiel der jüdische Häftling um. Schubert hatte ihn erdrosselt und ersoffen." (Johann Wrobel, Aussage vom 23.11.1958, KZ-Verbrechen vor deutschen Gerichten, S. 196; vgl. auch die bei Langbein, Widerstand, S. 191, wiedergegebene diesbezügliche Zeugenaussage von Wrobel vor dem Düsseldorfer Treblinka-Prozeß am 1.2.1965) 
Leben gekommen ${ }^{407}$. Neben einer zur gleichen Zeit im KZ Mauthausen durchgeführten Vernichtungsaktion ${ }^{408}$ forderten die Verbrechen in der Sachsenhausener "Isolierung“ die höchste Zahl an Opfern unter den Bibelforscher-Häftlingen. Die Terrorgewalt gegen die IBV-Angehörigen ging aber nicht nur auf die Willkür von niedrigen SS-Chargen zurück; auch die Führungsspitze des „Dritten Reiches“ hielt ein rigoroses Vorgehen gegen Kriegsdienstgegner wie die Zeugen Jehovas für angebracht.

\section{Die Gestapo-Exekutionen}

Zu Kriegsbeginn steigerte die SS auf Anweisung „von oben“ ihre „Bemühungen“, die Zeugen Jehovas im wehrpflichtigen Alter zur Abgabe von Erklärungen zu veranlassen, mit denen sie ihre Bereitschaft zum Wehrdiensteinsatz bekunden sollten. Der Chef der Sicherheitspolizei, Reinhard Heydrich, hatte zu dieser Zeit den folgenschwersten Eingriff in die der Justiz zukommenden Obliegenheiten der Strafverfolgung bereits lanciert. Als letzten Schritt zur Etablierung einer konkurrierenden „Polizeijustiz“ verfügte Heydrich die Vollstreckung von verfahrenslosen Exekutionen. An die Stelle von gerichtlichen Todesurteilen trat der Befehl des Reichsführers-SS.

Mit geheimem Runderlaß vom 3. September 1939 hatte Heydrich den Leitern aller Staatspolizei(leit)stellen „Grundsätze der inneren Staatssicherung während des Krieges“ übermittelt, deren einleitende Bestimmung lautete: „Jeder Versuch, die Geschlossenheit und den Kampfwillen des deutschen Volkes zu zersetzen, ist rücksichtslos zu unterdrücken. " 409 Für das polizeiliche Vorgehen gegen ,jede defaitistische Regung" wurde alles auf Schnelligkeit abgestellt: sofortige Festnahme, unverzügliche Berichterstattung an den Chef der Sicherheitspolizei, „da gegebenenfalls auf höhere Weisung brutale Liquidierung solcher Elemente erfolgen“ werde. Mit diesen „Grundsätzen“ hatte sich die Gestapo - jenseits der „Kriegssonderstrafrechtsverordnung“ - ein eigenes Instrumentarium zur Bekämpfung von ,Zersetzungsäußerungen“ und sogenannten „Kriegsdelikten“ geschaffen. Das nahe Berlin gelegene KZ Sachsenhausen diente der Gestapo fortan als Exekutionsort.

Am 15. September 1939 rüstete man dort zu der ersten öffentlichen Hinrichtung 410 . Die Lagerleitung hatte ,,in aller Stille“411 in der Zimmerei aus dicken Boh-

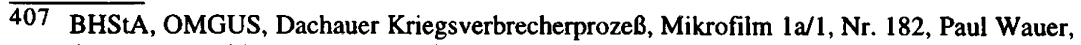
Aussage vom 21.5.1945; vgl. auch Todeslager Sachsenhausen, S. 43.

408 Siehe S. 325, Anm. 19.

409 BA, R 58/243, B1. 278-280 (278), Der Chef der Sicherheitspolizei, Erlaß vom 3.9.1939. In einer Präzisierung vom 20.9.1939 erläuterte Heydrich „zur Beseitigung aller Mißverständnisse“, daß zwischen den Fällen zu unterscheiden sei, ,,die auf dem bisher üblichen Wege erledigt werden können und solchen, welche einer Sonderbehandlung zugeführt werden müssen " - womit erstmals jener euphemistische terminus technicus gebraucht wurde. "Sonderbehandlung" sei in den Fällen angebracht, „die hinsichtlich ihrer Verwerflichkeit, ihrer Gefährlichkeit oder ihrer propagandistischen Auswirkung geeignet sind, ohne Ansehen der Personen durch rücksichtslosestes Vorgehen (nämlich durch Exekution) ausgemerzt zu werden." (BA, R 58/243, Bl. 213f., Der Chef der Sicherheitspolizei, Fernschreiben vom 20.9.1939)

410 Der Hinrichtung Dickmanns waren im KZ Sachsenhausen bereits einige vom RFSS angeordnete Exekutionen vorausgegangen; diese wurden jedoch nicht öffentlich vollzogen.

411 Naujoks, Sachsenhausen, S. 142. 
len eine Doppelwand fertigen lassen, deren Zwischenraum mit Sandsäcken ausgefüllt wurde und die als Kugelfang diente. Auf dem Appellplatz war ein kleiner Kiesberg aufgeschüttet worden. Für die Häftlinge gab es an diesem Freitag früher als sonst Feierabend. Nach dem Abendappell, der dieses Mal ,in großer Eile“ abgewickelt wurde, durften die Gefangenen nicht abtreten. Die Bibelforscher wurden nach vorn gerufen und mußten in der ersten Reihe in unmittelbarer Nähe zur Todeswand antreten. Um den Appellplatz nahmen zwei Züge SS-Wachmannschaften Stellung. Der Überzug, der die in Anschlag gebrachten Maschinengewehre verdeckte, wurde entfernt.

Die SS, die ein Exempel zu statuieren beabsichtigte, inszenierte ein ,großes Schauspiel“. Aus dem Zellenbau wurde ein an den Händen gefesselter Gefangener vorgeführt. Es handelte sich um den 39jährigen August Dickmann aus Dinslaken, der nach Verbüßung einer Gefängnisstrafe im Oktober 1937 ins KZ Sachsenhausen eingeliefert worden war, obgleich er die „Verpflichtungserklärung“ unterschrieben hatte $^{412}$. Im Lager hatte Dickmann später um Annullierung der Unterschrift gebeten. Anfang September, drei Tage nach Kriegsbeginn, war er wohl auch deshalb zur „Politischen Abteilung“413 gerufen worden. Seine Frau hatte ihm den Wehrpaß ins Lager nachgesandt, als dieser an seine Heimatadresse geschickt worden war. Dies nahm die Gestapo zum Anlaß, den Zeugen Jehovas aufzufordern, sich zur Wehrdienstleistung bereit zu erklären. August Dickmann, der, bevor er den Gang zur „Politischen Abteilung“ antreten mußte, seinen Glaubensbrüdern verkündet hatte, die SS könne mit ihm machen, was sie wolle, er werde ,keinen Kompromiß mehr eingehen“, weigerte sich. Die SS beließ es jedoch nicht dabei, ihn zu verprügein: Der Zeuge Jehovas wurde anschließend nicht, wie bei den „Befragungen“ in der Vorkriegszeit üblich, zurück in den Block geschickt, sondern im Arrestbunker in eine Einzelzelle gesperrt. Aufgrund der Abfolge der Ereignisse kann davon ausgegangen werden, daß die Gestapo, während Dickmann dort einsaß, über den Vorgang nach Berlin berichtet hat, wo man zu der Auffassung gelangt sein muß, daß der Verweigerungsfall sich für die in den „Grundsätzen“ zur Bekämpfung von Kriegsvergehen vorgesehene „Sonderbehandlung“ eigne. An jenem 15. September sollte diese nunmehr im KZ Sachsenhausen „vollzogen“" werden.

Nachdem der Zeuge Jehovas vor die Holzwand geführt worden war, versuchte die SS ihn noch im Angesicht des Todes moralisch zu zermürben. Vor dem Kugelfang dirigierte man ihn hin und her, einen Schritt nach rechts, einen nach links. Dann wurden die Lautsprecher angeschaltet und der Lagerkommandant Hermann Baranowski, mittlerweile zum SS-Oberführer und somit in den Generalsrang erhoben, verlas über Mikrophon die Exekutionsanordnung, wonach August Dickmann wegen Wehrdienstverweigerung auf Befehl des Reichsführers-SS zu erschießen sei. Anschließend richtete Baranowski an den Todeskandidaten die Worte: „Kommando: Kehrt“. Über die folgende Minute berichtete der Hamburger Kommunist und seinerzeitige „Erste Lagerälteste“ von Sachsenhausen, Harry Naujoks:

412 Zur Einlieferung in KZ-Haft trotz Unterschriftsleistung siehe S. 313.

413 Die Bezeichnung „Politische Abteilung“ trug die Dienststelle der Gestapo in den einzelnen Konzentrationslagern. Bei ihr wurden alle Fragen um Einweisung und Entlassung der "Schutzhäftlinge" bearbeitet und die Schutzhaftakten verwaltet. 
„Dann trat das Erschießungskommando vor die Wand und gab auf Kommando Feuer. August Dickmann brach zusammen. Auf einen Wink Baranowskis sprang sein Adjutant Hauptsturmführer Höß an den auf der Erde Liegenden heran, zog die Pistole und schoß ihm in den Kopf. Der Körper bäumte sich noch einmal auf, und dann war alles zu Ende. “414 Vier Bibelforscher, unter ihnen Heinrich Dickmann, der Bruder des Erschossenen, mußten die Leiche in den bereitstehenden Sarg legen. Heinrich Dickmann mußte ihn zunageln.

Nach der Erschießung wurde den meisten Häftlingen wegzutreten befohlen. Obgleich in Sachsenhausen der Tod längst als täglicher Begleiter zum Leben der Gefangenen gehörte, herrschte innerhalb der Lagergemeinschaft Entsetzen und - vielleicht erstmals - ein breit getragenes Solidaritätsgefühl mit den auch von ihren Mitgefangenen bis dahin oftmals nur belächelten Zeugen Jehovas. Der bayerische Arzt und Räterevolutionär Arthur Schinnagel berichtet über diesen Vorgang: „Nach der Heimkehr in die Baracken standen die Häftlinge bewegt in Gruppen zusammen und äußerten sich mit schlichten Worten der Anerkennung über einen Mithäftling, welcher für seine Überzeugung in den Tod gegangen war." 415

Die Bibelforscher-Häftlinge hatten indes auf dem Appellplatz verbleiben müssen. Kommandant Baranowski richtete an sie eine Ansprache und kündigte an, daß ihnen allen das gleiche Schicksal bevorstünde, wenn sie nicht die ,Verpflichtungserklärung" unterschreiben und ihre Wehrdienstverweigerung aufgeben würden. Nach Angaben des Zeugen Jehovas Gustav Auschner drohte er ihnen, daß sie zu je 30 bis 40 Mann in die Sandkuhle geführt und erschossen werden würden ${ }^{416}$. Baranowski habe befohlen, daß diejenigen, die nicht erschossen werden wollten, vortreten sollten. Nach einer längeren Pause seien zwei Zeugen Jehovas vorgetreten, aber nicht um zu unterschreiben, sondern um dem Kommandanten bekanntzugeben, daß sie sich unter dem Eindruck des Miterlebten nunmehr korrigieren möchten und deshalb ihre bereits vor etwa einem Jahr unter dem ,Revers“ geleistete

$\overline{414}$ Naujoks, Sachsenhausen, S. 142. Der von dem vormaligen Dachauer Schutzhaftlagerführer Baranowski im August 1938 aus Dachau angeforderte Rudolf Höß, dessen direkte Tatbeteiligung bei der Tötung Dickmanns mehrfach bezeugt ist, berichtete in seinen nach Kriegsende in der Untersuchungshaft in Krakau niedergeschriebenen Erinnerungen selbst ausführlich über die Erschießung von Zeugen Jehovas in Sachsenhausen (vgl. Kommandant in Auschwitz, S. 75-78). So sei im Fall von „zwei besonders fanatischen Bibelforschern“, die im Lager ihre Musterung verweigerten, von der Kommandantur aus diesem Grunde beim RFSS eine Exekutionsverfügung erwirkt worden. Nachdem den beiden Zeugen Jehovas dies im Arrest eröffnet worden war, seien sie - so die stark überzeichnete Schilderung des späteren KZ-Kommandanten von Auschwitz - ,außer Rand und Band vor Freude und Verzückung“ geraten: „Immer wieder rangen sie die Hände, schauten verzückt nach oben und riefen ununterbrochen: ,Bald sind wir bei Jehova, welch ein Glück, daß wir dazu auserwählt sind.“ Höß weiter: „Sie hatten schon einige Tage vorher einer Exekution ihrer Glaubensbrüder beigewohnt, wo sie kaum zu halten waren. Sie wollten immerzu ebenfalls erschossen werden. [...] Mit völlig verklärtem Gesicht, die Augen nach oben gerichtet, die Hände zum Gebet gefaltet und erhoben gingen sie in den Tod. Alle die dies Sterben sahen, waren ergriffen, selbst das Exekutionskommando." (Ebenda, S. 75f.)

415 Arthur Schinnagel, Bericht in: Niemand und nichts vergessen, S. 142; vgl. auch Naujoks, Sachsenhausen, S. 143. Wolfgang Szepansky urteilt: „Die SS-Führung wollte eine Demonstration veranstalten und hoffte auf eine Kapitulation ihrer Opfer, diese aber blieben standhaft bei ihrem Glauben und starben als Märtyrer. Das war eine Niederlage für die SS und wurde im allgemeinen so betrachtet." (Szepansky, Weg, S. 173)

Bericht von Gustav Auschner, zit. in: Erwachet!, 8.4.1989, S. 14. 
Unterschrift jetzt zurückzögen. Das Exempel schien das Gegenteil dessen bewirkt zu haben, was die SS beabsichtigt hatte. Berichten zufolge verließ Baranowski tobend und vor Wut schnaubend den Appellplat ${ }^{417}$. Die zwei Zeugen Jehovas sowie zwei weitere Glaubensbrüder, die schon seit längerem wegen Grußverweigerung eine Bunkerstrafe verbüßten, wurden anschließend auf den „Bock“ geschnallt und ausgepeitscht. Für alle Bibelforscher-Häftlinge gab es an diesem wie den folgenden Tagen „Strafsport“ und mannigfache weitere Schikanen ${ }^{418}$. Zugleich mußten sie in den nächsten Tagen nacheinander bei der „Politischen Abteilung“ erscheinen. Wie Heinrich Dickmann, der Bruder des Erschossenen, berichtet, haben ihm zwei Gestapo-Beamte, die extra aus Berlin angereist seien, um den „Effekt“ der öffentlichen Exekution zu beurteilen, auf seine Feststellung hin, er sei „Zeuge Jehovas und werde es' auch bleiben", erklärt, er werde dann der nächste sein, der erschossen werde ${ }^{419}$.

Obgleich einige Zeugen Jehovas in den Einzelbefragungen schließlich dem Druck nachgaben und den „Revers“ unterschrieben ${ }^{420}$, verzichtete die SS nach dieser fehlgeschlagenen Demonstration auf weitere öffentliche Exekutionen von kriegsdienstverweigernden Zeugen Jehovas ${ }^{421}$. Die in den nächsten Monaten und Jahren folgenden, vom Reichsführer-SS angeordneten Hinrichtungen einzelner IBV-Angehöriger, deren genaue Zahl unbekannt ist, für Sachsenhausen aber bei ungefähr zehn liegen dürfte ${ }^{422}$, betrafen - soweit bekannt - ausschließlich Fälle

417 Die Kommandoführung bei der Exekution von August Dickmann gehörte zu den letzten Amtshandlungen des Lagerkommandanten. Seit Mitte September 1939 konnte der 55jährige Hermann Baranowski aufgrund einer schweren Erkrankung seine „Dienstgeschäfte“ nicht mehr ausführen; Anfang 1940 verstarb er. Da die Zeugen Jehovas den Kommandanten „Vierkannt" seit langem verfluchten - nach Paul Buder schloß die Sachsenhausener Bibelforschergemeinde in ihr Gebet die Bitte ein: „Wenn Du, Jehova Gott lebst, dann zeige es diesem Mann" -, kursierte im Lager (stets ein Hort für derartige Gerüchte) und unter der SS (in vielem dem Aberglauben zugetan) die „Parole“, Baranowski sei „von den Bibelforschern in den Tod gebetet" worden (vgl. Jahrbuch 1974, S. 169; KmW, KW D 87, Buder, Wewelsburg, S. 12; EB Richard Rudolph, 9.9.1986). Für den Zeugen Jehovas und ehemaligen Sachsenhausen-Häftling Richard Rudolph ist diese wie auch ähnliche in der Literatur geschilderte Begebenheiten ein Zeichen dafür, ,wie weit die Phantasie“ im Lager tatsächlich gegangen sei.

gl. Der Wachtturm, 1.8.1991, S. 28 (Bericht von Ernst Wauer)

419 Zit. nach Graffard/Tristan, Bibelforscher, S. 85 (Rückübersetzung durch den Verf.).

420 Nach einem Bericht von Gustav Auschner haben in Sachsenhausen von den zu der Zeit ca. 450 Bibelforschern 16 bis 18 den „Revers“ unterschrieben. Die SS legte ihnen die Erklärung jeweils einzeln vor, um sie aus der Gemeinschaft lösen zu können (FGN, NHS 13-7-0-1, Auschner, Bericht vom 8.7.1969). In den Erinnerungen von Harry Naujoks, dem „Ersten Lagerältesten“, ist davon die Rede, daß sich nach der Erschießung von August Dickmann 90 Zeugen Jehovas zur Unterschriftsleistung bereit erklärt hätten, wobei Naujoks hinzufügt: „Viele zogen ihre Unterschrift aber wieder zurück.“ (Naujoks, Sachsenhausen, S. 143)

421 Auch für andere Konzentrationslager sind keine weiteren vom Reichsführer-SS wegen Kriegsdienstverweigerung angeordneten und $\mathrm{zu}$ Abschreckungszwecken öffentlich vollstreckten Exekutionen von Zeugen Jehovas bekannt. Es kann deshalb angenommen werden, daß der mit dem Fall Dickmann beschrittene Weg, bei Ablehnung der Wehrdienstleistung durch Bibelforscher-Häftlinge die Hinrichtung anzuordnen, eingestellt worden ist - wohl deshalb, weil die SS ansonsten fast alle in den Konzentrationslagern gefangengehaltenen Zeugen Jehovas vor die Todeswand hätte stellen müssen.

422 Über die Zahl der im KZ Sachsenhausen exekutierten Zeugen Jehovas liegen verschiedene Einzelangaben vor, wobei es sich teilweise auch um die gleichen Fälle handeln könnte: Mehrere Berichte sprechen davon, daß außer Dickmann noch zwei weitere Zeugen Jehovas Ende 1939 erschossen wurden (vgl. Szepansky, Weg, S. 173; EB Harry Dubinsky, 15.4.1986). Vermutlich Anfang 1940 wurden die Bibelforscher Weiß und Zibold erschossen (EB Richard 
von Zeugen Jehovas, die der „Lagerordnung“ zuwidergehandelt hatten (Grußverweigerung, Verweigerung der Arbeitsaufnahme in der Rüstungsindustrie u. ä.) oder die der Arbeitsdienstpflicht nicht nachgekommen waren. Die SS verlegte diese Exekutionen zumeist in die Abgeschiedenheit des Sachsenhausener Industriehofes, wo sich eine gesonderte Erschießungsanlage befand.

Meldungen über die Erschießung August Dickmanns wurden auch über Presse und Rundfunk bekanntgegeben. Die über das „Deutsche Nachrichtenbüro“ verbreitete Pressebekanntmachung des Reichsführers-SS und Chefs der Deutschen Polizei hatte folgenden Wortlaut: „Erschossen wurden: [...] 2. am 15.9.1939 wegen Weigerung, seine Pflicht als Soldat zu erfüllen, August Dickmann, geboren 7.1.10 aus Dinslaken. D. begründete seine Weigerung mit der Erklärung, er sei ,Zeuge Jehovas‘. Er war ein fanatischer Anhänger der internationalen Sekte der ernsten Bibelforscher. "423

Auch das Reichsjustizministerium erlangte erst durch Presseveröffentlichungen davon Kenntnis, daß SS und Gestapo begonnen hatten, mit außergerichtlichen Exekutionen „Kriegsdelikte“ zu ahnden ${ }^{424}$. Nachdem am 8. September erstmals in den Zeitungen eine Meldung über eine vom Reichsführer-SS angeordnete Hinrichtung erschienen war, hatte das Ministerium noch am selben Tag bei der Polizeiführung um Auskunft und Aufklärung gebeten. Von dort antwortete man, daß Hitler dem Reichsführer-SS eine entsprechende Ermächtigung erteilt habe. Zu einer weitergehenden Unterrichtung war SS-Gruppenführer Reinhard Heydrich nicht bereit; ,der Justizminister möge sich“, so lautete Heydrichs Rat, „unmittelbar mit dem

Rudolph, 9.9.1986). Im Verfahren gegen Schubert vor dem Landgericht Bonn wurde von der Erschießung von vier Zeugen Jehovas 1939/1940 im Industriehof berichtet (vgl. KZ-Verbrechen vor deutschen Gerichten, S. 198). Laut Höß handelte es sich während seiner Tätigkeit in Sachsenhausen (1.8.1938 bis 4.5.1940) um „eine ganze Anzahl“ (Kommandant in Auschwitz, S. 75). Grüber, Erinnerungen, S. 154, berichtet von einer weiteren Exekution aus dem Jahre 1941 an einem Zeugen Jehovas, der die Unterschrift unter dem „Revers“ wieder zurückgenommen hatte. Ende 1943 wurde der 17jährige Jonathan Stark erhängt (vgl. Leber, Lebensbilder, S. 20).

Die vor den Augen aller Gefangenen vollzogene Hinrichtung Dickmanns, die Androhung von Massenerschießungen, die standhafte Weigerung der Zeugen Jehovas, deren Absonderung in der den Gefangenen des großen Lagers nicht zugänglichen Isolierung sowie die später erfolgten einzelnen weiteren Exekutionen haben den Boden für verklärte Darstellungen bereitet. Beispielsweise soll der in Sachsenhausen im Zellenbau in Einzelhaft internierte Martin Niemöller davon berichtet haben, daß die SS ,eine zeitlang bei jedem Morgenappell einen Zeugen Jehovas“ herausholte. Sie habe ihn gefragt, , ob er jetzt bereit sei, Wehrdienst zu leisten. Verneinte er, so wurde er vor versammelter Mannschaft gehenkt. Alle verneinten, ohne Ausnahme“" (Hutten, Seher, S. 119; vgl. auch Bredemeier, Kriegsdienstverweigerung, S. 85). Unzutreffend ist auch die Feststellung Kogons, wonach zu Kriegsbeginn im KZ Sachsenhausen auf jede Weigerung der Bibelforscher hin ,,zehn aus ihren Reihen erschossen [wurden]. Nach vierzig Opfern gab es die SS auf.“ (Kogon, SS-Staat, S. 265) Diese Notiz bei Kogon, der sich als Buchenwald-Häftling bei der 1945 in kürzester Zeit erfolgten Abfassung seines Werkes hinsichtlich der anderen KZs auf die ihm zugetragenen Schilderungen verließ, ist in der Literatur vielfach als Beispiel für den Widerstand der Zeugen Jehovas übernommen worden (vgl. beispielsweise Langbein, Widerstand, S. 188). Unter Berufung auf Kogon und auf nicht näher bezeichnete Parallelberichte ,,in der gesamten KZ-Literatur“ ist bei Zipfel sogar die Rede von ,,regelrechten Massenerschießungen“ (Zipfel, Kirchenkampf, S. 195), die bei Kriegsbeginn in Sachsenhausen an Zeugen Jehovas vorgenommen worden seien.

423 Zitiert in einem Aktenvermerk des Reichsjustizministers Gürtner vom 28.9.1939, Broszat, Strafjustiz, S. 408.

424 Zum folgenden vgl. Broszat, Strafjustiz, S. 390ff.; Gruchmann, Justiz, S. 675-680. 
Führer in Verbindung setzen" 425 . Als am folgenden Tag der vom Chef der Wehrmachtrechtsabteilung um Stellungnahme gebetene preußische Ministerpräsident und Luftwaffenoberbefehlshaber Hermann Göring erklärte, „daß Todesstrafen niemals ohne Urteil vollstreckt werden könnten “426, verfestigte sich bei der Justiz der Verdacht, daß eine eigenmächtige Kompetenzausweitung seitens der SS- und Polizeiführung vorliegen könnte. Nachdem wenige Tage später in der Presse die Bekanntmachung über die Hinrichtung Dickmanns sowie eines weiteren „,wegen vorsätzlicher Brandstiftung und Sabotage“ erschossenen Mannes veröffentlicht wurde, wandte sich Reichsjustizminister Dr. Gürtner über den Chef der Reichskanzlei an Hitler. Gürtner, der hinsichtlich der ,im nichtbesetzten Gebiet des Reiches“ bei der Ahndung von Handlungen gegen die Kriegsgesetze gegebenen „konkurrierenden Zuständigkeit“ zwischen den Rechtsprechungsorganen einerseits und der Polizei andererseits prinzipielle Einwände geltend machte - und damit zugleich der SS stillschweigend das Recht zu verfahrenslosen Exekutionen in Polen zugestand -, stützte seine Gegenvorstellungen hauptsächlich auf das Argument, derartige Sondervollmachten für die Polizei seien völlig überflüssig, da die Justiz mit den ihr zur Verfügung stehenden Mitteln, insbesondere den Sondergerichten, vollauf in der Lage wäre, die ihr gestellte Aufgabe wahrzunehmen ${ }^{427}$. Am 14. Oktober ließ Hitler seinem Justizminister über den Chef der Reichskanzlei, Reichsminister HansHeinrich Lammers, mitteilen, daß eine allgemeine Vollmacht an die SS durch ihn nicht erteilt worden sei. Die drei von Gürtner beanstandeten Erschießungen, unter ihnen die von August Dickmann, habe er persönlich angeordnet. Auch zukünftig könne er im Einzelfall ,nicht darauf verzichten, weil die Gerichte (Militär- u. Civil-) den besonderen Verhältnissen des Krieges sich nicht gewachsen zeigten“428.

Es ist davon auszugehen, daß diese „Führerschelte“ im Justizministerium allerdings als unbegründet und ungerecht empfunden wurde. Die Verfahren gegen Kriegsdienstverweigerer endeten schließlich mit dem gleichen Resultat. Allein bis zu diesem Zeitpunkt, also in den ersten sechs Wochen des Krieges, hatten Wehrmachtgerichte in mindestens sechs Fällen Zeugen Jehovas wegen ,Zersetzung der Wehrkraft" zum Tode verurteilt ${ }^{429}$.

\section{Trotz allem die Kriegsproduktion abgelehnt}

Doch selbst angesichts des durch die Führungsspitze des „Dritten Reiches“ gedeckten rigorosen Vorgehens, der demonstrativen Macht der KZ-Kommandanturen und des brutalen Terrors der SS gelang es nicht, die Resistenz der Zeugen Jehovas

425 So die Wiedergabe in den Aufzeichnungen des Reichsjustizministers Gürtner vom 28.9.1939, Broszat, Strafjustiz, S. 408.

426 Zit. nach Gruchmann, Justiz, S. 678.

427 Aufzeichnungen des Reichsjustizministers Franz Gürtner vom 28.9.1939, abgedruckt in: Broszat, Strafjustiz, S. 408f.

428 So die Wiedergabe der durch Lammers übermittelten Worte Hitlers in einem Aktenvermerk Gürtners vom 14.10.1939, abgedruckt in: Broszat, Strafjustiz, S. 411. Gruchmann, Justiz, S. 679, äußert die Vermutung, daß es durchaus möglich sei, daß Hitler die Verantwortung für die drei erfolgten Erschießungen erst nachträglich ,übernommen“ hatte. 
$\mathrm{zu}$ brechen. Ähnlich wie in Sachsenhausen wurde auch in anderen Konzentrationslagern anläßlich von „Sonderappellen“ mit der Erschießung von allen ihre Verweigerungshaltung nicht aufgebenden Bibelforscher-Häftlingen gedroht. Im KZ Buchenwald wurden die Zeugen Jehovas wenige Tage nach Kriegsbeginn beim Appell durch den Schutzhaftlagerführer SS-Obersturmbannführer Arthur Rödl aufgerufen, sich zum Wehrdienst bereit zu erklären. Obgleich mit Maschinengewehren bewaffnete Wachtruppen Aufstellung genommen hatten und Berichten zufolge alles danach ausgesehen habe, ,als solle eine Massenexekution stattfinden“ ${ }^{430}$, meldete sich niemand. Zwar machte die SS ihre Drohung nicht wahr, doch hatte die Unnachgiebigkeit die strafweise Einweisung in das Steinbruch-Kommando und den zeitweiligen Ausschluß von jeglicher Behandlung im Krankenrevier zur Folge ${ }^{431}$.

Obgleich derartige „Sonderappelle“ mehrfach stattfanden ${ }^{432}$ und die SS jeweils mit harten Strafen und Essensentzug reagierte, blieb die Zahl derjenigen, die sich zum „Unterschreiben“ und zum „Abschwören“ bereit erklärten, insgesamt niedrig $^{433}$. Und dies, obwohl die SS auch versuchte, durch subtilere Methoden die Zeugen Jehovas dazu zu bewegen, ihren Glauben zu widerrufen und durch ihre Unterschrift zu bezeugen, daß sie bereit seien, in die Wehrmacht einzutreten. So mußten beispielsweise Zeugen Jehovas Briefe von Angehörigen, in denen sie zum Unterschreiben aufgefordert wurden, laut und öffentlich verlesen. $\mathrm{Zu}$ diesem Zweck wurde dann extra ein Schemel beim Appell aufgestellt, auf den der betreffende Häftling zu steigen hatte. Nach dem Verlesen wurde ihm die Frage gestellt, ob er denn nun unterschreiben würde. Verneinte dies der Bibelforscher - was regelmäßig passierte -, schlossen sich Schimpftiraden an und es setzte Prügel. Im KZ Mauthausen versuchte die Lagerleitung, die angetretenen Bibelforscher-Häftlinge noch auf andere Weise zu ,überzeugen“, wie Hubert Mattischek berichtet:

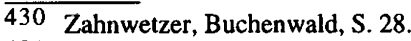

431 Vgl. Kogon, SS-Staat, S. 265.

432 Für das KZ Buchenwald wird von folgenden Daten berichtet: 6. Januar 1938, Ostersonntag 1939, Pfingsten 1939, 6. September 1939; vgl. Freund, Buchenwald, S. 128ff.; Grünewald, Geschichte der Kriegsdienstverweigerung, S. 30-33; Menzinger, Jugend, S. 119; DÖW, Nr. 1458, Otto Horn, Bericht über das KZ Buchenwald.

433 Genaue Angaben über die Zahl der Zeugen Jehovas, die in der KZ-Haft die „Verpflichtungserklärung" abgegeben haben, sind nicht möglich. Mit Sicherheit kann allerdings davon ausgegangen werden, daß der Anteil der „Unterschreibenden“ deutlich niedriger ist als bei der Vorlage des „Revers“ während der Gestapo-Haft bzw. nach Haftverbüßung (siehe S. 304f.). Nach den wenigen vorliegenden Angaben haben in Neuengamme von den dort insgesamt 140 bis 150 Zeugen Jehovas zwei Personen unterschrieben (vgl. Suchowiak, Mai 1945, S. 14; EB Karl Hanl, 24.11.1987). Im KZ Mauthausen sind bei einer Gesamtzahl von ca. 200 IBVHäftlingen im Jahre 1939 ein, 1940 drei und 1942 zwei Zeugen Jehovas - vermutlich nach Abgabe des „Revers“ - entlassen worden (vgl. Maršálek, Mauthausen, S. 273; Museum Mauthausen, Schreiben vom 18.6.1986 an den Verf.). Etwas größere Zahlen liegen für Buchenwald (30 abgegebene „Erklärungen“; Kautsky, Teufel und Verdammte, S. 139), für Sachsenhausen (bis zu 90, darunter viele Zurücknahmen; Naujocks, Sachsenhausen, S. 143) und für Ravensbrück vor; die 1943 dort heimlich abgefaßten „Briefe“" nennen eine Zahl von 50, die "mit dem Teufel Kompromisse" schlossen (UaP Gerhard Kaiser, Briefe. Nachrichten für die Zeugen Jehovas und ihre Gefährten, S. 5; vgl. auch Buber-Neumann, Gefangene, S. 248). Auch die - allerdings unbezifferten - Angaben der WTG (,eine große Anzahl Brüder“, Jahrbuch 1974, S. 178) deuten darauf, daß die Zahl der abgegebenen „Erklärungen“", wenngleich insgesamt gering, so doch größer gewesen sein wird, als es zuweilen in der Literatur und von Mitgefangenen anderer Gruppen dargestellt wird (vgl. beispielsweise Maislinger, Die Zeugen Jehovas/Tirol, S. 370; Wiechert, Totenwald, S. 150). 
„Man ließ Bibeltexte, aus dem Zusammenhang gerissen, vor uns allen verlesen, wie z. B. Matt. 22:21, wo davon die Rede ist ,dem Cäsar die Dinge zu geben, die des Cäsars sind“. Der Kommandant warf uns bei der Gelegenheit vor, daß wir selbst gegen die Bibel verstößen, wenn wir den Cäsar (er meinte Hitler und die deutsche Obrigkeit) bei seinen Forderungen nicht unterstützten. “434

Anläßlich von „Haftprüfungsterminen“, eingegangenen Anfragen von Wehrmeldeämtern oder aus anderen Gründen ${ }^{435}$ wurde den Bibelforscher-Häftlingen im Lagerführerbüro oder durch die „Politische Abteilung“ wiederholt die „Verpflichtungserklärung " zur Unterschrift vorgelegt. Den Zeugen Jehovas, von denen die im Abstand von einigen Monaten - manchmal auch von ein, zwei Jahren - vorgenommenen Befragungen auch als „Treuevernehmungen“ bezeichnet wurden, machte neben dem Ansinnen, ihren Glauben als „Irrlehre“ zu verwerfen, in den Kriegsjahren noch ein weiteres Moment das „Unterzeichnen“ unmöglich. Sie wußten, daß sie - insofern sie wehrpflichtig waren - nach der Haftentlassung mit einer Einberufung zur Wehrmacht zu rechnen hatten. Da für sie der feste Grundsatz galt, keine Waffe zu gebrauchen, stand ihnen vor Augen, mit der Unterschrift wahrscheinlich ihr eigenes Todesurteil zu unterzeichnen ${ }^{436}$. Schon deshalb sahen sie keine Möglichkeit, durch die „Verpflichtungserklärung“ ihre „Freiheit“" zu erlangen. Im KZ verblieb ihnen dagegen wenigstens die Hoffnung, daß Jehova Gott, dem sie treu geblieben waren, sie aus dem Leid und der Bedrängnis herausführen und retten werde. Der Gruppendruck, die unter ihnen herrschende soziale Kontrolle und die Angst, die Gemeinschaft mit den Glaubensgeschwistern aufzugeben, aber auch die Furcht, den zukünftigen himmlischen Lohn zu verlieren, taten ein übriges. Ein Zeuge Jehovas schildert seine damaligen Empfindungen: „Wenn ich sterben muß, nun - dann muß ich eben sterben, aber unterschreiben werde ich nicht. Ich dachte

$\overline{434}$ Bericht von H. Mattischek in: Hartmann, Kriegsdienstverweigerung (1982), S. 92-95 (94). Auch den Zeugen Jehovas gut gesonnene Mitgefangene versuchten diese davon zu überzeugen, daß es für sie besser sei, wenn sie die „Verpflichtungserklärung“ unterschrieben (vgl. Buber-Neumann, Gefangene, S. 246, 254 f.; dies., Milena, S. 172f.). Da die SS den Bibelforschern diese Möglichkeit biete, sollten sie nach deren Ansicht davon auch Gebrauch machen, um ihr schweres Los im Lager zu erleichtern. Die Mitgefangenen sahen in der Angelegenheit eher einen formalen Akt und rieten von daher zu einer taktischen Herangehensweise. So schlug der Blockälteste Albin Lüdke den Bibelforschern vor, für sich selbst die Unterschrift gar nicht ernst zu nehmen, denn es genüge ja, wenn die SS dies tue. Wenn sie von sich aus der Erklärung keine weitere Bedeutung beimessen würden, hindere sie dies schließlich nicht, ihre Überzeugung zu bewahren. Obgleich ein solches Votum die Bedeutung der „Loyalitätsfrage“ für die Zeugen Jehovas verkannte und jene hinter derartigen Argumenten gewöhnlich eine von "Satan“ ausgehende Versuchung sahen, gehörte Lüdke zu den jenen politischen Funktionshäftlingen, die sie gleichwohl sehr schätzten (siehe S. 418, Anm. 401).

Solche Anlässe konnten beispielsweise auch Briefe von Angehörigen sein. Vgl. dazu den ausführlichen Bericht von Albert van de Poel über die „Befragung“ des Zeugen Jehovas Ernst Raddatz (Poel, Neuengamme, S. 105-109). Danach wurde Raddatz 1942 zum Kommandanten befohlen und ihm dort ein Brief seiner Frau vorgelegt, in dem diese ihren Mann zu unterschreiben bat, da sie als alleinige Bewirtschafterin des Hofes am Ende ihrer Kräfte sei und sich nicht mehr zu helfen wisse. Der bei Poel wiedergegebene Dialog zwischen dem Kommandanten und Raddatz zeigt die Verkehrung der Welten: Der Kommandant steht fassungslos vor der Hartherzigkeit des Zeugen Jehovas, ohne auch nur entfernt zu begreifen, daß Raddatz in dem Gedanken, den eigenen Glauben zu verleugnen, für sich keine Handlungsalternative zu erkennen vermochte.

436 Vgl. Garbe, Gott mehr gehorchen, S. 206. 
an die Königin Esther, sie sagte: ,Wenn ich umkommen soll, so komme ich um. Ich war mir bewußt, wenn ich unterschreibe, dann wäre mein ganzes Glück dahin."437

$\mathrm{Da}$ die Versuche der SS fast vollständig fehlschlugen, hatte seinen Grund auch darin, daß die Gestapo zur Überprüfung der „Glaubwürdigkeit“ eine längere Beobachtungszeit für erforderlich hielt, bevor eine Haftentlassung verfügt wur$\mathrm{de}^{438}$. Durch das „Weiterverbleiben in Haft“" wollte sich der Reichsführer-SS - wie es in den Erinnerungen von Rudolf Höß heißt - „vergewissern, ob die Lossage echt und überzeugt geschehen sei“439. Die Unterschriftsbereitschaft wurde dadurch weiter verringert. Der jüdische Buchenwald-Häftling Benedikt Kautsky stellt dazu in seinem Bericht über die „Befragungsappelle“ der Zeugen Jehovas fest: „Einmal gelang es während des Krieges durch besonders intensive Bearbeitung, einen etwas größeren Prozentsatz - ich glaube etwa 30 von mehr als 400 - vor allem die Jüngeren, zur Unterschrift zu bewegen. Diese Abtrünnigen wurden sofort von den anderen boykottiert; bald stellte sich heraus, daß die Verleugnung der Überzeugung sich nicht lohnte: nur ein Teil der Unterschreibenden wurde entlassen. Die SS verurteilte dadurch natürlich jeden späteren Versuch zur Erfolglosigkeit. “440

Da jene Bibelforscher-Häftlinge, die sich unter großen Gewissensqualen schließlich zur Unterschrift bereit fanden, dies nur aus einer extremen Zwangslage heraus taten, waren sie auch danach noch häufig schwankend und einem hohen psychischen Druck ausgesetzt. Von der SS wurden sie ihren Glaubensbrüdern als „Vorbild“ vorgeführt. So mußten sie sich beispielsweise auf dem Appellplatz öffentlich zu ihrer Unterschriftsleistung bekennen.

An denjenigen, die ,unterschrieben“ hatten, haftete der Makel des „Abfalles“ und der „Untreue“. Ihre Glaubensgeschwister verhängten über sie den - von den Zeugen Jehovas selbst so bezeichneten - „Gemeinschaftsentzug“. Da sie jedoch, wenn sie verständliche Gründe nannten, weshalb sie nicht anders glaubten handeln zu können, und wenn sie ihre „Reue“ durch die Zurücknahme der Unterschrift zum Ausdruck brachten, in der Gemeinschaft der Zeugen Jehovas Wiederaufnahme finden konnten, entschlossen sich den Berichten zufolge sehr viele derjenigen, die unterschrieben hatten, nach kurzer Zeit dazu, bei der „Politischen Abteilung“ vorstellig zu werden und ihre revidierte Meinung zu Protokoll zu geben ${ }^{441}$. Rudolf Höß kommentierte dies so: „Den Abtrünnigen wurde von ihren ,Geschwistern“ bös zugesetzt ob ihres Abfalles von Jehova. Und manche, besonders Frauen, haben aus Gewissensbissen die Unterschrift wieder zurückgezogen. Der fortdauernde moralische Druck war zu stark. Die Bibelforscher in ihrem Glauben zu erschüttern, war gänzlich unmöglich; auch die sogenannten Abtrünnigen wollten Jehova unbedingt die Treue halten, auch wenn sie sich von der Glaubensgemeinschaft lossagten. “442

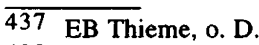

438 Die „Beobachtungsphase“ erstreckte sich zuweilen über mehr als ein Jahr; vgl. Jahrbuch 1974, S. 177.

439 Kommandant in Auschwitz, S. 77.

440 Kautsky, Teufel und Verdammte, S. 139.

441 Vgl. Grüber, Erinnerungen, S. 154; Jahrbuch 1974, S. 170f., 178; Naujoks, Sachsenhausen, S. 143.

442 Kommandant in Auschwitz, S. 77. 
Die Weigerung der Zeugen Jehovas, ihren Glauben zu verleugnen, umfaßte auch die prinzipielle Ablehnung aller Handlungen, die ihnen ihre Glaubenslehre verbot. In dieser Hinsicht waren dadurch, daß die Konzentrationslager ab 1942 verstärkt in die Rüstungsfertigung einbezogen wurden, auf die Zeugen Jehovas neue, schwere Belastungen zugekommen ${ }^{443}$. Ihre Ablehnung, für den Krieg zu produzieren, galt der SS als Arbeitsverweigerung, auf die für KZ-Gefangene schwerste Strafen bis hin zur Todesstrafe standen. Als beispielsweise im März $1943 \mathrm{im} \mathrm{KZ} \mathrm{Buchenwald}$ die Produktion von automatischen Sturmgewehren „K 43“ und Lafetten für die Flak in den - seit dem Sommer des Vorjahres im Bau befindlichen - Gustloff-Werken aufgenommen wurde, verweigerten die zu diesem Einsatz abkommandierten Bibelforscher-Häftlinge die Arbeitsaufnahme. Obgleich die SS zahlreiche „Lagerstrafen“ verhängte, die Verweigerer mit 25 Schlägen auf dem „Bock“ bestrafte und einige in die Strafkompanie überstellte, ließen sich die weitaus meisten Zeugen Jehovas nicht zu dieser Arbeit zwingen. Die in Buchenwald straff organisierte Bibelforschergruppe versuchte mit aller Kraft zu vermeiden, daß ihre Geschlossenheit und ihre ablehnende Haltung zur Rüstungsproduktion - und sei es auch noch so geringfügig - ,aufgeweicht“" werden könnten. In der 1945 nach der Befreiung verfaßten Erklärung der Buchenwalder Zeugen Jehovas heißt es dazu: „Ein paar, die unterm Druck williger Handlanger des Teufels, aus Furcht, geschlagen oder getötet zu werden, solche Arbeit annahmen, wurden sofort aus der Gemeinschaft dieses neutralen Volkes ausgeschlossen." 444

Von den Gruppenangehörigen wurde verlangt, sich stets in unbedingtem Gehorsam dem „biblischen Gebot“ gegenüber zu verhalten. Ein Zeuge Jehovas, der im November 1942 im Anschluß an eine mehrjährige Gefängnisstrafe ins KZ Buchenwald eingeliefert und zunächst im Entwässerungskommando eingesetzt worden war, berichtet davon, daß ihn die Bibelforschergemeinschaft, als er zu Schweißarbeiten in den Gustloffwerken eingeteilt wurde, nachhaltig dazu ,ermuntert“ habe, eine Mitarbeit in der Rüstungsfertigung kategorisch abzulehnen. Über die möglichen Folgen dieses Schrittes schien der im Lager noch vergleichsweise unerfahrene Häftling jedoch im unklaren gelassen worden zu sein: „Da ich Bibelforscher war, hatte ich den Auftrag von der Gruppe erhalten, diese Arbeit abzulehnen, ganz gleich was kommt. [...] Ich war mir der Gefahr nicht bewußt. Da das alles alte Hasen waren, dachte ich, es hat seine Richtigkeit."445 Nachdem der Zeuge Jehovas bei Arbeitsantritt die Aufnahme der geforderten Tätigkeit abgelehnt hatte, brachte man ihn mit dem Bemerken „Rüstungsarbeit verweigert“ ins Lager zurück. Dort wurde er dem Arbeitseinsatzleiter mit den Worten übergeben, „das ist das faule Schwein, das im Gustloffwerk nicht arbeiten will“. Dann wurde ihm kurzerhand erklärt, daß er jetzt aufgehängt werde. Vorerst mußte er am Lagertor Aufstellung nehmen. Dort, mit den Nerven schon völlig am Ende, überbrachte ihm schließlich ein Häftlingsläufer, der ebenfalls Bibelforscher war, den Befehl, daß er sich zur

$\overline{443}$ Zur Weigerung von Bibelforscher-Häftlingen, in der Rüstungsproduktion zu arbeiten, vgl. auch Langbein, Widerstand, S. 190; Pechel, Widerstand, S. 107; Der Wachtturm, 15.11. 1980 , S. 7; DhN, Ng. 2.8, Bericht von Jan van Bork.

444 Von Zeugen Jehovas in Buchenwald nach der Befreiung verfaßte Erklärung, abgedruckt in: Grünewald, Geschichte der Kriegsdienstverweigerung, S. 30-33 (32).

445 R. Weissenborn, Bericht aus dem Lagerleben, GBu, 32/IX-70. 
Arbeitsaufnahme in der „Arbeitsstatistik“ zu melden habe. Der Zeuge Jehovas schilderte später seine Empfindungen: „Ich glaubte zu träumen. Ich hörte noch, wie der Läufer sagte, wir haben dich die ganze Zeit im Auge behalten, jetzt hast du es überstanden."

In bezug auf die Verweigerung der Tätigkeit in der Rüstungsproduktion blieb der SS letztlich nichts anderes übrig, als der Haltung der Zeugen Jehovas Rechnung zu tragen. Die Verweigerer wurden anderen Kommandos, zumeist den in den Lagerwerkstätten tätigen Handwerkerkolonnen, zugeteilt ${ }^{446}$. Zu heftigen Auseinandersetzungen unter den Bibelforscher-Häftlingen - bei denen Einvernehmen herrschte, daß die Gebote der Bibel einem Christen die Herstellung von Waffen und Munition verbieten - führte jedoch die Frage, wo die Grenzziehung bei der Ablehnung von „Kriegsdiensten“ jeweils genau zu verlaufen habe ${ }^{447}$. Für die „Gemäßigten“ galt nur die direkte Mitwirkung an der Herstellung von zur Tötung bestimmtem Kriegsgerät als Arbeit für den Krieg, während für die „Radikaleren“ auch andere Tätigkeiten eine Unterstützung für die Kriegsführung darstellten, die - so ihre Ansicht - deshalb ebenso aus Glaubensgründen zu verweigern seien. Beispielsweise kam es zu einem solchen Konflikt, als in einer Werkstatt im KZ Buchenwald die Produktion von Skiern aufgenommen wurde, weil man erfahren hatte, daß die Bretter für die im russischen Winter steckengebliebenen Wehrmachtseinheiten bestimmt waren. Willi Töllner, der Wortführer der Bibelforschergemeinde in Buchenwald, verkündete, daß die in der Werkstatt eingesetzten Zeugen Jehovas auch diese Arbeit verweigern müßten, da es sich bei den zur Ausrüstung der Truppe dienenden Skibrettern um Kriegsgerät handele.

Die Mehrheit der Zeugen Jehovas folgte willig diesem Beschluß, doch eine kleinere Gruppe schloß sich der Beurteilung Töllners nicht an. Diese Gruppe argumentierte, daß man mit Skibrettern niemanden töten könne und es deshalb etwas anderes sei, an deren Herstellung mitzuwirken, als Granaten zu produzieren. Diese Arbeit zu verweigern, beschwöre unnötigerweise eine Strafaktion durch die SS herauf, die es gerade auch im Sinne der kranken und geschwächten Glaubensgeschwister zu verhindern gelte. Außerdem müsse es erlaubt sein, dem eigenen persönlichen Gewissen zu folgen und nicht dem Gewissen eines anderen. Als die in der Werkstatt für die Ski-Produktion eingesetzten Zeugen Jehovas, die sich zu der Minderheitsauffassung bekannten, dort die Arbeit nicht einstellten, wurden sie wegen ihres als „unbiblisch“ gewerteten Verhaltens kurzerhand aus der Buchenwalder Bibelforschergemeinschaft ausgeschlossen. Ein Zusatzgrund für diese scharfe Reaktion mag auch gewesen sein, daß die Handlungsweise der Minderheit dem ,leitenden Bruder“ Töllner praktisch den - nach dem ,theokratischen Prinzip“ gebotenen - Gehorsam aufgekündigt hatte.

Wie in keinem anderen Lager bestimmte jener Willi Töllner, eine charismatische Führergestalt, den auch Mitgefangene anderer Häftlingsgruppen als ,glänzenden

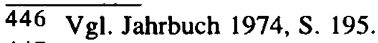

447 Die folgende Darstellung über die Zeugen Jehovas in Buchenwald beruht auf: Jahrbuch 1974, S. 174f.; EB Bruno Knöller, 23.11.1987; EB Alois Moser, 23.5.1986; EB Johannes Rauthe, Geschichtsbericht, S. 56-65. 
Redner"448 erlebten, die Geschicke der Buchenwalder Bibelforschergemeinde. Von Ende 1937 an hielt Töllner heimlich Vorträge und Predigten im Lager; für viele Zeugen Jehovas wurde er zu einem Idol, dem „Wunder von Buchenwald“449. Ausgehend von der Position, daß die Zeugen Jehovas eine einheitliche „Front gegen die Welt Satans" bilden müßten, wurde unter seiner Leitung die Bibelforschergruppe streng hierarchisch organisiert; von den einzelnen Mitgliedern wurde Unterordnung verlangt. Unter den Bedingungen eines KZ-Lagers erwies sich eine solche Binnenstruktur durchaus als vorteilhaft. So gelang es der Buchenwalder Bibelforschergruppe durch ihr kollektives Auftreten, sich vergleichsweise gut zu behaupten und auch „Untergrundaktivitäten“ (heimliche Zusammenkünfte, Schriftenvervielfältigung) zu organisieren. Der ausgeschlossenen Minderheit gegenüber verhielten sich die nahezu 400 Zeugen Jehovas, die sich zu Töllner bekannten, allerdings strikt abweisend. Sie wurden als „Feinde des Königreichs“ bezeichnet, die von jedem „Treuen“ gemieden werden müßten. Für diese Zeugen Jehovas - unter ihnen auch einige IBV-Funktionäre -, die damit ohne die Solidarität der Gemeinschaft auskommen mußten, bedeutete dies eine „schwere Prüfung“. In einem Bericht beschrieb einer von ihnen seine damaligen Empfindungen so: „Als ich wußte, daß ich auch ausgeschlossen war, war ich seelisch derart herunter und deprimiert, daß ich mich fragte, wie so etwas möglich sein könne. [...] Ich habe oft auf den Knien gelegen und zu Jehova gebetet, er möge mir ein Zeichen geben. Ich fragte mich, ob ich etwa selbst daran schuld sei und auch er mich ausgeschlossen habe. Da ich eine Bibel hatte, habe ich darin bei verdunkeltem Licht gelesen und fand großen Trost bei dem Gedanken, daß dies mir zur Prüfung widerfahren sei. Sonst wäre ich zugrunde gegangen, denn es war ein gewaltiger Schmerz, von der Gemeinschaft der Brüder ausgeschlossen zu sein. “450 Eine Situation, wie sie in Buchenwald durch die Spaltung der Bibelforschergemeinde existierte und die bis zum Kriegsende andauerte, entstand sonst in keinem anderen Lager. Spannungen und Auseinandersetzungen über die Frage, welche Arbeiten als dem Krieg dienende Tätigkeiten abzulehnen seien, gab es auch andernorts, doch führte dies nicht zum offenen und dauerhaften Bruch.

Eine ähnlich radikale Position wie die Buchenwalder Mehrheit bezogen viele Bibelforscherinnen im KZ Ravensbrück. Auch sie verweigerten jegliche Arbeit, die ihrer Auffassung nach den Krieg förderte. So lehnten die in der Näherei eingesetzten Frauen es standhaft ab, Uniformen für die Waffen-SS zu nähen ${ }^{451}$. Als

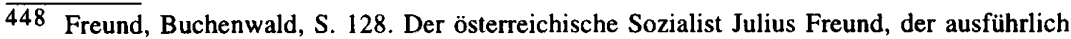
einen Wortdisput zwischen dem ,,Sprecher der Bibelforscher" und einem SS-Mann bei einem „Sonderappell“ Ostern 1939 referiert, nannte Töllner nicht beim Namen, anderen Quellen zufolge handelte es sich jedoch bei dem Sprecher um eben diesen (vgl. Bericht Wanner in: Menzinger, Jugend, S. 119). Nach Freund entwickelte der ,Sprecher der Bibelforscher [...] ein Programm, als wäre er in Freiheit. In vollem Einklang mit seinen Ansichten, ohne dieselben abzuschwächen, legte er dem SS-Mann und somit den Nazis überhaupt ganz offen seinen Standpunkt klar, wie ich es noch nie gehört hatte; ich hätte es mir nicht träumen lassen, daß ein Häftling im Lager trotz aller Gefahren und Strafen so mutig sprechen könnte." (Freund, Buchenwald, S. 128)

449 Jahrbuch 1974, S. 174.

450 Bericht von Wilhelm Bathen in: Jahrbuch 1974, S. 175.

451 Vgl. Die Frauen von Ravensbrück, S. 147; EB Günther Pape, 19.5.1986; EB Charlotte Tetzner, 21.9.1986, 3.10.1986. 
ihnen ein anderes Mal Nähtaschen als Arbeitsvorlage gezeigt wurden, beratschlagten sie in der Unterkunft zusammen mit ihren Glaubensschwestern über die einzunehmende Haltung. Wie eine der Beteiligten später berichtete, beschloß der zu der Zeit mit fast 400 Bibelforscherinnen belegte Block 17 einstimmig, diese Arbeit abzulehnen, da die Frauen vermuteten - und wie sich herausstellte nicht zu Unrecht -, daß es sich dabei nicht um Nähtäschchen, sondern um Patronentaschen handelte $^{452}$. Die SS reagierte mit der Verhängung schwerster Strafen. So wurden jeweils mehrere Frauen in eine Einzelzelle des Arrestbunkers gesperrt. Drei Wochen unterlagen sie den Bedingungen des sogenannten ,verschärften Arrestes“, sie bekamen nur alle vier Tage einmal Suppe. Auch lehnten es Bibelforscherinnen in Ravensbrück $a b$, Stroh für Wehrmachtspferde abzuladen. Ebenso verweigerten sie das Wickeln von Verbandspäckchen ${ }^{453}$. Nanda Herbermann, die als Mitarbeiterin eines regimekritischen Jesuitenpaters verhaftet und ins $\mathrm{KZ}$ Ravensbrück verschleppt worden war, berichtet von einer anderen Verweigerungsaktion und ihren Folgen:

„Wenn ich an einen Tag im Lager zurückdenke, dann steigt mir noch jetzt der heiße Zorn hoch und die Fäuste ballen sich vor Empörung. Es war im Sommer. Der gesamte Block sollte [...] Luftschutzkeller bauen. Diese Arbeit wurde von dem niederträchtigen Kommandanten Kögel gerade den Bibelforschern übertragen, weil er wußte, daß in ihren Statuten jegliche Arbeit für Kriegszwecke strengstens untersagt ist. Er wollte sie dazu zwingen. Aber allesamt verweigerten sie standhaft die Ausführung dieses Befehls. Der Kommandant, zum Äußersten gereizt, ordnete für jeden Bibelforscher zehn Stockhiebe an. Alle mußten antreten zum Strafempfang. Ich sehe noch diese Prozession der meist alten, lieben Mütterchen. [...] Nun wurden sie wie eine Horde Vieh zur Schlachtbank getrieben, in diesem Fall zum Bock, auf den sie der Reihe nach geschnallt wurden. [...] und dann ging es los, der Reihe nach. [...] Sie aber beteten, still und ergeben. Heroisch haben sie sich gehalten, standhaft diese zehn Stockhiebe für ihren, Glauben` entgegengenommen. Als sie hiernach aus dem Zellenbau wieder hinaustraten, versuchten sie, Haltung zu bewahren, so gut es ging. Viele von ihnen schlichen, gekrümmt und gebeugt vor Schmerz, mit ihren geschändeten, alten Körpern dahin. Es waren unter ihnen manche Frauen von sechzig Jahren und darüber. [...] Manche der alten Mütterchen haben diese Schläge nicht überstanden." 454

Margarete Buber-Neumann, die als politische Gefangene seit Oktober 1940 Blockälteste einer der beiden Bibelforscherbaracken in Ravensbrück war, berichtet davon, daß eines Tages auf dem Block über die Verweigerung von Kriegsarbeit „,heftige Debatten im Gange“" waren 455 . Die Kolonne „Angorazucht" 456 legte die Arbeit nieder, da die dort eingesetzten Bibelforscherinnen festgestellt hatten, daß die Wolle der Kaninchen für Wehrmachtszwecke (Ausfütterung von Fliegerjacken)

452 DÖW, Maria Herfort, Bericht über die Lage der Bibelforscher in Ravensbrück.

453 Vgl. Die Frauen von Ravensbrück, S. 147; Kommandant in Auschwitz, S. 77; Langbein, Widerstand, S. 190.

454 Herbermann, Abgrund, S. 125.

455 Die Frauen von Ravensbrück, S. 146f.

456 Angorazuchten gab es in Buchenwald, Dachau, Ravensbrück, Neuengamme und noch zahlreichen weiteren Lagern. In ihnen wurden 1943 insgesamt 25.000 Kaninchen gehalten. Vgl. Konzentrationslager: Hasen im Buch, in: Der Spiegel, 22.1.1968, S. 36. 
verwandt wurde 457 . Noch am gleichen Tag schloß sich die Gärtnereikolonne „Kellerbruch" an, da das geerntete Gemüse an ein SS-Lazarett geschickt wurde. Im ganzen verweigerten ungefähr neunzig Zeugen Jehovas die Arbeit. Die SS ließ sie auf dem Hof des Zellenbaus drei Tage und Nächte Strafe stehen. Anschließend wurden sie für vierzig Tage in den „Bunker“ in Dunkelarrest genommen. Zudem bestrafte man sie mit dreimal 25 Stockhieben. Doch trotz der harten Bestrafung änderten die Frauen ihre Haltung nicht ${ }^{458}$.

Auch in den anderen Konzentrationslagern nahmen Zeugen Jehovas eher schwerste Strafen in Kauf, als „Arbeiten für den Krieg“ zu verrichten. In Hohenlychen, als Außenlager dem KZ Ravensbrück zugeordnet, hielt eine Gruppe von Bibelforschern, die dort zum Baumfällen eingesetzt wurde, mit der Arbeit inne, als sie von den Wachposten erfuhren, daß das Holz „für Kriegszwecke“ benötigt würde. Obgleich sie vom SS-Arbeitsführer vor die Alternative gestellt wurden, entweder die Arbeit wieder aufzunehmen oder erschossen zu werden, standen, wie Alois Moser berichtet, ,alle Brüder als eine ,feste Front " da“459. Zwar wurde der Zeuge Jehovas, der dem Kommando als Kapo vorstand, ins Stammlager zurückversetzt, von der angekündigten Sanktion nahm die SS jedoch Abstand und beschäftigte die Kolonne fortan mit Arbeiten in der Landwirtschaft. Neben den kollektiven Verweigerungsaktionen standen auch zahlreiche ähnlich begründete Handlungen von einzelnen. So verweigerte im KZ Schirmeck (Elsaß), in dem nur eine kleine Zahl von Zeugen Jehovas inhaftiert war, eine Bibelforscherin die Ausbesserung von Militärkleidung. Um ihre Resistenz zu brechen, wurde sie in den Arrestbunker gesperrt. Die SS erreichte jedoch nicht, was sie wollte; nach sieben Monaten Internierung in Einzelhaft wurde die Frau aus dem Bunker zurück ins Lager verlegt ${ }^{460}$. Bei einem in der Malerei des SS-Betriebes „Deutsche Ausrüstungswerke“ im KZ Sachsenhausen eingesetzten Zeugen Jehovas ging die Ablehnung jeder Kriegsproduktion so weit, daß er, wie der ehemalige politische $\mathrm{Ge}$ fangene Wolfgang Szepansky berichtet, „,sogar das Anstreichen von Kriegsspielzeug ablehnte“461.

Die „Fundamentalisten“ unter den Bibelforschern verweigerten auch über den Bereich des Arbeitseinsatzes hinaus weitere Handlungen, die sie mit ihrem Gewis-

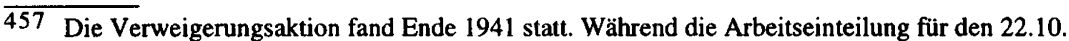
1941 noch 20 IBV-Häftlinge im Kommando „Angora-Zucht" aufweist (vgl. Füllberg-Stolberg, Pötzinger, S. 328), gibt die Aufstellung vom 4.1.1942 für dieses Kommando keine IBV-Häftlinge mehr an (vgl. Müller, C., Klempnerkolonne, Dokumententeil nach S. 112).

$458 \mathrm{Vgl}$. Buber-Neumann, Gefangene, S. 278. Buber-Neumann berichtet, daß im Herbst 1942 ,alle ,extremen“ Bibelforscherinnen" mit einem Transport nach Auschwitz gebracht worden seien. Außerdem seien „zwölf oder fünfzehn von den Extremen“, die ebenfalls ins $\mathrm{KZ}$ Auschwitz überstellt, aber anschließend nach Ravensbrück zurücktransportiert wurden, am Tage ihrer erneuten Ankunft im Ravensbrücker Lager mit einem Gefängniswagen zum Lagertor hinausgefahren worden. Da kurze Zeit später ihre Häftlingskleider mit Winkel und Gefangenennummer zur Effektenkammer zurückgekommen seien, nimmt Margarete Buber-Neumann an, daß die SS „das Todesurteil wegen Arbeitsverweigerung an ihnen vollstreckt" habe (ebenda, S. 299).

459 EB Alois Moser, 23.5.1986.

460 Vgl. Der Wachtturm, 1.1.1979, S. 22; ein ähnlicher Vorgang ist geschildert in Kommandant in Auschwitz, S. 117.

461 Szepansky, Weg, S. 176. 
sen nicht glaubten vereinbaren zu können. Als Anfang des Jahres 1942 im KZ Buchenwald die deutschen Gefangenen aufgerufen wurden, einen Beitrag für die Wollspende zugunsten der deutschen Truppen an der Ostfront zu leisten - Häftlinge, die neben dem KZ-eigenen Pullover noch einen weiteren Pullover hatten, sollten diesen abgeben -, erklärten die Bibelforscher-Häftlinge, daß sie dem nicht nachkommen würden ${ }^{462}$. Wie der luxemburgische Zeuge Jehovas Viktor Bruch berichtet, weigerten sie sich geschlossen, ,auch nur ein Taschentuch für Kriegszwecke abzugeben“463. Daraufhin mußten die Bibelforscher-Häftlinge am 15. Januar 1942, einem bitterkalten Wintertag, auf dem Appellplatz stundenlang „Strafe“ stehen. Die SS nahm ihnen die Pullover sowie Handschuhe, Ohrenschutz und selbst die Unterkleidung weg. Lederschuhe wurden konfisziert und mußten gegen halboffene schwere Holzschuhe eingetauscht werden. Außerdem hatten die nun nur noch mit einem Drillich bekleideten Gefangenen als Strafmaßnahme zusätzliche Arbeit zu verrichten: „Bei Scheinwerferlicht mußten wir ein hügeliges Gelände zu einem Sportplatz ebnen, eine schwere Arbeit nach Feierabend, bei hartgefrorenem Boden und 20 Grad Kälte. "464 Nach drei Wochen wurde diese Tortur beendet.

In Ravensbrück reagierten zahlreiche Bibelforscherinnen auf die harte $\mathrm{Be}$ strafung wegen „Arbeitsverweigerung“ in den Kommandos „Angorazucht“ und „Kellerbruch“, indem sie sich nach ihrer Entlassung aus dem Arrest weigerten, am Zählappell teilzunehmen ${ }^{465}$. Margarete Buber-Neumann berichtet über die Folgen:

„Man verteilte sie über die Baracken des ganzen Lagers, und die Blockältesten erhielten den Befehl, sie mit Gewalt zum Zählappell zu bringen. Menschliche Blockälteste ließen sie zum Antreten hinaustragen, aber auf manchen Blocks schleifte man sie zu jedem Appell auf die Lagerstraße. Da hockten dann die alten Frauen während der langen Zeit des Appells zusammengekauert auf dem Boden bei Regen und Kälte. Doch sie verweigerten weiter die Kriegsarbeit und das freiwillige Appellstehen. Der neue Schutzhaftlagerführer Redwitz machte sich ein besonderes Vergnügen, die Bibelforscher beim Zählappell zu verhöhnen. Einmal forderte er sie auf, sofort aufzustehen. Sie reagierten nicht. Er brüllte lauter. Er hatte keinen Erfolg. Da befahl er der ,Lagerpolizei', sofort einige Eimer Wasser zu holen, und ließ die kauernden Bibelforscher über und über begießen." 466

Demonstrative Aktionen, wie die Verweigerung des Zählappellstehens, waren unter den Zeugen Jehovas jedoch stark umstritten ${ }^{467}$. Dies galt noch mehr für

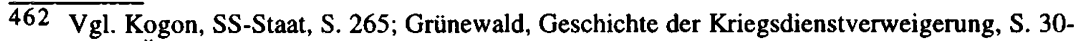
33; DÖW, Nr. 1458, Otto Horn, Bericht über das Konzentrationslager Buchenwald; Erwachet!, 22.6.1985, S. 10-13.

463 Bericht von Viktor Bruch, Jahrbuch 1976, S. 39.

464 Ebenda.

465 In seinen Erinnerungen weiß der ehemalige Kommandant des KZ Auschwitz, Rudolf Höß, über Bibelforscherinnen in Ravensbrück zu berichten, daß sie sich „nur im ungeordneten Haufen" zählen ließen (Kommandant in Auschwitz, S. 77).

466 Buber-Neumann, Gefangene, S. 279. Vgl. auch die (leicht abweichende) Schilderung bei Müller, C., Klempnerkolonne, S. 27f.; Langbein, Widerstand, S. 190 (Bericht von Hermine Jursa).

467 Margarete Buber-Neumann, die innerhalb der Bibelforschergemeinde im KZ Ravensbrück drei „Fraktionen“ unterschied, ,die ,Extremen', die schwankende Mitte und die ,Gemäßigten““, 
Handlungen, deren praktische Wirkung sich im Grunde gegen sie selbst richtete. So verzichteten einige Glaubensschwestern in Ravensbrück auf die - allerdings ohnehin für Zeugen Jehovas wegen Beschränkung auf fünfundzwanzig Worte beinahe zur Farce gewordene - Schreiberlaubnis, da sie es ablehnten, daß ihre Briefe mit dem Führerporträt als Briefmarke versehen wurden ${ }^{468}$. Eine Gruppe von ungefähr 25 „Extremen“ beschloß, geführt durch Ilse Unterdörfer, eine enge Mitarbeiterin des Reichsdieners Erich Frost, unter Berufung auf das mosaische Gesetz (,niemand unter euch darf Blut genießen“469), fortan auf den Verzehr von Blutwurst zu verzichten und deren Annahme bei der Essensausgabe zu verweigern ${ }^{470}$. Ihren Entschluß gaben sie in einer mit ihren Namen versehenen Erklärung auch öffentlich bekannt. Laut Margarete Buber-Neumann lachte die SS ,sich ins Fäustchen" ${ }^{471}$ und entzog den auf die Blutwurst verzichtenden Frauen gleich noch die zur „Ration“ gehörende Margarine. Obgleich die Blutwurst in der Regel nur einmal wöchentlich am Sonntag ausgegeben wurde, wuchs sich angesichts der kargen Zuteilung der „seltsame Essenstreik“, so die Sozialistin Herta BrünenNiederhellmann, für die streng dem „biblischen Gebot" folgenden Bibelforscherinnen ,zu einer Katastrophe“ aus ${ }^{472}$.

Die Mehrzahl der in den Konzentrationslagern inhaftierten Zeugen Jehovas beteiligte sich an derartigen demonstrativen Aktionen nicht. Zwar verweigerten nahezu alle Bibelforscher-Häftlinge - insgesamt gesehen - äußerst standhaft die Arbeit in der Rüstungsproduktion bei der Herstellung von Waffen und anderem Kriegsgerät; darüber hinausgehende Verweigerungsaktionen lehnten viele Zeugen Jehovas aber als zu ,radikal“ ab. Während beispielsweise die Bibelforscherinnen im KZ Ravensbrück zur Versorgung der Kaninchen in der „Angorazucht“ wegen der Ablieferung der Wolle an die Wehrmacht prinzipiell nicht bereit waren, scheinen die im KZ Neuengamme inhaftierten Glaubensbrüder darin nichts Verwerfliches gesehen zu haben. Etwa drei Jahre lang arbeiteten fünfzehn von ihnen im dortigen „Angora-Kommando“. Diese Arbeitsstätte wurde sogar - da die Bedingungen für heimliche Zusammenkünfte und das Verstecken von Schriften in dem abgelegenen Kommando mit einem relativ erträglichen SS-Scharführer und einer anfangs ausschließlich aus Bibelforschern bestehenden Belegschaft vergleichsweise gut waren - zu einem Zentrum des „IBV-Widerstandes“ in Neuengamme. Da im „Angora-Kommando“ die Abfälle der SS-Küche an bis zu 3.800 Kaninchen verfüttert wurden, konnten die dort eingesetzten Zeugen Jehovas auch EBbares

berichtet von „,regelrechten Fraktionskämpfen“; die Bibelforscherinnen „,bezichtigten einander des Verrats an den Glaubenssätzen, wozu sie Vergleiche aus der biblischen Geschichte heranzogen“ (Buber-Neumann, Gefangene, S. 257f.).

468 EB Bruno Knöller, 23.11.1987.

469 Leviticus 17, 12; vgl. auch Genesis 9, 3f.: „Alles, was sich regt und lebt, das sei eure Speise [...] Nur Fleisch mit seiner Seele - seinem Blut - sollt ihr nicht essen.“; sowie Apostelgeschichte 15, 29: „Enthaltet euch des Blutes”.

470 Vgl. Buber-Neumann, Gefangene, S. 257f.; Kater, Bibelforscher, S. 215.

471 Buber-Neumann, Gefangene, S. 257.

472 Interview Herta Brünen-Niederhellmann, in: Elling, Frauen, S. 79. Sybil Milton gilt diese Aktion als ein Beispiel, daß eine feste religiöse Fundierung, die allgemeinhin die Selbstbehauptungsmöglichkeiten im Konzentrationslager steigerte (Glaube als innerer Halt), auch „negative Implikationen für das Überleben“" anzunehmen vermochte (Milton, Frauen, S. 15). 
abzweigen, das qualitativ die allgemeine Häftlingsverpflegung übertraf. Sie ließen diese Reste jenen Glaubensgeschwistern zukommen, die dringend Zusatznahrung benötigten ${ }^{473}$. Eine kleinere Gruppe von Zeugen Jehovas arbeitete im KZ Neuengamme auch bei der Motorenfabrik Carl Jastram. Da sie den Einsatz in der Produktion (Teilefertigung für den U-Boot- und den Flugzeugbau, Reparatur von Bootsmotoren) ablehnten, wurden sie dort in anderen Funktionen (Hausmeister, Reinigungsdienst, Magazinverwaltung) eingesetz ${ }^{474}$.

Nicht nur Auseinandersetzungen über das biblisch gebotene Verhalten, auch unterschiedliche Deutungen und Voraussagen konnten zu - allerdings zumeist nur vorübergehenden - Schismen führen. So war es Mitte 1937 im KZ Sachsenhausen im Zusammenhang mit Spekulationen über den Zeitpunkt des Beginns der Entscheidungsschlacht „Harmagedon“ zu Fraktionierungen gekommen. Ein Zeuge Jehovas glaubte anhand der Bibel das Datum festgestellt zu haben, an dem die satanischen Mächte vernichtet und sie aus dem Konzentrationslager befreit werden würden. Voraussagen über den Zerfall des Hitlerregimes und das Ende der Torturen übten verständlicherweise eine große Anziehung aus. Der evangelische Pfarrer und ehemalige Sachsenhausen-Häftling Dr. Werner Koch hat in einem - die Ablehnung der religiösen Auffassungen der Zeugen Jehovas nachdrücklich betonenden - Bericht beschrieben, was sich seiner Erinnerung nach an jenem bestimmten Junitage, an dem ,der Herr ... die Herrschaft des Dritten Reiches und aller Reiche vernichten" sollte, zutrug:

„Immer wieder gehen an diesem Tag die Blicke der Bibelforscher himmelan. Voll freudiger Erwartung. Es gibt um die Mittagszeit ein paar Wolken - aber nichts geschieht! Am Nachmittag ermattet ihre Spannung zusehends. Niedergeschlagen marschieren sie abends unter dem üblichen Schreien und Schimpfen der SS zurück ins Lager. Nach dem Abendappell sieht man, wie die Ältesten die Köpfe zusammenstecken und erregt miteinander diskutieren. Am nächsten Morgen ist bereits alles wieder klar: Man hat ein paar Zahlen aus dem Alten und dem Neuen Testament in einer falschen Weise miteinander kombiniert. Ein Rechenfehler ist schuld daran, daß das Datum der Wiederkunft des Herrn falsch angesetzt worden ist." 475

\section{Rückhalt im Glauben}

Ihre unerschütterliche Glaubenszuversicht, das stark ausgeprägte Zusammengehörigkeitsgefühl und ihre gegenseitige solidarische Hilfe gaben den Zeugen Jehovas die innere Kraft, ihrer Überzeugung auch in den Konzentrationslagern weitgehend treu zu bleiben. Von diesem Fundament aus gelang es ihnen, trotz der Schikanen der SS, ihren Selbstbehauptungswillen die ganze Zeit hindurch zu bewahren. Mitgefangene, die später über die Zeugen Jehovas berichteten, wiesen fast immer

473 Vgl. Arbeit und Vernichtung, S. 113, 116; DhN, Ng. 5.6.1.; FGN, NHS 13-7-4-1.

474 EB Richard Rudolph, 9.9.1986.

475 Koch, W., Leben im Widerstand, S. 219. Zu dogmatisch motivierten Zwistigkeiten unter den in den Konzentrationslagern inhaftierten Zeugen Jehovas vgl. auch Doyon, Hirten, S. 232f.; Jahrbuch 1974, S. 174; EB Bruno Knöller, 23.11.1987. 
auf die Kameradschaftlichkeit in der Gruppe hin ${ }^{476}$. Der ehemalige BuchenwaldHäftling Moritz Zahnwetzer faßte dies in die Worte, daß die Bibelforscher im Lager „das Band brüderlichen Christentums“ umschlungen habe: „Ihre Nächstenliebe offenbarte sich täglich und stündlich in gegenseitiger Hilfe. Und so ist ihre verhältnismäßig geringe Zahl der Todesopfer zu erklären, welche die unmenschlichen Verhältnisse in Buchenwald allgemein gefordert haben." 477 Auch Margarete BuberNeumann, die sich ansonsten kritisch zu den Zeugen Jehovas, ihrer Glaubenslehre und der durch diese zuweilen bewirkten Voranstellung des „biblischen Gebotes“ vor dem menschlich Gebotenen (z. B. Unnachgiebigkeit in der „Reversfrage“ selbst bei einer sterbenskranken Glaubensschwester) äußerte, würdigte die das Überleben im Lager erleichternde Handlungsweise der Bibelforscherinnen. Auf dem Block sei weder gestohlen, betrogen noch denunziert worden: „Jede dieser Frauen war nicht nur äußerst pflichtbewußt, sondern fühlte sich auch für die Gemeinschaft der ganzen Baracke verantwortlich. “478

Der Gemeinschaftsgeist der Bibelforscher-Häftlinge ermöglichte es ihnen, kollektive Strategien des Überlebens zu entwickeln und dadurch die Belastungen des Lageralltages zu mildern. Dabei stellte sich für sie die von der SS zum Zwecke der Absonderung anfangs angeordnete gemeinsame Unterbringung als letztlich sogar sehr vorteilhaft heraus. Spätere Versuche, sie durch Vereinzelungsstrategien zu entsolidarisieren, konnten kaum noch greifen.

Da die Zeugen Jehovas sich intensiv um ihre kranken und schwachen Glaubensgeschwister kümmerten und ihnen von ihren Rationen abgaben, konnten viele selbst mit schweren Erkrankungen gesund gepflegt werden, auch jene, die angesichts der normalen „Krankenbehandlung“ im KZ sonst wohl kaum eine Überlebenschance gehabt hätten. Insbesondere zu Zeiten, in denen die Zeugen Jehovas strafweise von der Aufnahme im Krankenrevier ausgeschlossen waren und ihnen jegliche medizinische Hilfe verwehrt wurde, bewährte sich diese Solidarität: Auf den „Blocks“ organisierten die Zeugen Jehovas ihren eigenen Betreuungsdienst ${ }^{479}$.

In den Bibelforscherunterkünften entwickelten sich feste solidarische Strukturen. So bildeten die Zeugen Jehovas beispielsweise „Geld- und Paketgemeinschaften“. Den ,reichsdeutschen“ und zeitweilig auch ausländischen Häftlingen war es in den Konzentrationslagern gestattet, sich einmal monatlich Geld bis zu einem festgelegten Höchstbetrag (z. B. 30 Reichsmark) ins Lager schicken zu lassen, mit dem sie durch Kantineneinkauf die karge Verpflegung etwas aufbessern konnten. In den Kantinen waren allerdings nur wenige, zum Großteil minderwertige Lebensmittel erhältlich, die überdies von der SS zu überhöhten Preisen abgegeben wurden. Da einige Zeugen Jehovas aus ärmlicheren Verhältnissen gar kein oder nur wenig Geld - zumal wenn ihre Angehörigen ebenfalls inhaftiert waren - von zu Hause erhielten, andere hingegen nach Kräften unterstützt wurden, bildeten sie zu-

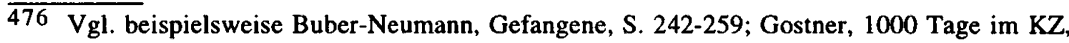
S. 46; Herbermann, Abgrund, S. 126; Kautsky, Teufel und Verdammte, S. 139, 178; Meier, Neuengamme, S. 31f.

477 Zahnwetzer, Buchenwald, S. 29.

478 Buber-Neumann, Gefangene, S. 246.

479 Vgl. Erwachet!, 22.6.1985, S. 12; EB Richard Rudolph, 9.9.1986. 
sammen in den einzelnen Blocks eine Geldgemeinschaft ${ }^{480}$. Das Geld kam sofort in einen gemeinsamen Topf, der von einem Glaubensbruder oder einer Glaubensschwester verwaltet wurde. Jeder bekam schließlich den gleichen Betrag, wobei sie die Auszahlung über einen längeren Zeitraum streckten, so daß bis zum nächsten Geldempfang möglichst die Kasse nicht ganz verebbte. Das „Einteilen“ und „Verteilen" scheint gut funktioniert zu haben. Alle hatten immer gleich viel oder auch gleich wenig Geld zur Verfügung. Neid oder Mißgunst konnte auch von daher unter den Bibelforscher-Häftlingen nicht so leicht auftreten. Von Zeugen Jehovas, die sich nicht an der Geldgemeinschaft beteiligen mochten, weil sie zu den finanziell Bessergestellten gehörten, wird nur in wenigen Einzelfällen berichtet. Doch auch diese schlossen sich zumeist nach einer kurzen Bedenkzeit der Solidarkasse an, da der Verlust der Gemeinschaft für sie schwerer wog als der Verlust ihrer (relativen) finanziellen Privilegien.

Ab Herbst 1942 war es den Häftlingen in den Konzentrationslagern gestattet, sich von ihren Angehörigen Lebensmittelpakete schicken zu lassen ${ }^{481}$. Die daraufhin in einigen Lagern unter den Zeugen Jehovas gebildeten Paketgemeinschaften funktionierten nach ähnlichen Regeln. Voraussetzung dafür waren sehr gut entwickelte Solidarstrukturen, wie sie beispielsweise bei der Bibelforschergemeinde im KZ Neuengamme anzutreffen waren. Bekamen dort Zeugen Jehovas ein Paket, so behielten sie es weder für sich, noch gaben sie es dem Blockältesten zur Aufbewahrung (wobei derartige Dienste in der Regel durch einen Paketanteil zu honorieren waren). Die Pakete wurden vielmehr sogleich den Glaubensbrüdern ausgehändigt, von diesen mit Hilfe einer Waage genau abgewogen, der Inhalt wurde gleichmäßig unter den an der „Paketgemeinschaft" Beteiligten aufgeteilt und anschließend noch am gleichen Abend oder in den nächsten Tagen verzehrt. Auf diese Weise hatten die Zeugen Jehovas in Neuengamme ,fast jeden Abend ein Stückchen Wurst, mal ein bißchen Butter oder ein Kleckschen Marmelade oder ein kleines Stück Kuchen"482. Die Vorteile von Paketgemeinschaften waren offenkundig. Dadurch, daß die Waren sofort auf alle aufgeteilt wurden, gab es für Neid und Mißgunst der „Habenichtse“ auf die (Paket-)Beziehenden keinen Anlaß. Ein Schutz vor einem möglichen Diebstahl war nicht notwendig, und auch dem Verderben von Lebensmitteln konnte so wirksam begegnet werden.

Zunutze kam den Zeugen Jehovas auch das ihnen eigene Streben nach Ordnung und Sauberkeit - Tugenden, die unter den schwierigen hygienischen Verhältnissen in den Konzentrationslagern den einzigen Schutz gegen Infektionskrankheiten und die gefürchtete Verlausung boten. Eine gut organisierte Arbeitsteilung und die strikte Einhaltung hygienischer Regeln gewährleisteten in ihren Unterkunftsbaracken einen höchstmöglichen Grad an Sauberkeit ${ }^{483}$. In diesem „Reich der

480 Die folgende Darstellung beruht in erster Linie auf: EB Karl Hanl, 24.11.1987; EB Alois Moser, 23.5.1986; EB Richard Rudolph, 31.5.1986.

481 Anordnung Himmlers vom 29.10.1942, BA, NS 3-425. Pakete mit Kleidungsstücken waren schon seit Herbst 1941 erlaubt.

482 EB Richard Rudolph, 9.9.1986; vgl. auch Meier, Neuengamme, S. $31 \mathrm{f}$.

483 Welch penibelen Ordnungsregeln in den Bibelforscher-Blocks im KZ Niederhagen galten, beschreibt Kerstin John: "So zogen sie vor dem Schlafengehen ihre Häftlingskleidung aus, 
Ordnung“, so die Blockälteste der Bibelforscherinnen in Ravensbrück, Margarete Buber-Neumann, lief der gesamte Blockmechanismus, beispielsweise das Essenausteilen und der Bettenbau, ,ab wie ein Uhrwerk“484. Durch ihre geradezu peinlich genaue - und für andere Mitgefangene eher befremdliche - Beachtung der Lagerbestimmungen waren die Zeugen Jehovas auf diesem Gebiet für die SS die „Vorzeige-Gefangenen“ per se. Im KZ Ravensbrück wurde deshalb die Unterkunft der Bibelforscherinnen zum „Besichtigungsblock“, in den die SS die verschiedenen Besuchskommissionen beim Rundgang durch das Lager führte ${ }^{485}$. Insofern nutzte die SS die ordnungsliebenden und durchaus pflichtbewußten Zeugen Jehovas gelegentlich auch noch dazu, ein falsches Bild von den tatsächlichen Verhältnissen in den nationalsozialistischen Konzentrationslagern zu suggerieren. Doch so diszipliniert und hundertprozentig wie die Zeugen Jehovas die Lagerordnung solange diese nicht gegen ihre Glaubenssätze verstie $\beta$ - einzuhalten versuchten, so vehement sperrten und verweigerten sie sich dann, wenn für sie die Dinge umgekehrt standen.

Mit anderen Häftlingsgruppen im $\mathrm{KZ}$ pflegten die Zeugen Jehovas allerdings keine Zusammenarbeit. Eine Teilnahme an dem von den politischen Gefangenen getragenen Lagerwiderstand beziehungsweise eine Kooperation lehnten sie ab. Sabotage und politisch zielgerichtete Aktionen gegen die SS meinten sie mit ihrem Glauben nicht vereinbaren zu können. Auch noch im Lager versuchten sie, ihre bibelforscherische „Neutralität“ zu wahren ${ }^{486}$. Zudem konnte ihr Bekenntnis zur Wahrheitsliebe die im Lagerwiderstand aktiven politischen Häftlinge in Gefahr bringen ${ }^{487}$. Gleichwohl gab es einzelne Kontakte. So schleuste in Ravensbrück

falteten sie und legten sie auf die gesäuberten Schuhe im Tagesraum, bevor sie nur in Unterwäsche den Schlafraum betraten“" (John, Wewelsburg, S. 137).

Buber-Neumann, Gefangene, S. 245.

485 Vgl. ebenda, S. 250ff.; Füllberg-Stolberg, Pötzinger, S. 330; Pingel, Häftlinge, S. 91.

486 Vgl. Marłálek, Mauthausen, S. 274; Pingel, Häftlinge, S. 91. Obwohl die Zeugen Jehovas von sich aus keine Ambitionen zeigten, sich an der "Häftlingsselbstverwaltung" zu beteiligen, und die Mitwirkung an den Aktionen der „Politischen“ ablehnten, aber ihnen auch nicht entgegenzuwirken beabsichtigten, blieb das Verhältnis zu den Gruppen, die den Lagerwiderstand trugen, dennoch oftmals - als Ergebnis der Wirrungen des Lageralltags - nicht konfliktfrei. Denn zum einen versuchten die Bibelforschergruppen sehr wohl ihr Eigeninteresse durchzusetzen, was leicht mit dem von anderen Gruppen kollidieren konnte. Beispielsweise gab es in Buchenwald eine heftige Auseinandersetzung um das ,Bezugsrecht" eines gemauerten Neubaublockes, das sowohl von den in der Häftlings(selbst)verwaltung eingesetzten und zur ,Kernbelegschaft' gehörenden Gefangenen als auch von den ebenfalls seit Jahren internierten Zeugen Jehovas für sich proklamiert wurde. Zum anderen trübte auch das Verhalten von einzelnen Funktionshäftlingen der „Politischen“, die meinten, ihre Aufgabe durch das Einschreiten gegen illegale Bibelforscher-Aktivitäten erfüllen zu müssen, das Verhältnis zwischen „Politischen“ und Bibelforschern.

487 Diese - allerdings nicht durchgängig beobachtete (so wird auch durch Mitgefangene berichtet, daß sie ,durch ihre kaltblütige, zähe Art, mit der sie schwiegen oder logen“ [Meier, Neuengamme, S. 31f.], das Lager in Erstaunen setzten) - Eigenschaft bot Anlaß, die Integrität der Bibelforscher-Häftlinge generell in Zweifel zu ziehen. So führte der spätere Hannoversche Landesbischof Hanns Lilje ihren häufigen Einsatz als Kalfaktoren darauf zurück, daß es wegen ihrer, auch die Grenze der Kameradschaftlichkeit nicht gelten lassenden Wahrheitsliebe für die Gestapo leicht gewesen sei, „mit ihrer Hilfe die anderen Gefangenen zu beaufsichtigen“ (Lilje, Im finstern Tal, S. 58 f.). Unter Berufung auf diese Quelle berichtet Kater, Bibelforscher, S. 215, von angeblichen „Spitzeldiensten der Zeugen Jehovas“; selbst Pingel, Häftlinge, S. 91, kolportiert die Vermutung, „die Bibelforscher“ seien von der SS „sogar als Spitzel gegen andere Häftlinge eingesetzt worden“. Für die Annahme des gezielten Einsatzes 
eine Bibelforscherin, die bei einer SS-Familie als Haushaltsgehilfin eingesetzt wurde, Nachrichten ausländischer Radiosender über den Kriegsverlauf in das Lager ein ${ }^{488}$.

Viele Mithäftlinge bewunderten, trotz Negation, Skepsis und Unverständnis bezüglich der Glaubensansichten der Zeugen Jehovas, deren Gemeinschaftsgeist und solidarische Basis. Das Beispiel der Bibelforschergemeinde vermochte stark auf andere Häftlinge auszustrahlen. Einen Eindruck davon vermittelt ein von Edgar Kupfer-Koberwitz berichtetes Gespräch, das jener 1940/41 im KZ Neuengamme mit einem jungen jüdischen Mithäftling führte, der kurz zuvor aus Dachau überstellt worden war. Dieser tschechische Schneider, der in dem Block einquartiert worden war, den die Juden im KZ Neuengamme mit den Bibelforschern teilten ${ }^{489}$, äußerte sich voll Bewunderung über deren gottesfürchtige und solidarische Haltung, über ihren inneren Halt, die Harmonie, die sie trage, und den Reichtum, den er bei aller Not in ihren Augen habe leuchten sehen. Über die erste Begegnung mit den Zeugen Jehovas nach seiner Ankunft in Neuengamme berichtete der aus Dachau überstellte Mann:

„Als wir Juden von Dachau in den Block kamen, versteckten die anderen Juden, was sie hatten, um nicht teilen zu müssen. Du schüttelst den Kopf, aber es ist doch so. Draußen haben wir uns gegenseitig geholfen, aber hier, wo es um Leben und Tod geht, will jeder sich zuerst retten und vergißt den anderen. Aber denke dir, was taten die Bibelforscher? Sie müssen zur Zeit schwer arbeiten, irgend eine Reparatur an einer Wasserleitung machen. In diesem kalten Wetter stehen sie den ganzen Tag im Eiswasser. Kein Mensch begreift, wie sie es aushalten. Sie sagen, Jehova gibt ihnen die Kraft dazu. Sie brauchen ihr Brot sehr nötig, denn sie haben Hunger wie wir auch. Aber was taten sie? Sie trugen alles Brot zusammen, das sie hatten, nahmen sich die Hälfe davon und legten die andere Hälfte ihren Brüdern hin, ihren Glaubensbrüdern, die jetzt von Dachau kamen. Und sie bewillkommten sie und küßten sie. Bevor sie aßen, beteten sie, und nachher hatten alle verklärte und glückliche Gesichter. Sie sagten, daß keiner mehr Hunger hatte. Siehst du, da habe ich mir gedacht: Das sind die wahren Christen, so habe ich sie mir immer vorgestellt. “490

Auch innerhalb der Konzentrationslager setzten die Zeugen Jehovas alle Bemühungen daran, für ihren Glauben neue Anhänger zu gewinnen. Zahlreiche Mitgefangene wurden - oftmals zu deren Leidwesen - zu Objekten von Bekehrungsversuchen ${ }^{491}$. Selbst in Todesgefahren haben Bibelforscher noch Zeugnis abgelegt und ihren Mithäftlingen die biblische Botschaft verkündet. Als am 3. Mai 1945 das in der Neustädter Bucht vor Anker liegende Schiff „Cap Arcona“, auf dem die SS annähernd 5.000 aus dem KZ Neuengamme „evakuierte" Häftlinge unter katastro-

von Zeugen Jehovas als Spitzel zur Untergrabung des Lagerwiderstandes ließen sich vom Verf. hingegen keine weiteren Belege finden. Obgleich die Zeugen Jehovas diesem reserviert gegenüberstanden, wird es unter ihnen - nicht zuletzt aufgrund ihrer „Enthaltsamkeit" im Kampf um die „Häftlingsselbstverwaltung" - mit ziemlicher Sicherheit nicht mehr, sondern vielleicht eher weniger V-Leute der „Politischen Abteilung“ gegeben haben als in anderen Häftlingsgruppen.

488 Vgl. Weinzierl, Österreichische Frauen, S. 182.

489 Siehe S. 479.

490 Kupfer-Koberwitz, Mächtigen, S. 286.

491 Vgl. Buber-Neumann, Gefangene, S. 259; Meier, Neuengamme, S. 31f.; Kautsky, Teufel und Verdammte, S. 138; Wiechert, Totenwald, S. 148 f.; Zahnwetzer, Buchenwald, S. 27. 
phalen Bedingungen zusammengedrängt hatte, nach einem Angriff britischer Jagdbomber in Flammen stand, gelang es nur wenigen hundert Häftlingen, sich von Bord zu retten. $\mathrm{Zu}$ ihnen gehörte ein 33jähriger Zeuge Jehovas, der aus Düsseldorf gebürtige Symphoniker Ernst Schneider. Nach mehr als zwei Stunden im kalten Wasser, sich aneinanderklammernd und völlig entkräftet, wurde er zusammen mit zwei russischen Häftlingen von einem KZ-Leidensgenossen und Glaubensbruder, dem Hamburger Seemann Alfred Knegendorf, mittels eines Seiles auf das inzwischen gekenterte und an einem Ende zu etwa sieben Meter aus dem Wasser ragende Schiffswrack gehievt ${ }^{492}$. Nachdem er sich dort etwas erholt hatte, begann er den zwei Russen, die wie er soeben dem Tode entronnen waren, die Glaubenslehre der Zeugen Jehovas zu verkündigen und von der Hoffnung auf Gottes Friedensreich zu predigen. In den wenige Tage später von ihm angefertigten Tagebuchnotizen, die über die Schiffskatastrophe berichten, vermerkte der eifrige Verkündiger: „Ich habe in diesem Zustand, soweit es mir möglich war, auf die Tatsache hingewiesen, wenn sie ewiges Leben hier auf der Erde erhalten wollen, wo Gerechtigkeit, Friede, Wohlfahrt und Glück in vollkommenen Zuständen sein wird, sollen sie sich der Theokratie, dem Königreich Gottes, welches jetzt hier auf Erden aufgerichtet wird, unterordnen. “493

Der unverdrossene Missionsdrang der Zeugen Jehovas blieb nicht ohne Resonanz; in der Aussichtslosigkeit der KZ-Haft fand die von ihnen eifrig gepredigte Botschaft vom kommenden „Königreich Gottes“ Gehör. Gefangene anderer Gruppen schlossen sich ihnen an. Nicht wenige scheinen dabei jedoch eher von dem Wunsch getrieben worden zu sein, den „Segnungen“ der Bibelforschergemeinschaft teilhaftig zu werden, als durch eine innerlich nachvollzogene Erkenntnis des „wahren Glaubens“. Da die Zeugen Jehovas sich allerdings nicht mit verbalen Bekehrungsaussagen zufriedengaben, sondern die Interessenten über längere Zeit einer äußerst intensiven Gewissensprüfung unterzogen - ihre ,Attraktivität ' und das Problem der opportunistischen ,Bekehrungen“ blieb auch ihnen selbst nicht verborgen -, hatten viele Übertritte nicht lange Bestand. Jene, die sich mit innerer Überzeugung angeschlossen hatten, blieben hingegen in der Regel mit den Zeugen Jehovas auch dann noch verbunden, als die Lagertore sich 1945 wieder öffneten.

Zumeist waren es ausländische Häftlinge, in erster Linie Russen, und Angehörige nichtpolitischer Kategorien, die sich dem Bibelforscherglauben gegenüber aufgeschlossen zeigten ${ }^{494}$. In Einzelfällen kam es auch zu „Bekehrungen“ jüdischer

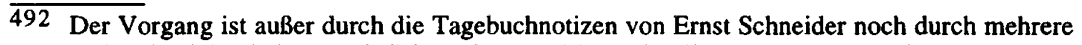
andere Berichte belegt. Vgl. Schön, Ostsee '45, S. 531-533; VVN HH, Komiteeakten H 34; Erinnerungsberichte von Alfred Knegendorf (29.1.1985) und Karl Hanl (24.11.1987), zwei Zeugen Jehovas, die sich ebenfalls auf den gekenterten Schiffsbauch retten konnten.

493 UaP Günther Schwarberg, Tagebuch von Ernst Schneider (20.4.-20.5.1945). Nach etwa fünf Stunden nahm ein Rettungsboot die Häftlinge in Empfang. Inwieweit die Missionsbemühungen bei den beiden Sowjetbürgern, die nach den Angaben von Ernst Schneider etwas Deutsch sprechen konnten, fruchteten, bleibt in dem Bericht offen.

494 Zur Zahl der Bekehrungen gibt es nur vereinzelte Angaben. Einer „Resolution“ aus dem Mai 1945 kann entnommen werden, daß sich unter den 230 Sachsenhausener Bibelforschern, die bei der Evakuierung des Lagers eine Marschkolonne bildeten, 36 „Menschen guten Willens“ befanden (siehe S. 472). Für das KZ Ravensbrück wird von 70 Bekehrungen berichtet (Weinzierl, Österreichische Frauen, S. 182; Lichtenegger, Wiens Bibelforscherinnen, S. 221, 278); nach anderen Angaben schlossen sich 300 junge Russinnen den Zeugen Jehovas an (Gebhard, 
Gefangener ${ }^{495}$. Doch selbst Gefangene mit kommunistischer und atheistischer Gesinnung, die in großer weltanschaulicher Distanz zu allem Religiösen standen, waren so tief beeindruckt von der Glaubenszuversicht und dem Gemeinschaftsgeist der Zeugen Jehovas, daß sie sich zu ihnen hingezogen fühlten. Einige von ihnen nahmen schließlich den Bibelforscherglauben an. Der folgende Bericht mag die Gründe und die Schwierigkeiten eines solchen Schrittes veranschaulichen.

Charlotte Tetzner, geborene Decker, die Tochter eines in Deutschland lebenden kroatischen Kommunisten, wurde am 15. April 1941, wenige Tage nach dem deutschen Überfall auf Jugoslawien, zusammen mit ihren Eltern von der Gestapo verhaftet ${ }^{496}$. Während ihr Vater in das Konzentrationslager Dachau eingeliefert wurde, kam sie gemeinsam mit ihrer Mutter in das $\mathrm{KZ}$ Ravensbrück. Dort begegneten ihr erstmals Zeugen Jehovas. Da sie in einem atheistischen Elternhaus erzogen worden war, verspürte sie keine Neigung, ,irgendetwas anzuhören, was mit Glauben zu tun hatte“. Sie hatte zunächst ,wie die meisten KZ-Häftlinge“ über den Bibelforscherglauben gelacht. Dies änderte sich gründlich, nachdem sie im Juli 1941 die Nachricht erhielt, daß ihr Vater im KZ Dachau getötet worden war ${ }^{497}$. Ihre Mutter erlitt einen Nervenzusammenbruch. Charlotte Tetzner geriet in eine schwere Krise. Das Bedürfnis nach religiöser Sinngebung keimte auf. Sie berichtet: „Von nun an bewegte sich etwas in mir. Ich öffnete meinen Sinn und Verstand ernsthaften Gesprächen mit den Zeuginnen. [...] Mehr und mehr wurde ich erfaßt und erfüllt von einem Glauben, der nichts mit Gefühlsduselei zu tun hat. Außerdem sah ich, mit welcher Konsequenz gerade diese Glaubensgruppe (die einzige religiöse, von der man als Gruppe sprechen konnte, denn Kirchen- oder Sektenmitglieder gab es nur vereinzelt) selbst im $\mathrm{KZ}$ noch Kriegsarbeiten bzw. solche, die mit Militär und Krieg in Zusammenhang standen, ablehnte.“

Charlotte Tetzner, die als politische Gefangene den ,roten Winkel“" trug, empfand zunehmend Gemeinsamkeiten mit den Bibelforscherinnen und schloß sich ihnen an. Als sie am 15. Dezember 1941 zusammen mit ihrer Mutter entlassen werden sollte, legte ihr die Oberaufseherin Langefeld im Lagerführerbüro zu ihrer Überraschung plötzlich den „Bibelforscher-Revers“ zur Unterschrift vor ${ }^{498}$. Die damals 21 jährige lehnte es spontan ab, die Erklärung zu unterzeichnen. Daraufhin

Zeugen Jehovas, S. 209; Jehovas Zeugen in Gottes Vorhaben, S. 168). Im KZ Mauthausen sollen „einige“" getauft worden sein; für das benachbarte Lager Gusen wird berichtet, daß fünf Polen getauft wurden (Jahrbuch 1989, S. 133).

495 Vgl. Max Liebster: Befreit! Wir möchten uns dafür dankbar erweisen, in: Der Wachtturm, 1.1.1979, S. 20-23; Jahrbuch 1974, S. 174; EB Marco Max Feingold, 1.11.1987.

496 Die folgende Darstellung beruht auf: EB Charlotte Tetzner, 5.7.1986, 18.8.1986, 21.9.1986, 3.10.1986. Ein Erinnerungsbericht von ihr ist auch in einem 1992 in den USA erschienenen Sammelband mit Berichten weiblicher Auschwitz-Häftlinge veröffentlicht worden, vgl. Charlotte Tetzner: Temporary Stabsgebaeudlerin, in: Shelley, Auschwitz, S. 247-256.

In einer Liste Dachauer KZ-Gefangener wird das Todesdatum mit 7.7.1941 angegeben, demnach starb ihr Vater Anton Decker nur einen Monat nach seiner am 6. Juni registrierten Ankunft im KZ Dachau (Schreiben der KZ-Gedenkstätte Dachau vom 2.2.1987 an den Verf.). Einzelheiten über die Todesursache konnten nicht in Erfahrung gebracht werden.

498 Weitere Fälle, in denen Gefangenen, die weder als Bibelforscher in das Lager eingeliefert noch als Zeugen Jehovas getauft worden waren, die „Verpflichtungserklärung“ zur Unterschrift vorgelegt worden ist, sind dem Verf. bislang nicht bekanntgeworden. Es kann vermutet werden, $\mathrm{daB}$ dieser Vorgang wohl auf der Eigeninitiative der SS-Lagerführung und nicht auf Anordnungen des Gestapa bzw. des RSHA beruhte. 
mußte sie die ihr bereits für die Entlassung ausgehändigte Zivilkleidung wieder ablegen und wurde zurück ins Lager kommandiert, während ihre Mutter entlassen wurde.

Die SS-Lagerführung, deren Reaktion zwischen totalem Unverständnis und Wut über die unerschrockene Aufrichtigkeit der jungen Frau schwankte, scheint sich durch diese Haltung ausgesprochen herausgefordert gefühlt zu haben. Von einem zur Entlassung anstehenden Häftling, der nominell gar nicht zu den Bibelforschern gehörte, hatte man ein solches Zeugnis nicht erwartet. In den nächsten Monaten wurde die junge Frau wiederholt zur Kommandantur und zur ,Politischen Abteilung“ (Gestapo), zur Oberaufseherin und zum Arbeitseinsatzführer gerufen: „Man versuchte es mit Verlockungen, mit Drohungen, mit Spott.“ Es sei eine „,anhaltende Nervenprobe" gewesen, doch sie habe in ihrem neu gewonnenen Glauben den nötigen Rückhalt gefunden. Anläßlich eines Besuches von Himmler wurde sie dem Reichsführer-SS persönlich vorgeführt. „Wahrscheinlich glaubte man, mit diesem letzten Mittel eine Sinnesänderung bei mir zu bewirken. Ich antwortete ihm nur, daß ich, solange man mir nichts Besseres bieten könne, bei meinem Glauben bleibe."

Charlotte Tetzner verblieb daraufhin im KZ. Sie wurde als Schreibkraft zur Oberaufseherin Maria Mandel beordert. Als diese Anfang 1942 ins KZ AuschwitzBirkenau versetzt wurde, um im dortigen Frauenlager zur Schutzhaftlagerführerin aufzusteigen, bedeutete dies auch für Frau Tetzner die Überstellung nach dort. Mit dem ersten Häftlingstransport aus Ravensbrück traf sie am 26. März 1942 im KZ Auschwitz ein ${ }^{499}$. Charlotte Tetzner, die erneut als ,politisch“ eingeordnet wurde, empfand diese Klassifizierung jetzt als nicht mehr zutreffend und stickte sich daraufhin selbst einen lila Winkel, den sie an ihrer Häftlingskleidung anbrachte ${ }^{500}$. Damit wollte sie ihre Verbundenheit mit den Bibelforschern und ihr Bekenntnis als Zeugin Jehovas auch äußerlich kenntlich machen. Obgleich ihr dies viel Ärger mit den SS-Aufseherinnen einbrachte, gaben diese schließlich nach und beließen ihr den Winkel ${ }^{501}$.

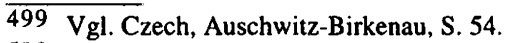

500 Von ähnlichen Begebenheiten wird mehrfach berichtet, vgl. Buber-Neumann, Gefangene, S. 259; EB Alois Moser, 23.5.1986; EB Richard Rudolph, 31.5.1986, 9.9.1986. Richard Rudolph erinnert sich an einen polnischen Häftling, der im „Entkrautungskommando“ im KZ Neuengamme mit Zeugen Jehovas zusammenarbeitete. Er habe seinen "roten Winkel“ abgelegt und sich einen „,lila Winkel“ geschneidert. Wegen dieses Winkeltausches habe die SS ihn mit 25 Stockhieben bestraft.

501 Charlotte Tetzner wurde in den folgenden Jahren als Bürokraft in der Schreibstube bei der Schutzhaftlagerführerin Mandel in Birkenau, wo sie mit dem ganzen Grauen des Vernichtungslagers konfrontiert wurde, und als Stenotypistin im SS-Lazarett eingesetzt. Im Zuge der Räumung der Lager erlebte und erlitt sie noch vier weitere Verfolgungsstationen: GroB-Rosen Mauthausen, Bergen-Belsen und Mittelbau-Dora. Während ihrer Tätigkeit im Auschwitzer SS-Lazarett lernte Charlotte Tetzner den in der Schreibstube des Standortarztes Dr. Eduard Wirths eingesetzten und in dieser Zeit zur Führungsspitze des organisierten Lagerwiderstandes (,Kampfgruppe Auschwitz“) gehörenden Hermann Langbein kennen. Langbein ist ihr „,vorbildliches Verhalten" noch gut in Erinnerung, wie er in einem Schreiben an den Verf. vom 22.1.1985 mitteilte. 
Die unaufhörlichen Missionsbemühungen machten auch vor dem Wach- und SS-Personal nicht halt ${ }^{502}$, wobei dieses nicht selten schwerwiegende Folgen für die „Königreichsverkündiger“ nach sich zog: Als ein im Haushalt des Buchenwalder KZ-Kommandanten Karl Koch als Kalfaktor beschäftigter Bibelforscher versuchte, seine religiösen Überzeugungen der Familie des Kommandanten nahezubringen, gab Ilse Koch ihrem Mann auf, den Häftling „wegen Fehlverhaltens“ zur Bestrafung zu bringen ${ }^{503}$. Zuweilen stießen die Zeugen Jehovas aber auch auf Interesse; selbst von Fällen, in denen SS-Leute heimlich mit ihnen die Bibel lasen, wird berichtet ${ }^{504}$. Aus welchen Situationen heraus sich Möglichkeiten zu Bekehrungsversuchen bei SS-Angehörigen boten und welche Bedeutung diese in Einzelfällen zu gewinnen vermochten, zeigt die folgende Episode, die sich im KZ Neuengamme zutrug. In diesem Lager hatte sich zwischen dem Bibelforscher Richard Rudolph, seit dem Frühjahr 1943 als Koch in der SS-Küche eingesetzt, und dem als Magazinverwalter fungierenden SS-Mann mit der Zeit ein gewissermaßen freundschaftliches Verhältnis entwickelt ${ }^{505}$. Ausschlaggebend dafür war nicht nur der tägliche Umgang miteinander und die Wertschätzung des für die Proviantbewirtschaftung rechenschaftspflichtigen SS-Mannes für den pflichtbewußten Häftling, bei dem er keine Unterschlagung zu befürchten brauchte, sowie der beide verbindende erlernte Beruf des Bäckers, sondern auch die religiöse Ansprechbarkeit des Magazinverwalters. Jenem SS-Rottenführer namens Gustav Ahrend, der erst vor kurzem nach Kriegseinsatz an der Ostfront als Wachmann ins KZ Neuengamme versetzt worden und von dem Erlebtem anscheinend nicht unbeeindruckt geblieben war, predigte der Bibelforscherhäftling nun jeden Morgen in der Abgeschiedenheit des Proviantraumes vom herannahenden Königreich Gottes. Sie waren zu großer Vorsicht gezwungen, denn ,weder SS-Männer noch andere Mitgefangene durften auch nur das Geringste davon erfahren".

Ein Jahr später beschützte diese Freundschaft Richard Rudolph vor dem Schlimmsten. Im Spätsommer 1944 strafweise auf Transport in das Außenlager Salzgitter-Watenstedt geschickt, hatte er dort die ihm aufgetragene Arbeit verweigert. Der Zeuge Jehovas und langjährige KZ-Häftling sollte in der Bombengießerei der Stahlwerke Braunschweig (,Reichswerke Hermann Göring“) als „Kapo“ ein Arbeitskommando sowjetischer Häftlinge anführen. Von den SS-Offizieren des Lagers zur Rede gestellt, lehnte er dies unter Verweis auf seine religiöse Überzeugung, die ihm jegliche Arbeit in der Munitionsherstellung verbiete, kategorisch ab. Daraufhin kündigte ihm der Stützpunktleiter SS-Obersturmführer Arnold Strippel an, daß er, sobald die Genehmigung vorliege, wegen Arbeitsverweigerung hingerichtet werde. Vorläufig wurde er in die Strafkompanie eingewiesen. Mittlerweile hatte jener Rottenführer Ahrend, der einige Zeit zuvor ebenfalls vom Neuengammer Stammlager nach Watenstedt gekommen und dort zum Verantwortlichen der Häftlingsküche avanciert war, von dem Vorgang erfahren. Ihm gelang es nach ungefähr

502 Vgl. John, Wewelsburg (1996), S. 140; Kater, Bibelforscher, S. 216; Zürcher, Kreuzzug, S. 105.

503 Vgl. Durand, Buchenwald, S. 57.

504 Vgl. Jahrbuch 1989, S. 132; KmW, KW D 87, Buder, Wewelsburg, S. 96.

505 Die Schilderung beruht auf - mit Unterlagen im DhN abgeglichenen - Berichten von Richard Rudolph (18.2.1986, 9.9.1986, 5.8.1987); zu Ahrend vgl. Curio-Haus-ProzeB, S. 455. 
sieben Tagen, Rudolph aus der Strafkompanie herauszubekommen und ihn in der Häftlingsküche unterzubringen. Als Ahrend einige Monate später durch den Rapportführer davon erfuhr, daß die Hinrichtung zur Vollstreckung angeordnet worden sei ${ }^{506}$, versteckte er seinen Schützling zunächst in einem Keller und organisierte über die Arbeitsstatistik die Falschmeldung, daß der Häftling bereits mit einem Transport das Lager verlassen habe. Kurze Zeit später bewerkstelligte er es, daß Richard Rudolph auf einem Proviantwagen verborgen tatsächlich das Lager verließ. Im Rückblick urteilt Rudolph, der betont, daß der SS-Mann damit für ihn sein Leben aufs Spiel gesetzt habe: „Ich kann nur sagen: Ich habe persönlich verspürt, daß der Name Jehovas ein starker Turm ist. “507

Die Bekehrungen Andersgläubiger zum Bibelforscherglauben galten den Zeugen Jehovas als Zeichen dafür, daß ihr Gott sich auch im Lager nicht von der Gemeinschaft abgewandt hatte und für die „Mehrung des Königreichswerkes“ sorgte. Glaubensstärke und Gemeinschaftsbande gaben den Zeugen Jehovas den erforderlichen Rückhalt, um den Schikanen der SS trotzen und die Härten des Lagers überstehen zu können. Die sich 1942 abzeichnende Veränderung ihres Lageralltages nutzten sie konsequent für ihre Aktivitäten und die bibelforscherischen Zwecke.

\section{Schriftenschmuggel und Gestapo-Aktion}

Als sich für die Zeugen Jehovas Mitte des Krieges die Lage in den Konzentrationslagern verbesserte und sie vielfach in „Vorzugsstellungen“ kamen $^{508}$, boten sich für sie in verstärktem Maße Möglichkeiten zur Herstellung und Weitergabe von Schriften und damit zur Organisation ihres „Verkündigungswerkes“ auch innerhalb der Gefangenschaft. Insbesondere in kleinen, ausschließlich mit BibelforscherHäftlingen besetzten und mit „Spezialaufgaben“ betrauten Arbeitskommandos, zum Beispiel der „Bildhauer-Werkstatt“ in Buchenwald 509 oder dem Restkommando in Wewelsburg ${ }^{510}$, konnte die illegale Schriftenherstellung und -vervielfältigung aufgenommen werden. Es gelang den Zeugen Jehovas sogar, zumindest zeitweilig zwischen den verschiedenen Lagern ein regelrechtes Kuriernetz aufzubauen ${ }^{511}$.

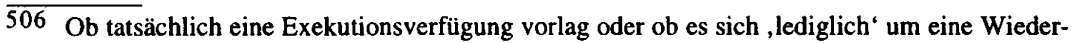
holung der Monate zuvor von dem Stützpunktleiter Strippel ausgesprochenen Hinrichtungsdrohung handelte, konnte nicht geklärt werden.

507 Richard Rudolph: Bericht über besondere Erfahrungen aus der Nazizeit. Heidelberg o. D. (Kopie in Besitz des Verf.). Rudolph stand auch später noch in losem Kontakt mit Ahrend, der nach Haft im britischen Internierungslager Neumünster freikam.

508 Siehe S. $451 \mathrm{ff}$.

509 In der „Bildhauer-Werkstatt“ im KZ Buchenwald (siehe S. 458, Anm. 570), in der zeitweise bis zu fünfzehn Zeugen Jehovas arbeiteten, fühlten jene sich relativ geschützt, dort waren sie unter sich und brauchten keinen Verrat durch andere Häftlinge zu fürchten. Selbst SS-Angehörige durften die Bildhauer-Werkstatt, ein besonderes Steckenpferd des Lagerkommandanten Karl Koch, nur mit dessen Genehmigung betreten. Die Zeugen Jehovas nutzten diese Möglichkeit, um in großer Zahl Bibelforscherschriften herzustellen, beispielsweise Abschriften aus dem ins Lager geschmuggelten Buch „Rechtfertigung“ oder handschriftliche Vervielfältigungen der Tagestexte; eine Bibel hatte man sich zu jener Zeit auch besorgen können. Vgl. EB Johannes Rauthe, Geschichtsbericht, S. 56-65.

510 Vgl. John, Wewelsburg (1996), S. 128f.; siehe auch oben S. 338f.

511 Die folgenden Ausführungen beruhen auf EB Alois Moser, 23.5.1986; EB Richard Rudolph, 10.9.1986; Erwachet!, 22.6.1985, S. 10-13; VVN HH, Komiteeakten M 25 und T 1. Zur 
Dabei wurden persönliche Briefe, aber auch „biblische Auslegungen“ und Berichte zur Situation im KZ zumeist von jenen Bibelforschern, die tagsüber zu Arbeiten außerhalb der Lager abkommandiert waren, über Mittelspersonen, „tote Briefkästen“ oder ähnlichem an Glaubensgeschwister übermittelt. Diese herausgeschmuggelten Texte wurden, sofern sie nicht ausschließlich dazu gedacht waren, die eigenen Angehörigen zu stärken und über das persönliche Befinden zu unterrichten, von nichtinhaftierten Zeugen Jehovas - teils handschriftlich, teils maschinell - vervielfältigt und weiterverbreitet. Die so entstandenen „Mitteilungen“ gelangten anschließend über die „Untergrundbewegung“ auf dem umgekehrten Weg in andere Lager hinein 512 .

$\mathrm{Da}$ die bis dahin in den einzelnen Lagern weitgehend isolierten Bibelforschergruppen - einen gewissen Informationsfluß hatte es lediglich durch Überstellungen zwischen den Konzentrationslagern gegeben - zu verschiedenen Fragen jeweils eigene Standpunkte entwickelt hatten, stießen mit dem Schriftenaustausch auch unterschiedliche Positionen aufeinander. So konnte es passieren, daß nun gewissermaßen Lehrstreitigkeiten zwischen den Konzentrationslagern ausgetragen wurden - wohl eines der bemerkenswertesten Geschehnisse in der an kuriosen Momenten nicht armen Geschichte der Zeugen Jehovas. Pointiert, aber in der Tendenz zutreffend ausgedrückt, handelte es sich um einen ,Kampf um die Wahrheit ' zwischen den ,radikaleren' Anschauungen der Buchenwalder Bibelforschergemeinde unter Willi Töllner auf der einen und den im Vergleich dazu ,gemäßigteren' Positionen, wie sie in Sachsenhausen unter dem Einfluß des dort inhaftierten Reichsdieners Erich Frost ${ }^{513}$ und in Neuengamme unter der von Ernst Wauer geführten Bibelforschergemeinschaft vorherrschend waren, auf der anderen Seite. Während die Buchenwalder Gruppe der Auffassung war, daß die „Gemäßigten“ das unerschrockene, allein auf Jehova vertrauende Bekenntnis einer zu weit gehenden Kompromißbereitschaft opferten, waren jene der Ansicht, daß die Glaubensbrüder in Buchenwald eigensinnige Ausleger seien, die eine Priesterherrschaft über den

zentralen Rolle, die den auf dem Gut Hartzwalde eingesetzten Zeugen Jehovas für den „Schriftenaustausch" zukam, siehe S. 466, Anm. 597.

$512 \mathrm{Zu}$ den maßgeblich beteiligten IBV-Gruppen um Engelhard, Riet und Fritsche siehe S. 337342.

513 Neben Frost zählten mit Paul Balzereit und Fritz Winkler auch zwei weitere frühere Leiter des deutschen IBV-Zweiges zu den Bibelforscher-Häftlingen in Sachsenhausen. Die SS versuchte, die sich an diesen Führungspersonen festmachenden Gegensätze und Konflikte um den IBVKurs zu nutzen, um die Bibelforschergemeinde zu spalten. So führte die SS den seit Ende 1937 in Sachsenhausen inhaftierten ehemaligen Direktor der WTG, Paul Balzereit, als „Umfaller" vor und forderte die Bibelforscher auf, es ihrem früheren „Oberhaupt“ gleichzutun. Obgleich er „unterschrieben“ hatte, wurde Balzereit erst über ein Jahr später aus Sachsenhausen entlassen. Von der Gemeinschaft der Bibelforscher wurde er weitgehend gemieden. Die Autorität von Erich Frost, der Anfang 1941 nach Verbüßung einer dreieinhalbjährigen Gefängnisstrafe eingeliefert wurde, war im Lager dagegen ungebrochen; er gehörte zu den „Wortführern" der Häftlingsgruppe. Einmal wurde er, weil er Vorträge in den Bibelforscherbaracken hielt, mit der Einweisung in die Strafkompanie und mit 25 Stockschlägen auf dem berüchtigten „Bock“ bestraft. Mit der Zeit verbesserte sich die Lage von Frost - wie die seiner Glaubensgeschwister - spürbar; so wurde der frühere Leipziger Kapellmeister von der SS bei ihren „geselligen Zusammenkünften" zur musikalischen Umrahmung herangezogen. Angaben nach Jahrbuch 1974, S. 150, 198; Der Wachtturm, 15.4.1956, S. 247; FGN, NHS 13-7-04, Erich Frost, Schreiben vom 15.7.1969; EB Willi Lehmbecker, 7.2.1987; EB Alfred Skoda, 24.6.1984. 
„Wachtturm“ anstrebten, durch ihre Bewunderung Töllners einen „Kult“ errichteten und „Heiligenverehrung“ betrieben ${ }^{514}$.

Die 1943 im KZ Ravensbrück abgefaßten „Briefe. Nachrichten für die Zeugen Jehovas und ihre Gefährten“, die von nichtinhaftierten „Mitverbundenen in der Theokratie", mit einer erläuternden Vor- und Nachbemerkung versehen, vervielfältigt und - soweit möglich - an Zeugen Jehovas im ganzen Reichsgebiet verbreitet wurden, stellen ein höchst bemerkenswertes Zeugnis dar, weil sie ausführlich von den Lehrstreitigkeiten zwischen den verschiedenen Fraktionen berichten, die sich in Ravensbrück unter den Bibelforscherinnen herausgebildet hatten. Vier „Gliederungen“ werden genannt: die „ganz Extremen“, die nahezu jede Einfügung in die Lagerordnung ablehnten (,wirklich Wahnsinn“, so die Kommentierung); diejenigen, die durch ihre Radikalität meinten, „Harmagedon beschleunigen“ zu können und beispielsweise ,das Nichtessen der Blutwurst zum Hauptgegenstand“ erhoben; diejenigen, die „,den Hauptkampf schon als vorüber sehen“, da sie den in Europa tobenden Krieg als die „Vollstreckung“ des göttlichen „Urteils an den Nationen“ deuteten; und schließlich die Zuversichtlichen, die „wachsam und nüchternen Geistes“ durch alle Prüfungen hindurch darauf vertrauten, „daß Jehova sein Volk nicht verlassen“" werde, getreu der Losung „Gott ist getreu, wenn wir treu sind.“515 Die Verfasserinnen, die sich dieser vierten Gliederung zurechneten, sahen in der Uneinigkeit das Werk Satans, der nichts unversucht gelassen habe, „Gottes Volk“ im Lager durch Hunger und Folter („Prüfungen fürs Fleisch“), aber auch durch Anfechtungen des Geistes zum Abfall vom Glauben zu verleiten. Da sie die Zersplitterung auch auf den Mangel an ,geistiger Speise“ zurückführten, waren sie angesichts des ihnen seit Ende 1942 auf verdecktem Wege möglichen Bezuges von „Wachtturm“-Exemplaren nunmehr voller Hoffnung, daß Jehova-Gott die Seinen fortan auf den richtigen Weg weisen und neue Einheit stiften werde.

Die Aktivitäten der Bibelforscher-Häftlinge, ihre verstärkten Außenkontakte und der Schriftenschmuggel blieben nicht gänzlich unbemerkt. Nach vereinzelten Vorstößen der Gestapo rügte im September 1943 der Chef des Wirtschafts-Verwaltungshauptamtes, SS-Obergruppenführer Oswald Pohl, die KZ-Verwaltungen dahingehend, daß sie sich durch die guten Arbeitsleistungen der Zeugen Jehovas dazu verleiten ließen, ihre Sicherungspflichten zu vernachlässigen. Im zentralen Runderla $\beta$ des WVHA vom 10. September 1943 betreffs „Staatsfeindliche Propaganda der Bibelforscher in den Konzentrationslagern und auf den Arbeitsplätzen" faßte Pohl die bisherigen Erkenntnisse zusammen:

„In jüngster Zeit wurden Propagandaschriften der Internationalen Bibelforschersekte beschlagnahmt, aus denen ersichtlich ist, daß die in den Konzentrationslagern einsitzenden BibelforscherHäftlinge Gelegenheit haben 1.) des Nachts unbewachte Zusammenkünfte in den Konzentrationslagern (in Waschräumen pp.) durchzuführen, 2.) illegalen Briefverkehr mit Bibelforscher-

$\overline{514}$ Nach der Befreiung 1945 meldete die Buchenwalder Gruppe einen Führungsanspruch innerhalb des deutschen IBV-Zweiges an. Es kam dann aber zu einer gütlichen Einigung; die Spaltung wurde überwunden, und beide „Flügel“ arbeiteten gemeinsam am „Verkündigungswerk“, wenn auch, wie ein Gesprächspartner erklärte, „manche Wunden geblieben“ sind.

515 UaP Gerhard Kaiser, Briefe. Nachrichten für die Zeugen Jehovas und ihre Gefährten (Hervorhebung im Original). 
Häftlingen anderer Lager zu führen und 3.) sogar Briefe an in Freiheit befindliche Bibelforscher aus dem Lager heraus und Antwortbriefe wieder herein zu schmuggeln. In diesen Briefen werden Ereignisse im Lager und die Leiden der Bibelforscher geschildert, die von Lügen und $\mathrm{Haß}$ gegen das Reich nur so strotzen. Der Bibelforscher darf ja lügen, wenn es seiner Jehovalehre zum Vorteil gereicht. In den Schriften, die dem zuständigen Referat des Reichssicherheitshauptamtes zugeleitet wurden, werden eine Reihe von Konzentrationslagern namentlich aufgeführt, in denen der Briefschmuggel dieser Art möglich war. Was an den Angaben auch wahr sein mag oder nicht, fest steht, daB in der Beaufsichtigung der Bibelforscher in den Konzentrationslagern eine gleichgültige Nachlässigkeit eingetreten ist. Diese Gleichgültigkeit in der Beaufsichtigung und Beobachtung ist sicher durch die Tatsache entstanden, daß die Bibelforscher gute und hervorstechende Arbeitsleistungen zeigen, ganz gleich, wo sie eingesetzt werden. Um diesen unmöglichen Zustand zu beheben, ordne ich versuchsweise an, daß mit sofortiger Wirkung die in den Konzentrationslagern befindlichen Bibelforscher-Häftlinge auseinandergelegt werden. Es ist dabei so zu verfahren, daß in jeden Block unter die anderen Häftlinge 2-3 Bibelforscher-Häftlinge gelegt werden. Durch geeignete Überwachung (V-Männer pp.) ist festzustellen, ob die Bibelforscher-Häftlinge versuchen, ihre Lehre an die anderen Häftlinge heranzutragen bezw. ihre Tätigkeit für die I.B.V. nach anderen Richtungen fortsetzen. Über die Erfahrungen ist erstmalig am 15.10.43, weiterhin vierteljährlich, zu berichten." 516

$\mathrm{Zu}$ den Folgen dieses Erlasses gehörte, daß nun auch in jenen Lagern, in denen dies bislang noch nicht geschehen war, das Auseinanderlegen der zuvor gemeinschaftlich untergebrachten Bibelforscher-Häftlinge veranlaßt wurde ${ }^{517}$. Im KZ Neuengamme, wo die ,illegalen“ Aktivitäten ebenfalls zugenommen hatten, wurden Ende 1943 die Zeugen Jehovas auf alle Baracken verteilt ${ }^{518}$. Aber auch mit weiteren Auflagen - beispielsweise durften die jedem Block zugewiesenen fünf bis sechs Zeugen Jehovas nicht gemeinsam an einem Tisch sitzen, und sonntags, und damit in der einzigen arbeitsfreien Zeit, durften Bibelforscher-Häftlinge sich selbst außerhalb der Unterkünfte nicht zusammen sehen lassen - konnte die Lagerieitung des $\mathrm{KZ}$ Neuengamme dieser Entwicklung nicht wirksam entgegenwirken und die von den vorgesetzten Dienststellen angeordnete weitgehende Unterbindung der Aktivitäten der Bibelforscher erreichen.

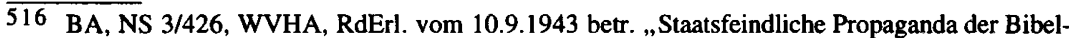
forscher in den Konzentrationslagern und auf den Arbeitsplätzen". Ungefähr zur gleichen Zeit, als Pohl durch diesen Erlaß die Pflichtversäumnisse der KZ-Verwaltungen beklagte, ereigneten sich ähnliche Dinge gewissermaßen unter seinen eigenen Augen. Auf Gut Comthurey (bei Fürstenberg/Mecklenburg und damit nahe gelegen zum KZ Ravensbrück), das Oswald Pohl als „Lehen" erhalten hatte und auf dem seine Familie während des Krieges lebte, hatte der tägliche Umgang mit den als Arbeitskräften geschätzten Zeugen Jehovas ebenfalls jene „Nachlässigkeit" bewirkt. So berichtet Ilse Unterdörfer, die dort als Anweisehäftling eingesetzt wurde: „Einige von uns [Bibelforscherinnen] schliefen dort; sie kamen also gar nicht mehr in das Lager [Ravensbrück]. So gelang es mir, mit Bruder Franz Fritsche aus Berlin in Verbindung zu kommen, mit dem ich mich am Abend in einem Wald, der zum Gut gehörte, zu einer über eine Schwester in Berlin brieflich vereinbarten Zeit traf. Von ihm erhielt ich immer eine ganze Reihe von Wachtturm-Ausgaben." (Bericht Ilse Unterdörfer, Jahrbuch 1974, S. 199)

517 Im KZ Ravensbrück war bereits 1942 zeitweilig die geschlossene Gemeinschaftsunterbringung von Bibelforschern aufgehoben worden. Vgl. Buber-Neumann, Gefangene, S. 258f., 268. Zur im KZ Dachau 1939/40 erfolgten versuchsweisen Verlegung einzelner Bibelforscher in mit Gefangenen anderer Gruppen belegte Baracken siehe S. 449.

518 Jehovas Zeugen in Gottes Vorhaben, S. 171. 
Im KZ Buchenwald wurden Mitte November 1943 die Zeugen Jehovas auf die anderen Häftlingsunterkünfte verteilt. Lediglich 40 von ihnen blieben auf ihrem alten Block, den die SS mit französischen Gefangenen auffüllte. Die Neubelegung gestaltete sich jedoch als Fehlschlag für die SS, da sich unerwünschte Effekte zeigten: Aufgrund des „guten Einvernehmens mit den Neuankömmlingen“ wurden sechs Zeugen Jehovas sogleich „wegen Agitation“ zur „Meldung“ gebracht und strafversetzt ${ }^{519}$. Hatte schon die Separierung der Bibelforscher bei der Arbeit und die Isolierung von den Mitgefangenen bei der Unterbringung ihren Widerstandsgeist und inneren Zusammenhalt nicht angreifen können, sondern ihn vielmehr noch gestärkt, so verkalkulierte die SS sich jetzt mit der angeordneten Auseinanderlegung der Zeugen Jehovas erneut. Die in der Absicht, die Gemeinschaftsstrukturen zu zerschlagen und die Glaubensangehörigen durch Vereinzelung zu demoralisieren, betriebene Aufteilung der Bibelforscher auf verschiedene Blocks nutzten jene dazu, neue Interessenten für ihren Glauben zu gewinnen und gleichsam als „Sprengel in der Diaspora“" 520 zu wirken.

Dabei konnte den SS-Leuten vor Ort dieses Phänomen nicht unbekannt sein. Als beispielsweise im KZ Dachau die SS schon 1939/40 begriff, welche ungeheure gegenseitige Stärkung für die Bibelforscher die gemeinsame Unterbringung bedeutete, wurden - wie ein Zeuge Jehovas berichtete - ,einige Brüder versuchsweise in Baracken mit politischen Häftlingen versetzt" ${ }^{\text {"521 }}$. Doch schon kurz darauf habe die SS feststellen müssen, daß nicht wenige politische Häftlinge ,für die Wahrheit eingestellt waren", und deshalb kamen die Verlegten erneut zu ihren Glaubensbrüdern in die Baracken 15, 17 und 19 zurück. Über die weiteren Schritte der Lagerleitung heißt es in dem Bericht des Zeugen Jehovas: „Was nun? Für einige Monate wurden zu uns versuchsweise politische Häftlinge [...] in unsere $\mathrm{Ba}$ racken genommen, dann zu einer Zeit wieder heraus; und es kamen zur Abwechselung, geistliche Würdenträger' und zuletzt statt diesen hatte man uns ,Berufsverbrecher' $[\ldots]$ gebracht, um uns wieder zu beobachten, wie wir uns mit denen verhalten." 522

Das ganze Experimentieren der Lagerverwaltungen blieb für sie erfolglos. In Dachau veranstalteten die Zeugen Jehovas fast jeden Abend Bibelstunden ${ }^{523}$, in Gusen wurde getauft und das „Gedächtnismahl“ beim Schein einer Kerze in einem

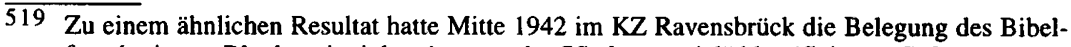
forscherinnen-Blocks mit einhundert von der SS als ,, asozial“ klassifizierten Gefangenen geführt, mit deren Hilfe die SS hoffte, die Bibelforscherinnen bespitzeln zu können. So sollten sie die Zeugen Jehovas melden, wenn sie jene bei religiösen Gesprächen beobachteten. Doch auch dies erwies sich für die SS als Fehlschlag. Margarete Buber-Neumann berichtet, daß die Bibelforscherinnen ,sich liebevoll der ,Schmuckstücke“" annahmen; Fürsorge und Missionsanstrengungen blieben nicht ohne Erfolg: „In kurzer Zeit häuften sich die Fälle: Asoziale, Zigeuner, eine Polin, eine Jüdin, Leichtpolitische meldeten sich ,nach vorn' und erklärten, von nun ab ,Zeugen Jehovas ' zu sein, und baten um einen lila Winkel und Verlegung in den Bibelforscher-Block. Die SS beschimpfte sie, schmiß sie raus und ergriff als erste hysterische Maßnahme die sofortige Verlegung der hundert Asozialen von unserem Block." (BuberNeumann, Gefangene, S. 259)

520 Pingel, Häftlinge, S. 90.

521 EB Alois Moser, 23.5.1986.

522 Ebenda.

523 Vgl. Gostner, 1000 Tage im KZ, S. 46. 
Waschraum gefeiert ${ }^{524}$, in Ravensbrück wurde - unter Ausnutzung der Weihnachtszeit - mit Beteiligung von Bibelforscherinnen aus sechs Nationen eine dreitägige „Hauptversammlung“ abgehalten, die in ihrem Ablauf den in Freiheit gehaltenen Kongressen entsprach ${ }^{525}$, in Neuengamme fanden sich Zeugen Jehovas und Interessierte auf den Blocks zu Studiengruppen zusammen ${ }^{526}$, auch in Buchenwald hielten die Zeugen Jehovas regelmäßig heimliche Andachten; zweihundertfünfzig von ihnen feierten um Mitternacht gemeinsam das „Gedächtnismahl“, an manchen Tagen nutzten sie eine Regentonne für heimliche Taufen ${ }^{527}$. Die Gegenmaßnahmen der SS hatten nicht verhindern können, daß die Zeugen Jehovas ihre Glaubenslehren auch innerhalb der Konzentrationslager weiterverbreiteten. Die Organisation des Verkündigungswerkes war in einzelnen Lagern bereits soweit gediehen, daß allmonatlich in einer Übersicht über die „Gesamtzahl der Zeugnisse“ nach außerhalb berichtet wurde. Bei der Berichterstattung wurde getrennt zwischen den Missionsanstrengungen, die gegenüber Mithäftlingen unternommen worden waren, und der „Gesamtzahl der Zeugnisse, die an SS-Angehörige gegeben wurden“ 528 .

Die unaufhörlichen Missionsbemühungen und die vielfältigen Untergrundaktivitäten, teils mit Verbindung nach außerhalb, erforderten aus der Sicht der übergeordneten Stellen nachhaltigere Gegenmaßnahmen. Gegen Ende April und in den ersten Maitagen 1944 reagierte die Gestapo dann im großen Stil mit polizeilichen Durchsuchungen der Zeugen Jehovas in den KZs, mit Beschlagnahmeaktionen und Verhängungen von Lagerstrafen, um dem ,illegalen Treiben“ ein Ende zu bereiten.

„Extra aus Berlin“ reiste die Gestapo „zu einem großen Schlag“ nach Neuengamme an ${ }^{529}$. Frühmorgens stand sie plötzlich da. Alle Zeugen Jehovas wurden auf dem Appellplatz zusammengetrieben. Sie mußten sich nackt ausziehen, ihre Sachen wurden ,gefilzt“. Gleichzeitig gab es eine gründliche Durchsuchung der Unterkünfte und Arbeitsstellen. Es wurden Bibeltexte, „Wachtturm“- und „Trost“Artikel gefunden. Alles Entdeckte wurde - den einzelnen Häftlingen zugeordnet auf den Appellplatz gelegt: Bei nahezu jedem lag ,ein kleines Häufchen“. Die Gestapo-Beamten steckten die Fundstücke in große Kuverts und schrieben den Namen des Häftlings, zu dem sie gehörten, auf den Umschlag. Danach wurden einige Zeugen Jehovas mit Stahlpeitschen ,grün und blau“ geschlagen, man erteilte ihnen „Torsperre“ 530 , schickte sie in die Strafkompanie, und anschließend wurden zwei Bibelforscher in ein Außenlager strafversetzt.

$\overline{524}$ Vgl. Jahrbuch 1989, S. 133. Auf die gleiche Weise wurde 1943 auch in Ravensbriick das Gedeächtnismahl gefeiert, bei dem - wie der Bericht genau vermerkt - 172 Zeugen Jehovas die Symbole entgegennahmen (UaP Gerhard Kaiser, Briefe. Nachrichten für die Zeugen Jehovas und ihre Gefährten, S. 7).

525 Ebenda, S. 5.

526 Siehe S. 488.

527 Vgl. Doyon, Hirten, S. 231; Zahnwetzer, Buchenwald, S. 28; EB Alois Moser, 23.5.1986.

528 EB Johannes Rauthe, Geschichtsbericht, S. 59.

529 Die folgende Darstellung beruht auf den Berichten von Gustav Auschner (Bericht vom 8.7.1969, FGN, NHS 13-7-0-1; auszugsweise veröffentlicht in Arbeit und Vernichtung, S. 197); Karl Hanl (24.11.1987); Richard Rudolph (31.5.1986; 9.9.1986) und Ernst Wauer (29.5.1986; Der Wachtturm, 1.8.1991, S. 25-29). Der Zeitpunkt, an dem die Gestapo-Aktion in Neuengamme stattfand, ist ungewiß.

530 Gefangene, über die die SS „Torsperre“" verhängte, durften nicht in Arbeitskommandos außerhalb der Lager eingesetzt werden. 
Von den Gestapo-Aktionen, die in ähnlicher Weise wie in Neuengamme auch in den anderen Konzentrationslagern stattfanden, nahmen auch Mithäftlinge anderer Kategorien Notiz. Der Norweger Odd Nansen, der im KZ Sachsenhausen inhaftiert war, notierte in seinem Tagebuch unter dem Datum des 28. April 1944: „Es scheint eine Aktion gegen alle Bibelforscher im Gange zu sein. Es gibt viele von ihnen hier im Lager. Sie haben anscheinend dieser Tage ein Flugblatt abgesandt des Inhalts, daß der Führer zu irgendeiner bestimmten Zeit sterben wird. Solche Flugblätter soll man auch innerhalb des Lagers gefunden haben. Die Aktion hatte zur Aufgabe, sie zu finden. Als wir gestern von der Arbeit hereinmarschieren, wurden alle Bibelforscher am Appellplatz aufgestellt und gefilzt, d. h. sie wurden ausgezogen und durch und durch untersucht." Die Gestapo fand einige Schriften, und das Ganze wurde ,von Schlägen begleitet“; doch dabei blieb es ${ }^{531}$.

In Buchenwald fand die Gestapo-Aktion in den ersten Tagen des Mai 1944 statt. Auf dem Appellplatz wurden alle Bibelforscher einer ,gründlichen Leibesvisitation nach staatsfeindlichen Schriften“ unterzogen; ebenfalls wurden ihre Arbeitsplätze durchstöbert. Zum Ausgang der Gestapo-Aktion vermerkte Eugen Kogon in seinem Bericht: „Ergebnis nach tagelangem Warten: nichts."532 Im Frauen-KZ Ravensbrück griff die Gestapo am 3./4. Mai $1944 \mathrm{zu}$. Zwar wurden auch hier harte Maßnahmen ergriffen und 15 ,Rädelsführerinnen“ in den berüchtigten Zellenbau eingewiesen ${ }^{533}$. Berichten der Zeugen Jehovas zufolge dauerte es aber „nicht lange, bis die Schwestern [...] an ihre alten Arbeitsplätze zurückkehren konnten, nachdem die zuständigen Abteilungsleiter sie angefordert hatten "534. Das Interesse der SS an den für sie „nützlichen Eigenschaften“ der Zeugen Jehovas - an deren besonderer Eignung als Arbeitskraft - und die wirtschaftlichen Erfordernisse des Lageralltages überwogen schließlich: Die „,KZ-Normalität“ setzte sich durch.

\section{Begehrte Posten, verbesserte Lage}

Seit etwa 1942 besserte sich die Lage der Zeugen Jehovas in den Konzentrationslagern. Waren sie zuvor neben den Juden und den Homosexuellen im besonderen Maße dem Terror der SS ausgesetzt, so trat nun eine merkliche Entlastung ein ${ }^{535}$. Dabei reflektierte diese Veränderung auch eine allgemeine Entwicklung: Mit zu-

$\overline{531}$ Nansen, Tagebuch, S. 158f. Ins Außenkommando Berlin-Lichterfelde war die Gestapo bereits am 26.4.1944 gekommen. Auch dort blieb es letztlich trotz Drohungen dabei, daß alle in Lichterfelde eingesetzten Bibelforscher anschließend erneut ,in den Arbeitsprozeß eingereiht“ wurden (Jahrbuch 1974, S. 203f.).

532 Kogon, SS-Staat, S. 266.

533 MGRa, RA, Bd. 25, Nr. 332, Berta Hartmann: Erlebnisse der Zeugen Jehovas in den FrauenKonzentrationslagern. Unveröffentlichtes Manuskript, 1948. Nach siebenwöchiger Arreststrafe im Zellenbau wurden die 15 Bibelforscherinnen zurück ins Lager in den Strafblock verlegt. Daß der Bekennermut der Zeugen Jehovas bis zuletzt ungebrochen war, belegt auch eine der letzten Meldungen des Ravensbrücker KZ-Kommandanten Suhren an das WVHA. Unter dem Datum vom 6.4.1945 meldet er, daß sich „,das Verhalten der Bibelforscher [...] im Bezug auf Staatsfeindliche Propaganda gegenüber den bisherigen Berichten nicht geändert“ habe (MGRa, RA, Bd. 36, Nr. 710).

534 Jahrbuch 1974, S. 204.

535 Siehe auch die Datenauswertung zu den Lebens- und Arbeitsbedingungen der Bibelforscher im KZ Neuengamme im 4. Abschnitt dieses Kapitels, S. 485-487. 
nehmender Belegung der Konzentrationslager mit ausländischen Häftlingen erhöhte sich ganz generell der „Stellenwert“ von nichtjüdischen deutschen Gefangenen innerhalb der Lagerordnung ${ }^{536}$, und bei den Bibelforschern handelte es sich eben um eine mehrheitlich (reichs-)deutsche Häftlingsgruppe. Die SS benötigte zur Organisation der sich beständig vergrößernden Lager rasch und vermehrt die Zuhilfenahme von erfahrenen Häftlingen. Dabei wurde zunächst für solche Aufgaben wie „Häftlingsselbstverwaltung“ und „Lagerbewirtschaftung“ fast ausschließlich auf deutsche Gefangene zurückgegriffen. Gleichzeitig wuchs für die SS durch die verstärkte Einbindung der Konzentrationslager in die Kriegswirtschaft und Rüstungsproduktion die Bedeutung der Arbeitskraft der Gefangenen ganz enorm ${ }^{537}$. Während das wirtschaftliche Interesse der SS an denjenigen Häftlingen, die sie als Fachkräfte nutzte, deren Überlebenschancen deutlich verbesserte ${ }^{538}$, bedeutete der extensive Arbeitseinsatz zugleich für Hunderttausende von KZGefangenen, die bei völlig unzureichender Verpflegung und unter Auflage härtester Arbeitsbedingungen ausgebeutet wurden, den Tod.

Daneben gehen die verbesserten Existenzbedingungen im Falle der Bibelforscher-Häftlinge jedoch auch auf einige gruppenspezifische Eigenheiten zurück, die mit der Verhaltensweise dieser Häftlingsgruppe im Zusammenhang stehen. Durch ihren Fleiß, ihre Sorgfalt und Akribie, mit denen die uiberwiegend aus handwerklich-gewerblichen Berufen stammenden Zeugen Jehovas alle ihnen erteilten Aufträge - sofern diese nicht ihren Glaubensgrundsätzen widersprachen - gewissenhaft zu erledigen pflegten ${ }^{539}$, hatten sie sich in den Augen von Arbeitseinsatzführern der SS zu begehrten Kräften gemacht. Sie galten als korrekt, zuverlässig und - für die SS-Verwalter das wichtigste Argument - als vertrauenswürdig540. Schiebungen und gegen sie gerichtete Intrigen brauchte die SS bei Bibelforschern im Regelfall nicht zu befürchten.

Zwei Eigenschaften ließen sie überdies zu geradezu prädestinierten Arbeitskräften für kleine Außenkommandos werden: Sie arbeiteten gut, auch ohne daß es des Antreibens und somit ständiger Aufsicht bedurfte, und sie lehnten aus Glaubensgründen eine Flucht aus dem Lager ab.

$\overline{536}$ Zur sozialen Struktur der Häftlingsgemeinschaft und der Herausbildung einer Hierarchie der einzelnen nationalen und sozialen Gruppen vgl. Botz, Überleben, S. 22ff.; Pawelczyńska, Differenzierung.

537 Zum 1942 eingetretenen Strukturwandel der Konzentrationslager, der auf eine extensive Ausnutzung des KZ-Häftlingsarbeitskräftepotentials zu Rüstungszwecken und anderen kriegswirtschaftlichen oder militärischen Vorhaben zielte und mit einer Anfang März 1942 vollzogenen organisatorischen Umgestaltung der KZ-Verwaltung einherging (Eingliederung der Inspektion der Konzentrationslager in das mit Wirkung vom 1.2.1942 neugeschaffene WirtschaftsVerwaltungshauptamt der SS), vgl. Broszat, Konzentrationslager, S. 108ff.; Pingel, Häftlinge, $S$. $123 \mathrm{ff}$.

$538 \mathrm{Vgl}$. Pingel, Häftlinge, S. 151ff.

539 Vgl. Bettelheim, Aufstand, S. 135. Korrektheit und Arbeitseifer der Zeugen Jehovas fanden bei politischen Gefangenen, die danach trachteten, dem KZ-System - wenn möglich - durch Langsamarbeiten und Ausschußproduktion materiell Schaden zuzufügen, keine ungeteilte Zustimmung. Sie störten sich daran, daß als Vorarbeiter eingesetzte Zeugen Jehovas „oft die ihnen von der SS erteilten Aufträge zu pünktlich ausführen wollten“ (Kautsky, Teufel und Verdammte, S. 138f.).

540 Vgl. King, The Nazi State and the New Religions, S. 169. 
Da sie ihre Geschicke ganz in die Hand ihres Gottes Jehova gelegt sahen, empfanden sie eine Flucht als Auflehnung gegen die göttliche Vorsehung. Damit verband sich die feste Überzeugung, daß Jehova durch die schwere Verfolgung und die schlimme Zeit im KZ etwas bezwecke und „seinem Volk“ dadurch eine Prüfung auferlegt sei. Dem dürften sich die „Auserwählten“ nicht entziehen, sondern dies erschien ihnen als eine große Herausforderung, die es zu bestehen galt. Hinzu kam ihre Zuversicht, daß Jehova Gott in Kürze sein Reich auf Erden errichten, die Tore der Lager und Gefängnisse öffnen und sie in die Freiheit führen werde $^{541}$. Wer sein Schicksal angesichts dessen in die eigenen Hände nehmen wollte oder Gedanken an eine Flucht aufkommen ließ, drückte damit - so sah es die Mehrzahl der Zeugen - sein Mißtrauen gegenüber Jehova aus. Hinzu kam, daß die Flucht eines einzelnen die ganze Gruppe der Bibelforscher-Häftlinge gefährdet hätte, zumal diese aufgrund ihrer Zuverlässigkeit bei der Erfüllung von Arbeitsaufgaben mittlerweile ihre Stellung im Lager hatte verbessern können.

Da von Bibelforscher-Häftlingen keine Fluchtversuche zu erwarten waren ${ }^{542}$, wurden sie gern und oft in schwierig zu überwachenden Außenkommandos (Landwirtschaft, Transporte, Be- und Entladearbeiten $u$. ä.) eingesetzt ${ }^{543}$. Vielfach setzten die SS-Offiziere solche Arbeitskolonnen ausschließlich aus Zeugen Jehovas zu-

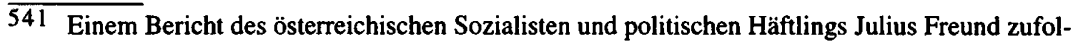
ge gab ein "Sprecher der Bibelforscher" bei einem „Sonderappell“ im KZ Buchenwald, als den Zeugen Jehovas die Freilassung bei Abgabe einer „Verpflichtungserklärung“" zugesichert wurde, einem SS-Oberscharführer zur Antwort: „Wir bleiben hier; denn es kommt die Stunde, wo das Unwetter hereinbrechen wird, um die ganze Menschheit zu bestrafen. Wir wollen mit Geduld abwarten, bis uns Jehova ein Zeichen gibt. Dann erst werden wir dieses Lager verlassen." (Freund, Buchenwald, S. 129)

542 In einigen wenigen Einzelfällen wurden Fluchten von Bibelforscher-Häftlingen bekannt, die allerdings zumeist in den letzten Kriegswochen stattfanden, offensichtlich um einer befürchteten Tötung bei der Auflösung der Lager oder auf den Evakuierungsmärschen zu entgehen. Eine bemerkenswerte Ausnahme stellt der Fall eines Zeugen Jehovas dar, der nach jahrelanger Straflagerhaft aufgrund einer schweren Erkrankung im Frühjahr 1943 als „, haftunfähig“" entlassen worden war. Als dieser am 4.12.1944 erneut verhaftet wurde, konnte er auf dem Weg zur Wache fliehen, wobei er den Kugeln des ihn verfolgenden Polizeimeisters nur knapp entging. Am nächsten Tag wurde er jedoch aufgegriffen. Wiederum hatte er Glück, da das Gefängnis in Chemnitz bei einem alliierten Großangriff stark beschädigt wurde und dadurch die Gefangenen fliehen konnten. Vgl. EB Alfred Skoda, 24.6.1984.

543 Vgl. Pingel, Häftlinge, S. 91 . Auch zum Aufbau von noch nicht mit Sicherungsanlagen umgebenen Lagern wurden Zeugen Jehovas vorrangig herangezogen. So verlegte die SS Anfang 1940 aus dem Lager in Wewelsburg, zu dessen Aufbau zunächst „BV-Häftlinge“ - in Nazidiktion "Berufsverbrecher" - herangezogen wurden, diese nach Ausbruchsversuchen zurück in das Hauptlager Sachsenhausen und ersetzte sie ausschließlich durch BibelforscherHäftlinge. Der Austausch wurde von der SS angeordnet, da die Fluchtversuche durch ihr brutales Ende (ein „BV'er" wurde im Nachbardorf hinterrücks erschossen) erhebliche Unruhe unter der ländlichen Bevölkerung ausgelöst hatten. Mit dem Abzug der „Kriminellen“ und dem an ihrer Stelle erfolgenden Einsatz von Bibelforschern bezweckte die SS, eine Wiederholung solcher Vorkommnisse von vornherein ausschließen zu können. Neben der kaum gegebenen Fluchtgefahr bildete der bei dem Ausbau der Wewelsburg zur SS-Ordensburg bestehende Bedarf an qualifizierten Facharbeitern und Handwerkern das zweite wichtige Argument für die Heranziehung der Bibelforscher. Erst ab Spätsommer 1940, als in der Gemarkung Niederhagen mit der Einrichtung eines neuen Lagerkomplexes begonnen wurde, erfolgte die Einweisung von Häftlingen nach Wewelsburg, die nicht der Gruppe der Bibelforscher angehörten. Die Zeugen Jehovas bildeten jedoch auch in den folgenden Jahren die Stammbelegschaft im dortigen KZ. Vgl. Hüser, Wewelsburg, S. 72ff.; John, Wewelsburg (1996), S. 37ff.; S. $76 \mathrm{ff}$. 
sammen, zumal die SS generell deren Separierung auch im Arbeitseinsatz anstrebte, um auf diese Weise die Möglichkeiten zur Missionierung von Mitgefangenen einzuschränken. Nach und nach wurde es üblich, daß die SS bei „Bibelforscherkommandos" die Stärke des Wachpersonals verringerte. Beispielsweise wurde im KZ Neuengamme bei Bibelforscherkolonnen, die zu Mäharbeiten auf den Wiesen auBerhalb des Lagers eingesetzt waren, die Bewachung auf einen SS-Wachposten je fünf Häftlinge reduziert, während für andere Kommandos, die nicht aus Bibelforschern bestanden, eine Wache für je zwei Häftlinge als erforderlich galt ${ }^{544}$.

Wenn auch die Arbeit in den zumeist recht kleinen Kolonnen mühsam sein konnte und die Häftlinge den Launen der jeweiligen Aufseher ausgesetzt waren, so boten diese Einsätze doch oftmals die Möglichkeit, zusätzliche Verpflegung zu organisieren $^{545}$.

Die im KZ Neuengamme im „Entkrautungskommando“ eingesetzten Zeugen Jehovas nutzten beispielsweise den Umstand, daß sich beim Säubern der Entwässerungsgräben mittels Rechen und Harken im zusammengezogenen Schlick auch Fische verfingen. Die Häftlinge verstanden es, diese zur Aufbesserung der KZ-Kost zu verwenden: „Mittags bekamen wir in Thermophoren unsere dünne Mahlzeit mit einem Wagen an die Arbeitsstelle gebracht, und da legten wir Fischstücke vor dem Empfang der warmen Suppe in unsere Eßschüssel. Dafür haben wir Gott gedankt." 546 So waren die Fische zwar noch halbroh, aber die wässerige Kohl- oder Rübensuppe gab auf diese Weise wenigstens ein wenig Kraft.

Da bei den kleineren Kommandos häufig ein besonderes Interesse an guten Arbeitsergebnissen bestand, zumal dort, wo sie landwirtschaftlichen oder gewerblichen Kleinbetrieben zuarbeiteten, konnte es vorkommen, daß gute Leistungen auch honoriert wurden. Dies war insbesondere dann der Fall, wenn die Gefangenen von den Kommandoführern für Privatzwecke (vom Holzhacken bis zum Bau eines Gartenhäuschens) eingesetzt wurden ${ }^{547}$. So bekam beispielsweise eine aus Bibelforscher-Häftlingen des KZ Neuengamme gebildete 20köpfige Mähkolonne, nachdem sie eine Holzhütte errichtet hatte, eine Zeitlang von dem dankbaren SS-Mann einmal wöchentlich einen Sack Kartoffeln als Zusatzverpflegung548.

Auch höhere SS-Führer nutzten Bibelforscher-Häftlinge für Sonderaufgaben. Der Kommandant des KZ Dachau, Hans Loritz, ließ bereits seit 1938 Zeugen Jehovas für sich arbeiten. Damals wurden sie eines Tages auf den Appellplatz gerufen, und aus ihrer Mitte wurden neun Personen für einen besonderen Arbeitseinsatz

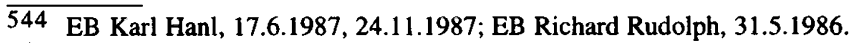

545 Die sich beim Arbeitseinsatz im Freien für Zusatznahrung bietenden Gelegenheiten nutzen zu können, hing stets vom Wohlwollen der begleitenden SS-Wachposten ab. So konnte das „Ansichnehmen“ von Fallobst ebenso wie das Sammeln von Wiesenkräutern oder Nesseln zu Schlägen durch die Posten oder sogar zu einer „Strafmeldung“ führen.

546 EB Ernst Wauer, 29.5.1986.

547 So ließ sich beispielsweise selbst der für Fragen des Arbeitseinsatzes zuständige und im September 1941 zur Kontrolle der Lagerleitung ins KZ Neuengamme entsandte „Schutzhaftlagerführer E“, SS-Hauptsturmführer Otto Söldner, im Nachbardorf Kirchwerder von Bibelforscher-Häftlingen eine kleine Bootsanlage bauen. Vgl. EB Richard Rudolph, 31.5.1986; DhN, Ng. 5.1.1.

548 Vgl. EB Karl Hanl, 17.6.1987; DhN, Ng. 9.2.5. 
ausgewählt ${ }^{549}$. Ein LKW brachte diese neun zusammen mit einem politischen Häftlingskapo und einigen SS-Männern zum Wolfgangsee ins Salzkammergut. Dort hatte Loritz in der Nähe von St. Gilgen ein Grundstück erworben, auf dem er eine Villa mit Bootshaus und Landesteg errichten lassen wollte. Die vorbereitenden Arbeiten (Roden, Ausschachten, Steinefahren, Betonieren) mußten nun die KZ-Häftlinge unter sehr schwierigen Bedingungen verrichten. Ihre Unterbringung erfolgte in einem nahe gelegenen Gefängnis. Im Januar 1940 wurde SS-Oberführer Loritz als Nachfolger des verstorbenen Hermann Baranowski zum Kommandanten des KZ Sachsenhausen ernannt. Die Fortführung der Bauarbeiten blieb davon jedoch unbeeinträchtigt. Nun zog Loritz für die weiteren Arbeiten Sachsenhausener Bibelforscher-Häftlinge heran, wobei er das Arbeitskommando „Am See“ auf ungefähr 25 Gefangene vergrößerte 550 .

Der Leiter des Zentralamtes in der für die KZ-Verwaltung zuständigen Amtsgruppe D im Wirtschafts-Verwaltungshauptamt, SS-Obersturmbannführer Arthur Liebehenschel, ließ ebenfalls am Wolfgangsee bauen. Einem Bericht des Sachsenhausener Bibelforscher-Häftlings Paul Wauer zufolge wurde vom Mai bis August 1942 eine Gruppe von 15 Gefangenen dort beim Hausbau beschäftigt ${ }^{551}$.

Aber auch die SS-Organisation als Ganzes machte sich den gefahrlosen Einsatz von Bibelforschern zunutze. Seit 1940 arbeiteten Zeugen Jehovas in Sudelfeld am Wendelstein beim Außenanlagen-Ausbau des SS-Berghotels und Erholungsheimes Bayrischzell552. Dem Kommando gehörten 1940/41 ungefähr 30 bis 50 Zeugen Jehovas sowie einige politische Gefangene an; die Unterbringung erfolgte ,eng zusammengepfercht" in einer Garagenanlage. Die Verpflegung in dem Kommando, in dem bis 1945 eine wechselnde Zahl von Bibelforscher-Häftlingen eingesetzt wurde, beschrieben Beteiligte im Rückblick hingegen als gut. Später verbesserte sich auch die Unterbringung. Willi Lehmbecker, der im zweiten Halbjahr 1943 vom KZ Sachsenhausen nach Obersudelfeld verlegt wurde, berichtet: „Obwohl wir Brüder in der Gefangenschaft waren, hatten wir an einem Bergabhang eine Baracke unter leichter Bewachung. Wir hatten ziemliche Bewegungsfreiheit, doch mußten alle Brüder schwer arbeiten. [...] Ehe ich dort ankam, hatten Brüder die Straße, die den Berg rauf zum Hotel führte, angelegt. Wieviel Leid und Tränen hierbei geflossen sind, kann man nicht erzählen. "553

Ebenfalls rund 30 bis 50 Zeugen Jehovas mußten zeitweilig für das SS-Sanatorium Hohenlychen arbeiten. In dem am Großen Lychensee in der Abgeschiedenheit der Uckermark gelegenen Erholungsheim verkehrte in den letzten Kriegsjahren die Führungsriege von NSDAP und SS: Oswald Pohl, Albert Speer, Josef

$\overline{549}$ Vgl. KZGDa, Archiv Nr. 481, Heinrich Lutterbach, Bericht vom 26.10.1963 über das Kommando Wolfgangsee; Jahrbuch 1974, S. 198.

550 Vgl. BHStA, OMGUS, Dachauer Kriegsverbrecherprozeß, Mikrofilm 1a/1, Nr. 184, Paul Wauer, Aussage vom 21.5.1945; Jahrbuch 1974, S. 198f.; Lienau, Zwölf Jahre Nacht, S. 181. Im August 1942 wurde Loritz „wegen Schiebereien“ seines Postens enthoben; vgl. Höhne, Orden, S. 355.

551 Vgl. BHStA, OMGUS, Dachauer Kriegsverbrecherprozeß, Mikrofilm 1a/1, Nr. 184, Paul Wauer, Aussage vom 21.5.1945.

552 Vgl. EB Karl Hanl, 17.6.1987, 24.11.1987; EB Alois Moser, 23.5.1986; EB Willi Lehmbecker, 15.4.1971, 7.2.1987.

553 EB Willi Lehmbecker, 15.4.1971. 
Goebbels, Himmler und auch einige Male Hitler selbst. In Hohenlychen suchten sie Ruhe für kontemplative Gespräche; die Bibelforscher-Häftlinge wurden in Zivil gekleidet ${ }^{554}$.

Auch in anderen SS-Einrichtungen und Parteidienststellen wurden Zeugen Jehovas eingesetzt. Mehrere IBV-Häftlinge des KZ Sachsenhausen waren einem Kommando des Reichssicherheitshauptamtes in Berlin-Lichterfelde zu Bau- und Handwerkerarbeiten zugeteilt; ebenfalls waren Zeugen Jehovas in einem dem KZ Dachau zugeordneten Kommando „Reichskanzlei München“555. Im Frühjahr 1944 waren 15 Bibelforscherinnen dem „Hedin-Institut für Innerasien“ zugeordnet, einem zum „Ahnenerbe“ der SS gehörenden Reichsinstitut, das seit dem August 1943 im Schloß Mittersill im Pinzgau residierte 556.

Ähnlich gute Bedingungen - zumindest im Vergleich zu den allgemeinen Lebensumständen in einem Konzentrationslager - hatten jene Bibelforscher-Häftlinge, die in den letzten Kriegsjahren zum Arbeitseinsatz auf landwirtschaftlichen Gütern abkommandiert wurden. Dabei wurden in erster Linie nationalsozialistische Führungskader oder Personen begünstigt, die über entsprechende Beziehungen verfügten. Beispielsweise waren bereits seit Anfang 1942 zehn Bibelforscherinnen als Hausgehilfinnen in Küche und Gärtnerei auf dem Gut Hartzwalde des HimmlerLeibarztes Dr. Felix Kersten tätig 557 . Lina Heydrich, Witwe des 1942 verstorbenen RSHA-Chefs und Herrin von Gut Jungfern-Breschan, wurden im Februar 1944 fünfzehn Bibelforscher-Häftlinge als Arbeitskräfte zugeteilt ${ }^{558}$. Auf dem in unmittelbarer Nähe des KZ Ravensbrück gelegenen Gut Comthurey, das dem Chef des SS-Wirtschafts-Verwaltungshauptamtes Oswald Pohl als Landsitz diente, waren zeitweilig bis zu 50 Zeugen Jehovas beschäftigt. Als Alois Moser 1943/44 zusammen mit einer Gruppe von Glaubensbrüdern auf Comthurey einen Schweinestall zu bauen hatte, war nur ein SS-Mann als Wache dem Kommando beigegeben: „Mit

554 EB Alois Moser, 23.5.1986.

555 Vgl. Jahrbuch 1974, S. 203f.; Szepansky, Weg, S. 154; AfW 310504; VVN HH, Komiteeakten W 9; EB Willi Lehmbecker, 15.4.1971.

556 Vgl. Kater, Ahnenerbe, S. 214, 416, Anm. 230; Kater, Bibelforscher, S. 217. Für die Zeit vom 1.9.1944 bis 31.3.1945 war auch im Haushalt von Dr. Ernst Schäfer, dem zuständigen „Ahnenerbe“-Abteilungsleiter für Innerasienforschung, eine Bibelforscherin beschäftigt. Diese Vergünstigung wurde auch SS-Standartenführer Wolfram Sievers, dem Leiter des SS-Amtes Ahnenerbe in Berlin, zuteil; in seinem Haushalt arbeitete die aus dem KZ Ravensbrück überstellte Bibelforscherin Hedwig Patzer.

557 Hartzwalde war eines der ersten Privatgüter, auf dem Bibelforscher-Häftlinge eingesetzt wurden. Ausweislich einer im KZ Ravensbrück geführten „Aufstellung über die Arbeitseinteilung für den 4.1.42“ waren dort bereits zu diesem Zeitpunkt Zeugen Jehovas beschäftigt. Vgl. Müller, C., Klempnerkolonne, o. S. (Dokumententeil nach S. 112). 1943 wurde zusätzlich zu den Frauen ein ebenfalls ca. zehn Personen starkes Männer-Kommando für landwirtschaftliche Arbeiten (Rüben- und Kartoffelanbau) und zum Bau eines Jagdhauses nach Hartzwalde abgeordnet. Vgl. EB Franz Birk, 31.1.1971; EB Klingenberg, 16.5.1992.

558 Der Witwe von SS-Obergruppenführer Reinhard Heydrich, der seit September 1941 zugleich das Amt des stellvertretenden Reichsprotektors von Böhmen und Mähren bekleidete, war vom Reich das Gut Jungfern-Breschan bei Odolenswasser (Böhmen) übereignet worden. Nachdem dort zunächst für eineinhalb Jahre ein aus Theresienstadt überstelltes jüdisches Häftlingskommando arbeiten mußte, war dieses am 11.2.1944 durch ein fünfzehnköpfiges Bibelforscherkommando (zehn Deutsche, drei Niederländer, ein Tscheche und ein Pole) aus dem KZ Flossenbürg ,ersetzt" worden. Die im Pferdestall untergebrachten Gefangenen mußten Instandsetzungsarbeiten verrichten und Grund und Boden bewirtschaften (Angaben nach BA, NS 19/18; Jahrbuch 1974, S. 198). 
der Zeit hatten die Bibelforscher von dem nur einen diensthabenden SS-Wachbeamten so ein großes Vertrauen bekommen, daß wir an Sonntagen ,ohne Wache * in den Wald gehen durften, um Heidel- bzw. Schwarzbeeren zu pflücken. Jeder brachte seine Aluminium-Eßschale voll heim." 559

Zuweilen wurden Bibelforscher-Häftlinge auch einzeln auf Bauernhöfen eingesetzt. So arbeitete ein Zeuge Jehovas auf einem Hof in Fridolfing (Oberbayern); im Juni 1943 bot Himmler einem oberbayerischen Landwirt aus Tristenau einen Bibelforscher-Häftling als Erntehelfer an ${ }^{560}$. Die auf Güter oder Bauernhöfen eingesetzten Zeugen Jehovas wurden teilweise speziell für die jeweilige Aufgabe aus den Konzentrationslagern angefordert. So wies das Wirtschafts-Verwaltungshauptamt mit Fernschreiben vom 2. Juni 1943 alle Lagerkommandanten an, mitzuteilen, ob einer der ,dort einsitzenden Bibelforscher-Häftlinge in der Lage ist, einen Bauernhof zu bewirtschaften“" 561 .

Zahlreiche Bibelforscher-Häftlinge wurden in den landwirtschaftlichen Unternehmungen (KZ-Außenstellen) eingesetzt, die von der im Januar 1939 gegründeten SS-eigenen „Deutschen Versuchsanstalt für Ernährung und Verpflegung GmbH“ betrieben wurden ${ }^{562}$. Zumeist arbeiteten die Zeugen Jehovas dort mit anderen Gefangenen zusammen, nur bei kleineren Betrieben gab es auch ,reine“ Bibelforscherkolonnen. Unternehmungen der Versuchsanstalt, die Zeugen Jehovas beschäftigten, waren zum Beispiel das Gut Ravensbrück, das Gut Werderhof (nahe dem KZ Stutthof) und die Fischzuchtanlagen in Unterfahlheim (bei München). In den großen landwirtschaftlichen Betrieben des KZ Auschwitz, in denen insgesamt ungefähr 3.000 Häftlinge eingesetzt waren ${ }^{563}$, arbeiteten Zeugen Jehovas auf dem Gut Raisko (Abteilung Pflanzenzucht beim Kaiser-Wilhelm-Institut) und in der Geflügelfarm Harmense ${ }^{564}$. Auch im KZ Mauthausen wurden Zeugen Jehovas zur Arbeit in außerhalb des Lagerbereichs gelegenen landwirtschaftlichen Betrieben eingesetzt, so unter anderem auf den Höfen namens Rumbler, Fechter, Fuchsberger und Preller. In St. Lambrecht, einem größeren landwirtschaftlichen Betrieb, der bis 1942 dem KZ Dachau unterstand, haben Bibelforscherinnen als Köchinnen gearbeitet $^{565}$.

559 EB Alois Moser, 23.5.1986; vgl. auch die Berichte von Gertrud Pötzinger in FüllbergStolberg, S. 330, und von Ilse Unterdörfer im Jahrbuch 1974, S. 199f.

560 Vgl. Heiber, Reichsführer!, S. 218; siehe auch S. 467, Anm. 601.

561 MAu, WVHA, 2.6.1943. Zugleich sollte gemeldet werden, „ob sich unter den dort befindlichen Bibelforscher-Häftlingen Vorarbeiter in Sägewerken oder Sägewerksarbeiter befinden“".

562 Mit der „Versuchsanstalt für Ernährung und Verpflegung" bezweckte die SS-Führung, auf dem gesamten Ernährungsgebiet die Unabhängigkeit Deutschlands von Exporten zu erreichen. So wurde mit den Heil- und Gewürzkräuterplantagen in Dachau und Buchenwald das Ziel verfolgt, ausländische Gewürze durch in Deutschland angebaute zu ersetzen. In den später über 50 Betrieben in Land-, Forst- und Fischwirtschaft wurden neben der Produktion Forschungsund Züchtungsversuche durchgeführt. Vgl. Georg, Unternehmungen der SS, S. 62-66.

563 Vgl. Auschwitz. Geschichte und Wirklichkeit, S. 25f.; Kommandant in Auschwitz, S. 116f.

564 In der „Geflügelfarm Harmense“, einem Außenkommando des KZ Auschwitz, das der Züchtung von „Rassegeflügel“" (Hühner, Gänse, Fasanen etc.) diente, wurden seit Juni 1942 ca. zehn Bibelforscherinnen eingesetzt, die abgesondert von den übrigen ca. 100 Häftlingen untergebracht waren. Die Bibelforscherinnen führten die Küche, arbeiteten im „Ambulatorium“ und stellten zeitweise auch die Blockälteste. Vgl. Zieba, Geflügelfarm Harmense, S. 41ff. Vgl. Chêne, Mauthausen, S. 131. 
Auch für die Bibelforscher-Häftlinge, die nicht zu einem „Sondereinsatz“ auBerhalb abkommandiert wurden, verbesserten sich die Bedingungen in der Regel zusehends, wenngleich sie in den KZs weiterhin der Willkür der SS ausgeliefert waren. In den Konzentrationslagern wurden zahlreiche Zeugen Jehovas auf „Vorzugsarbeitsplätzen“ und in sogenannten „Vertrauensstellungen“ eingesetzt ${ }^{566}$. Dies waren für die Betreffenden durchaus „,begehrte Posten“. Sie arbeiteten als Spezialhandwerker, als Schreiber für SS-Offiziere und auch als SS-Bedienstete (Barbiere, Kalfaktoren und Köche ${ }^{567}$ ). Als Barbiere wurden Zeugen Jehovas allerdings bereits seit Mitte der dreißiger Jahre von der SS herangezogen. In dem Bericht eines Bibelforschers heißt es dazu: „Der Kommandant und die übrigen Chargen ließen sich [...] von einem Z.J. rasieren, weil sie glaubten, daß ein Z.J. nicht fähig sei, ihnen bei einer solchen Gelegenheit den Hals durchzuschneiden." 568

Für andere sensible „Spezialaufgaben“ zog die SS ebenfalls in stärkerem Maße Zeugen Jehovas heran. So arbeiteten im KZ Buchenwald Bibelforscher im Fotolabor ${ }^{569}$ und in der unter der besonderen Obhut des Lagerkommandanten Karl Koch stehenden „Bildhauer-Werkstatt“570. Im KZ Ravensbrück setzte die SS im Zellenbau (Lagergefängnis) Bibelforscherinnen als Kalfaktoren ein ${ }^{571} .1943$ wurde extra eine Bibelforscherin aus Ravensbrück ins KZ Buchenwald überstellt, um die dort internierte Prinzessin Mafalda von Hessen, Tochter des italienischen Königs Viktor

566 Eine im KZ Ravensbrück erstellte „Aufstellung über die Arbeitseinteilung für den 4. Januar 1942“ (Einsatz für Lagerzwecke) vermittelt einen Überblick über den Arbeitseinsatz von 212 Bibelforscherinnen und belegt den hohen Anteil von „Vorzugsarbeitsplätzen“. Nach dieser Aufstellung (abgedruckt in: Müller, C., Klempnerkolonne, Dokumententeil nach S. 112) waren 51 Bibelforscherinnen in - dem WVHA direkt unterstellten - landwirtschaftlichen Betrieben eingesetzt (Kommandos Kellerbruch, Gutshof und Hühnerfarm) sowie zehn auf dem Kersten-Gut Hartzwalde. In der Lagergärtnerei waren sechs Bibelforscherinnen eingesetzt, bei den Ställen zwölf (Landwirtschaft insgesamt: 79). Von den vier Kommandos, die unter der Rubrik „SS-Dienststelle und Siedlung“" aufgeführt sind, waren drei ausschließlich aus IBVHäftlingen zusammengesetzt: 16 Bibelforscherinnen im „Personalbau“, sieben in den „Führerhäusern“ und weitere 16 in den „Unterführerhäusern“. Im Kinderheim arbeiteten vier Bibelforscherinnen. Des weiteren arbeiteten sieben Zeuginnen im Büro der Bauleitung, fünf waren dort mit Reinigungsarbeiten beschäftigt, zehn arbeiteten in der Arbeiterkantine, vier wurden im Büro der Textil- und Lederverwertung zu Reinigungsarbeiten herangezogen (SS-Bedienstete insgesamt: 69). 18 Bibelforscherinnen wurden bei der Kommandantur zum ,Schnee schaufeln“ eingesetzt, 16 zum „Holz tragen und schichten“ (Hilfsarbeiten insgesamt: 34). Bei den Kommandos, die in der Aufstellung unter „Rüstungsbetriebe“ subsumiert sind, findet sich nur einmal der Eintrag „IBV“, und zwar arbeiteten 30 Bibelforscherinnen im Marine-Lager.

Der 1943/44 in der SS-Küche im KZ Neuengamme eingesetzte Richard Rudolph, ein gelernter Bäcker, erhielt sogar eine Ausbildung als „Diätkoch“, um anschließend die 13 SS-Offiziere des Lagers nach den vom Kommandanten Max Pauly - in dieser Frage mindestens ebenso engagiert wie der Reichsführer-SS und Diplom-Landwirt Himmler - entwickelten Vorstellungen einer gesunden Ernährung zu bekochen. Vgl. EB Richard Rudolph, 9.9.1986.

568 Zürcher, Kreuzzug, S. 105; vgl. auch Chêne, Mauthausen, S. 130; Jahrbuch 1974, S. 198; King, New Religions, S. 169.

569 Vgl. GBu, 31-826, Karl Siebeneichler, Bericht vom 24.4.1945.

570 EB Johannes Rauthe, Geschichtsbericht, S. 58. Rauthe, der von Beruf Bildhauer war, berichtet, daß er in Buchenwald gesondert für diese Tätigkeit abgestellt worden sei. Er habe für den Aufbau der Werkstatt spezielles Bildhauerwerkzeug und -material zugewiesen bekommen und als „Kapo“ qualifizierte Mithäftlinge als Zuarbeiter (Steinmetze, Keramiker, Zimmermann, Drechsler etc.) selbst aussuchen dürfen. Er wählte dazu ausschließlich Bibelforscher aus.

571 Vgl. Buber-Neumann, Gefangene, S. 277, 318; Müller, C., Klempnerkolonne, S. 131 . 
Emanuel III., zu betreuen ${ }^{572}$. Für prominente Gefangene (sogenannte „Sonderhäftlinge") gab es in Buchenwald, wie in anderen KZs auch, gesonderte Unterkünfte außerhalb des Schutzhaftlagers. In dieser „Siedlung Fichtenhain“ - so der offizielle Name - waren auch andere Zeugen Jehovas als Kalfaktoren bzw. Bedienstete eingesetzt. Beispielsweise mußte der Bibelforscher-Häftling Joachim Escher im sogenannten „Falkenhof“ den dort von der Gestapo festgehaltenen früheren französischen Ministerpräsidenten Léon Blum und den ehemaligen Innenminister Georg Mandel umsorgen, für sie das Haus reinigen, Essen auftragen und das Geschirr spülen ${ }^{573}$.

Bei den SS-Führern waren Zeugen Jehovas als Hausgehilfinnen - so Rudolf Höß - ,sehr begehrt“ 574 . In den Haushalten der SS-Familien wurden den Bibelforscherinnen nicht nur Reinigungsarbeiten übertragen, für deren sorgfältige Ausführung sie bekannt waren, sondern ihnen wurde auch die Essenszubereitung und selbst die Kinderbetreuung anvertraut. In der Zuteilung der geschätzten Haushaltshilfen hielt sich die SS an die Führerhierarchie. So waren laut „Arbeitseinsatzplan“575 im Herbst 1944 im KZ Auschwitz 15 Bibelforscherinnen in Haushalten von SS-Offizieren tätig, unter anderem bei dem Standortarzt Dr. Eduard Wirths sowie bei Josef Kramer, dem Kommandanten des KZ Auschwitz II (Birkenau). Während jene ebenso wie neun weitere SS-Führer ,nur“ eine Hausgehilfin hatten, verfügten Lagerkommandant Rudolf Höß und der mit ihm dienstranggleiche SSObersturmbannführer Dr. Joachim Caesar, der Leiter der landwirtschaftlichen Betriebe des KZ Auschwitz, jeweils über zwei Bibelforscherinnen. Über die beiden bei der Familie Höß eingesetzten Zeugen Jehovas hat der Lagerkommandant in seinen Erinnerungen ausschließlich lobende Worte gefunden: „Meine Frau sagte oft, sie selbst könne nicht besser um alles besorgt sein, als die beiden Frauen. Besonders rührend waren sie um die Kinder besorgt, um alle, die großen wie die kleinen. Diese hingen auch an ihnen, als wenn sie zur Familie gehörten. In der ersten Zeit befürchteten wir, daß sie die Kleinen für Jehova retten wollten. Aber nein, das taten sie nicht. Nie haben sie über religiöse Dinge zu den Kindern gesprochen. Dies war eigentlich verwunderlich bei ihrer fanatischen Einstel-

572 Vgl. Jehovas Zeugen in Gottes Vorhaben, S. 170; Kogon, SS-Staat, S. 193, 196. Nach der Flucht der italienischen Regierung Badoglio und der königlichen Familie zu den Alliierten war Prinzessin Mafalda von Hessen 1943 als Geisel gefangengenommen worden. Sie starb an den Folgen von Verletzungen, die sie sich beim Luftangriff auf Buchenwald am 24.8.1944 zuzog. Vgl. Buchenwald, Mahnung und Verpflichtung, S. 349.

573 Vgl. John, Wewelsburg (1996), S. 162.

574 Kommandant in Auschwitz, S. 116. Dies wird auch durch einen Bericht einer Zeugin Jehovas bestätigt. Die damals knapp über 20jährige Charlotte Tetzner, die im KZ Auschwitz als Stenotypistin im SS-Lazarett eingesetzt und als zuverlässige und korrekte Arbeitskraft geschätzt war, berichtet davon, daß etliche SS-Offiziere sie in ihrem Haushalt haben wollten, $\mathrm{da}$ sie aber für diese Arbeit nicht freigegeben wurde. Als sie im Jahre 1943 an Typhus litt, sorgte sich beispielsweise der SS-Lagerarzt Dr. Werner Rhode, der sich bereits vor ihrer Erkrankung vergeblich um ihre Freistellung als Bedienstete für seinen Haushalt bemüht hatte, persönlich um sie und erschien - im Gegensatz zu seinen sonstigen Gepflogenheiten täglich zur Visite in dem für die sogenannten „Kommandierten“ (Bedienstete, Schreibkräfte etc.) vorbehaltenen Krankenbau. Vgl. EB Charlotte Tetzner, 18.8.1986.

575 Arbeitseinsatzplan für Häftlinge vom Frauenlager Auschwitz I für den 6.10.1944, abgedruckt in: Friedman/Hołuj, Oswięcim, S. 217. 
lung. "576 Doch nicht alle Hausgehilfinnen lösten jede ihnen gestellte Aufgabe zur vollsten Zufriedenheit: „Es gab auch wunderliche Geschöpfe darunter. Eine war bei einem SS-Führer, die machte alles, was sie nur von den Augen ablesen konnte, aber sie weigerte sich grundsätzlich, die Uniformen, Mütze, Stiefel, alles was mit dem Militärischen zusammenhing, zu säubern, ja sie rührte sie nicht einmal an. "577

Auch außerhalb der KZ-Verwaltungen wurden Bibelforscherinnen als Hausgehilfinnen geschätzt. Ausgewählte Gefangene aus dem KZ Ravensbrück wurden 1943 zu Familien von SS-Führern abgeordnet, um diesen als Kindermädchen und Putzhilfe zu dienen ${ }^{578}$. Es hat fast den Anschein, als gehörte in den Reihen der SS ab einer gewissen Besoldungsgruppe - ersatzweise die nötigen Beziehungen - die Gestellung eines Dienstmädchens zu den üblichen Gratifikationen ${ }^{579}$. So waren Bibelforscherinnen unter anderem beschäftigt beim WVHA-Chef Oswald Pohl, beim Chef der Amtsgruppe C (Bauwesen) im WVHA, SS-Obergruppenführer Dr. Hans Kammler, und beim Leiter des Amtes W I (Steine und Erden) im WVHA, SS-Sturmbannführer Karl Mummenthey580.

In den letzten Kriegsjahren wurden Zeugen Jehovas auch häufiger mit „Funktionen“ im Rahmen der „Häftlingsselbstverwaltung“ betraut. Zumeist handelte es sich um die Einnahme von „Vorarbeiter“- und „Kapo“-Posten; „Blockältesten“-Funktionen übten Zeugen Jehovas hingegen nur sehr selten aus ${ }^{581}$.

Häftlinge anderer Gruppen berichten, daß Zeugen Jehovas in Funktionen sich im allgemeinen sehr ,vorbildlich“ verhalten haben ${ }^{582}$. Der dänische Neuengamme-

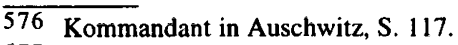

577 Ebenda.

578 Von Gertrud Pötzinger, die in Oranienburg im Haushalt eines SS-Sturmbannführers (vermutlich Max Kiefer, Leiter des Amtes C II/Sonderbauaufgaben im WVHA) als Kindermädchen eingesetzt war und die jene SS-Familie auch bei ihrer Flucht im April 1945 begleitete, sind mehrere Berichte veröffentlicht in: Füllberg-Stolberg, Pötzinger, S. 325-332; Graffard/ Tristan, Bibelforscher, S. 164, 212; Der Wachtturm, 1.10.1984, S. 26-31. Zu ihrer Biographie vgl. auch Jacobeit, Ravensbrückerinnen, S. $60 \mathrm{ff}$.

579 Wenn die Praxis dem entsprach, was Oswald Pohl der (nicht so recht zahlungswilligen) Witwe Reinhard Heydrichs mitteilte, dann hatten allerdings die SS-Führer an die Reichskasse einen Obulus zu entrichten: „Jeder von uns, z. B. auch der Reichsführer-SS, muß für die in seinem Haushalt abgestellte Häftlingskraft neben der Unterbringung und der Beköstigung noch einen vom Reich festgesetzten Lohn bezahlen." (Pohl, Schreiben vom 26.8.44 an Lina Heydrich, BA, NS 19/18, o. Bl.)

580 Paul Buder berichtet davon, daß auch bei Heinrich Himmler eine Bibelforscherin als „Dienstmädchen" eingesetzt gewesen sein soll (KmW, KW D 87, Buder, Wewelsburg, S. 74).

581 Eine Ausnahme stellt das KZ Niederhagen dar, in dem die Zeugen Jehovas, die in Wewelsburg in der Phase des Lageraufbaus vom Februar bis September 1940 allein die Belegschaft stellten, auch in den folgenden Jahren nach Einlieferung von mehreren hundert deutschen Gefangenen anderer Kategorien sowie einigen tausend Ausländern (zumeist russischen Häftlingen) weiterhin die Kerngruppe bildeten und zahlreiche Funktionen übernahmen (vgl. Hüser: Wewelsburg, S. 81). Zeugen Jehovas waren in Wewelsburg unter anderem als Lagerälteste (G. Klohe, O. Martens, W. Wilke), als Lagerschreiber (W. Müller, B. Draht), als Blockälteste (G. Früchtl, H. Dickmann u. a.), als Kalfaktoren (P. Buder, J. Schmook u. a.) sowie in mehreren Kommandos als Kapos und Vorarbeiter eingesetzt (Angaben nach KmW; DdW, AN 707, Herbert Baron: Jahre des Grauens; EB Klingenberg, 16.5.1992; EB Alois Moser, 23.5.1986; Jahrbuch 1974, S. 175f.; John, Wewelsburg (1996), S. 78, 147).

582 Vgl. beispielsweise: Einer muß überleben, S. 25; Langbein, Auschwitz, S. 280. Zeugen Jehovas, die ihre Stellung zuungunsten von Mithäftlingen mißbrauchten oder als Vorarbeiter schlugen, gab es anscheinend nur in sehr wenigen Fällen. Derartige Verhaltensweisen werden einem Lagerältesten und noch einigen weiteren „Funktionshäftlingen“ in Wewelsburg (Jahr- 
Häftling Lauritz G. Damgaard, der in einem Gärtner-Kommando einem Zeugen Jehovas unterstellt war, hat diesen in bester Erinnerung: „August, der Bibelforscher [...] war einer der Alten im Lager. Das, und daß er Deutscher war, war sein Anspruch, Vorarbeiter zu sein. Er war, vom Nazi-Gesichtspunkt aus, ein elender Vorarbeiter. Von allen anderen Gesichtspunkten ein erstklassiger Vorarbeiter und ein großartiger Mensch. Er schlug nicht, trieb uns nicht und deckte uns sowohl gegen die SS als gegen seine Häftlings-Obermänner, zu denen er jedoch ein gutes Verhältnis hatte." 583 Solche Einzelerlebnisse werden gestützt durch die Beobachtungen von Bruno Bettelheim, Psychoanalytiker und Häftling der Konzentrationslager Dachau und Auschwitz, dessen Bericht auch anspricht, weshalb die SS gleichwohl Bibelforscher zu Kapos auswählte: „Wenn sie das geworden waren und die SSLeute ihnen einen Befehl gaben, bestanden sie darauf, daß die Häftlinge die Arbeit gut und in der dafür vorgesehenen Zeit verrichteten. Sie waren zwar die einzige Gruppe von Häftlingen, die andere Lagerinsassen nie beschimpften oder mißhandelten (im Gegenteil, sie waren in der Regel recht höflich gegenüber ihren Mithäftlingen), aber die SS-Leute bevorzugten sie dennoch als Kapos, weil sie arbeitsam, geschickt und zurückhaltend waren." 584

\section{„Beobachtungen" und „Ideen" des Reichsführers-SS}

Der Einsatz inhaftierter Bibelforscherinnen in SS-Haushalten war am 6. Januar 1943 vom Reichsführer-SS angeordnet worden ${ }^{585}$, der sich mit dieser Frage persönlich und mit einer ungewöhnlichen Intensität befaßt hat. Himmler hatte bei Besuchen auf dem $25 \mathrm{~km}$ nördlich von Oranienburg gelegenen Gut Hartzwalde, das er seinem Leibarzt und Masseur, dem finnischen Medizinalrat Dr. Felix Kersten, zur Verfügung gestellt hatte und auf dem zehn Bibelforscherinnen als landwirtschaftliche Hilfskräfte und Hauspersonal eingesetzt waren ${ }^{586}$, nach seinen ei-

buch 1974, S. 175f.; EB Alois Moser, 23.5.1986; UaP Gerhard Kaiser, Briefe. Nachrichten für die Zeugen Jehovas und ihre Gefährten, S. 9) und einem Vorabeiter im Außenkommando Alderney (FGN, NHS 13-7-5-5; EB Otto Spehr, 27.9.1986) angelastet.

583 EB Lauritz G. Damgaard, 23.9.1986.

584 Bettelheim, Aufstand, S. 135. Zur Frage, wie Zeugen Jehovas als Vorarbeiter reagierten, wenn jemand in ihrem Kommando nicht so arbeitete, wie es für die Aufgabenerfüllung notwendig erschien, erklärte ein Zeuge Jehovas: „Der Bruder Kapo ging zum Häftling hin, schrieb seine Häftlingsnummer auf und stellte diesen Mann am nächsten Tag in ein anderes Arbeitskommando zu politischen Kapos. Das war die Strafe! [...] Die Häftlinge verspürten, daß das Leben für sie angenehmer und ruhiger gestaltet wurde, weil es keine Treiber und Schreier gab." (EB Alois Moser, 23.5.86)

585 RFSS, Befehl vom 6.1.43 (RF/Dr. I 37/43), zitiert im Schreiben des Chefs der Sicherheitspolizei und des SD vom 15.7.1943 an den RFSS, abgedruckt in: Friedman/Hołuj, Oświęcim, S. 183-186.

586 Kersten, der seit 1939 Himmler behandelte und der es verstand, das Vertrauen des Reichsführers-SS zu gewinnen, erfuhr - wie Besgen schildert - in der Unterhaltung mit den Zeugen Jehovas zum ersten Mal etwas über die tatsächlichen Verhältnisse in den Konzentrationslagern (Besgen, Der stille Befehl, S. 146). Der Medizinalrat, der später bei der Rettungsaktion von KZ-Gefangenen im Frühjahr 1945 („Bernadotte-Aktion“ des Schwedischen Roten Kreuzes) eine wichtige Rolle spielte, machte seinen Einfluß auf Himmler in der Weise geltend, $\mathrm{da} B$ er wiederholt auf bessere Arbeits- und Lebensbedingungen für die Gefangenen in den deutschen Konzentrationslagern drängte (vgl. Kersten, Totenkopf und Treue). In der späteren Zeit veranlaßte Himmler auf Kerstens Bitte hin sogar die Entlassung einer der auf dem Gut 
genen Worten die Gelegenheit wahrgenommen, ,dort die Frage der Ernsten Bibelforscher von allen Seiten zu studieren“. Der Reichsführer-SS teilte seine Beobachtungen in einem ausführlichen Schreiben ${ }^{587}$ den Spitzen der beiden zuständigen SS-Behörden mit, dem Chef des Wirtschafts-Verwaltungshauptamtes, SS-Obergruppenführer Oswald Pohl, und für das Reichssicherheitshauptamt dem Chef der Gestapo, SS-Gruppenführer Heinrich Müller. Dieses Schreiben dokumentiert sehr deutlich die einsetzende Veränderung in Himmlers Einstellung zu den Zeugen Jehovas ${ }^{588}$. Zunächst referierte der Reichsführer-SS darin das Urteil der Hausherrin. Frau Kersten habe ihm bestätigt, „daß sie noch nie ein so gutes, williges, treues und gehorsames Arbeitspersonal hatte wie die zehn Frauen“. Die Frauen übernähmen freiwillig jede Arbeit, selbst abends und an Sonntagen betätigten sie sich. Offene Bewunderung klingt an, wenn Himmler von Episoden wie der folgenden berichtet: „Eine der Frauen bekam einmal 5 RM Trinkgeld von einem Gast. Sie nahm das Geld an, um das Haus nicht zu blamieren, lieferte es aber bei Frau Kersten ab, weil der Besitz von Geld im Lager verboten wäre." Bei so viel Ehrlichkeit und Gewissenhaftigkeit konnten dem Führer der SS - deren Selbstverständnis als „Elite des deutschen Volkes“ die Wirklichkeit einer korrupten Bande nicht verdecken konnte - schon Neidgefühle erwachsen: „Insgesamt ergänzen diese Tatsachen mein Bild, das ich von diesen Bibelforschern habe. Es sind unerhört fanatische, opferbereite und willige Menschen. Könnte man ihren Fanatismus für Deutschland einspannen oder insgesamt für die Nation im Kriege einen derartigen Fanatismus im Volke erzeugen, so wären wir noch stärker, als wir heute sind!“ Allerdings fügte der Reichsführer-SS sogleich hinzu: „Natürlich ist die Lehre dadurch, daß sie den Krieg ablehnt, derart schädlich, daß wir sie nicht zulassen können, wenn wir nicht den größten Schaden für Deutschland haben wollen.“

Da Himmler es für „unmöglich“ hielt, „daß man in diesem Zustand des Reiches eine Kriegsdienstverweigerung hinnehme“, weil dieses ,unabsehbare Folgen haben" müßte, suchte er oft - wie er dem von ihm ebenfalls auf das Problem der Bibelforscher angesprochenen „Beauftragten des Führers für die Überwachung der gesamten geistigen und weltanschaulichen Erziehung der NSDAP“, Alfred Rosenberg, berichtete - das persönliche Gespräch mit diesen Häftlingen, ,um sie zu verstehen und eventuell sie zu überzeugen" 589 . Dieses sei aber unmöglich gewesen,

beschäftigten Frauen aus der KZ-Haft, damit sie in Kerstens zweiter Wohnung in Schweden als Hausgehilfin arbeiten konnte. Auch brachte Kersten von seinen Fahrten nach Schweden Bibelforscherschriften mit auf sein Gut. Vgl. Gebhard, Zeugen Jehovas, S. 209; Jahrbuch 1974, S. 196, 199.

587 Das Schreiben Himmlers an Müller und Pohl ist abgedruckt in: Jahrbuch 1974, S. 196f.; das dort undatiert abgedruckte Schreiben konnte archivarisch nicht ermittelt werden; es ist aber mit großer Wahrscheinlichkeit davon auszugehen, daß es sich um die im Schreiben vom 15.7.1943 als Bezug genannte und kurz inhaltlich referierte Anordnung vom 6.1.1943 handelt. Vgl. auch Gebhard, Zeugen Jehovas, S. 206; Hutten, Seher, S. 120.

588 Der Bewußtseinswandel des Reichsführers-SS in der Bibelforscherfrage blieb den Zeugen Jehovas nicht verborgen. So kolportierten sie bereits 1943/44 in den Lagern die Nachricht, Himmler habe seine Meinung über die Bibelforscher zu ändern begonnen. Dazu trug wohl wesentlich der Eindruck bei, den die auf dem Gut von Kersten in Hartzwalde eingesetzten Bibelforscher-Häftlinge aus den Begegnungen mit Himmler gewonnen hatten. Vgl. Gebhard, Zeugen Jehovas, S. 206; Jahrbuch 1974, S. 195-197; EB Klingenberg, 16.5.1992.

589 Aussage von Alfred Rosenberg am 16.4.1946 vor dem Internationalen Militärgerichtshof in Nürnberg, Der Prozeß gegen die Hauptkriegsverbrecher, Band XI, S. 563. 
„da sie auf alle Fragen mit auswendig gelernten Zitaten, Bibelzitaten“ geantwortet hätten, so daß damit ,nichts anzufangen“ gewesen sei.

Aufgrund seiner „Beobachtungen“" war Himmler aber klargeworden, daß es in der Behandlung der „Bibelforscherfrage“ einer gänzlich anderen Strategie bedürfe: „Strafen verfangen bei ihnen gar nicht, da sie mit Begeisterung von jeder Strafe erzählen. [...] Jede Strafe ist für sie ein Verdienst im Jenseits. Deshalb wird sich jeder echte Bibelforscher [...] ohne weiteres hinrichten lassen und ohne weiteres sterben. Jeder Dunkelarrest, jeder Hunger, jedes Frieren ist ein Verdienst, jede Strafe, jeder Schlag ist ein Vorzug bei Jehova. " 590 Himmler, der eingesehen zu haben schien, daß man den religiösen Widerstand der in den Konzentrationslagern einsitzenden Aktivistenschar der Zeugen Jehovas selbst mit Terror nicht zu brechen vermochte, erteilte dann folgende Weisung: „Ich ersuche, den Einsatz der Bibelforscher und Bibelforscherinnen in die Richtung zu lenken, daß sie alle in Arbeiten kommen - in der Landwirtschaft z. B. -, bei denen sie mit Krieg und allen ihren Tollpunkten nichts zu tun haben. Hierbei kann man sie bei richtigem Einsatz ohne Aufsicht lassen, sie werden nie weglaufen. Man kann ihnen selbständige Aufträge geben, sie werden die besten Verwalter und Arbeiter sein." Des weiteren regte Himmler an, Bibelforscherinnen zukünftig als Personal in den „Lebensborn“Heimen einzusetzen, „nicht als Pflegerinnen, aber als Köchinnen, Hausmädchen, Wäscherinnen und für derartige Aufgaben"591. Auch an den Einsatz in kinderreichen Privathaushalten sei unter Umständen zu denken. Die Frauen dürften keinesfalls in Sträflingskleidung arbeiten, überhaupt könne der Gefangenenstatus weitgehend aufgegeben werden. In diesem Zusammenhang ging Himmler auch auf die seit einigen Monaten im Reichssicherheitshauptamt - anscheinend auf seine Initiative hin - erneut diskutierte Frage der „Verpflichtungserklärung“ ein, wobei seine Bemerkung bei den Mitarbeitern des Sektenreferates einiges Kopfschütteln ausgelöst haben mag: „Bei all diesen für solche Aufgaben abgestellten Halbfreigelassenen wollen wir schriftliches Abschwören oder sonstige Unterschriften vermeiden und lediglich die Verpflichtung auf Handschlag vornehmen. “592

590 Zit. nach Jahrbuch 1974, S. 196f. (siehe oben Anm. 587).

591 Ebenda, S. 197. Himmlers Vorschlag, Bibelforscherinnen in „Lebensborn“-Heimen einzusetzen, wurde aufgegriffen und verwirklicht (vgl. Friedman/Holuj, Oświęcim, S. 184; Jahrbuch 1974, S. 197). So wurde die aus Amsterdam stammende Mathilde Stuhlmüller-Legenstein, die wegen Betätigung für die IBV 1941 verhaftet und ins KZ Ravensbrück verschleppt worden war, im Juli 1943 - nachdem sie von einer „Transportliste nach Auschwitz“ gestrichen worden sei - statt dessen zum Arbeitseinsatz in das seit dem Vormonat als Außenkommando zum KZ Ravensbrück gehörende „Lebensbornheim" Taunus in Wiesbaden abgeordnet. Vgl. Bembenek, Außenkommando Lebensbornheim Taunus, S. 82; Kater, Bibelforscher, S. 217.

592 Zit. nach Jahrbuch 1974, S. 197. Dem Antwortschreiben Kaltenbrunners an den RFSS vom 15.7.1943 (abgedruckt in: Friedman/Hołuj, Oswiecim, S. 183-186) ist zu entnehmen, daß „befehlsgemäß mit Bericht vom 29.10.42 zwei neue Erklärungsentwürfe vorgelegt" worden waren. Dieser Bericht über die demnach von Himmler angeregte Neufassung der „Verpflichtungserklärung“ konnte archivarisch nicht ermittelt werden. (Das gleiche gilt für einen kurz zuvor, am 10.9.1942, vom Gestapa herausgegebenen Runderlaß, dessen „Betreff“ darauf hindeutet, daß dort ebenfalls die Reversvorlage thematisiert wurde: „Behandlung nach ihrer Entlassung aus dem Gefängnis und vor Einweisung in ein KZ-Lager. Belehren nach Richtlinien.") $\mathrm{Da}$ in dem genannten Antwortschreiben Kaltenbrunners jedoch eingehend auf den genannten Bericht vom 29.10.1942 Bezug genommen wird, sind Aussagen über Motiv und Intention der Neufassung möglich. Demnach sollte mit einem neuen Wortlaut des „Revers“ der Tatsache Rechnung getragen werden, daß ,einzelne Bibelforscher oft an den Formulierun- 
Dieser Vorstoß Himmlers, der in der Lagerpraxis hinsichtlich der Vorschläge zu einem konfliktfreien Arbeitseinsatz in Außenkommandos und Vertrauensstellungen bereits teilweise vorweggenommen worden war - die SS-Offiziere vor Ort hatten den hohen „Nutzwert“ der Zeugen Jehovas längst erkannt -, war nicht der Gefühlsduselei eines Schwarmgeistes entsprungen oder gar durch humanitäre Gesichtspunkte bestimmt, sondern die in Aussicht gestellten Konzessionen (Verzicht auf Bestrafungsaktionen, Nicht-Heranziehung zu Rüstungsarbeiten, Arbeitseinsatz in Vorzugsstellungen, KZ-Entlassungen ohne schriftliche Abschwörungserklärung) waren von dem nüchternen Kalkül des für SS und Reich größten Nutzens bestimmt. Jene positiven Eigenschaften der Zeugen Jehovas galt es für die eigenen Interessen zu mobilisieren. Der Reichsführer-SS schickte sich an, die „Bibelforscherfrage“ mehr vom ,praktischen“ als vom ideologischen Standpunkt aus zu betrachten.

Doch in den Gestapo-Büros wird man von diesen Ideen nicht sehr angetan gewesen sein. Während der oberste Polizeiführer des Reiches über den Status von „halbfreigelassenen“ Zeugen Jehovas sinnierte, beschäftigte man sich dort gerade nach Kräften (und oft vergebens) damit, die Aktivisten aus den IBV-Zirkeln - die vor allem im Westen und Süden Deutschlands erstaunliche Aktivität entfaiteten aufzuspüren und dingfest zu machen, um sie hinter Zuchthausmauern oder KZStacheldraht verschwinden zu lassen.

Es dauerte dann jedoch noch fast ein halbes Jahr, bis Himmler den erbetenen Bericht über die Durchführung seiner Vorschläge erhielt. Ernst Kaltenbrunner, seit dem 30. Januar des Jahres neuer Leiter im Reichssicherheitshauptamt und damit Nachfolger des am 5. Juni 1942 durch tschechische Patrioten in Prag getöteten Heydrich, berichtete unter dem Datum des 15. Juli 1943 an den in der Feld-Kommandostelle weilenden Reichsführer-SS, daß der ,angeordnete Einsatz von inhaftierten Bibelforscherinnen zur Arbeitsleistung in SS-Haushalten und in Lebensbornheimen [...] in den verflossenen Wochen schon laufend erfolgt" sei, Entlassungen solcher Häftlinge hingegen „,bisher noch nicht durchgeführt“ worden seien. $\mathrm{Zu}$ den Vorstellungen seines Amtes über die von Himmler vorgeschlagene Vorgehensweise teilte Kaltenbrunner mit:

gen der Abschwörungserklärung, besonders daran, daß sie ihre eigene Überzeugung als Irrlehre bezeichnen sollten, Anstoß nahmen, sonst sich aber bereit erklärten, den staatlichen Anordnungen Folge zu leisten und jede ihnen übertragene Arbeit auszuführen“. Mit den beiden neuen Erklärungsentwürfen wurde ein abgestufes Vorgehen beabsichtigt. Die eine Textfassung sollte „für solche Bibelforscher in Aussicht genommen“ werden, „die sich völlig frei von der Irrlehre der IBV gemacht haben und sich zum Kriegsdienst bekennen“. Der zweite „inhaltlich wesentlich gemilderte Entwurf" sollte nur denjenigen Bibelforschern zur Unterschrift vorgelegt werden, ,, die sich innerlich zwar noch nicht völlig umgestellt hatten, aber nach einer längeren Beobachtungszeit im Lager die Gewähr dafür zu bieten scheinen, daß sie sich nach erfolgter Freilassung in jeder Hinsicht tadellos führen und zu keinerlei Beanstandungen Anlaß geben würden". Außerdem war vorgesehen, die Vorlage dieser „gemilderten Verpflichtungserklärung“ auf „weibliche Bibelforscher und solche männlichen zu beschränken, die nicht mehr im wehrdienstpflichtigen Alter stehen“ (ebenda). Zum Zeitpunkt des Antwortschreibens Kaltenbrunners (15.7.1943) war eine Entscheidung über die neuen Erklärungsentwürfe „,noch nicht ergangen“. Ob diese „differenzierte“ neue Verfahrensweise später noch in großem Stil in die Praxis umgesetzt worden ist, ist nicht bekannt. 
„Entlassungen von Bibelforscherinnen durch bloße Verpflichtung auf Handschlag werden nur in ganz besonderen Ausnahmefällen und nur bei solchen Personen vorgenommen, die nach dem übereinstimmenden Urteil des Lagers und des Arbeitgebers, bei dem sie beschäftigt sind, die absolute Gewähr dafür bieten, daß sie unbeschadet ihrer innerlichen religiösen Überzeugung nach ihrer Freilassung sich streng an die durch Handschlag eingegangenen Verpflichtungen halten und jede öffentliche Äußerung über ihre eigene religiöse Anschauung sowie über die Lehren der IBV überhaupt unterlassen. [...] Die Entscheidung darüber, ob eine Bibelforscherin auf bloße Verpflichtung durch Handschlag entlassen wird, trifft das RSHA auf Grund der Beurteilung des Lagerkommandanten und des Arbeitgebers nach sorgfältiger Prüfung der Umgebung, in der der Häftling nach erfolgter Entlassung zu leben gedenkt. ${ }^{\text {“593 }}$

Wie die einschränkende Formulierung schon erkennen läßt, meldete der neue Dienstherr des Reichssicherheitshauptamtes gegenüber den Vorschlägen seines „Reichsführers“ Bedenken an ${ }^{594}$. Im Blick darauf, daß nach den Beobachtungen des RSHA bei der gegebenen Kriegslage Glaubenslehren und Prophezeiungen vom bevorstehenden „Weltuntergang" in der Öffentlichkeit, „besonders auf dem Lande“, zunehmend Anklang fänden, hielt Kaltenbrunner ein zu weitgehendes Entgegenkommen für nicht angebracht. Wenn die entlassenen Zeugen Jehovas entgegen ihrer Verpflichtung handelten, könne dem Reich ein großer Schaden dadurch entstehen, weil Weissagen über Dauer und Ende der gegenwärtigen Weltordnung die „hauptsächliche Beschäftigung aller IBV'er“ sei und keine andere Gruppe solche Gedankengänge „mit einem solchen Fanatismus wie die Angehörigen der IBV“ verbreite. Kaltenbrunner, der somit für eine stärkere Berücksichtigung sicherheitspolitischer Belange plädierte, schlug deshalb vor, „die Häftlinge von sich aus auf die Möglichkeit ihrer Entlassung vorerst nicht aufmerksam zu machen und eine Entlassung überhaupt erst dann vorzunehmen, wenn der Wunsch dazu von der Bibelforscherin selbst vorgetragen wird" 595 .

Soweit festzustellen, hat das Reichssicherheitshauptamt die Entlassungspraxis auch zunächst weiterhin restriktiv gehandhabt; zur Entlassung von Bibelforscherinnen ohne Unterschriftsleistung scheint es 1943/44 nur in den von Kaltenbrunner

593 Der Chef der Sicherheitspolizei und des SD, Schreiben vom 15.7.1943, abgedruckt in: Friedman/Holuj, Os więcim, S. 183-186 (185). Zu dem Verfahren der „Entlassung ohne Unterschriftsleistung" ist dem Schreiben zu entnehmen, daß die betreffenden Bibelforscherinnen durch Handschlag gegenüber dem Lagerkommandanten bestimmte - in dem Schreiben selbst nicht näher bezeichnete - Verpflichtungen eingehen mußten. Der Kommandant hatte die Gefangenen darauf hinzuweisen, daß sie mit ihrer „sofortigen erneuten Festnahme“ zu rechnen hätten, falls sie ,gegen eine der übernommenen Verpflichtungen“ verstoßen würden. Über die erfolgte „Verpflichtung“ war ein Protokoll anzufertigen. Dieses war dem RSHA vorzulegen, das - wie es in dem Schreiben Kaltenbrunners heißt - „daraufhin unverzüglich die Entlassung anordnet" (ebenda, S. 185f.).

594 Die in dieser ausführlichen Stellungnahme zum Ausdruck kommende zurückhaltende, wenn nicht gar ablehnende Haltung Kaltenbrunners kontrastiert deutlich mit der von ihm am 12. April 1946 vor dem Internationalen Militärgerichtshof in Nürnberg geleisteten Aussage. Dort sprach er im Blick auf die Bibelforscher von einer „unbilligen Härte gegenüber glaubensbedingter Einstellung" und behauptete, seinen Interventionen bei Thierack und Himmler sei es zu verdanken, daß in den letzten Kriegsjahren gegenüber den Bibelforschern eine nachsichtigere Halterung eingenommen worden sei. Siehe S. 351f.

595 Der Chef der Sicherheitspolizei und des SD, Schreiben vom 15.7.1943, abgedruckt in: Friedman/Holuj, Oswięcim, S. 186. 
angesprochenen ,ganz besonderen Ausnahmefällen“ gekommen zu sein. Allerdings hatten insbesondere die als Haushaltshilfen bei Familien von SS-Führern eingesetzten Bibelforscherinnen faktisch den Status von „Halbfreigelassenen“. So bekamen beispielsweise die in den „Führerhäusern“ beschäftigten Bibelforscherinnen in den KZs Auschwitz und Ravensbrück Spezialausweise, die es ihnen gestatteten, sich tagsüber und generell während der Arbeitszeit außerhalb des Lagerbereiches frei zu bewegen ${ }^{596}$. Diese Regelung entsprach den Interessen der SS-Familien, denn nun konnten sie Einkäufe und Besorgungen durch ihre Hausgehilfinnen erledigen lassen.

Als 1943 auch ein aus männlichen Bibelforscher-Häftlingen bestehendes Kommando auf das Kersten-Gut Hartzwalde abgestellt wurde, sollte - wie Franz Birk, der diesem Kommando angehörte, berichtet - ,zum ersten Mal geprüft werden, ob man Zeugen Jehovas ohne Bewachung zur Arbeit einsetzen kann"597. Zunehmend größere Bewegungsfreiheit erhielten im letzten Kriegsjahr auch andere auf landwirtschaftlichen Gütern und in einigen besonderen Außenkommandos eingesetzte Zeugen Jehovas. Teilweise wurde sogar die Schutzhaft aufgehoben, wobei die Entlassenen aber zur gleichen Arbeit verpflichtet blieben.

Auch an dieser Regelung war Heinrich Himmler persönlich beteiligt, wie sein Einsatz für die Belange der Witwe seines Gefolgsmannes Heydrich belegt. Im Oktober 1944 erhielt diese eine Anfrage, wie sie die Leistungen und das Verhalten der auf ihrem Gut eingesetzten 15 Bibelforscher beurteile. Außerdem wurde sie gebeten, zu der Frage einer möglichen Entlassung der Häftlinge Stellung zu nehmen, die dann erfolgen könne, wenn diese mit ihrer Unterschrift [!] erklären würden, sich künftig jeder „Propaganda“ für ihren Glauben zu enthalten. Wie Frau Heydrich auf diese Anfrage reagierte - wenn man ihrer Darstellung Glauben schenken darf-, sei aus ihrer Autobiographie zitiert: „Ich habe lange Zeit darüber nachgedacht und dann gesagt: ,Wie wäre es, wenn Ihr freikommt - ohne [!] unterschreiben zu müssen. 'Alle waren begeistert, und so schrieb ich an Himmler und bat ihn um die Freilassung meiner Häftlinge, die auch als freie Menschen bei mir bleiben wollten. Himmler stimmte diesem Vorschlag zu. Er sah ein, daß Zeugen Jehovas, Kriegsdienstverweigerer, in einem besetzten Gebiet die besten Garanten für ein friedliches Leben seien.“598 Die von Frau Heydrich auf ihre Initiative zurückgeführte „unter-

596 Vgl. Buber-Neumann, Gefangene, S. 247f.; Kater, Bibelforscher, S. 217; Langbein, Auschwitz, S. 280. Der Bibelforscher Viktor Bruch aus Esch (Luxemburg), der Mitte 1944 von Majdanek zum KZ Auschwitz ,evakuiert“ wurde, berichtet davon, daß die Glaubensschwestern, die ohne Bewachung in die Stadt gehen konnten, „um Einkäufe für ihre Herrin zu machen", bei diesen Gelegenheiten mit Zeugen Jehovas von außerhalb in Verbindung traten (Jahrbuch 1976, S. 40).

597 EB Franz Birk, 31.1.1971. Da die in Hartzwalde eingesetzten Zeugen Jehovas mit Billigung Kerstens ihre in den nahe gelegenen Konzentrationslagern Ravensbrück und Sachsenhausen einsitzenden Glaubensgeschwister mit Nahrungsmitteln versorgen durften, konnte dies von ihnen zur Kontaktaufnahme und zum Informationsaustausch genutzt werden. Durch die vergleichsweise große Bewegungsfreiheit der dort arbeitenden Zeugen Jehovas entwickelte sich mit der Zeit Hartzwalde gewissermaßen zu einem Zentrum der IBV-Untergrundaktivitäten. Von dort aus wurde der Schriften- und Briefschmuggel in und aus den benachbarten Lagern organisiert. Vgl. Gebhard, Zeugen Jehovas, S. 209; EB Friedrich Klingenberg, 16.5.1992; EB Günther Pape, 19.5.1986.

Heydrich, Leben, S. 128. 
schriftslose" Entlassung der Bibelforscher-Häftlinge auf Jungfern-Breschan wurde drei Monate später von Himmler angeordnet. Mit Schreiben vom 14. Januar 1945 teilte er dem Chef der Sicherheitspolizei und des SD und dem Chef des SS-Wirtschafts-Verwaltungshauptamtes mit:

„Im Rahmen der Aktion, Bibelforschern auf einzelnen Gütern in Isolierungsaufenthalt als kleine Kolonien ihre unbedingte Freiheit zu lassen, um gerade damit im Auslande beste politische Wirkung zu erzielen, wünsche ich, daß die Bibelforscher, die bei Frau Heydrich in JungfernBreschan sind, ebenfalls unter den gleichen Bedingungen wie die anderen mit Ortsbegrenzung Freigelassenen aus der Haft entlassen werden. [...] Damit kann auch jede Bewachung wegfallen. Die Entlassung muß in der üblichen feierlichen Form vor sich gehen. ${ }^{5599}$

Die Vergünstigung sollte jedoch nicht allen 15 dort eingesetzten Zeugen Jehovas zuteil werden, sondern nur den zehn Deutschen und den drei Niederländern unter ihnen. Was mit ihren beiden anderen Glaubensgeschwistern passieren sollte, liest sich bei Himmler so: „Nicht entlassen werden sollen die zwei tschechischen Bibelforscher, die bei Frau Heydrich waren. Diese müssen dort weg." Die dreizehn Zeugen Jehovas wurden auch tatsächlich freigelassen; der ehemalige Kapo habe sich einen Hund angeschafft und - so Lina Heydrich - ,spazierte von nun an als Grandseigneur über die Felder" 600 .

Den diplomierten Landwirt Heinrich Himmler hatten die sprichwörtlichen Arbeitstugenden, die er an den Bibelforschern „,beobachtet“ hatte, tief beeindruckt und, obwohl er sie für "Angehörige einer verrückten Sekte"601 hielt, war er

$\overline{599}$ BA, NS 19/18, o. Bl., RFSS, Schreiben vom 14.1.1945.

600 Heydrich, Leben, S. 128. Mitte April 1945 trat Lina Heydrich zusammen mit dem übrigen Gutspersonal und den Zeugen Jehovas die Flucht an. Als im Oktober 1946 der Vater von Lina Heydrich einen der in Jungfern-Breschan eingesetzten Zeugen Jehovas mit der Bitte anschrieb, für seine Tochter ein gutes Wort einzulegen, übermittelte dieser ihm nach einigem Zögern eine Antwort, in der er die Verhältnisse auf Jungfern-Breschan schildert, so wie sie die Zeugen Jehovas erleben mußten: „In der ersten Woche unserer Dienstzeit bei Ihrer Tochter sagte einmal der Kommandant unseres Kommandos, sie müsse unbedingt dafür sorgen, daß die Häftlinge etwas mehr zu essen bekämen, da sonst die Gefahr bestände, daß sie ihr bei der Arbeit zusammenbrechen würden. Darauf sie: ,Sorgen Sie dafür, daß mir hier keiner stirbt. Sagen Sie früh genug Bescheid, dann tauschen wir sie aus, dann kommen andere'. Aber sie von sich aus dachte nicht daran, uns mehr zu essen zu geben. Wenn Jehova nicht für uns gesorgt hätte, indem er die Herzen der Tschechen bewegt hätte, so wären wir inmitten ihrer Güter verhungert. [...] Wenn Ihre Tochter wahre Reue empfindet über das, was mit ihrem Wissen und mit ihrer Gutheißung dem Volke Gottes zugefügt wurde, welches auch sie dazu benutzte und mißbrauchte, ihre ungerechten Reichtümer zu mehren, dann [...] wird sie Jehova um Vergebung bitten, anstatt Menschen um Rehabilitation." (Heinrich Vieker, Schreiben o. D., abgedruckt in: Struckmeier, Heinel, S. 179)

601 Heinrich Himmler, Schreiben vom 26.6.1943 an Johann Marx, abgedruckt in: Heiber, Reichsführer!, S. 218. Diese Charakterisierung wählte Himmler, um einem oberbayerischen Landwirt, dessen (vermutlich bei der SS dienendem) Sohn kein Ernteurlaub gewährt wurde, den Einsatz eines Bibelforscher-Häftlings als Erntehelfer anzudienen: „Da ich Verständnis für Ihre mißliche Lage habe, in der Sie sich befinden, beabsichtige ich, Ihnen einen Schutzhaftgefangenen abzustellen und zwar einen Bibelforscher, einen Angehörigen einer verrückten Sekte, der glaubt, Jehova habe ihm verboten, den Eid auf den Führer zu leisten und für das Vaterland zu kämpfen. Die Bibelforscher sind Leute, die selbst der Ansicht sind, Jehova habe ihnen auferlegt, sie müßten 15 und noch mehr Jahre im Gefängnis sein und sonstige Schwierigkeiten auf sich nehmen. Insgesamt sind es aber Menschen, die sehr brav arbeiten, die aber auf dem einen Gebiet, wie man bei uns in Bayern sagt, ,spinnen'. Um Ihnen irgendwie behilflich zu sein, möchte ich Ihnen einen derartigen Bibelforscher aus einem Lager abstellen.“ 
zugleich von ihrer Glaubensstärke stark fasziniert. Wenn man dem AuschwitzKommandanten Rudolf Höß glauben darf - und es scheint an dieser Stelle keinen Grund zu geben, dies nicht zu tun -, dann haben Himmler und der Inspekteur der Konzentrationslager Theodor Eicke bei vielen Gelegenheiten und ,immer wieder“ den ,gläubigen Fanatismus“ der Bibelforscher als „Vorbild“ für ihre eigenen Mannen herausgestellt: „Genauso fanatisch, so unerschütterlich wie der Bibelforscher an Jehova glaube, genauso müsse der SS-Mann an die Idee des Nationalsozialismus, an Adolf Hitler glauben." Zu solch gläubigen Fanatikern ihrer Weltanschauung müßten auch die SS-Männer werden, denn ,nur durch Fanatiker, die gewillt sind, ihr Ich ganz aufzugeben für ihre Idee, könne eine Weltanschauung getragen und auf die Dauer gehalten werden" 602 .

Schließlich verfiel Himmler noch auf den Gedanken, die Zeugen Jehovas in seine geopolitischen Nachkriegspläne mit einzubeziehen. Mit Schreiben vom 21. Juli 1944 übermittelte er an SS-Obergruppenführer Kaltenbrunner diverse Vorstellungen und Erwägungen zu dem Fragenkomplex, „wie Rußland“ zu „,beherrschen und befrieden“ sei, wenn „,im Laufe der nächsten Jahre“ von deutscher Seite „große Flächen des russischen Landes“ zurückerobert worden seien (woran der oberste SS-Führer nicht zu zweifeln schien). Neben dem Aufbau eines „Neu-Kosakentums“ im Grenzraum - Himmler schwebte das Bild eines seine eigene Bauernstelle gegen die drohende Kollektivierung verbissen verteidigenden Wehrbauern vor ${ }^{603}$ - gelte es im Hinterland das Volk ,in eine friedliche und uns gegenüber waffenlose Form zu bringen“. Dazu führte Himmler im einzelnen aus:

„Jeder Gedanke, eine Art Nationalsozialismus einzuführen, ist Wahnsinn. Die Menschen müssen jedoch eine Religion oder Weltanschauung haben. Die orthodoxe Kirche zu unterstützen und wieder aufleben zu lassen, wäre falsch, da sie immer wieder die Organisation der nationalen Sammlung sein wird. Die katholische Kirche hereinzulassen, wäre mindestens ebenso falsch. Es erübrigt sich jedes Wort zur Begründung dieser Ansicht. [...] Es muß von uns jede Religionsform und Sekte unterstützt werden, die pazifizierend wirkt. Bei allen Turk-Völkem kommt die buddhistische Glaubenslehre in Betracht, bei allen anderen Völkern dagegen die Lehre der Bibelforscher. Die Bibelforscher haben, wie Ihnen wohl bekannt sein wird, folgende für uns unerhört positive Eigenschaften: Abgesehen davon, daß sie den Kriegsdienst und die Arbeit für den Krieg, also den Einsatz für irgendeine - wie sie es bezeichnen - , abbauende' Betätigung verweigern, sind sie schärfstens gegen die Juden und gegen die katholische Kirche und den Papst eingestellt. Ferner sind sie unerhört nüchtern, trinken und rauchen nicht, sind von emsigem Fleiß und von großer Ehrlichkeit; sie halten das gegebene Wort. Weiter sind sie ausgezeichnete Viehzüchter und Landarbeiter. Sie sind nicht auf Reichtum und Wohlhabenheit aus, weil ihnen das für das ewige Leben schadet. Das sind insgesamt alles ideale Eigenschaften, wie überhaupt festzustellen ist, daß die wirklich überzeugten, idealistischen Bibelforscher ähnlich wie die Mennoniten beneidenswert gute Eigenschaften haben. [...] Aus diesem Grunde wünsche ich, da $B$ in den Lagern die uns schon als echt bekannten Bibelforscher nochmals durch Prüfungskommissionen überprüft werden, damit alle diejenigen, die sich erst im Lager oder kurz vor ihrer Verhaftung aus Zweckmässigkeitsgründen als

$\overline{602}$ Kommandant in Auschwitz, S. 78.

$603 \mathrm{Zu}$ Himmlers Begeisterung für den Wehrbauer-Gedanken vgl. Kersten, Totenkopf und Treue, S. 162ff.; weitere Literaturnachweise bei Kater, Bibelforscher, S. 191, Anm. 52. 
Bibelforscher bekannt haben, ausgeschieden werden. Dadurch wird außerdem verhindert, daß die Bibelforschereigenschaften kommunistisch ausgenutzt werden, oder daß sich Leute Bibelforscher nennen, dabei die Eigenschaften des Fleißes vermissen lassen und faul sind, wie ich das da oder dort auf Bauernhöfen, z. B. in Fridolfing/Obb. erlebt habe. Es ist damit auch die Möglichkeit gegeben, die echten Bibelforscher in den $K L$ in allen Vertrauensstellungen, die eine Versuchung in geldlicher oder sonstiger materieller Beziehung mit sich bringen, zu verwenden und besonders gut zu behandeln. Damit wiederum schaffen wir uns die Ausgangsbasis zum Einsatz dieser deutschen Bibelforscher in Rußland in kommenden Zeiten und haben damit die Missionare, mit denen wir das russische Volk durch die Verbreitung der Bibelforscherlehre pazifizieren können."604

Diese ,phantastisch anmutenden Pläne" 605 Himmlers sind insofern konsistent, als sie den Gedanken, die Eigenschaften der Zeugen Jehovas für eigene Zwecke zu funktionalisieren, konsequent weiterführen. Der Reichsführer-SS wollte den Nutzen aus dem von ihm mittlerweile erkannten Sachverhalt ziehen, daß die „Neutralität" den Zeugen Jehovas nicht nur gebot, sich bestimmten Forderungen des nationalsozialistischen Staates zu versagen, sondern auch zur Folge hatte, daß sie sich selbst jeder umstürzlerischen und damit im eigentlichen Sinne staatsgefährlichen Aktivität enthielten. Die perfide Idee, durch Ausnutzen des Missionseifers der Zeugen Jehovas den Gedanken der Wehrlosigkeit in die Völker der Sowjetunion zu tragen und sie somit als machtpolitische Größe zu paralysieren, zeigt eine ganz eigentümliche Verbindung zwischen tumbem Pragmatismus und ideologischem Wahn; sie ist Ausdruck eines ,hybriden Instrumentalismus der Ideen, der über Religionen und Menschen einfach nach politischer Zweckmäßigkeit verfügen $\mathrm{zu}$ können glaubte"606. Himmlers Vorstellungen von einem germanischen Großreich, das sich zur Sicherung seiner zukünftigen Ostgrenze der Bibelforscherlehre be-

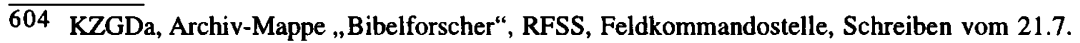
1944. Das mit dem Briefkopf des RFSS versehene Schreiben, dessen an Kaltenbrunner gerichtetes Original nicht erhalten geblieben ist, existiert in verschiedenen Fassungen bzw. Überarbeitungsstufen. Eine 1968 von Heiber, Reichsführer!, S. 272-274, publizierte ungezeichnete Abschrift - drei Jahre zuvor auszugsweise bei Zipfel, Kirchenkampf, S. 200f., wiedergegeben -, die nur in Form einer Durchschrift vorliegt, enthält vier Gliederungspunkte und vereinzelt auch abweichende sprachliche Formulierungen, während eine mit Eingangsstempel des Chefs des SS-Rasse- und Siedlungshauptamtes vom 22.9.1944 versehene Abschrift einen weiteren (fünften) Punkt enthält. Der 1954 von Ritter, Wunschträume Himmlers, S. 162168 , publizierte Wortlaut des unkorrigierten Diktats entspricht im Umfang der zuletzt genannten Fassung, ist jedoch im Gegensatz zu dieser in sechs Punkten gegliedert.

Das Schreiben ist hier nach dem beim Chef des Rasse- und Siedlungshauptamtes eingegangenen Exemplar wiedergegeben, weil zum einen dem Wortlaut des von Ritter veröffentlichten unkorrigierten Diktates in sprachlicher und stilistischer Hinsicht der Charakter einer Rohfassung deutlich anhaftet und weil zum anderen die zeitlich letzte Überarbeitung (die von Heiber und Zipfel publizierte Fassung trägt den handschriftlichen Zusatz „28.9.“) unvollständig ist. Zipfel, Kirchenkampf, S. 201, nahm aufgrund der Abfassung mit einer Schreibmaschine großen Typs an, daß das nicht erhalten gebliebene Original der von ihm publizierten Abschrift zur Vorlage bei Hitler bestimmt war, dem Schriftstücke üblicherweise so zu unterbreiten waren. Dieses würde - so Zipfel - dann auch die Weglassung des letzten Punktes erklären, da Himmler vermutlich nicht wünschte, daß Hitler von den „Zugeständnissen“ in Sachen Bibelforscher Kenntnis erhielt.

605 Kater, Bibelforscher, S. 190. Zu der veränderten Einstellung nationalsozialistischer Ideologen zu den im Schreiben Himmlers ebenfalls erwähnten Mennoniten vgl. Götz, Schwarzmeerdeutschtum; siehe auch S. 117, Anm. 134.

606 Erdmann, Die Zeit der Weltkriege, S. 401. 
dient, zu Papier gebracht in der Phase des Niederganges der NS-Herrschaft und, nebenbei bemerkt, am Tage nach dem Attentat auf Hitler - eine wahrhaft groteske Machtfiktion.

\section{„Todesmarsch" in die Befreiung}

Unter den Zehntausenden von KZ-Gefangenen, die in den letzten Wochen des Krieges bei der Räumung der Lager von der SS erschossen, dem Hungertod ausgeliefert oder auf andere Weise getötet wurden, waren auch etliche Zeugen Jehovas. So starben mindestens zehn Angehörige der kleinen Neuengammer Bibelforschergemeinde zusammen mit 7.000 Mitgefangenen am 3. Mai 1945 beim Untergang der „Cap Arcona“ und der „Thielbek“ in der Neustädter Bucht ${ }^{607}$. Auf den Evakuierungsmärschen wurden alle Gefangenen, die nicht mehr laufen konnten, kurzerhand am Straßenrand erschossen. Wie es den Zeugen Jehovas auf einem solchen Schreckenszug erging, berichtet eindrucksvoll das im Mai 1945 von den Beteiligten selbst verfaßte „Memorandum über den Auszug der Zeugen Jehovas aus dem Konzentrationslager Sachsenhausen"608.

Am Morgen des 21. April 1945 begann die „Evakuierung“ der Häftlinge aus dem KZ Sachsenhausen. Unter den 33.000 Lagerinsassen, die in Marschkolonnen Richtung Ostsee getrieben wurden, befanden sich 230 Zeugen Jehovas, davon 17 - nach anderen Angaben 18 - weibliche Häftlinge. Den Zeugen Jehovas wurde dem „Memorandum“ zufolge von der SS gestattet, einen geschlossenen Marschblock zu bilden, obgleich dieser nicht die Sollstärke von 500 Personen erreichte und die Aufstellung nach Nationalitäten angeordnet worden war. Bevor sie ausrückten, war es ihnen gelungen, ihre kranken „Glaubensgenossen“ aus dem Revier zu sich zu holen. Sie wollten die Kranken auf keinen Fall in der Ungewißheit des Lagers zurücklassen. Auch unter den Tausenden seit Anfang 1945 in das KZ Sachsenhausen evakuierten weiblichen Häftlingen, die teils im „kleinen Lager“, teils in der „Isolierung“ gesondert untergebracht worden waren, befanden sich noch einige Bibelforscherinnen. Eine schwerkranke polnische Zeugin Jehovas lag im Revier des Frauenlagers. Über die ihr geleistete Hilfe berichtet das Memorandum: „Diese mitzubekommen, war unsere vornehmste Sorge. Wir beschlossen deshalb, diese Schwester - wenn es sein müßte - direkt gewaltsam aus dem Frauenlager zu entführen, was dann auch einem Bruder am anderen Morgen gelang. Sie kam in Männerkleidung zu uns und wurde unserer wärmsten Obhut anbefohlen.“

Auf dem Marsch wahrten die Zeugen Geschlossenheit, teilten das wenige Essen und stützten sich gegenseitig: „Auch von den Schwächsten und Kranken blieb nicht einer am Wege liegen - trotzdem wir mehrere Brüder von 65 bis 72 Jahre bei uns

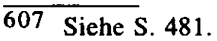

608 UaP Johan Wildschut, Memorandum über den Auszug der Zeugen Jehovas aus dem Konzentrationslager Sachsenhausen, Mai 1945. Dieser Quelle entstammen, sofern nicht anders angegeben, die folgenden Zitate. Wichtige Angaben zum Schicksal der Bibelforscher-Häftlinge bei der „Evakuierung“ des KZ Sachsenhausen können ferner entnommen werden: Graffard/ Tristan, Bibelforscher, S. $210 \mathrm{ff}$.; Jahrbuch 1974, S. 207-210; Louis Piéchota: Ich überlebte den „Todesmarsch“, in: Der Wachtturm, 15.11.1980, S. 5-10; EB Johan Wildschut, 25.6.1986. 
hatten." Bereits während des Marsches versuchten sie in den Dörfern mit der Bevölkerung in Kontakt zu kommen, um ihnen die Königreichsbotschaft zu predigen. Die SS-Bewachung der Kolonne der „Violetten“ unter dem Kommando eines Unterscharführers tolerierte dies, da es den Bibelforscher-Häftlingen dadurch gelang, Zusatzverpflegung sowie Scheunen als Unterkunft für die Nacht zu organisieren. Nach mehreren Tagen beschwerlichen Fußmarsches machten die Kolonnen im Wald von Below (bei Wittstock) halt ${ }^{609}$. Über 30.000 Häftlinge waren in den Tagen vom 26. bis 29. April in dem kleinen Buchenwald auf engstem Raum zusammen und von einer starken Postenkette umgeben. Unter den schwierigen Verhältnissen - großer Wassermangel, kaum Verpflegung etc. - bewährte sich besonders der Vorteil einer geschlossenen und disziplinierten Häftlingsgemeinschaft. Etwas abseits am Nordrand begannen die Zeugen Jehovas sofort nach ihrer Ankunft damit, behelfsmäßige Behausungen zu errichten. Eine Feuerstelle wurde angelegt und Abort-Gruben ausgehoben. Andere „Glaubensgenossen“ sammelten alles Eßbare, vor allem Nesseln und Wurzeln. Auch entschlossen sie sich, trotz der erforderlichen Kraftanstrengung und der ungewissen Aufenthaltsdauer einen Brunnen auszugraben. In Gemeinschaftsarbeit gelang dies, obwohl sie nur ihre Eßschüsseln als Hilfs- und Arbeitsmittel hatten. In fünf bis sechs Meter Tiefe stießen sie auf etwas Grundwasser. Die erfolgreiche Wassersuche brachte dem „Memorandum“ zufolge jedoch nicht nur Vorteile mit sich: „Dieses ,Wunder' hatte sich natürlich bald herumgesprochen und war später der Anlaß zu manchem Kampf mit den neidvollen Nachbarn."

Bereits während des Aufenthaltes im Belower Wald schufen die Zeugen feste Organisationsstrukturen - und legten gewissermaßen schon hier den Grundstein für den Wiederaufbau des Verkündigungswerkes in der Nachkriegszeit. Sie teilten sich in neun - später in zehn - Gruppen auf, denen jeweils ein Gruppendiener vorstand. Die Gruppendiener bildeten ein gemeinsames Leitungsgremium. Die klare Zuordnung bedeutete in dieser schwierigen Lage, wie das „Memorandum“ vermerkt, eine große Erleichterung: „Indem nun jeder wußte, zu welcher Gruppe er gehörte, war es leicht, Essen zu verteilen, Bekanntmachungen durchzugeben und auch ungestört Versammlungen abzuhalten.“

Als nach drei Tagen, am 29. April um 9.00 Uhr früh, das Lager im Belower Wald aufgehoben wurde und der Abmarsch begann, waren insgesamt Hunderte von Hungertoten zu beklagen, während die Zeugen Jehovas die ,schreckliche Dürrezeit" unbeschadet überstanden hatten. Am 2. Mai 1945 kam ihre Marschkolonne in einen Wald nahe Schwerin. Die Zeugen Jehovas registrierten eine zunehmende Nervösität der SS: „Plötzlich fingen unsere ,Helden“ an zu schlottern. Die meisten redeten uns plötzlich mit ,Kameraden“ an." Die SS begann, sich abzusetzen. Durch einen SS-Mann wurde den Häftlingen signalisiert, sich angesichts des Herannahens der sowjetischen Truppen zu den ebenfalls nur noch wenige Kilometer entfernten amerikanischen Verbänden zu begeben. Wegen des allgemeinen Chaos zögerten die Zeugen Jehovas und verblieben zunächst noch, wo sie waren: „Wir wollten völlig Jehova vertrauen, der uns in den vergangenen elf Tagen so

609 Zum Todeslager im Wald von Below vgl. Sachsenhausen, Dokumente, S. 125-127. 
zahlreiche, sichtbare Beweise seiner Führung, seiner Nähe und Kraft gegeben [...] hatte." Wie sich bald herausstellte, entgingen sie dadurch dem absurden Beschuß durch versprengte SS-Leute, der noch zahlreiche Opfer unter den hektisch aufgebrochenen Häftlingen forderte.

Am 3. Mai gegen 11.00 Uhr vormittags brachen auch die Zeugen Jehovas auf, Richtung Schwerin. Wenige Stunden später durchschritten sie die erste amerikanische Postenkette. Die Jahre der Gefangenschaft hatten ein Ende; die Stunde der Befreiung war gekommen. Ungefähr 6.000 Mitgefangene waren auf dem „Todesmarsch" ums Leben gekommen, am Wegesrand erschossen oder erschlagen, verhungert, an Entkräftung gestorben. Von den 230 Bibelforscher-Häftlingen, die Sachsenhausen verlassen hatten, hatten ausnahmslos alle diese Tortur überlebt. Die Zeugen Jehovas führten dies selbst auf ihren Zusammenhalt und die sich gegenseitig bekundete „christliche Liebe“ zurück; hinter der „wunderbaren Befreiung“ sahen sie „Jehovas schützende Hand“610.

Zunächst kamen die Zeugen in ein provisorisches Auffanglager in Zippendorf, einem Vorort von Schwerin, in dem sie bis zum 5. Mai verblieben. In dieser Zeit verfaßten sie auf einer „Beuteschreibmaschine“ aus Wehrmachtbeständen das „Memorandum über den Auszug der Zeugen Jehovas aus dem Konzentrationslager Sachsenhausen“. Außerdem beschlossen sie, ihren Glaubensgeschwistern in aller Welt eine „Resolution“ zukommen zu lassen. In dieser „Entschließung der in einem Walde bei Schwerin in Mecklenburg versammelten 230 Zeugen Jehovas aus zehn verschiedenen Nationen“ erklärten sie unter anderem:

„Wir versammelten Zeugen Jehovas senden unsere allerherzlichsten Grüße an das treue Bundesvolk Jehovas und seine Gefährten in aller Welt [...] Es sei Euch kund, daß unser großer Gott, dessen Name Jehova ist, sein Wort wahrgemacht hat an seinem Volke [...] Eine lange harte Prüfungszeit liegt nun hinter uns [...] Die Absicht des Feindes, Gottes treues Volk in diesem Lande durch unzählige, teuflische Gewaltmethoden, sowie tausend mittelalterlicher, jesuitischer Inquisitionsmethoden körperlicher und geistiger Art, als auch durch vielerlei Schmeicheleien und Verführungskünste zur Untreue zu verleiten, ist dank des Herrn großer Hilfe und seines gnädigen Beistandes den dämonischen Hassern der Theokratie nicht gelungen. [...] Die große Streitfrage ist wiederum zum Ruhme Jehovas ausgetragen worden."611

Sie versäumten auch nicht, darauf hinzuweisen, daß ihnen ,der Herr Jehova“ bereits im KZ Sachsenhausen, ,eine reiche Beute schenkte, indem er uns 36 Menschen guten Willens hinzufügte, die bei unserem Auszug aus Sachsenhausen aus freien Stücken erklärten, , wir wollen mit euch ziehen, denn wir haben gesehen, daß Gott mit euch ist"“.

Mit dem Einsturz des Hitlerreiches war zwar nicht, wie von ihnen noch Jahre zuvor fest geglaubt, der Anbruch des „Tausendjährigen Reiches“ gekommen. Ihrer Glaubenszuversicht tat dies aber keinen Abbruch, hatte sich für sie doch in ihrer Befreiung göttliches Heilshandeln vollzogen und damit Jehova seinem Volk ein Zeichen der Treue dargeboten. Die aus jahrelanger KZ-Haft Befreiten empfanden

610 Louis Piéchota: Ich überlebte den „Todesmarsch“, in: Der Wachtturm, 15.11.1980, S. 5-10.

611 Entschließung der in einem Walde bei Schwerin in Mecklenburg versammelten 230 Zeugen Jehovas aus 10 verschiedenen Nationen, Mai 1945, UaP Johan Wildschut. 
ebenso wie die Israeliten in alter Zeit. Sie deuteten die Erfahrungen des „Todesmarsches“ als ein Exodus-Erlebnis biblischer Dimension: So wie Jehova Gott die Seinen aus Ägypten führte und später aus dem babylonischen Exil erlöste, so habe er nun sein Volk aus der Knechtschaft befreit ${ }^{612}$. Sie leiteten deshalb das „Memorandum über den Auszug der Zeugen Jehovas aus dem Konzentrationslager Sachsenhausen“ mit einer Anlehnung an die ersten Verse des Psalmes 126 ein: „Als Jehova die Gefangenen Zions zurückführte, waren wir wie Träumende, da ward unser Mund voll Lachens und unsere Zunge voll Jubels. Da sagte man unter den Nationen: Jehova hat Großes an ihnen getan, Jehova hat Großes an uns getan: Wir waren fröhlich!" 613

\section{Die Zeugen Jehovas im KZ Neuengamme: Beschreibung einer Häftlingsgruppe}

Untersuchungen über Häftlingsgruppen in den nationalsozialistischen Konzentrationslagern stützen sich fast ausnahmslos auf die Wahrnehmungen von ehemaligen Gefangenen, auf Aussagen von SS-Leuten oder anderen Tatbeteiligten und auf die zentralen Anweisungen und Erlasse der KZ-Kommandanturen und höheren Dienststellen (RSHA, WVHA, RFSS pp.). Äußerst selten erfolgte hingegen eine sich empirischer Methoden bedienende Auswertung der im jeweiligen Lager geführten Statistiken und der aus Individualakten zu erhebenden Personaldaten ${ }^{614}$. Ursache für dieses Forschungsdefizit ist im wesentlichen der schlechte Überlieferungsstand der KZ-Akten. Wegen der weitgehenden Aktenvernichtung - meistens unmittelbar vor Auflösung der Lager durch die SS vorgenommen, um die Spuren ihrer Verbrechen zu verwischen - lassen sich selbst so einfache Größen wie die Häftlingszahl oftmals nicht exakt angeben. Vor diesem Hintergrund ist auch die folgende Untersuchung über die Bibelforscher-Häftlinge im Konzentrationslager Neuengamme lediglich ein Versuch der Annäherung, der viele Unzulänglichkeiten in sich birgt, gleichwohl aber angebracht erscheint, um nicht allein auf vage Vermutungen und Schätzungen angewiesen zu sein.

$\overline{612}$ Vgl. Erwachet!, 22.6.1985, S. 13.

613 UaP Johan Wildschut, Memorandum über den Auszug der Zeugen Jehovas aus dem Konzentrationslager Sachsenhausen, o. D. [Mai 1945].

614 Eine statistische Datenerhebung über die KZ-Haft von Bibelforschern erfolgte allerdings zu Vergleichszwecken im Rahmen eines Forschungsprojektes über die Verfolgung von Homosexuellen (vgl. Der rosa Winkel, S. 325-365; neben den Bibelforschern wurde als weitere Vergleichsgruppe die Kategorie der „politischen Schutzhäftlinge“ herangezogen). Die von Lautmann, Grikschat und Schmidt 1977 vorgelegte Untersuchung stützte sich schwerpunktmäßig auf die beim Internationalen Suchdienst in Arolsen (Hessen) verwahrten - und seinerzeit den interessierten Historikern noch zugänglichen - Häftlingsakten der KZs Buchenwald, Dachau, Flossenbürg und Mauthausen (Häftlingspersonalkarten, Effekten- und Transportlisten, Arbeitseinsatzkarten, Krankenblätter, Todesmeldungen pp.). Insgesamt flossen Daten von 751 Bibelforscher-Häftlingen in die Untersuchung ein. 
Auch für die Zahl der Bibelforscher, die im KZ Neuengamme inhaftiert waren, liegt kein unmittelbarer Aktenbeleg vor615. Veröffentlichungen über dieses Lager nennen - insofern sie die Häftlingsgruppe der Zeugen Jehovas überhaupt quantifizieren - folgende Zahlen: „einige Hundert“616, „,ca. 300-500“617, „bei Kriegsende etwa 200"618. Die in Erinnerungsberichten und in Gesprächen mit ehemaligen Häftlingen, die der Gruppe der Bibelforscher in Neuengamme angehörten, genannten Angaben liegen durchweg niedriger; unabhängig voneinander bezifferten die befragten Personen die Zahl auf 70 bis $80^{619}$. Aufgrund des engen Zusammenhaltes und der zeitweise gesonderten Unterbringung dieser Gruppe war den Beteiligten eine Einschätzung der Größe ihrer Glaubensgemeinschaft gut möglich; noch nach über vier Jahrzehnten konnten die ehemaligen Häftlinge sich an Dutzende von Namen ihrer Leidensgenossen erinnern. Die Gesamtzahl der Zeugen Jehovas, die im KZ Neuengamme inhaftiert waren, ist gleichwohl höher. Aufgrund der für diese Arbeit getätigten Forschungsrecherchen ist davon auszugehen, da $B$ sie sich zwischen 150 und 160 bewegt. Die Differenz läßt sich vor allem dadurch erklären, daß der Bezugspunkt von Erinnerung die relative Größe ist, also die Zahl der jeweils gleichzeitig im Lager Inhaftierten, während die bei der absoluten Summe zu berücksichtigenden Veränderungen des Häftlingsbestandes im Zeitablauf sich der unmittelbaren Wahrnehmung weitgehend entziehen.

Als Datenbasis ${ }^{620}$ für die vorliegende Häftlingsgruppen-Beschreibung konnten bei der Auswertung Angaben über 116 Personen zugrunde gelegt werden ${ }^{621}$. An-

615 Die Bezugsgröße für diese Untersuchung bildete die Gesamtheit der ins KZ Neuengamme in den Jahren 1940 bis 1945 eingelieferten Zeugen Jehovas. Da die SS vor der Räumung des Lagers Ende April 1945 die in der Kommandantur, der Schreibstube und der Politischen Abteilung geführten Häftlingsakten und Karteien verbrennen ließ, ist eine genaue Angabe über die Zahl der Gefangenen, die den violetten Winkel der Bibelforscher tragen mußten, nicht möglich.

616 Poel, Neuengamme, S. 105.

617 Eiber, Arbeitssklaven, S. 559.

618 Meyer, Nacht über Hamburg, S. 60.

619 EB Karl Hanl, 24.11.1987: „ca. 80“; EB Richard Rudolph, 30.5.1986: „um 80“; EB Ernst Wauer, 29.5.1986: „ca. 70“; Willi Seidel, Schreiben vom 3.1.1985: „über 70“. Vgl. auch die auf Häftlingsberichten beruhende Angabe von ,etwa siebzig“ im Jahrbuch 1974, S. 192. In einem schriftlichen Bericht des Zeugen Jehovas Gustav Auschner aus dem Jahre 1969 ist die Zahl sogar nur mit ,ungefähr 50-60“ beziffert worden (FGN, NHS 13-7-0-1).

620 Für die Erhebung von Daten wurden Quellen unterschiedlicher Provenienz herangezogen. Dabei handelte es sich um mündliche und schriftliche Befragungen ehemaliger Häftlinge, um Unterlagen der Hamburger VVN (Anträge auf Ausstellung eines Verfolgtenausweises, Aufzeichnungen, Briefe), des Dokumentenhauses der KZ-Gedenkstätte Neuengamme (Transportund Effektenlisten, Laborbücher, Totenbücher, Standesamtsunterlagen, Häftlingsberichte, Prozeßakten), der Amicale Internationale de Neuengamme/Nachlaß Hans Schwarz in der FGN (Nummern- und Namenskarteien auf der Grundlage von Selbstauskünften Überlebender, Korrespondenz) und des Amtes für Wiedergutmachung.

621 Die Angaben zu elf weiteren namentlich ermittelten Bibelforscher-Häftlingen des KZ Neuengamme mußten unberücksichtigt bleiben, da über den Namen hinaus zu wenige bzw. nicht hinreichend gesicherte Daten festgestellt werden konnten. Ebenfalls abgesehen wurde von einer Aufnahme der Daten von 17 Bibelforschern, die im Außenlager Alderney/I. SS-Baubrigade inhaftiert waren. Die Baubrigade, die im September/Oktober 1942 aus Häftlingen des KZ Sachsenhausen zusammengestellt und zuerst in Düsseldorf und Duisburg zu Aufräumarbeiten nach Bombenangriffen eingesetzt worden war, wurde im März 1943 nach ihrer Verlegung auf die besetzte britische Kanalinsel Alderney dem KZ Neuengamme unterstellt. Da dieses Kommando dem Hauptlager jedoch ausschließlich ,verwaltungstechnisch“ zugeordnet 
gesichts einer Gesamtzahl von 140 bis 150 ins KZ Neuengamme eingelieferten Zeugen Jehovas erscheint diese Basis als methodisch akzeptable Größe.

Im Dezember 1938 war ein erstes Vorauskommando von 100 Häftlingen, die den grünen Winkel (,Berufsverbrecher“) trugen, aus dem KZ Sachsenhausen nach Hamburg-Neuengamme verlegt worden, um eine stillgelegte Ziegelei wieder betriebsfertig zu machen. Nach 14 Monaten, am 29.2./1.3.1940, traf ein zweiter Häftlingstransport ein, um nunmehr mit dem Aufbau eines größeren Lagers zu beginnen. Neben politischen Gefangenen gehörten 40 Bibelforscher zu dem insgesamt ca. 100 bis 120 Personen umfassenden Transport. Zu diesem Zeitpunkt war danach jeder fünfte bis sechste Gefangene in Neuengamme ein Zeuge Jehovas. Die Bibelforscher-Häftlinge erschienen - da sie keineswegs auf Flucht sannen - zum Einsatz auf dem damals noch nicht umzäunten Baugelände besonders geeignet.

Mit einem 520-Mann-Transport aus Sachsenhausen kam am 4. Juni eine kleine Gruppe weiterer Bibelforscher-Häftlinge - ihre genaue Zahl ist unbekannt - im Lager an. Nachdem das vormalige Außenkommando Neuengamme im Laufe des Frühjahres zu einem eigenständigen Konzentrationslager erhoben worden war, erfolgten nun in kurzen Abständen weitere Einlieferungen. Während die Zahl der anderen Häftlingsgruppen stark anstieg, vergrößerte sich die Bibelforschergruppe jedoch nur noch langsam. Die im Winter 1940/41 in Neuengamme eintreffenden Gefangenen waren bereits mehrheitlich Ausländer. Schon bald überstieg ihre Zahl die der deutschen Häftlinge bei weitem. In der nach Tausenden zählenden Lagergesellschaft ${ }^{622}$ bildeten die Bibelforscher schließlich eine ganz kleine Minorität. Nachdem am 23. Januar 1941 im Rahmen eines aus Dachau überstellten 484Mann-Transportes 30 Zeugen Jehovas ins Lager eingeliefert worden waren, vergrößerte sich ihre Zahl in den folgenden Jahren kaum noch.

Die überwiegende Mehrzahl der Neuengammer Bibelforscher-Häftlinge wurde aus einem anderen Konzentrationslager überstellt (86\%), während der Anteil derjenigen, die als Gestapo-,,Zugänge“ direkt in das Lager eingewiesen wurden, gering war und blieb. Anhand der ermittelbaren Verhaftungsdaten ließ sich feststellen, daß die meisten bereits über eine langjährige Hafterfahrung in Gefängnissen und Konzentrationslagern verfügten, bevor sie ins $\mathrm{KZ}$ Neuengamme eingeliefert wurden. Die Inhaftnahme war in 58,9 \% der Fälle vor Beginn des Jahres 1938 erfolgt $^{623}$. Als frühestes Verhaftungsdatum konnte der 7 . Dezember 1934 ermittelt

war, die Häftlinge selbst aber in keiner Verbindung zu Neuengamme standen, erschien die Einbeziehung des Alderneyer Kommandos - nicht zuletzt wegen der vielen Besonderheiten dieses Arbeitseinsatzes - als nicht angebracht. Zu den Zeugen Jehovas in der I. SS-Baubrigade vgl. Ein KZ-Außenlager in Düsseldorf-Stoffeln, S. 71, 82 f., 97; Jahrbuch 1974, S. 118.

622 Der Häftlingsbestand im Hauptlager Neuengamme betrug zum Jahresende 1940: ungefähr 2.850-2.900; Jahresende 1941: circa 4.500-4.800 (einschließlich 1.000 sowjetische Kriegsgefangene, die im Oktober 1941 in einen zum „Kriegsgefangenen-Arbeitslager“ erklärten Bereich des $\mathrm{KZ}$ eingewiesen wurden und von denen 652 innerhalb weniger Monate verhungerten oder durch Benzininjektionen getötet wurden); Mitte 1942: 2.800-3.300; Mitte 1943: 5.5006.000; Mitte 1944: 8.000-10.000; gegen Kriegsende: 13.000-14.000. Zahlenangaben nach Kaienburg, Vernichtung durch Arbeit, S. 155f., 339.

623 Da allgemein festgestellt werden kann, daß die Inhaftierung von Bibelforschern in der überwiegenden Mehrzahl der Fälle in den Jahren 1935 bis 1939 erfolgte, veränderte sich der Bestand der während des Krieges in den Konzentrationslagern inhaftierten Bibelforscher-Häftlinge nur geringfügig. Die Zahl der Neueinlieferungen - in erster Linie ausländische Zeugen 
werden. Unmittelbar im Anschluß an eine zweijährige Gefängnishaft wurde dieser Zeuge Jehovas 1936 in das KZ Sachsenhausen überstellt und vier Jahre später nach Neuengamme, wo er bis zum Kriegsende verblieb. Damit verbrachte dieser Bibelforscher fast 101/2 Jahre in Haftstätten des „Dritten Reiches“624. Insgesamt gesehen verblieben die im KZ Neuengamme einsitzenden Zeugen Jehovas im Durchschnitt 6,9 Jahre in diversen Haftanstalten. Viele waren die längste Zeit davon in Neuengamme, wo die lange gemeinsame Aufenthaltszeit und die in den Anfangsjahren gemeinsame Unterbringung die Homogenität und Solidarität der Gruppe förderte.

Von insgesamt 99 Bibelforscher-Häftlingen des KZ Neuengamme konnten die Einlieferungsdaten ermittelt werden:

Tabelle 4: Überstellungen von Zeugen Jehovas ins KZ Neuengamme

\begin{tabular}{lrl}
\hline Datum & Personenzahl & überstellt von \\
\hline 29.2 .11 .3 .1940 & 40 & KZ Sachsenhausen \\
04.06 .1940 & 10 & KZ Sachsenhausen \\
17.08 .1940 & 1 & Gefängnis Wolfenbüttel \\
15.09 .1940 & 1 & Gefängnis Wolfenbüttel \\
10.12 .1940 & 1 & KZ Buchenwald \\
23.01 .1941 & 30 & KZ Dachau \\
29.01 .1941 & 1 & Gefängnis Vechta \\
Febr. 1941 & 1 & unbekannt \\
23.10 .1941 & 1 & Polizeigefängnis Fuhlsbüttel \\
Juli 1942 & 1 & Niederlande \\
02.11 .1942 & 3 & KZ Dachau \\
September 1942 & 6 & Niederlande \\
Juni 1944 & 1 & Polizeigefängnis Fuhlsbüttel \\
Oktober 1944 & 1 & Amersfoort/Niederlande \\
Januar 1945 & 1 & KZ Sachsenhausen \\
& 99 & \\
\hline
\end{tabular}

Nahezu die Hälfte der in das Konzentrationslager Neuengamme eingewiesenen Bibelforscher-Häftlinge gehörte den Geburtsjahrgängen 1895-1905 an.

Jehovas - glich gewissermaßen nur jene Verluste aus, die in der Buchhaltung der SS als „Abgänge“ (Todesfälle, Überstellungen, Entlassungen) gezählt wurden. Die Feststellung Katers, daß „, nach Ausbruch des Krieges [...] die Zahl der Bibelforscher in den Lagern weiter an[stieg]“ (Kater, Bibelforscher, S. 208), läßt sich angesichts dessen nicht aufrechterhalten.

Als für Franz Pawelka am 3. Mai 1945 die über zehnjährige Haft endete, stand er kurz vor Vollendung seines 60. Lebensjahres. In Neuengamme war er lange Zeit in der Revierschreibstube und daneben für circa zweieinhalb Jahre als SS-Bediensteter tätig. Da er von Beruf Barbier war und das entsprechende Vertrauen genoB, ließen sich SS-Offiziere von ihm frisieren und rasieren. 
Tabelle 5: $\quad$ Geburtsjahrgänge der im KZ Neuengamme inhaftierten Bibelforscher

\begin{tabular}{rrrrrr}
\hline 1881-1885: & 7 & $1886-1890:$ & 9 & $1891-1895:$ & 13 \\
1896-1900: & 15 & $1901-1905:$ & 24 & $1906-1910:$ & 9 \\
1911-1915: & 5 & $1916-1920:$ & 2 & $1921-1925:$ & 2 \\
& & & & Summe: & 86 \\
\hline
\end{tabular}

Zum Zeitpunkt der Einlieferung in das KZ Neuengamme lag der Mittelwert des Lebensalters bei 40,8 Jahren ${ }^{625}$. Während jedoch ein Fünftel der BibelforscherHäftlinge bei der Ankunft im KZ Neuengamme das 50. Lebensjahr bereits überschritten hatte, lag nur bei 7,5 Prozent von ihnen das Alter unter 30 Jahren, als sie in das Lager eingewiesen wurden 626 .

Das relativ hohe Durchschnittsalter der Bibelforscher-Häftlinge zeigt sich insbesondere im Verhältnis zur Gesamtheit der KZ-Gefangenen. Für Neuengamme sind Angaben über den Altersaufbau der anderen Häftlingsgruppen allerdings nicht zu ermitteln. Demgegenüber liegen für Buchenwald entsprechende Zahlen vor, da die SS sich dort anhand von Ștatistiken periodisch einen Überblick über die Altersverteilung ihrer Gefangenen verschaffte. So konnten anhand der „Unterteilung in Altersstufen der im K.L. Buchenwald einsitzenden Häftlinge nach dem Stande vom 30.1.1941"627 folgende Prozentwerte berechnet werden:

Tabelle 6: $\quad K Z$ Buchenwald: Unterteilung in Altersstufen (nach dem Stande vom 30.1.194I)

\begin{tabular}{lrrrr}
\hline & \multicolumn{2}{r}{$\begin{array}{r}\text { Bibelforscher } \\
\text { in } \%\end{array}$} & \multicolumn{2}{c}{$\begin{array}{c}\text { Gesamtheit aller Häftlinge } \\
\text { absolut }\end{array}$} \\
\hline in $\%$ \\
bis 20 Jahre & - & 0 & 139 & 1,9 \\
30-40 Jahre & 10 & 3,3 & 1124 & 15,3 \\
40-50 Jahre & 69 & 23,0 & 2400 & 32,6 \\
50-60 Jahre & 136 & 45,4 & 2314 & 31,4 \\
60-70 Jahre & 70 & 23,3 & 1134 & 15,4 \\
70-80 Jahre & 15 & 5,0 & 246 & 3,3 \\
insgesamt & - & 0 & 5 & 0,1 \\
\hline
\end{tabular}

Während die Altersstruktur der anderen Häftlingskategorien nur unwesentlich von derjenigen der Gesamtheit abweicht, zeigen die Werte bei den Bibelforschern

$\overline{625}$ Diese Angabe entspricht nahezu exakt derjenigen, die in der Untersuchung von Lautmann, Grikschat und Schmidt genannt worden ist (41 Jahre). Vgl. Der rosa Winkel, S. 331.

626 Nach der von Kirsten John vorgelegten Auswertung der Geburtsdaten von 198 im KZ Niederhagen (Wewelsburg) inhaftierten Zeugen Jehovas waren dort sogar nur 5,5\% der Bibelforscher-Häftlinge jünger als 30 Jahre. Vgl. John, Wewelsburg (1996), S. 42.

627 BA, NS 4 Bu/vorl. 141. Eine Überprüfung anhand anderer Stichtage (29.6.1940/29.11.1940/ 30.9.1941) ergab keine nennenswerten Unterschiede. 
signifikante Unterschiede. Die graphische Darstellung veranschaulicht die andere Gestalt der Alterspyramide der Bibelforscher.

Abbildung 4: KZ Buchenwald: Unterteilung in Altersstufen (nach dem Stande vom 30.1.194I)

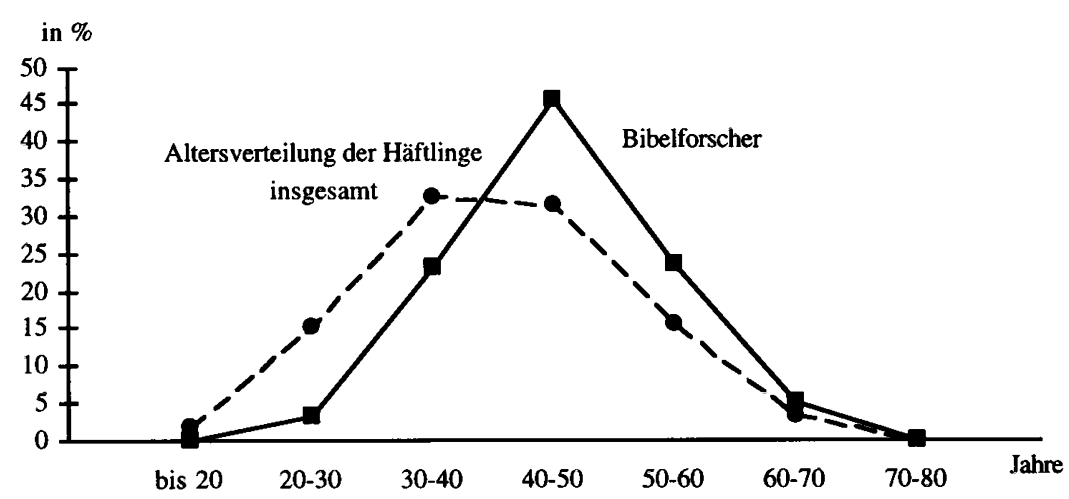

In aller Regel waren die Neuengammer Bibelforscher-Häftlinge verheiratet (annähernd $90 \%$ ). Die Kinderzahl scheint relativ niedrig gewesen zu sein (Durchschnittswert 1,6). Über den sozialen Status der im KZ Neuengamme inhaftierten Zeugen Jehovas liegen allerdings nur fragmentarische Angaben vor. In ihrer überwiegenden Mehrheit entstammten sie der unteren Mittelschicht und der Unterschicht, Angehörige der oberen Mittelschicht gab es unter ihnen nur sehr wenige.

Für 55 Personen liegen die Berufsangaben vor:

Tabelle 7: $\quad$ Berufsangaben der im KZ Neuengamme inhaftierten Bibelforscher

$\begin{array}{lrll}\text { Fabrik-, Land- und Gelegenheitsarbeiter: } & 15 & \text { Seeleute: } & 3 \\ \text { Facharbeiter: } & 11 & \text { Selbständige: } & 3 \\ \text { Handwerker: } & 10 & \text { Untere und mittlere Beamte: } & 3 \\ \text { Angestellte: } & 4 & \text { Sonstige (zwei Musiker und } & 3 \\ \text { Landwirte: } & 3 & \text { ein bildender Künstler): } & 3\end{array}$

Die Mehrzahl der IBV-Angehörigen übte somit vor der Verhaftung einen manuellen Beruf aus. Für das Überleben im Lager waren die Vertrautheit und ebenso die Belastbarkeit mit körperlicher Arbeit wichtig. Handwerkliche Kenntnisse und Fertigkeiten verhalfen oftmals zur Aufnahme in ein vergleichsweise erträgliches Arbeitskommando. Aufgrund ihres Arbeitseifers erwarben die Bibelforscher-Häftlinge sich rasch den Ruf von zuverlässigen Kräften.

Die 40 Bibelforscher, die mit dem Transport vom 29.2./1.3.1940 aus Sachsenhausen überstellt worden waren, wurden in der Zeit des Lageraufbaus gemeinsam mit den 180 Häftlingen anderer Kategorien, die sich zu jener Zeit im „Außenkom- 
mando Neuengamme" befanden, in einer auf dem Gelände befindlichen Ziegelei einquartiert. Als Unterkunft diente der Dachboden über der Trockenanlage. Nachdem die ersten drei Lagerbaracken bezugsfertig waren, erfolgte am 4. Juni 1940 der Umzug ins ,Schutzhaftlager“.

Seit dem zweiten Halbjahr 1940 waren die Bibelforscher zusammen mit jüdischen Häftlingen abgesondert von den anderen Gefangenen untergebracht ${ }^{628}$. Als „Blockältester" war von der SS ein Kommunist aus Mönchengladbach eingesetzt, der bereits seit dem 1. März 1933 in verschiedenen Konzentrationslagern inhaftiert war und den die IBV-Angehörigen aus seiner Tätigkeit als Funktionshäftling in der Isolierung in Sachsenhausen kannten und zum Teil in nicht guter Erinnerung hatten. Die Aufgabe des „Stubenältesten“ für die Seite des Blockes, auf der die Zeugen Jehovas lagen, war dem Neusser Bibelforscher Heinrich Heine übertragen worden. In dieser Zeit der gemeinsamen Gruppenunterbringung waren die Voraussetzungen gegeben, um ein festes System gegenseitiger Hilfe zu schaffen (Nahrungsmittelaufteilung, gemeinsame Geldverwaltung und ähnliches).

Nachdem bereits ein Teil der Zeugen Jehovas im Zusammenhang mit ihrer Abordnung zu besonderen Arbeitseinsätzen in andere Unterkünfte verlegt worden war ${ }^{629}$, erfolgte 1943 - vermutlich in Zusammenhang mit dem Runderlaß des Wirtschafts-Verwaltungshauptamts vom 10. September 1943, der ,mit sofortiger Wirkung“ die Auseinanderlegung der ,in den Konzentrationslagern befindlichen Bibelforscher-Häftlinge" 630 anordnete - die Aufhebung der gemeinsamen Unterbringung. In Gruppen zu je fünf bis sechs wurden die Zeugen Jehovas auf die verschiedenen Blocks aufgeteilt. Erst gegen Kriegsende scheint die SS in Neuengamme dann nicht mehr streng darauf geachtet zu haben, daß die Bibelforscher in möglichst kleinen Gruppen auf die Baracken verteilt waren.

In der Regel lehnten die Zeugen Jehovas in den KZs die Übernahme von Aufgaben im Rahmen der „Häftlingsselbstverwaltung“ $a b^{631}$. Im KZ Neuengamme wurden den Bibelforschern von der SS jedoch weit häufiger Funktionen in der Lagerorganisation zugewiesen, als dies von Mithäftlingen aus anderen Gruppen wahrgenommen wurde. Zwar bemühten sich die Bibelforscher-Häftlinge nicht um solche Positionen und beteiligten sich schon gar nicht am „Kampf“ um die Vorherrschaft in der „Häftlingsselbstverwaltung“, aber insbesondere im Fall von nur oder mehr-

628 Vermutlich für einige Monate waren anfangs in dem „Juden- und Bibelforscherblock“ auch Häftlinge der Strafkompanie und andere Gefangene einquartiert. Danach bestand die Belegschaft mit Ausnahme des Blockältesten nur noch aus Zeugen Jehovas und jüdischen Häftlingen. In Neuengamme waren bis Herbst 1942 (Übersetllungen nach Auschwitz) nur wenige hundert Juden inhaftiert. Vgl. Garbe/Homann, Jüdische Gefangene.

629 Diejenigen Zeugen Jehovas, die als sogenannte „Kommandierte“ zu Arbeiten im SS-Lager herangezogen wurden (SS-Küche, Bedienung im Offizierskasino, Friseur, Kfz-Fuhrpark, Pferdestall etc.) oder für SS-Leute als Schreiber tätig waren, wurden ebenso wie andere Kommandierte und höhergestellte Funktionshäftlinge im „Block 1 “ untergebracht, der eine geringere Belegung und bessere sanitäre Verhältnisse aufwies. Zum Wohnblock der "Prominenten“ oder - wie jener auch bezeichnet wurde - der „Läusefreien“ vgl. Kaienburg, Vernichtung durch Arbeit, S. 366; Meier, Frühwind, S. 160f., $164 \mathrm{f}$.

630 WVHA, RdErl. vom 10.9.1943, BA, NS 3/426; siehe auch S. $447 \mathrm{f}$.

631 Vom KZ Mauthausen wird beispielsweise berichtet, daß es dort während der gesamten Zeit der Existenz des Lagers ,offensichtlich keinen Bibelforscher [gab], der eine Häftlingsfunktion ausübte“ (Maršálek, Mauthausen, S. 274). 
heitlich aus Bibelforschern bestehenden Arbeitskommandos und Barackengemeinschaften erklärten sie sich zur Übernahme entsprechender Leitungsaufgaben bereit. Die generelle Aussage, daß die Zeugen Jehovas in den Konzentrationslagern ,zum Funktionärssystem [...] keinen Zugang" 632 erlangten, läßt sich angesichts des Befundes nicht weiter aufrechterhalten.

In Neuengamme übten nach den vorliegenden Angaben mindestens $10 \%$ der IBV-Angehörigen Häftlingsfunktionen aus, der Großteil von ihnen im Bereich des Arbeitseinsatzes. Als Vorarbeiter wurden Zeugen Jehovas unter anderem in den folgenden Arbeitskommandos eingesetzt: Angorakaninchenzucht, Betonplattenfertigung, Gärtnerei, Kartoffelkeller, Richtkolonnen Nr. 2 und Nr. 3 (Lageraufbau), Errichtung der ,Ley-Haus-Siedlung“ Lohbrügger Landstraße, Außenkommandos bei den Bergedorfer Firmen Behr (Holzverarbeitung) und Glunz (Eisenwarenhandlung), Bahnhofskommando (Be- und Entladen von Gütern), Entkrautungskolonne und Gleisträger. In den fünf zuletzt genannten Arbeitskommandos waren ausschließlich Bibelforscher eingesetzt, während in den anderen Kommandos die jeweiligen Vorarbeiter auch Gefangenen aus anderen Häftlingsgruppen vorstanden.

Zumindest ein Bibelforscher übte im KZ Neuengamme die Funktion eines Kapos aus: Eduard Lauterbach, der als Architekt in der ,Zentralbauleitung der WaffenSS“ für die in Neuengamme errichteten Bauten der Deutschen Ausrüstungswerke eingesetzt wurde ${ }^{633}$. Des weiteren waren in Neuengamme im Rahmen der „Häftlingsselbstverwaltung“ zwei Bibelforscher mit den Aufgaben eines ,Stubenältesten“ betraut. Im Jahre 1944 wurde ein Zeuge Jehovas im Außenlager HusumSchwesing und anschließend in Meppen-Dalum als Blockältester eingesetzt.

Abbildung 5: Zeugen Jehovas im KZ Neuengamme: Nationale Zusammensetzung

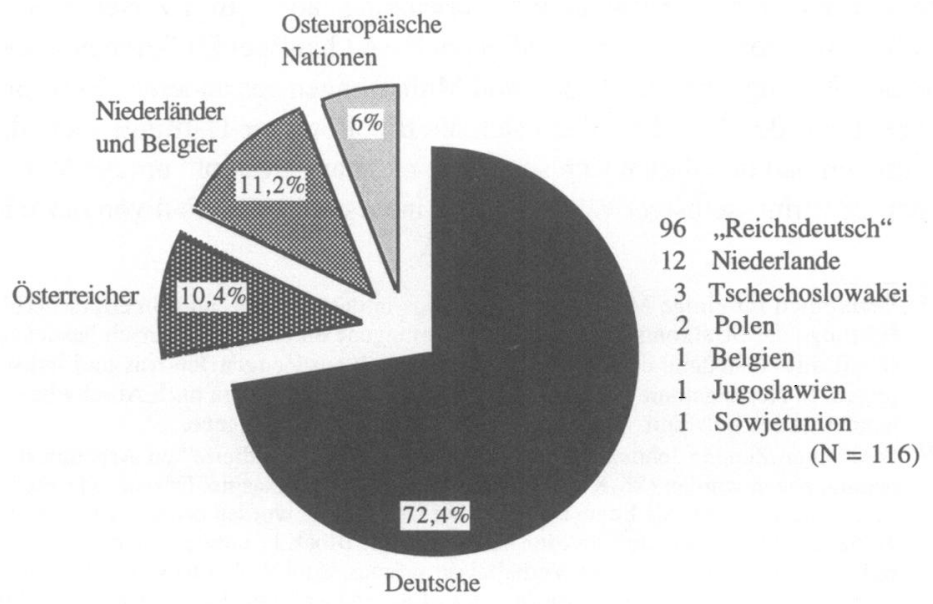

$\overline{632}$ Pingel, Häftlinge, S. 89; siehe auch S. $460 \mathrm{f}$.

633 Vgl. Meier, Frühwind, S. 392. 
Beim weitaus größten Teil der inhaftierten IBV-Angehörigen in Neuengamme handelte es sich um Deutsche und Österreicher (zusammen 82,8 \%), nur wenige Zeugen Jehovas kamen aus dem nicht zum deutschen Sprachraum zählenden Ausland. Auch in ihrer nationalen Zusammensetzung unterschied sich somit die Gruppe der Bibelforscher von der Lagerbelegschaft ${ }^{634}$. Die Eigenschaft, eine mehrheitlich (reichs-)deutsche Häftlingsgruppe zu sein, bestimmte nach der Verschleppung einer immer größeren Zahl von Ausländern in die Konzentrationslager zunehmend über den ,Stellenwert“ innerhalb der von der SS erstellten Lagerordnung.

Zumindest in den auf reichsdeutschem Gebiet gelegenen Konzentrationslagern war die Zahl der ausländischen Zeugen Jehovas in Relation zu ihren deutschen Glaubensgeschwistern stets sehr gering; ein größerer Prozentsatz läßt sich nur im Fall des KZ Mauthausen feststellen, in dem Ende 1944 beinahe ebenso viele polnische und tschechische wie ,reichsdeutsche“ IBV-Angehörige inhaftiert waren (46 Deutsche und Österreicher, 36 Polen und drei Tschechen) ${ }^{635}$.

Von den 116 Zeugen Jehovas, deren Daten berücksichtigt werden konnten, verstarben im Stammlager Neuengamme 26 Personen ${ }^{636}$, im Außenlager Drütte eine Person und mindestens zehn weitere im Zusammenhang mit der ,Evakuierung“ der Häftlinge am 3. Mai 1945 beim Untergang der „Cap Arcona“ und der „Thielbek“ in der Neustädter Bucht ${ }^{637}$. Ferner wurden zehn Bibelforscher ausweislich entsprechender Überstellungslisten als „Arbeitsunfähige“ oder „TBC-erkrankte Häftlinge“ auf „Invalidentransport“" geschickt. Bei drei von ihnen konnte in Erfahrung gebracht werden, daß sie einige Tage beziehungsweise wenige Wochen später gestorben sind. Das Schicksal der sieben anderen nach Majdanek und Dachau überstellten Häftlinge ist ungewiß. Mit Sicherheit ließ sich nur im Fall von 54 Neuengammer Bibelforscher-Häftlingen feststellen, daß sie die KZ-Haft überleben konnten.

634 Der Anteil der Deutschen unter den ungefähr 106.000 Häftlingen des KZ Neuengamme und der angeschlossenen Außenlager betrug 9,1\%. Die größten nationalen Gruppen bildeten die Russen $(18,7 \%)$, die Polen $(16,7 \%)$, die Franzosen $(11,4 \%)$, die Ukrainer $(10,4 \%)$, die Niederländer $(6,9 \%)$, die Belgier und Dänen (je 4,75 \%) sowie die Letten $(4,1 \%)$.

635 Vgl. Maršálek, Mauthausen, S. 274.

636 Die Angaben beruhen in erster Linie auf einer Auswertung der vom (KZ-)Standesamt Neuengamme ausgestellten Sterbeurkunden sowie der für den Zeitraum vom 1.5.1942 bis 15.3. 1945 (Außenlager nur bis 29.12.1944) erhalten gebliebenen „Totennachweise“, die im Krankenrevier des Lagers geführt wurden. Beide Quellen weisen zahlreiche Lücken und Fehler auf, können jedoch für das Stammlager (nicht für die Außenlager, für die sie nur einen Bruchteil aller Toten registrieren) bis zum Herbst 1944 im großen und ganzen (mit gewissen Ausnahmen wie z. B. den Exekutionen und der Fleckfieberepidemie 1942) als relativ vollständig gelten. Die in beiden Quellen erfaßten Namen (16.956) stellen aufgrund der großen Zahl von Außenlagern (über 80; 1944/45 waren in ihnen zusammen dreimal so viele Gefangene inhaftiert wie im Stammlager) sowie der über 10.000 Menschen, die bei der Evakuierung starben, insgesamt circa nur ein Drittel aller ums Leben gekommenen Häftlinge des $\mathrm{KZ}$ Neuengamme dar.

637 Einem Bericht zufolge (UaP Helmut Lasarcyk, Konrad Franke: Geschichte der Zeugen Jehovas in Deutschland. Vortrag [Transkription], Bad Hersfeld 1976, S. 38) sollen sich auf den Häftlingsschiffen insgesamt über 60 Zeugen Jehovas befunden haben, von denen 22 den britischen Bomberangriff überlebt hätten. Wegen fehlender Quellen läßt sich diese Aussage nicht verifizieren, gleichwohl könnte es sich hier zumindest teilweise um jene BibelforscherHäftlinge des KZ Neuengamme handeln, zu denen keine weiteren Daten erhoben werden konnten (siehe S. 474). 
Insgesamt ergibt sich folgendes Bild:

Tabelle 8: Verbleib der im KZ Neuengamme inhaftierten Bibelforscher

\begin{tabular}{|c|c|c|c|}
\hline Aus der KZ-Haft befreit: & $48(41,4 \%)$ & Verstorbene Häftlinge: & $37(31,9 \%)^{638}$ \\
\hline (davon 7 Überlebende der „Cap-Arcona“ & & „Invalidentransporte“: & $10(8,6 \%)$ \\
\hline Schiffskatastrophe vom 3. Mai 1945) & & Verbleib ungeklärt: & $15(13,0 \%)$ \\
\hline Entlassungen aus der Haft: & $2(1,7 \%)$ & & \\
\hline Überstellungen in andere KZs: & $4(3,4 \%)$ & Summe: & $116(100 \%)$ \\
\hline
\end{tabular}

Sind diese Zahlen noch relativ wenig aussagekräftig, so lassen sich durch eine genauere und zeitlich differenzierende Betrachtung Zusammenhänge mit den jeweiligen Arbeits- und Existenzbedingungen deutlich erkennen.

Abbildung 6: "Sterbefälle“ und „Invalidentransporte“ in Relation zum jeweiligen Bestand von
Bibelforscher-Häftlingen im KZ Neuengamme (quartalsweise erhobene Prozentwerte)

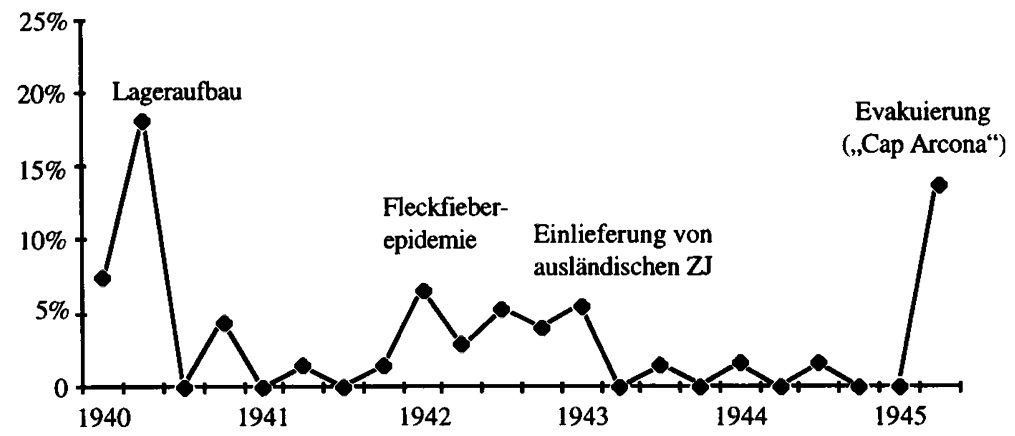

Bereits drei Monate nach Ankunft der ersten 40 Zeugen Jehovas in Neuengamme (Transport aus Sachsenhausen vom 29.2./1.3.1940) ist von ihnen aufgrund der mörderischen Bedingungen beim Lageraufbau jeder Fünfte zugrunde gegangen. Als „Todesursachen“ wurden im Sterberegister bei diesen acht 35- bis 56jährigen

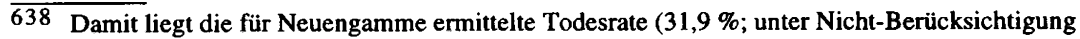
der kurz vor ihrer möglichen Befreiung Gestorbenen der „Cap Arcona“: 23,3 \%) unter der in der Untersuchung von Lautmann, Grikschat und Schmidt genannten (35\%; zum Vergleich: bei Politischen $41 \%$; bei Homosexuellen $60 \%$; Der rosa Winkel, S. 350). Der Hauptgrund für diese Differenz wird darin zu sehen sein, daß die besonderen Erniedrigungen und Mißhandlungen der Bibelforscher in den Konzentrationslagern zu jener Zeit schon langsam zurückzugehen begannen, als die ersten Zeugen Jehovas nach Neuengamme eingeliefert wurden. So gab es beispielsweise in Neuengamme niemals die Praxis, Bibelforscher grundsätzlich für eine gewisse Zeit in die Strafkompanie einzuweisen. 
Zeugen Jehovas Lungenentzündung, Herz- und Kreislaufversagen, Darmkatarrh, Rippenfellentzündung und allgemeine Körperschwäche eingetragen ${ }^{639}$.

Im Laufe des Jahres 1940 starben noch drei Bibelforscher-Häftlinge, einer von ihnen eventuell durch Selbsttötung ${ }^{640}$. Ebenfalls drei Zeugen Jehovas wurden im gleichen Zeitraum als ,,arbeitsunfähige Häftlinge“" nach Dachau verlegt.

Vom November 1940 bis zum Januar 1942 gab es in Neuengamme unter den Zeugen Jehovas bis auf eine Ausnahme - dem wegen Arbeits- und Grußverweigerung am 24. Oktober 1941 ,,auf Befehl des Führers und Reichskanzlers“ exekutierten Johann Trausner ${ }^{641}$ - keine weiteren Todesfälle ${ }^{642}$. Dies läßt vermuten, daß in jener Zeit die Überlebenschancen für Bibelforscher gestiegen sind; wie die folgenden Darlegungen zeigen werden, läßt sich diese Annahme insbesondere auf Grund von veränderten Arbeitsbedingungen, aber auch infolge der durch die $\mathrm{Ge}$ meinschaftsunterbringung in dieser Zeit gestiegenen Möglichkeiten solidarischer Hilfeleistung innerhalb der Gruppe der Zeugen Jehovas belegen.

639 Mehrere andere Bibelforscher erkrankten in dieser Zeit schwer und konnten sich erst nach Monaten wieder einigermaßen von den Strapazen erholen. Neben dem beständigen Antreiben, der provisorischen Unterbringung in der ,alten Ziegelei“ und den tiefen Frosttemparaturen im März 1940 lag eine weitere Ursache in der Person des seinerzeitigen Kommandoführers. Jener SS-Sturmbannführer Walter Eisfeld hatte bereits im KZ Sachsenhausen seine „Vorliebe“ für die Bibelforscher durch zahlreiche Drangsalierungen unter Beweis gestellt. Weiterhin muß berücksichtigt werden, daß die Bibelforscher in Neuengamme bereits entkräftet und ausgemergelt ankamen: Die Einquartierung in der „Isolierung" in Sachsenhausen und der zeitweilige Einsatz in der dortigen Strafkompanie waren nicht ohne Folgen geblieben (siehe S. 412ff.).

640 Die Eintragung über diesen am 13.6.1940 eingetretenen Sterbefall in den Standesamtsunterlagen lautet „Tod durch Überfahren, Unglücksfall“. Nach den Angaben eines Mithäftlings soll sich der Betreffende, der erst neun Tage zuvor mit Transport vom 4.6.1940 nach Neuengamme gekommen war und dem die SS es verwehrt habe, in eine Arbeitskolonne zu seinen Glaubensbrüdern zu kommen, daraufhin aus Verzweiflung vor einen LKW gestürzt haben (vgl. EB Richard Rudolph, 31.5.1986). Laut Kupfer-Koberwitz, Mächtigen, S. 401, gab es im KZ Neuengamme noch einen zweiten Fall von Selbsttötung; er berichtet von einem Bibelforscher, der Ostersamstag 1941 ,in den Draht" gegangen sei (eine Sterbeurkunde konnte in diesem Fall jedoch nicht ermittelt werden). Zwar gab es insgesamt einige Bibelforscher, die aus tiefer Verzweiflung über das schwere Los der KZ-Haft und wegen der nervenaufreibenden Konflikte zwischen den Forderungen des Glaubens und den Angeboten der SS in den Tod gingen (vgl. z. B. den von Schlotterbeck, Erinnerungen, S. 169-180, ausführlich geschilderten Fall eines nervlich gebrochenen Zeugen Jehovas, der den Qualen im KZ Welzheim ein Ende zu machen und sich mit einer Klinge zu töten versuchte), doch läßt sich - zumindest für die spätere Zeit - die 1937 in den „Deutschland-Berichten“ (S. 707) wiedergegebene Einschätzung, daß sich in den KZs ,unter den Ernsten Bibelforschern die meisten Selbstmorde und Selbstmordversuche ereigneten“, keineswegs bestätigen. Die Suizidrate unter den Zeugen Jehovas scheint eher vergleichsweise niedrig gewesen zu sein. Vgl. auch John, Wewelsburg (1996), S. 138.

641 Die Sterbeurkunde vermerkte als Todesursache: „8facher Brustdurchschuß” (DhN, Ng. 4.8.1.). Der aus St. Johann (Österreich) stammende Trausner hatte sich schon kurz nach seiner Ankunft in Neuengamme besonders strikt gegen die Befolgung aller Befehle gewandt, die nach seiner Überzeugung Handlungen betrafen, die einem Zeugen Jehovas aus Glaubensgründen auszuüben verboten waren. Nach Berichten von Mithäftlingen soll er bei der Lagerleitung Schikanen beanstandet und mehrere Male demonstrativ jeden Dienst für die SS als Götzendienst abgelehnt haben. Vgl. Maislinger, Andere religiöse Gruppen, S. 325; Poel, Neuengamme, S. 106; EB Karl Hanl, 24.11.1987; EB Richard Rudolph, 31.5.1986; FGN, NHS 13-7-0-1, Gustav Auschner, Bericht vom 8.7.1969.

642 Allerdings wurde im ersten Quartal 1941 ein erkrankter 51jähriger Wiener Bibelforscher nach Dachau abtransportiert; einige Monate später wurde von der SS ein 50jähriger erblindeter Bibelforscher mit einem ,Invalidentransport" aus dem Lager fortgeschafft. 
Eine Anfang 1942 im KZ Neuengamme grassierende Flecktyphusepidemie unterbrach diese Entwicklung jäh. Unter den mehr als 1.000 Häftlingen, die nicht zuletzt aufgrund der von der SS herbeigeführten katastrophalen medikamentösen Unterversorgung in dem bis Ende März 1942 unter Quarantäne gestellten Lager der Epidemie zum Opfer fielen, waren auch fünf Zeugen Jehovas ${ }^{643}$.

In den folgenden Monaten erfolgten im Rahmen von „Entkräftetentransporten“ vier Überstellungen von Bibelforschern nach Dachau. Im darauffolgenden Winter 1942/43 kam es erneut zu mehreren Todesfällen. Diese gingen hauptsächlich auf die vermehrte Einlieferung ausländischer Zeugen Jehovas zurück. So starben zwischen dem 18. Dezember 1942 und dem 29. März 1943 sechs niederländische IBVAngehörige, die jeweils erst seit drei bis sechs Monaten im Lager Neuengamme inhaftiert waren ${ }^{644}$. Im Gegensatz dazu ist bei den deutschen Häftlingen, die seit 1940/41 zur Häftlingsbelegschaft zählten, eine deutlich andere Entwicklung festzustellen. Vom Dezember 1942 bis zur Evakuierung im Mai 1945 starb nach den vorliegenden Daten bis auf eine Ausnahme ${ }^{645}$ kein deutscher Bibelforscher mehr im KZ Neuengamme.

Insgesamt zeigt sich, daß die zahlenmäßige Entwicklung der Todesfälle bei den Bibelforscher-Häftlingen gemessen an dem allgemeinen Anstieg der Sterblichkeit im Lager Neuengamme eine stark gegenläufige Tendenz aufweist ${ }^{646}$. Wenn auch aufgrund der geringen Zahl von Bibelforschern in diesem $\mathrm{KZ}$ bei der Interpretation Vorsicht angebracht ist, so läßt sich doch feststellen, daß es sich weder um eine zufällige Begebenheit noch um ein Spezifikum des KZ Neuengamme handelte. Auf die starke Abnahme der Todesrate bei Bibelforscher-Häftlingen in der Zeitperiode von 1942 bis 1945 ist auch bereits andernorts hingewiesen worden 647 .

Diese Entwicklung geht vor allem auf die folgenden Gründe zurück:

1. auf die im Verlauf des Krieges allgemeine (relative) Besserstellung von nichtjüdischen deutschen Häftlingen infolge der stetig zunehmenden Belegung der KZs mit ausländischen Gefangenen - und damit auf den kleineren, schrumpfenden Anteil der Zeugen Jehovas an der Häftlingsgesamtzahl;

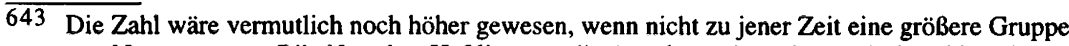
von Neuengammer Bibelforscher-Häftlingen - die Angaben schwanken zwischen 30 und 48 zum Schilfrohrschneiden auf die Ostseehalbinsel Darß abkommandiert gewesen wäre. Diese Häftlinge wurden erst nach Ablauf der Quarantäne nach Neuengamme zurückverlegt; ihre Abkommandierung und damit die Verschonung vor der Epidemie empfanden sie als eine Fügung Gottes.

644 Wenn auch die geringe Zahl von ausländischen Zeugen Jehovas eine vergleichende Auswertung im einzelnen nicht möglich macht, so läßt sich zumindest tendenziell auf eine höhere Todesrate von Ausländern auch innerhalb der Gruppe der Bibelforscher schließen. Unter Zugrundelegung der vorhandenen Daten beträgt die Sterblichkeit (ohne die am 3.5.1945 beim Untergang der „Cap-Arcona“ Gestorbenen) bei den ausländischen Zeugen Jehovas 35 \% (7 von 20), während der Prozentwert bei den (reichs-)deutschen Häftlingen 17,4 \% lautet.

645 Am 21.9.1944 verstarb ein 49jähriger IBV-Angehöriger aus Herne/Westfalen. Ein halbes Jahr zuvor, am 13.3.1944, war ein 58jähriger Zeuge Jehovas aus Oberschlesien in das Vernichtungslager Majdanek abtransportiert worden.

646 Anhand der Standesamtsunterlagen und der im Krankenrevier geführten (unvollständigen) Totenbücher läßt sich für das KZ Neuengamme folgende Entwicklung der Todesrate feststellen: 430 (1940), 434 (1941), 3140 (1942), 3985 (1943), 5527 (1944), 3440 (1.1.-15.3.1945).

647 Vgl. Pingel, Häftlinge, S. 186. 
2. zum überwiegenden Teil handelte es sich bei den Zeugen Jehovas um erfahrene „Konzentrationäre", deren Lagerresistenz sich bereits erwiesen hatte;

3. die vergleichsweise geringe Fluktuation hatte den Aufbau fester Innenbeziehungen ermöglicht;

4. die SS hatte die IBV-Angehörigen zunehmend in bevorzugte Arbeitsplätze eingewiesen.

Neben den „Invalidentransporten“ erfolgte lediglich in vier Fällen eine Überstellung von Bibelforschern aus Neuengamme in ein anderes Konzentrationslager - ein angesichts der für das KZ-System geradezu charakteristischen Häufigkeit von Verlegungen bemerkenswerter Vorgang. Auch die Zahl der vom Stammlager in ein Außenlager überstellten Bibelforscher ist auffällig niedrig. Soweit bekannt, kam es nur in acht Fällen zu einer solchen Abkommandierung, wobei drei der Häftlinge erst im letzten Halbjahr 1944 nach Neuengamme eingeliefert worden waren. Nach nur wenigen Wochen Aufenthalt im Stammlager wurden sie in die Außenlager Bremen-Farge, Husum-Schwesing und Meppen-Versen abtransportiert ${ }^{648}$.

Die geringe Zahl der Überstellungen deutet darauf hin, daß die SS die Bibelforscher im Lager als bewährte Arbeitskräfte und als Häftlinge in „Vertrauensstellungen" halten wollte. Von den 85 Bibelforschern, die im ersten Jahr des KZ Neuengamme dorthin eingeliefert wurden (die „Kernbelegschaft“), verblieben 55 $(=65 \%)$ bis zur Evakuierung ununterbrochen im Stammlager Neuengamme. Diese KZ-Gefangenen, die über eine langjährige Hafterfahrung verfügten und auch nach außen hin durch ihre niedrige Häftlingsnummer innerhalb der "Lagergesellschaft“ erkennbar waren, hatten seit 1942 fast alle einen bevorzugten Arbeitsplatz erlangt, der vergleichsweise gute oder gesicherte Existenzbedingungen bot (insoweit von „guten“ Bedingungen in einem KZ überhaupt die Rede sein kann). Da sie die ihnen übertragenen Aufgaben gewissenhaft erledigten, verstanden sie es, sich in ihrem jeweiligen Arbeitsbereich nahezu unersetzlich zu machen. Oftmals bewahrte die Protektion durch ihre unmittelbaren SS-Vorgesetzten sie vor einer Abkommandierung zu einem schlechter gestellten Arbeitseinsatz oder vor der Verlegung in ein Außenlager 649 .

Die Arbeitsbedingungen waren von zentraler Bedeutung für das Überleben im Lager. Die Zeugen Jehovas in Neuengamme waren an zahlreichen Arbeitsplätzen

648 Ein niederländischer Zeuge Jehovas wurde in das Außenlager Drütte überstellt. Lediglich bei den verbleibenden vier Fällen handelte es sich um Bibelforscher, die zu der 1940/41 eingelieferten „Kernbelegschaft“ gehörten. Von ihnen wurden zwei offenbar infolge der GestapoAktion von 1944 (siehe S. 450) strafweise in ein Außenlager versetzt. Verlegungen in den letzten Kriegswochen im Zuge der Evakuierung blieben unberücksichtigt.

Die Beweggründe für derartige Protektionen lassen sich beispielsweise aus einem Bericht von Werner Kahn, dem ehemaligen leitenden Ingenieur des Klinkerwerkes in Neuengamme, ersehen. Danach sollte ein Bibelforscher, der als Koch in der Werksküche arbeitete und von Haus aus Bergmann war, zusammen mit anderen Fachkräften auf Transport in ein Außenlager geschickt werden, um dort beim Ausbau unterirdischer Anlagen für die Rüstungsfertigung eingesetzt zu werden. Als Kahn davon erfuhr, begab er sich nach seinen Angaben zum Lagerkommandanten. Ihm gegenüber habe er darauf verwiesen, daß in der Werksküche nur ein Häftling einzusetzen sei, von dem mit Sicherheit angenommen werden könne, daß er keine Unterschlagungen machen würde. Aus diesem Grunde wäre der Betreffende an diesem Arbeitsplatz die ideale Kraft. Infolge dieser Intervention sei der Bibelforscher von der Transportliste wieder gestrichen worden. Vgl. EB Werner H. Kahn, 20.12.1984. 
eingesetzt. Insgesamt liegen 215 Angaben über den Einsatz in 38 verschiedenen Arbeitskommandos oder Arbeitsbereichen vor. Da Häftlinge während ihres KZAufenthalts selten über Jahre hinweg in ein und dem gleichen Kommandos beschäftigt wurden, waren in den meisten Fällen Mehrfachnennungen zu berücksichtigen. Bei anderen konnte hingegen teilweise kein einziger Beleg darüber ermittelt werden, wo der Arbeitseinsatz erfolgte. Von daher ist erneut darauf hinzuweisen, daß die Unvollständigkeit der Daten nur eine tendenzielle Aussage zuläßt.

Um die Nennungen nach dem Grad der Arbeitsbedingungen auswerten zu können, erfolgte eine Eingruppierung ${ }^{650}$ anhand der folgenden Gliederung:

\section{Arbeiten mit (vergleichsweise) guten Existenzbedingungen:}

Bedienstete im SS-Lager (Kantine, SS-Küche, Pferdestall), qualifizierte Fachleute und (Bau-)Spezialisten (Baubüro);

2. Arbeiten mit relativ gesicherten Existenzbedingungen:

Tätigkeiten im Lagerbereich (Küche, Schreibstube), Einsatz in kleinen Außenkommandos bei Gewerbebetrieben, Landwirtschaft (Angorakaninchenzucht, Gärtnerei etc.), Handwerkerkolonnen, Facharbeiter in der Produktion;

\section{Arbeiten mit schwierigen Existenzbedingungen:}

Bauarbeiten bzw. bauhandwerkliche Tätigkeiten, Betonteilefertigung, Bombenräumkommando, Bestattungskommando;

\section{Arbeiten mit schlechten bzw. sehr schlechten Existenzbedingungen:}

Masseneinsätze bei Erd- (Tiefbau-) und Transportarbeiten („Kommando Elbe“, Arbeit in den Tongruben, Ausschachtungen beim Bau des Lagers und des Klinkerwerkes), Gleisträger/Gleisbau, Schilfrohrschneiden auf der Ostseehalbinsel Darß, Strafkompanie.

Die Auswertung der Nennungen anhand dieser Gliederung ergab folgendes Bild über den Arbeitseinsatz von Zeugen Jehovas im KZ Neuengamme:

Tabelle 9: Zeugen Jehovas im KZ Neuengamme: Zugehörigkeit zu Arbeitskommandos

Arbeiten mit

guten Existenzbedingungen:

relativ gesicherten Existenzbedingungen:

schwierigen Existenzbedingungen:

schlechten bzw. sehr schlechten Existenzbedingungen:
Prozentwerte

$$
6,5
$$

32,5

27,0

34,0

100

$(\mathrm{N}=215)$

In knapp der Hälfte der Fälle handelte es sich um einen Arbeitseinsatz in einem Innenkommando (45,4 \%). Mit 54,6 \% der Nennungen ist der Anteil des Einsatzes zu Arbeiten außerhalb des Lagers und der Umzäunung bemerkenswert hoch. Dazu wurden die Zeugen Jehovas zumeist in kleinen, geschlossenen Gruppen zusam-

$\overline{650}$ Bei den angeführten Beispielen handelt es sich ausnahmslos um solche Kommandos, in denen Zeugen Jehovas eingesetzt waren. Zu den Bedingungen in diesen Arbeitskommandos vgl. auch Kaienburg, Vernichtung durch Arbeit, S. 198, 219 f. 
mengefaßt, die im allgemeinen unter verringerter Bewachung arbeiteten. „Reine“ Bibelforscherkommandos waren beispielsweise das sogenannte „Bahnhofskommando" (Abladen von Gütern), das Entkrautungskommando (Entschlickung von Entwässerungsgräben) sowie die Kommandos in den Bergedorfer Firmen Baumarkt Behr und Eisenwarenhandlung Glunz.

Zu signifikanten Ergebnissen führte der Versuch, die Daten über den Einsatz in Arbeitskommandos danach aufzuschlüsseln, zu welcher Zeitperiode der Lagergeschichte die jeweilige Tätigkeit ausgeübt wurde. Für die Auswertung erwies sich ein Vergleich der Zeiträume 1940 bis 1942 und 1943 bis 1945 als sehr aussagekräftig.

Tabelle 10: Zugehörigkeit zu Arbeitskommandos 1940 bis 1942 und 1943 bis 1945

\begin{tabular}{|c|c|c|}
\hline Arbeiten mit & $1940-1942$ & $1943-1945$ \\
\hline guten Existenzbedingungen: & 2,0 & 15,0 \\
\hline relativ gesicherten Existenzbedingungen: & 13,5 & 54,0 \\
\hline schwierigen Existenzbedingungen: & 27,0 & 18,0 \\
\hline \multicolumn{3}{|l|}{ schlechten bzw. sehr schlechten } \\
\hline Existenzbedingungen: & 57,5 & 13,0 \\
\hline Summe: & $100 \quad(\mathrm{~N}=111)$ & $(\mathrm{N}=78)$ \\
\hline
\end{tabular}

Aufgrund der sehr deutlichen Verschiebungen kann von einer zunehmenden Besserung der Existenzbedingungen ausgegangen werden ${ }^{651}$. Zwar stieg für nichtjüdische deutsche Häftlinge der nationalsozialistischen Konzentrationslager aufgrund der zunehmenden Bedeutung der Häftlingsarbeitskraft seit 1942/43 allgemein die Überlebenschance ${ }^{652}$, doch bleibt der Grad der Veränderung der Lage der Bibelforscher gleichwohl bemerkenswert.

Die Überschaubarkeit der Häftlingsgruppe, ihre Homogenität, der gemeinsame Glaube und der in den Jahren des gemeinsamen KZ-Aufenthaltes in Neuengamme gewachsene Zusammenhalt einerseits wie andererseits die sich für diese Gruppe verbessernde materielle Lage mitsamt ihrem Zugang zu bevorzugten Arbeitsplätzen bildeten auch die Basis für eine verstärkte Fortsetzung der Bibelforscheraktivitäten ${ }^{653}$. Die seit 1943 auf verschiedene Häftlingsblocks verteilte Neuengammer Bibelforschergemeinde untergliederte sich in sieben Studiengruppen, denen jeweils ein Studienleiter vorstand. Jede Gruppe versuchte, mindestens einmal wöchentlich zum „Buchstudium“ zusammenzukommen. Es gab dazu Abschriften vom „Wacht-

651 Nach Angaben des Niederländers Albert van de Poel, der als Häftling in der „Politischen Abteilung“ des KZ Neuengamme beschäftigt wurde, begann die vergleichsweise Besserstellung der Bibelforscher im Arbeitseinsatz 1942; seit dieser Zeit seien IBV-Häftlinge auch auf Vertrauensposten gekommen. Vgl. Poel, Neuengamme, S. 106.

652 Siehe S. 451f. Pingel geht davon aus, daß in der letzten Periode der Konzentrationslager ca. 15 bis $20 \%$ aller deutschen Häftlinge ,an relativ gesicherten, bevorzugten Arbeitsplätzen“ eingesetzt wurden (Pingel, Häftlinge, S. 168).

653 Zum folgenden vgl. Jehovas Zeugen in Gottes Vorhaben, S. 171; Ernst Wauer: Welche Freude, am Tisch Jehovas zu sitzen!, in: Der Wachtturm, 1.8.1991, S. 25-29; EB Richard Rudolph, 31.5.1986; EB Karl Hanl, 24.11.1987; EB Ernst Wauer, 29.5.1986. 
turm", die durch den als Schreiber beim Schutzhaftlagerführer, SS-Obersturmführer Albert Lütkemeyer, eingesetzten Ernst Wauer heimlich in dessen Büro angefertigt und mit Durchschlagspapier vervielfältigt wurden, und eine Bibel, die kursierte ${ }^{654}$. Zeitweilig soll es sogar gelungen sein, den Gruppen jeden Morgen beim Appell eine Abschrift des Tagestextes zukommen zu lassen.

Im Rahmen einer Anfang 1943 durchgeführten Missionskampagne wurde das Lager in Gebiete aufgeteilt und zu deren „Bearbeitung“ besondere „Stoßtrupps“ zusammengestellt: Um eine möglichst große Zahl von Mithäftlingen zu erreichen, gingen kleine Gruppen von Zeugen Jehovas von Block zu Block und gaben von ihrem Glauben ,Zeugnis“. Zu diesem Zweck wurden mehrsprachige ,Zeugniskarten“ erstellt, die eine kurze biblische Passage mit dem Angebot zu einem Gespräch über die Königreichshoffnung enthielten ${ }^{655}$. Selbst Vorträge wurden gehalten, die man für die russischen und polnischen Lagerinsassen übersetzte. Bekundeten Mitgefangene Interesse, so wurden „Nachbesuche“ vorgenommen und mit biblischen Unterweisungen begonnen.

Es gab ferner einen Schriftenschmuggel, der angesichts der gegebenen Umstände zeitweilig regelrecht florierte. Die Verbindung nach außen lief über ein Außenkommando in Bergedorf ${ }^{656}$. Zwischen vier und zehn Zeugen Jehovas, die täglich vom Lager aus unter Bewachung zur Arbeit in den sechs Kilometer entfernten Ort marschierten, mußten dort für die Eisenwarenfirma Glunz Schrauben und andere Metallteile sortieren. Die Schwester eines in diesem Kommando eingesetzten Glaubensbruders hatte davon erfahren und unerschrocken Verbindung aufgenommen. Diese Frau wurde dann die Mittelsperson für die Kontakte zwischen den im KZ Neuengamme inhaftierten Bibelforschern und einzelnen im Untergrund tätigen IBV-Gruppen. Sie brachte Schriften nach Bergedorf, die zunächst in den Kellerräumen der Firma Glunz versteckt wurden und von dort nach und nach ins $\mathrm{KZ}$ gelangten. Auf dem umgekehrten Weg wurden Briefe an Angehörige und biblische Auslegungen über die Situation der Inhaftierten aus dem Lager herausgebracht. Solche Berichte erreichten in den Jahren 1943/44 auch die Europazentrale der Wachtturm-Gesellschaft in der Schweiz.

Auch von Gedächtnismahlsfeiern berichten ehemalige Bibelforscher-Häftlinge aus Neuengamme. Sogar Taufen wurden mehrfach im Lager durchgeführt. Taufwillige - dies wird zum Beispiel von einem russischen und einem jungen polnischen Häftling berichtet - schleuste man ins Entkrautungskommando ein, das Entwässerungsgräben auszuheben hatte. Dort rutschten sie dann wie unbedarft aus.

$\overline{654}$ Diese Lutherbibel wurde nach einem Bombenangriff bei Bergungsarbeiten gefunden. Beim Einsatz des Aufräumkommandos stieß ein Zeuge Jehovas in den Trümmern eines zerstörten Hauses auf die Bibel und schmuggelte sie auf dem Rückweg ins $\mathrm{KZ}$.

655 Die Angabe Katers, die Bibelforscher hätten in Neuengamme und Buchenwald ,zeitweilig sogar Lagerzeitschriften [...] verfaßt und weitergereicht" (Kater, Bibelforscher, S. 214), kann als ein geradezu typischer Beleg für die mangelnde Vertrautheit von Historikern mit den religiösen Ausdrucksformen der Zeugen Jehovas gelten. Es handelte sich hier nicht um irgendwelche Zeitschriften, sondern um die erwähnten in mehreren Sprachen angefertigten ,Zeugniskarten“. Mit Hilfe solcher Karten, die auch die Kontaktaufnahme zu Personen ermöglichten, deren Sprache der „Verkündiger“ selbst nicht mächtig war, hatten die Bibelforscher ihr Predigtwerk auch in den Jahren zuvor außerhalb der Lager betrieben.

656 Die Darstellung beruht auf: EB Ernst Wauer, 29.5.1986; EB Karl Hanl, 24.11.1987; FGN, NHS 13-7-0-1, Gustav Auschner, Bericht vom 8.7.1969; Jahrbuch 1974, S. $192 \mathrm{f}$. 
Mit Worten wie ,wenn du schon reingefallen bist, dann tauch' wenigstens richtig ein" faßte daraufhin der in dem Kommando arbeitende Bibelforscherälteste den Kopf des Taufwilligen und senkte ihn unter dem Gejohle der SS-Bewacher, die das Ganze für eine Gaudi hielten, ins Wasser, während die andächtig verweilenden Zeugen Jehovas die Szene mit ihren stillen Gebeten begleiteten 657 .

Für die Zeugen Jehovas erwies sich bei solchen Begebenheiten einmal mehr der Sieg des Glaubens über die „Dumpfheit der weltlichen Mächte“. 